\title{
Automation Support for Security Control Assessments
}

Software Asset Management

Kelley Dempsey

Paul Eavy

Nedim Goren

George Moore

This publication is available free of charge from: https://doi.org/10.6028/NIST.IR.8011-3

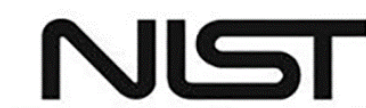

National Institute of Standards and Technology U.S. Department of Commerce 
NISTIR 8011

Volume 3

\title{
Automation Support for Security Control Assessments
}

Software Asset Management

\author{
Kelley Dempsey \\ Nedim Goren \\ Computer Security Division \\ Information Technology Laboratory \\ Paul Eavy \\ Federal Network Resilience Division \\ Department of Homeland Security \\ George Moore \\ Johns Hopkins University \\ Applied Physics Laboratory
}

This publication is available free of charge from:

https://doi.org/10.6028/NIST.IR.8011-3

December 2018

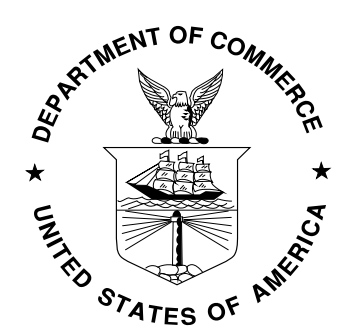

U.S. Department of Commerce

Wilbur L. Ross, Jr., Secretary

National Institute of Standards and Technology

Walter Copan, NIST Director and Under Secretary of Commerce for Standards and Technology 


\title{
National Institute of Standards and Technology Interagency Report 8011 Volume 3 210 pages (December 2018)
}

\section{This publication is available free of charge from: https://doi.org/10.6028/NIST.IR.8011-3}

Certain commercial entities, equipment, or materials may be identified in this document in order to describe an experimental procedure or concept adequately. Such identification is not intended to imply recommendation or endorsement by NIST, nor is it intended to imply that the entities, materials, or equipment are necessarily the best available for the purpose.

There may be references in this publication to other publications currently under development by NIST in accordance with its assigned statutory responsibilities. The information in this publication, including concepts and methodologies, may be used by federal agencies even before the completion of such companion publications. Thus, until each publication is completed, current requirements, guidelines, and procedures, where they exist, remain operative. For planning and transition purposes, federal agencies may wish to closely follow the development of these new publications by NIST.

Organizations are encouraged to review all draft publications during public comment periods and provide feedback to NIST. Many NIST information security publications, other than the ones noted above, are available at https://csrc.nist.gov/publications.

\section{Comments on this publication may be submitted to:}

\author{
National Institute of Standards and Technology \\ Attn: Computer Security Division, Information Technology Laboratory \\ 100 Bureau Drive (Mail Stop 8930) Gaithersburg, MD 20899-8930 \\ Email: sec-cert@nist.gov
}

All comments are subject to release under the Freedom of Information Act (FOIA). 


\title{
Reports on Computer Systems Technology
}

The Information Technology Laboratory (ITL) at the National Institute of Standards and Technology (NIST) promotes the U.S. economy and public welfare by providing technical leadership for the Nation's measurement and standards infrastructure. ITL develops tests, test methods, reference data, proof-of-concept implementations, and technical analyses to advance the development and productive use of information technology. ITL's responsibilities include the development of management, administrative, technical, and physical standards and guidelines for the cost-effective security and privacy of other than national security-related information in federal systems.

\begin{abstract}
The NISTIR 8011 volumes each focus on an individual information security capability, adding tangible detail to the more general overview given in NISTIR 8011 Volume 1, and providing a template for transition to a detailed, NIST guidance-based automated assessment. This document, Volume 3 of NISTIR 8011, addresses the Software Asset Management (SWAM) information security capability. The focus of the SWAM capability is to manage risk created by unmanaged or unauthorized software on a network. Unmanaged or unauthorized software is a target that attackers can use as a platform from which to attack components on the network.
\end{abstract}

\section{Keywords}

actual state; assessment; authorization boundary; automation; capability; continuous diagnostics and mitigation; dashboard; defect; desired state specification; firmware; information security continuous monitoring; ISCM; inventory management; malicious code; malware; mitigation; mobile code; ongoing assessment; root cause analysis; security capability; security control; security control item; software; software asset management; software file; SWID tag; whitelisting. 


\section{Acknowledgments}

The authors, Kelley Dempsey and Ned Goren of the National Institute of Standards and Technology (NIST), Paul Eavy of the Department of Homeland Security, and Dr. George Moore of the Applied Physics Laboratory at Johns Hopkins University, wish to thank their colleagues who reviewed drafts of this document and provided valuable input, including Nathan Aileo, Ujwala Arikatla, Mark Bunn, Jim Foti, John Groenveld, Susan Hansche, Blair Heiserman, Frank Husson, Mike Ko, Alan McClelland, Susan Pagan, David Waltermire, and Kimberly Watson. The authors also gratefully acknowledge and appreciate the comments and contributions made by government agencies, private organizations, and individuals in providing direction and assistance in the development of this document. 


\section{Table of Contents}

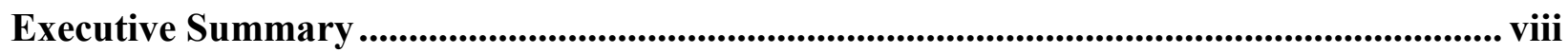

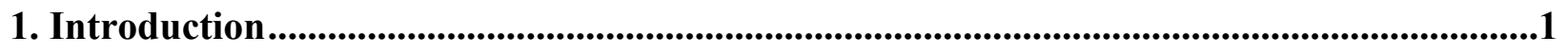

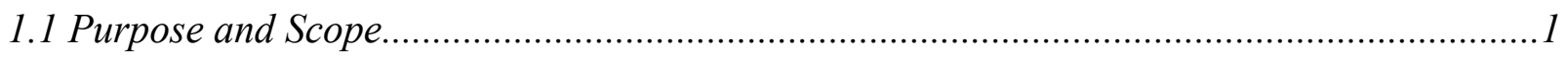

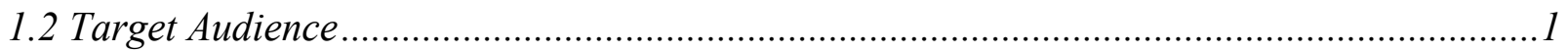

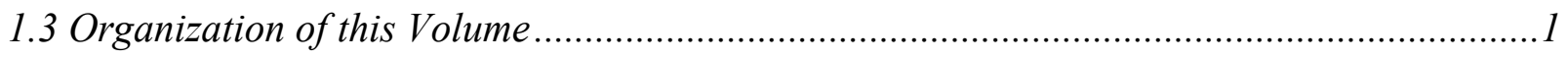

1.4 Interaction with Other Volumes in this NISTIR ..........................................................2

2. Software Asset Management (SWAM) Capability Definition, Overview, and Scope ..........3

2.1 SWAM Capability Description .............................................................................. 3

2.2 SWAM Attack Scenarios and Desired Result .................................................................. 7

2.3 Assessment Objects Protected and Assessed by SWAM ................................................ 9

2.4 Example SWAM Data Requirements ...................................................................... 14

2.5 SWAM Concept of Operational Implementation .............................................................. 16

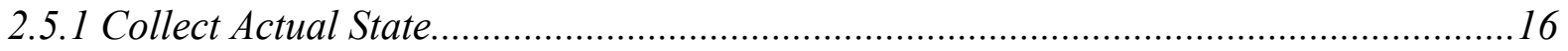

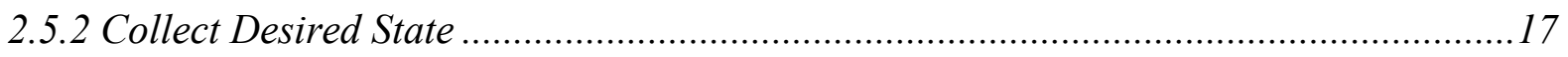

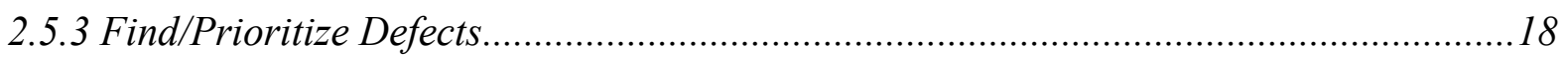

2.6 SP 800-53 Control Items that Support SWAM ............................................................. 18

2.6.1 Process for Identifying Needed Controls ............................................................ 18

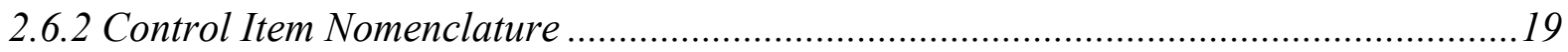

2.7 SWAM Specific Roles and Responsibilities ......................................................................20

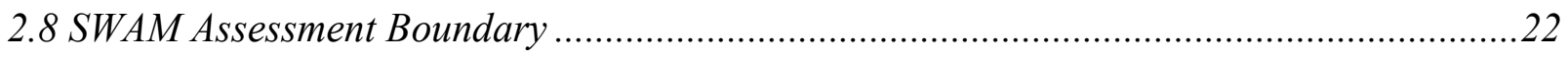

2.9 SWAM Actual State and Desired State Specification ...................................................22

2.10 SWAM Authorization Boundary and Inheritance ...........................................................23

2.11 SWAM Assessment Criteria Recommended Scores and Risk-Acceptance Thresholds......23

2.12 SWAM Assessment Criteria Device Groupings to Consider ..........................................23

3. SWAM Security Assessment Plan Documentation Template...........................................24

3.1 Introduction and Steps for Adapting This Plan ..........................................................24

3.1.1 Select Defect Checks to Automate ...............................................................................24

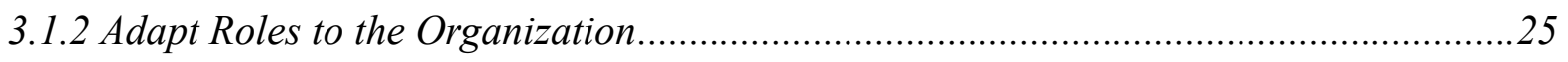

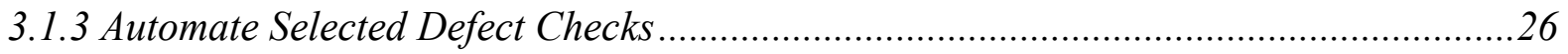


3.2 SWAM Sub-Capabilities and Defect Check Tables and Templates..................................27

3.2.1 Foundational Sub-Capabilities and Corresponding Defect Checks.............................28

3.2.2 Data Quality Sub-Capabilities and Corresponding Defect Checks ..............................37

3.2.3 Local Sub-Capabilities and Corresponding Defect Checks ......................................45

3.2.4 Security Impact of Each Sub-Capability on an Attack Step Model ............................... 74

3.3 SWAM Control (Item) Security Assessment Plan Narrative Tables and Templates............82

3.3.1 Outline Followed for Each Control Item .............................................................. 83

3.3.2 Outline Organized by Baselines............................................................................... 83

3.3.3 Low Baseline Security Control Item Narratives ......................................................85

3.3.4 Moderate Baseline Security Control Item Narratives ............................................115

3.3.5 High Baseline Security Control Item Narratives ...................................................148

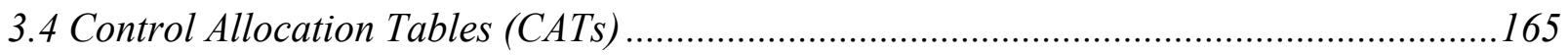

3.4.1 Low Baseline Control Allocation Table.................................................................. 166

3.4.2 Moderate Baseline Control Allocation Table .............................................................168

3.4.3 High Baseline Control Allocation Table ...................................................................... 169

Appendix A. Traceability of SWAM Control Items to Example Attack Steps................... A-1

Appendix B. Keyword Rules Used to Identify Controls that Support SWAM....................B-1

Appendix C. Control Items in the Low-High Baseline that were Selected by the Keyword Search for Controls that Support SWAM, but were Manually Determined to be False Positives....................................................................................................................... C-1

Appendix D. Control Items Not in the Low, Moderate, or High Baselines ........................ D-1

Appendix E. SWAM-Specific Acronyms and Abbreviations* ................................................E-1

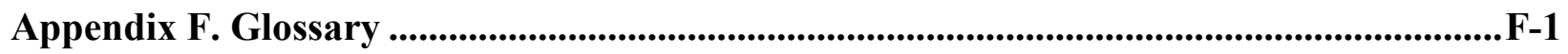

Appendix G. Control Items Affecting Desired and/or Actual State from All Defect Checks in this Volume........................................................................................................................ G-1 


\section{List of Figures}

Figure 1: SWAM Impact on an Attack Step Model .............................................................

Figure 2: Definition and Discussion of Software File for SWAM ...........................................10

Figure 3: Definition and Discussion of Software Products for SWAM ......................................10

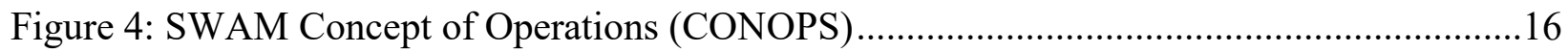

Figure 5: Primary Roles in Automated Assessment of SWAM .............................................22

Figure 6: Main Steps in Adapting the Plan Template............................................................24

Figure 7: Sub-Steps to Select Defect Checks to Automate......................................................24

Figure 8: Sub-Steps to Adapt Roles to the Organization .........................................................25

Figure 9: Sub-Steps to Automate Selected Defect Checks ....................................................26

\section{List of Tables}

Table 1: SWAM Impact on an Attack Step Model ..............................................................

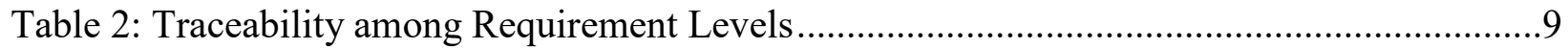

Table 3: Example SWAM Actual State Data Requirements .....................................................14

Table 4: Example SWAM Desired State Data Requirements ................................................15

Table 5: Operational and Managerial Roles for SWAM ..........................................................20

Table 6: Mapping of Attack Steps to Security Sub-Capability................................................74

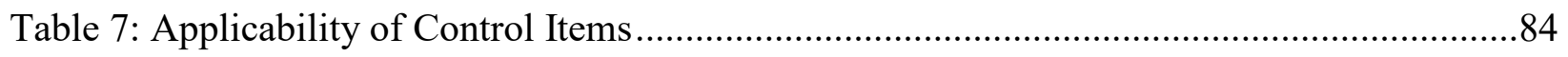

Table 8: Low Baseline Control (Item) Allocation Table ......................................................166

Table 9: Moderate Baseline Control (Item) Allocation Table ...................................................168

Table 10: High Baseline Control (Item) Allocation Table ...................................................169 


\section{Executive Summary}

The National Institute of Standards and Technology (NIST) and the Department of Homeland Security (DHS) have collaborated to produce this report which describes a process that automates the test assessment method described in NIST Special Publication (SP) 800-53A for the security controls catalogued in SP 800-53. The process is consistent with the Risk Management Framework as described in SP 800-37 and the Information Security Continuous Monitoring (ISCM) guidance in SP 800-137. The multi-volume NIST Interagency Report 8011 (NISTIR 8011) has been developed to provide information on automation support for ongoing assessment. NISTIR 8011 describes how ISCM facilitates automated ongoing assessment to provide near real-time security-related information to organizational officials on the security posture of individual systems and the organization as a whole.

NISTIR 8011 Volume 1 includes a description of ISCM Security Capabilities-groups of security controls working together to achieve a common purpose. The subsequent NISTIR 8011 volumes are capability-specific volumes. Each volume focuses on one specific ISCM information security capability in order to (a) add tangible detail to the more general overview given in NISTIR 8011 Volume 1; and (b) provide a template for the transition to detailed, standards-based automated assessments.

This publication, Volume 3 of NISTIR 8011, addresses the information security capability known as Software Asset Management (SWAM). The focus of the SWAM capability is to manage risk created by unmanaged or unauthorized software that are on a managed network. When software is unmanaged or unauthorized, they are vulnerable because the software files may be forgotten or unidentified. Moreover, when vulnerabilities are discovered on such software, responsibility to respond to the consequent risk is not assigned. As a result, the presence of unmanaged and unauthorized software means that devices are targets that attackers can use as a persistent platform from which to attack components on the network.

A well-designed SWAM program helps to:

- prevent compromised software from being installed or staying deployed on the network;

- prevent attackers from gaining a foothold;

- prevent attacks from becoming persistent; and

- restore required and authorized software as needed.

Automated ongoing assessment helps verify that software asset management is working by applying defect checks to test the effectiveness of the SWAM capability and the security controls that support the SWAM capability.

This volume outlines detailed step-by-step processes to meet the needs of a specific assessment target network and apply the results to the assessment of all authorization boundaries on that network. A process is also provided to implement the assessment (diagnosis) and response. Automated testing related to the controls for SWAM, as outlined herein, is consistent with other NIST guidance. 
It has not been obvious to security professionals how to automate testing of other than technical controls. This volume documents a detailed assessment plan to assess the effectiveness of controls related to authorizing and assigning software to be managed. Included are specific tests that form the basis for such a plan, how the tests apply to specific controls, and the kinds of resources needed to conduct the assessment and use the assessment results to mitigate defects found. For SWAM, it can be shown that the assessment of 92.6 percent ${ }^{1}$ of determination statements for controls in the SP 800-53 Low-Medium-High baselines can be fully or partially automated.

The methods outlined here for automated, ongoing assessment are designed to provide objective, timely, and complete identification of security defects related to SWAM at a lower cost than manual assessment methods. Using this defect information can drive the most efficient and effective remediation of the worst security defects found.

This volume assumes the reader is familiar with the concepts and ideas presented in the Overview (NISTIR 8011, Volume 1). Terms and acronyms used herein that are common to multiple capabilities are defined in Volume 1 Appendix B (glossary) and Appendix C respectively. Similarly, references used herein that are common to multiple capabilities are provided in Volume 1 Appendix A.

\footnotetext{
${ }^{1}$ Derived from the Control Allocation Tables (CAT) in this volume. With respect to security controls selected in the SP 800-53 Low-Medium-High baselines that support the SWAM capability, 75 of 81 determination statements (92.6\%) can be fully or partially automated.
} 


\section{Introduction}

\subsection{Purpose and Scope}

The purpose of the National Institute of Standards (NIST) Interagency Report (NISTIR) 8011 Volume 3 is to provide an operational approach for automating the ongoing assessment of NIST Special Publication (SP) $800-53^{2}$ security controls related to the Information Security Continuous Monitoring (ISCM)-defined security capability of Software Asset Management (SWAM) that is consistent with the principles outlined in NISTIR 8011 Volume $1 .^{3}$

The scope of this report is limited to security controls and control items that are implemented to manage the download, installation, and execution of unauthorized and malicious software (malware). ${ }^{4}$ In this case, malware refers to known and unknown malicious code, including software that executes a zero-day attack.

\subsection{Target Audience}

The target audience for this volume, because it is focused on SWAM, is of special relevance to those who authorize, download, install and/or execute software. However, it is also of value to others to help understand the risks software may be imposing on other assets.

\subsection{Organization of this Volume}

Section 2 provides an overview of the SWAM capability to clarify both scope and purpose and provides links to additional information specific to the SWAM capability. Section 3 provides detailed information on the SWAM defect checks and how the defect checks automate assessment of the effectiveness of SP 800-53 security controls that support the SWAM capability. Section 3 also provides artifacts that can be used by an organization to produce an automated security control assessment plan for most of the control items supporting Software Asset Management.

\footnotetext{
${ }^{2}$ Joint Task Force Transformation Initiative, Security and Privacy Controls for Information Systems and Organizations, (2013), (National Institute of Standards and Technology, Gaithersburg, MD), NIST Special Publication (SP) 800-53, https://doi.org/10.6028/NIST.SP.800-53r4.

${ }^{3}$ Dempsey K., et al (2017) Automation Support for Security Control Assessments: Overview (National Institute of Standards and Technology, Gaithersburg, MD), NIST Interagency Report (IR) 8011 Volume 1, https://doi.org/10.6028/NIST.IR.8011-1.

${ }^{4}$ Malware, also known as malicious code, refers to a software program that is covertly inserted into another software program with the intent to destroy data, run destructive or intrusive software programs, or otherwise compromise the confidentiality, integrity, or availability of the victim's data, applications, or operating system. Source: Souppaya M., Scarfone K., (2013) (National Institute of Standards and Technology, Gaithersburg, MD), Guide to Malware Incident Prevention and Handling for Desktops and Laptops, NIST Special Publication (SP) 800-83, https://doi.org/10.6028/NIST.SP.800-83r1.
} 


\subsection{Interaction with Other Volumes in this NISTIR}

Volume 1 of this NISTIR (Overview) provides a conceptual synopsis of using automation to support security control assessment and provides definitions and background information that facilitate understanding of the information in this and other capability-specific volumes.

This volume assumes the reader is familiar with the concepts and ideas presented in the Overview (NISTIR 8011, Volume 1). Terms and acronyms used herein that are common to multiple capabilities are defined in Volume 1 Appendix B (glossary) and Appendix C respectively. Similarly, references used herein that are common to multiple capabilities are provided in Volume 1 Appendix A.

The SWAM capability identifies software that is being placed or executed on hardware in the target network. SWAM supports other ISCM capabilities by providing the full census of software which can be used to check for other defects such as configuration settings (configuration setting management capability) and patches (vulnerability management capability).

SWAM is in turn supported by other ISCM capabilities such as the Privilege and Account Management capability (PRIV) ${ }^{5}$ for implementation as discussed further in Section 2.6.1.

The Boundary Management capability (BOUND) is designed to prevent the insertion of unauthorized software into any device within the assessment boundary from outside the boundary. In contrast, the SWAM capability focuses on detecting and removing, or denying execution of all unauthorized or unmanaged software; however, some SWAM tools can also block unauthorized software from being installed on the device. For example, email filters attempt to block delivery of malicious emails, which frequently contain malware. Network level antivirus scanners have a similar function. Detonation Chambers (See SP 800-53, control SC-44) can be used on software entering the network, to look for actions that might be malicious, by watching behavior of that software in an isolated environment. Detonation chambers can thereby sometimes detect zero-day attacks if equipped to look for patterns of malicious behavior as discussed further toward the end of Section 2.3.

It may appear that some software related controls are, erroneously, not included here. However, not all software-related controls are covered in SWAM. SWAM focuses on software authorization. Other aspects of software are addressed in other ISCM capabilities, for example: Configuration Settings Management (CSM) addresses software configurations; Vulnerability Management (VULN) addresses vulnerability management (Common Vulnerabilities and Exposures (CVE) and Common Weakness Enumeration CWE)) and includes patching needed to address security issues (as opposed to patching needed for functionality issues which is addressed by SWAM); and BOUND addresses movement of unauthorized software into the network through telecommunications, etc.

\footnotetext{
${ }^{5}$ See Volume One for a discussion of ISCM capabilities.
} 


\section{Software Asset Management (SWAM) Capability Definition, Overview, and Scope}

Software Asset Management recognizes that target network devices with unauthorized software ${ }^{6}$ are likely to be vulnerable. External and internal attackers search for and exploit such software, either for what the software itself can offer, or as a platform from which to persist on the network or to attack other assets. By removing or preventing execution of unauthorized or unmanaged software, SWAM helps reduce the probability that attackers find and exploit software.

A key attack vector is to place (or replace) software on a device in order to perform malicious activities. Such software, called malware, can support exfiltration of data (compromising confidentiality), changing of data (compromising integrity), disruption of operations (compromising availability) and/or establishment of remote command and control over the device to more flexibly perform malicious activity at the will of the attacker. Removing unauthorized or unmanaged software from devices, or blocking its execution, can reduce the success rate of malware attacks.

\section{Two Aspects of Software Asset Management}

In a broader context, software asset management (SAM) is a business practice that includes purchasing, deploying, maintaining, using, and disposing of software applications.

In NISTIR 8011, software asset management (SWAM) is specifically focused on making informed decisions about the software authorized to be present on each device, given business need and security risk, and then enforcing the authorizations.

\subsection{SWAM Capability Description}

The Software Asset Management capability provides an organization visibility into the software operating on its network(s) so it can manage and defend itself. The SWAM capability focuses on making and enforcing software authorization decisions, balancing business need with security risk, and providing a view of software management responsibility that helps prioritize identified defects and facilitate risk response decisions (e.g., mitigation or acceptance) by the responsible party.

SWAM identifies software that is present on the network (the actual state) and compares it with the desired state software inventory to determine if the software present is authorized. The SWAM capability is focused on ensuring that all software authorized to be installed on target

\footnotetext{
${ }^{6}$ Unauthorized software is software that has not been assessed and authorized to be installed on target network devices as part of an overall system authorization process or individually if the software was installed after the initial system authorization. The organization may also consider implementing a process to deauthorize old software versions as new versions are authorized (see SWAM-L07).
} 
network devices is fully identified and that an appropriate installation/execution control policy is applied.

In general, software authorization decisions can be expressed and enforced in one of two ways:

1. Software whitelisting ${ }^{7}$ (deny-all, permit-by-exception) blocks all software unless explicitly approved in a software whitelist.

2. Software blacklisting (allow-all, deny-by exception) blocks only software specifically prohibited (a software blacklist) and allows all other software.

A whitelist or blacklist is a product of the authorization process. Blacklisting and whitelisting are inseparable from authorization. Supporting blacklisting and whitelisting are a set of informed decisions made about what software to authorize - considering both business need for the software and security risk introduced by the software.

Attacks can come from previously unknown malware (aka zero-day attacks). Note that software blacklisting ${ }^{8}$ has effectively no impact on zero-day attacks because malware makers can make minor variations to software that evade blacklisting, thus allowing the attack to proceed. Conversely, software whitelisting can prevent zero-day attacks since whitelisting allows only explicitly approved software to execute.

Most software whitelisting implementations divide software into three categories:

1. Known good (allowed) software (such as a pre-approved whitelist)

2. Known bad software (such as a list of software that is not to be approved, similar to a blacklist, used to restrict the range of software that is whitelisted).

3. Other software, not yet assessed for whitelist eligibility (a graylist). ${ }^{9}$

\footnotetext{
${ }^{7}$ Software whitelisting is a deny-all, permit-by-exception strategy that only allows software to install, run, etc. by exception (i.e., if it is specified in an authorized software list as per NIST SP 800-53, CM-7(5)).

${ }^{8}$ As this volume is being written, blacklisting is not selected as a viable software authorization strategy for the low, moderate, or high baselines in the draft of NIST SP 800-53 Revision 5.

${ }^{9} \mathrm{~A}$ graylist is a list of discrete entities that have not yet been established as benign or malicious; more information is needed to move graylist items onto a whitelist or a blacklist. Source: Sedgewick A., et al (2015) Guide to Application Whitelisting (National Institute of Standards and Technology, Gaithersburg, MD), NIST Special Publication (SP) 800-167. https://doi.org/10.6028/NIST.SP.800-167, p. 2.
} 


\section{Note on Implementation of Application Whitelisting/Blacklisting}

This NISTIR proposes automated defect checks for software asset management, some of which (SWAM-F01 through SWAM-F03) are used to test approaches to software whitelisting that are currently in common use. Use of a different approach might call for development of a modified foundational defect check to test that approach, as the organization is expected to deploy defect checks that match the approach to whitelisting or blacklisting actually used. There are a range of options for implementing software whitelisting, each with its own associated strengths and disadvantages, as described in detail in NIST SP 800-167. ${ }^{10}$ Each organization is expected to conduct its own analysis and decide which variant of whitelisting or blacklisting is needed to manage risk effectively. Note that whitelisting methods are evolving - whitelisting is already a standard feature in most of the popularly used operating systems - so vigilance is required to ensure that new methods and options are considered as they appear and adopted as appropriate.

Organizations just beginning to whitelist may have a large quantity of software on the graylist. Some organizations may choose to temporarily allow (whitelist) the graylisted software. Others may block software on the graylist until the software is evaluated and approved. In either case, management of unassessed graylist software is an important task that may require a large amount of resources, especially in large or complex organizations.

In practice, organizations consider the following when whitelisting a software product:

1. Whether to use whitelisting technologies built into available operating systems (OSs). As of this writing, most OSs have application control technologies, and software vendors continually improve the functionality of the technologies in new versions. When such improvements are made, organizations may leverage the new OS releases to limit or further restrict applications to develop a cleaner, more streamlined whitelist. A relevant feature for consideration is whether the OS version provides a trust repository of data on known good and known bad products and software files, and whether the repository is kept current.

2. Maintaining different whitelists for different device sets. For example, certain software might only appear on whitelists for specific types of components such as file servers, database servers, or end user devices. Similarly, the common operating system or the default email client used by an organization does not require a decision on each device, but appears on all whitelists maintained by an organization. Known malware, meanwhile, does not appear on any whitelist.

3. Whitelisting in phases. An organization might choose to implement whitelisting in software environments with predictable software turnover rates first, perhaps choosing those sets of devices under centrally managed desktops. Or, an organization might choose high-risk environments with high impact baseline control needs first. Organizations might schedule environments with many non-standard, low-risk or rapidly changing software components near the end of the whitelisting implementation.

\footnotetext{
${ }^{10}$ Sedgewick A., et al (2015) Guide to Application Whitelisting (National Institute of Standards and Technology, Gaithersburg, MD), NIST Special Publication (SP) 800-167, https://doi.org/10.6028/NIST.SP.800-167.
} 
4. Testing. Monitoring or auditing mode, available in most whitelisting technologies, allows software managers to estimate the impact on resources before enforcing whitelisting. Monitoring allows planning for resource requirements in advance of actual implementation.

5. Attributes. Increasingly, organizations are implementing whitelisting products that support more granular whitelisting attributes, such as Software Identification (SWID) tags. ${ }^{11}$ In the Guide to Application Whitelisting (2015), the authors note:

Choosing attributes is largely a matter of achieving the right balance of security, maintainability, and usability. Simpler attributes such as file path, filename, and file size should not be used by themselves unless there are strict access controls in place to tightly restrict file activity, and even then there are often significant benefits to pairing them with other attributes. A combination of digital signature/publisher and cryptographic hash techniques generally provides the most accurate and comprehensive application whitelisting capability, but usability and maintainability requirements can put significant burdens on the organization.

The whitelisting/blacklisting strategy used in the ISCM process (as adapted for each agency) provides insight into what portion of the actual software assets are included in the desired state, and of those, how many have an assigned manager identified.

${ }^{11}$ Waltermire D., et al (2016), Guidelines for the Creation of Interoperable Software Identification (SWID) Tags (National Institute of Standards and Technology, Gaithersburg, MD), NIST Interagency Report (NISTIR) 8060, https://csrc.nist.gov/publications/detail/nistir/8060/final. 


\subsection{SWAM Attack Scenarios and Desired Result}

NISTIR 8011 uses an attack step model to summarize the six primary steps of cyber attacks that SP 800-53 controls work together to block or delay. The $S W A M$ security capability is intended to block or delay attacks only at the attack steps addressed in Figure 1: SWAM Impact on an Attack Step Model and Table 1: SWAM Impact on an Attack Step Model.

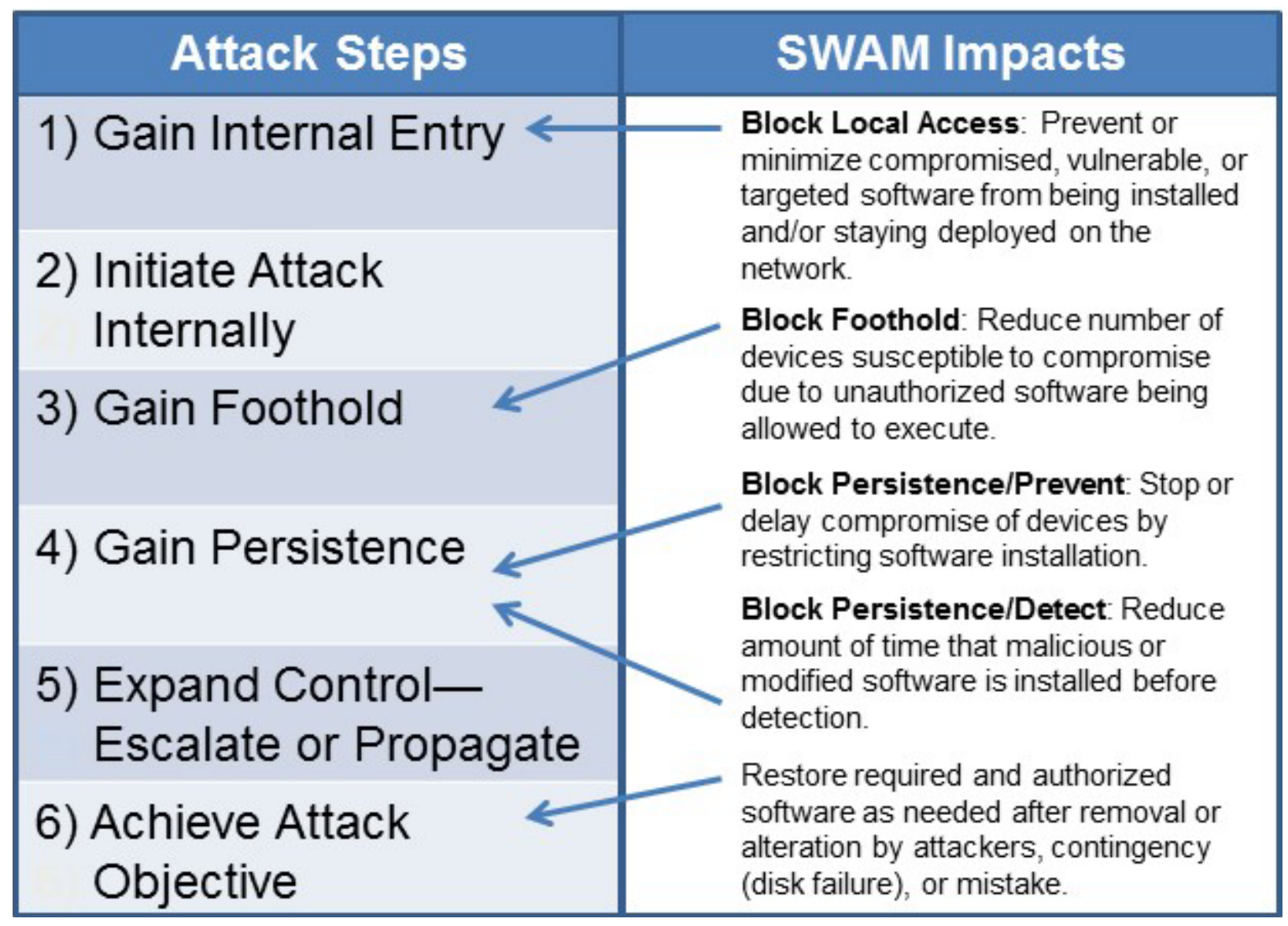

Figure 1: SWAM Impact on an Attack Step Model ${ }^{12}$

\footnotetext{
${ }^{12}$ The attack steps shown in Figure 1 apply only to adversarial attacks. (See NISTIR 8011, Volume 1, Section 3.2.)
} 
Table 1: SWAM Impact on an Attack Step Model

\begin{tabular}{|c|c|c|}
\hline $\begin{array}{c}\text { Attack Step } \\
\text { Name }\end{array}$ & Attack Step Purpose (General) & Capability-Specific Examples \\
\hline $\begin{array}{l}\text { 1) Gain } \\
\text { Internal Entry }\end{array}$ & $\begin{array}{l}\text { The attacker is outside the target boundaries and } \\
\text { seeks entry. } \\
\text { Examples include: spear phishing email sent; } \\
\text { distributed denial of service (DDoS) attack against } \\
\text {.gov initiated; unauthorized person attempts to gain } \\
\text { physical access to restricted facility. }\end{array}$ & $\begin{array}{l}\text { Block Local Access: Prevent or } \\
\text { minimize compromised, vulnerable, } \\
\text { or targeted software from entering or } \\
\text { being stored on the network or } \\
\text { devices in a way that would allow } \\
\text { installation or execution. }\end{array}$ \\
\hline $\begin{array}{l}\text { 3) Gain } \\
\text { Foothold }\end{array}$ & $\begin{array}{l}\text { The attacker has gained entry to the assessment } \\
\text { object and achieves enough compromise to gain a } \\
\text { foothold, but without persistence. } \\
\text { Examples include: unauthorized user successfully } \\
\text { logs in with authorized credentials; browser exploit } \\
\text { code successfully executed in memory and initiates } \\
\text { call back; person gains unauthorized access to } \\
\text { server room. }\end{array}$ & $\begin{array}{l}\text { Block Foothold: Reduce number of } \\
\text { devices susceptible to compromise } \\
\text { due to unauthorized software being } \\
\text { allowed to execute. }\end{array}$ \\
\hline $\begin{array}{l}\text { 4) Gain } \\
\text { Persistence }\end{array}$ & $\begin{array}{l}\text { The attack has gained a foothold on the object and } \\
\text { now achieves persistence. } \\
\text { Examples include: malware installed on host that } \\
\text { survives reboot or log off; basic input/output system } \\
\text { (BIOS) or kernel modified; new/privileged account } \\
\text { created for unauthorized user; unauthorized person } \\
\text { issued credentials/allowed access; unauthorized } \\
\text { personnel added to access control list (ACL) for } \\
\text { server room. }\end{array}$ & $\begin{array}{l}\text { Block Persistence/Prevent: Stop or } \\
\text { delay compromise of devices by } \\
\text { restricting software installation. } \\
\text { Block Persistence/Detect: Reduce } \\
\text { amount of time that malicious or } \\
\text { compromised software is installed or } \\
\text { remains active before detection and } \\
\text { removal. }\end{array}$ \\
\hline $\begin{array}{l}\text { 6) Achieve } \\
\text { Attack } \\
\text { Objective }\end{array}$ & $\begin{array}{l}\text { The attacker achieves an objective. Loss of } \\
\text { confidentiality, integrity, or availability of data or } \\
\text { system capability. } \\
\text { Examples include: exfiltration of files; modification of } \\
\text { database entries; deletion of file or application; } \\
\text { denial of service; disclosure of personally } \\
\text { identifiable information (PII). }\end{array}$ & $\begin{array}{l}\text { Restore required and authorized } \\
\text { software as needed, after being } \\
\text { removed or altered by attackers, } \\
\text { contingency (disk failure), or by } \\
\text { mistake. }\end{array}$ \\
\hline
\end{tabular}


Other examples of traceability among requirement levels. While Table 1 shows SWAM impacts on example attack steps, it is frequently useful to observe traceability among other sets of requirements. To examine such traceability, see Table 2: Traceability among Requirement Levels. To reveal traceability from one requirement type to another, look up the cell in the matching row and column of interest and click on the link.

Table 2: Traceability among Requirement Levels

\begin{tabular}{|c|c|c|c|c|}
\hline & $\begin{array}{c}\text { Example Attack } \\
\text { Steps }\end{array}$ & Capability & $\begin{array}{l}\text { Sub-Capability/ } \\
\text { Defect Check }\end{array}$ & Control Items \\
\hline $\begin{array}{l}\text { Example Attack } \\
\text { Steps }\end{array}$ & & $\begin{array}{l}\text { Figure } 1 \\
\text { Table } 1\end{array}$ & Table 6 & Appendix A \\
\hline Capability & $\begin{array}{l}\text { Figure } 1 \\
\text { Table } 1\end{array}$ & & Table 6 & Section $3.3^{a}$ \\
\hline $\begin{array}{l}\text { Sub-Capability/ } \\
\text { Defect Check }\end{array}$ & Table 6 & Table 6 & & Section $3.2^{\mathrm{b}}$ \\
\hline Control Items & Appendix A & Section $3.3^{a}$ & Section $3.2^{b}$ & \\
\hline
\end{tabular}

${ }^{a}$ Each level-four section (e.g., 3.3.1.1) is a control item that supports this capability.

${ }^{\mathrm{b}}$ Refer to the table under the heading Supporting Control Items within each defect check.

\subsection{Assessment Objects Protected and Assessed by SWAM}

As noted in Section 1.1, the assessment objects directly managed and assessed by the SWAM capability are software files and software products. However, the following clarification is relevant:

Software (code), as used here, includes a range of assets that might not always be thought of as software. Such software assets include:

- Installed software files and products listed in the operating system software database ${ }^{13}$ (e.g., Windows registry, Linux package manager);

- Software files and products residing on a hard drive, but not listed in the operating system database;

- Mobile code, ${ }^{14}$

- Firmware, if it can be modified ${ }^{15}$ (usually includes the BIOS); and

- Code in memory (which could be modified in place).

\footnotetext{
${ }^{13}$ Virtual machines are included in the operating system software database.

${ }^{14}$ Mobile code consists of software programs or parts of programs obtained from remote systems, transmitted across a network, and executed on a local system without explicit installation or execution by the recipient.

${ }^{15}$ Modifiable firmware is treated as software.
} 
Note: Software includes all software on the system. The term software is not limited to business software, and also includes, for example, operating system software and security software (e.g., firewalls, white-listing software, configuration management tools, vulnerability scanners, etc.). The term software also includes shared code used by a product (e.g., dynamic link libraries (DLLs), other shared libraries, etc.). Appendix G reflects the relationship between configuration management controls and SWAM-related control items.

Each of the above types of software may require different controls to effectively prevent the execution of malicious software.

Software files can be stored on a device's mass storage, loaded into memory, and executed. [See Figure 4]; or software files can be mobile code obtained from a website.

Software files can be authoritatively identified by a message digest ${ }^{16}$ computed from the software file. If an adversary tampers with the file, the tampering can be objectively and accurately confirmed by viewing the resulting change to the message digest.

Mobile code can be trusted based on the trust level assigned to any digital signature applied to the mobile code.

Files that include executable code are also software files (e.g., explicit executables, shared libraries, executable scripts, extensible stylesheet language (XSL) templates, documents that include macros that mix information with code). Because the files that include the executable code may change frequently, it is incumbent on the organization to identify and protect such files from unauthorized changes and to protect the system from files containing unauthorized changes, for example via use of a digital signature from a trusted source.

\section{Figure 2: Definition and Discussion of Software File for SWAM}

Software Products are collections of software files (generally sold as a unit) that work together to provide user functionality.

Examples of software products are operating systems (e.g., Apple IOS 11), office products (e.g., Microsoft Office), utilities (e.g., a database management system such as Oracle), or drivers that come with devices such as printers, scanners, monitors, etc.

A software product frequently has multiple versions. The versions include not only major versions (such as Oracle 12C), but also specific releases within versions, or minor versions, (such as 12.2) and the specific patches that may be applied to that release.

A unique product has the identical collection of software files with the same digital fingerprints as any other instance of that product. Any change in the files could be malicious.

Figure 3: Definition and Discussion of Software Products for SWAM

\footnotetext{
${ }^{16} \mathrm{~A}$ message digest results from applying a cryptographic hash function to an executable or file. The executable or file is the message, and the result of the computation is the digest. A message digest is also known as a cryptographic hash value or digital fingerprint.
} 
Installed software files for software products may be shared by several other products as is notably true for shared library software files. An update to any one of the files for a product may update the shared library used by other products. Given the definition of a unique software product above - as a collection of software files with the same digital fingerprints - changing the shared library changes each of the affected products into a different product.

Software uninstallers may also leave some residue of a product behind on devices. For example, the uninstaller might not delete certain software files in shared libraries (because the files could potentially be used by another product). Since it is a common exploit to insert malware into files that are already included in a whitelisted product (e.g., by modifying an approved software product to load malware), risk is increased by software file residue from software product deinstallation. The file residue might not be detectable when using product-level whitelisting if the product-level whitelisting does not use message digests; however, software file residue may be detected by file-level whitelisting using message digests since when the modified software file attempts to load, its modified message digest is detected and execution is prevented.

Instances where software files and products are missing from the operating system software database occur because some software products do not require formal installation. The software files and products are simply copied to the device's mass storage, and then executed without creating software database entries.

In software approval processes, the focus is on whitelisting/blacklisting ${ }^{17}$ of software products or software files. Because software products may be difficult to identify, focusing on software files is often more reliable. Identifying software at the product level (typically done via operating system software database entries) is significantly less reliable than identifying the product with a digital fingerprint for all files contained in the installation. However, it is still hard to identify the product (except probabilistically) because:

- The same product, even the same product version, might contain different files with different digital fingerprints, due to:

- Differences in installation media;

- Differences in installation options;

- Subsequent patching of the product;

- Subsequent patching of other products, e.g., that affect a shared DLL;

- Attacker action that modifies a product file; or

- Execution of an uninstalled file, not related to a registered product.

- When products are removed or upgraded, it is possible that not all software files are removed, as installers might not remove them fearing that particular files are still needed by other products. Such software files would remain subject to exploitation.

However, an organization that receives a product from a custom development team and/or a commercial off-the-shelf (COTS) supplier can register the contained (trusted) software files, and

\footnotetext{
${ }^{17}$ Whitelisting/blacklisting tools (and other utilities) might require execution of software agents on each device. The organization might find that collectively the software agents have some performance impact on the device. The overall selection of agents and configuration of agent behavior can be adjusted to allow adequate business performance by each device. See NIST SP 800-167 for more information on considerations for software whitelisting.
} 
thereby reliably track whether exactly that specific version and patch level of the software is what has been installed.

Recognizing that software whitelisting at the product level is unreliable, the following four provisions can provide the needed reliability to software whitelisting at the executable file level using digital fingerprints:

1. An authoritative directory of trusted software files (trusted repository). A trusted repository is developed by obtaining digital fingerprints from software files obtained as near to the trusted source as possible. The source might be a commercial software provider or an in-house custom software operation. When using open-source code, an authoritative directory might be more difficult to obtain, but can still be addressed by carefully examining the source code for the presence of CWEs and resolving issues found internally before trusting the code.

2. A means to compute digital fingerprints and register trusted software not included in the vendor's trust repository.

3. Software files received as digitally-signed files from trusted sources. If the code is mobile code, digital signing is an imperative (except perhaps on isolated disposable virtual machines). If mobile code is allowed, the trust can be established dynamically, based on the signature of the trusted source.

4. Whitelisting software loaded near the root of the operating system (OS). Whitelisting software loaded near the root of the OS blocks or requires permission to download, load-in-memory, and/or execute software that is not whitelisted.

Generally, a good software whitelisting product has all of capabilities (1), (2), (3), and (4), and supports automatic trust based on signature and/or identity of those who install the software.

It is important to note that SWID tags can make the process of identifying software products more deterministic by tagging products independent of the installation method and any associated patches.

As a result of the definition of software products, the use of shared files, and the ability to load software that is not inventoried in the operating system software database, it is very difficult to know what software products are on a device. Also, controlling software inventory based on software products listed in the operating system software database is highly unreliable, especially when compared to controlling software inventory based on digital fingerprints for software files. However, using software whitelisting with features 1 to 4, even while ignoring the operating system software database, resolves the unreliability issues.

Mobile code is distinguished by the fact that rather than being loaded from the device's mass storage, it is loaded at the time of use from the larger network (typically via a website). The code is managed externally, and may change frequently, rendering the device incapable of computing a valid digital fingerprint for the mobile code, and thus requiring other means to validate the code. Requiring the mobile code to be digitally signed by a trusted source is one method employed to validate such code. Another option is to block all mobile code not from a trusted website. 
A key alternate method for addressing mobile code is covered in NIST SP 800-53 control SC-44 (Detonation Chamber). Because SC-44 is not selected in the NIST SP 800-53B low, moderate, or high baselines, it is not included in this NISTIR. However, detonation chambers are effective in protecting against malicious mobile code, including mobile code downloaded from a web site, as well as mobile code in e-mails and attachments. Malicious mobile code is addressed further in the NISTIR 8011 volume on the boundary management capability.

Firmware is often considered to be a hybrid between hardware and software. For the purposes of this NISTIR, firmware is code stored in non-volatile memory that can be updated. The ability to update firmware allows hardware manufacturers great flexibility, reducing the need to replace hardware when issues are found or changes need to be made. Firmware that can be updated is subject to malicious code insertion, and thus needs protection under the SWAM capability. Generally, it is possible to compute a digital fingerprint for firmware. In addition, there are hardware mechanisms to validate firmware, such as the trusted platform module (TPM).

Code in memory is harder to protect than other forms of software addressed in this volume. Because changes to code in memory are very hard to detect, such changes can be very stealthy. However, the effects may be transient, lasting only until other code is loaded into memory. Since there are categories of in-memory attacks that do not disappear when other code is loaded into memory, assessment of controls related to code in memory are assigned to manual assessment. 


\subsection{Example SWAM Data Requirements ${ }^{18}$}

Examples of data requirements for the SWAM actual state are provided in Table 3. Examples of data requirements for the SWAM desired state are provided in Table 4.

Table 3: Example SWAM Actual State Data Requirements

\begin{tabular}{|c|c|}
\hline Data Item & Justification \\
\hline $\begin{array}{l}\text { The software installed on every device. To be } \\
\text { usable for automated assessment, the data must be } \\
\text { converted into a format that can be compared, by } \\
\text { machine, with the authorized software inventory. } \\
\text { Examples include: } \\
\text { - Software Identification (SWID) tag; }{ }^{\text {a }} \text { and } \\
\text { - Common Platform Enumeration (CPE). }{ }^{\mathrm{b}}\end{array}$ & $\begin{array}{l}\text { To identify when unauthorized software is } \\
\text { installed on a device }\end{array}$ \\
\hline $\begin{array}{l}\text { Data necessary to determine how long unauthorized } \\
\text { software has been present on a device. At a } \\
\text { minimum: } \\
\text { - Date/time unauthorized software was first } \\
\text { discovered; and } \\
\text { - Date/time unauthorized software was last seen. }\end{array}$ & $\begin{array}{l}\text { To determine how long unauthorized software } \\
\text { has been on a device. }\end{array}$ \\
\hline $\begin{array}{l}\text { Software blacklist }{ }^{a} \text { used to check device, to include } \\
\text { version number or date of last update. }{ }^{b}\end{array}$ & $\begin{array}{l}\text { - To determine if device was checked for } \\
\text { unauthorized software. } \\
\text { - To determine if the known-bad software } \\
\text { blacklist is up-to-date per policy. }\end{array}$ \\
\hline
\end{tabular}

${ }^{a}$ Note that RFC 8412 provides a notification mechanism for reporting software installations as they occur using SWID tag data. https://www.rfceditor.org/rfc/pdfrfc/rfc8412.txt.pdf.

b For more information on CPE, see https://csrc.nist.gov/projects/security-content-automation-protocol/specifications/cpe/.

${ }^{\mathrm{C}}$ Blacklisted software is software that is not authorized to execute on a system; or prohibited Universal Resource Locators or websites.

${ }^{d}$ For blacklists, it is essential to keep the blacklist current, as new "known bad" software items are found. (This is one of the features of blacklisting that makes it less effective.) Whitelists only need to be updated on an event driven basis, e.g., when a version of software is replaced by a new version.

\footnotetext{
${ }^{18}$ Specific data required is variable based on organizational platforms, tools, configurations, etc.
} 
Table 4: Example SWAM Desired State Data Requirements

\begin{tabular}{|c|c|}
\hline Data Item & Justification \\
\hline $\begin{array}{l}\text { Authorized hardware inventory, to include assigned } \\
\text { and authorized device attributes. See NISTIR } 8011 \\
\text { Volume } 2 \text {. }\end{array}$ & $\begin{array}{l}\text { To identify what devices to check against what } \\
\text { software defect checks. }\end{array}$ \\
\hline The associated value for device attributes. ${ }^{a}$ & To prioritize defects associated with devices. \\
\hline $\begin{array}{l}\text { Sets of attributes designated as mutually exclusive } \\
\text { per the organization's policy. }\end{array}$ & $\begin{array}{l}\text { For comparison with the set of assigned device } \\
\text { attributes. }\end{array}$ \\
\hline $\begin{array}{l}\text { 1. A listing of all authorized software for the } \\
\text { organization to include data necessary to } \\
\text { accurately identify the software product and } \\
\text { compare to actual state data collected (vendor; } \\
\text { product; version/release level/patch level; SWID } \\
\text { tag; CPE; etc.). } \\
\text { 2. Authoritative listing of executable software files } \\
\text { associated with product. (With digital fingerprint } \\
\text { of each file.) } \\
\text { 3. Software Manager by device and product } \\
\text { 4. Expiration policy. } \\
\text { 5. Authorization status (dates initially authorized, } \\
\text { last authorized, revoked, etc.) }\end{array}$ & $\begin{array}{l}\text { - To calculate expiration dates for the authorization } \\
\text { of software }(1,2,4,5) \text {. } \\
\text { - To enable automated removal of differences that } \\
\text { are not defects (all). } \\
\text { - To be able to uniquely identify the software }(1,2) \text {. } \\
\text { - To be able to validate that the software on the } \\
\text { device is truly the software authorized }(1,2,4,5) \text {. } \\
\text { - To know who to instruct to fix specific risk } \\
\text { conditions found (3). } \\
\text { - To assess each software manager's performance } \\
\text { in risk management (all). }\end{array}$ \\
\hline $\begin{array}{l}\text { Management responsibility for each software } \\
\text { management function for each authorized software } \\
\text { product. Local enhancements }{ }^{b} \text { might include: } \\
\text { - } \quad \text { Approvers being assigned; } \\
\text { - Managers being approved; and } \\
\text { - Managers acknowledging receipt. }\end{array}$ & $\begin{array}{l}\text { - To identify management responsibilities for } \\
\text { ensuring that licensing, patching, and } \\
\text { configuration standards are up-to-date. } \\
\text { - To know who to instruct to fix specific risk } \\
\text { conditions found. } \\
\text { - To assess each such person's performance in risk } \\
\text { management. } \\
\text { Note: If not specified explicitly, management responsibility } \\
\text { for each software management function is assumed to lie } \\
\text { with the device manager. }\end{array}$ \\
\hline $\begin{array}{l}\text { A set of Software Profiles for the organization to } \\
\text { include: } \\
\text { - } \quad \text { Associated attributes; } \\
\text { - } \quad \text { Authorized software; } \\
\text { - } \quad \text { Mandatory software; } \\
\text { - } \quad \text { Organizationally prohibited software blacklist; } \\
\text { - Industry blacklist; }{ }^{d} \text { and/or } \\
\text { - } \quad \text { Update frequency for blacklist. }\end{array}$ & $\begin{array}{l}\text { - To compare with the software present on a device } \\
\text { to determine defects. } \\
\text { - To define authorized and unauthorized software } \\
\text { on a per device basis. } \\
\text { - To determine when software no longer authorized } \\
\text { for the environment is being used for baselines. } \\
\text { - To determine if known-bad blacklists are out of } \\
\text { date. }\end{array}$ \\
\hline $\begin{array}{l}\text { Sets of device attributes that require a unique } \\
\text { software profile when assigned to the same device, } \\
\text { to include software profile(s) replaced and software } \\
\text { profile(s) used. }\end{array}$ & $\begin{array}{l}\text { To enforce more restrictive policies on devices that } \\
\text { are assigned sets of attributes (e.g., database server } \\
\text { and database authentication server). }\end{array}$ \\
\hline
\end{tabular}

${ }^{a}$ This value is defined by the organization, based on the value assigned by the organization to assets.

${ }^{b}$ Organizations can define additional data requirements and associated defects for the local environment.

c Software profiles have a one-to-many relationship with device attributes. One profile can have more than one device attribute associated with it (e.g., both Internal Web Server and External Web Server can map to the same Web Server software profile), but every device attribute is associated with exactly one software profile.

${ }^{\mathrm{d}}$ Known bad blacklists are quite large, very dynamic, and often maintained by an antivirus or antimalware vendor. It is not expected that the organization knows what software is on the list, but that they know what blacklist is to be used and how frequently it is to be updated. 


\subsection{SWAM Concept of Operational Implementation}

Figure 4: SWAM Concept of Operations (CONOPS) illustrates how SWAM might be implemented. The CONOPS is central to the automated assessment process.

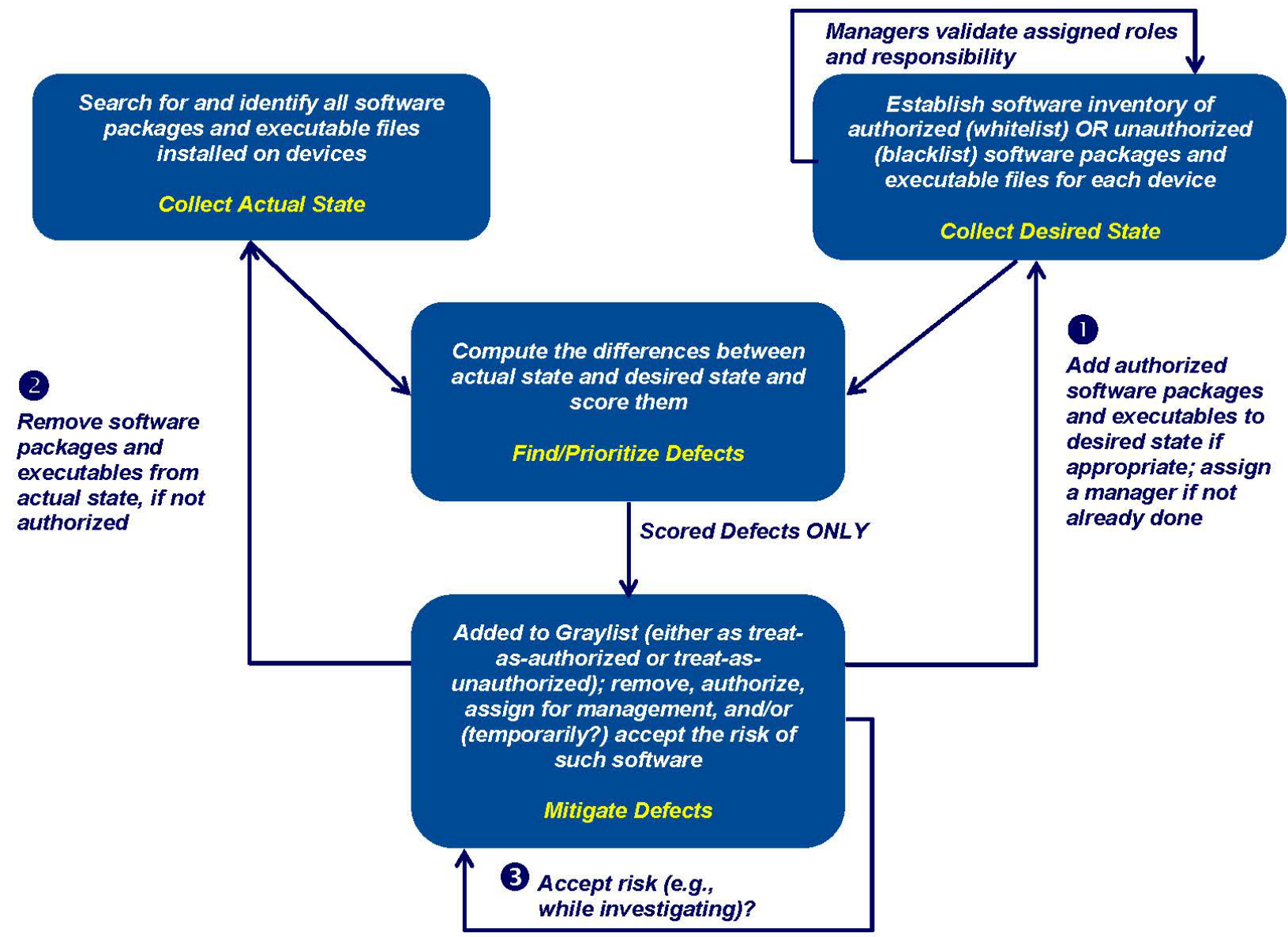

Figure 4: SWAM Concept of Operations (CONOPS)

The following is a brief description of the SWAM capability functionality:

SWAM identifies software (including virtual machines) that is actually present on target network devices (the actual state) and compares it with the desired state inventory to determine if the identified software is authorized for operation and installation on target network devices.

\subsubsection{Collect Actual State}

Use tools to collect information about what software files and products are installed on target network devices, including files on mass storage, mobile code, firmware, and code in memory. Methods to detect (and possibly respond to) unauthorized software may include (but are not limited to):

- Identify software products through use of the operating system software database; 
- Identify software files through the use of trusted digital fingerprint repositories;

- Link products to software files through a SWID tag;

- Whitelist authorized software and block all other software by default;

- Blacklist (and block by default) unauthorized and/or known malicious or unsafe software;

- Graylist (and block by default or allow by exception) until a determination is made of whether to authorize particular software;

- Require installation media to be digitally signed by a trusted source early in the supply chain to prevent tampering in the supply chain. Installation media can also include a signed SWID tag;

- Require all mobile code to be digitally signed by a trusted source; and

- Use a trusted platform module to verify the software used to boot the system.

Implementing some of the methods above to detect unauthorized software may require an agent on the host device to check new software (and software about to be executed) against associated policy constraints. A process to remove unauthorized software might also be implemented.

Unauthorized software may include any software not explicitly whitelisted or any software explicitly blacklisted. When unauthorized and/or malicious software is modified, even slightly, it is rendered invisible to blacklists, making blacklisting increasingly ineffective as malware variants become more easily produced. Because software whitelisting can block any unknown software, it is much more effective against unauthorized and/or malicious software.

The ISCM data collection process identifies the software files (and products) actually on the network and provides the information required to compare the software with the authorized inventory (desired state). Also, it is necessary to identify which devices in the target network are not reporting to discover the actual software operating on the devices. ${ }^{19}$

\subsubsection{Collect Desired State}

Create an authorized software inventory using policies, procedures, and processes suggested by the information security program or as otherwise defined by the organization. Expected output is an authorized software inventory that contains identifying information for software on a device - when it was authorized, when the authorization expires, and authorized digital signature. The digital signature may be contained in a SWID tag and/or in a separate trusted repository of known whitelisted/blacklisted software/signatures.

For maximum effectiveness, automated tools to manage software inventory using digital fingerprints include functionality to introduce new software into the trust repository. Such functionality allows the organization to include custom software unique to that organization, for

\footnotetext{
${ }^{19}$ Most monitoring software misses some devices on any given scan such as when mobile devices are off-network or when users turn devices off (e.g., while on vacation or official travel). The organization is expected to set standards for how many non-reporting devices to accept, and perhaps for how long (based on their practices and data collectors). The set standards are then measured by the data quality defect checks.
} 
example. However, care is taken not to inadvertently whitelist malicious code as part of the software introduction process.

\subsubsection{Find/Prioritize Defects}

Comparing the list of software objects discovered on the network (actual state) with the authorized software inventory list (desired state) often reveals that software objects exist on one list but not on the other. The comparison identifies both unauthorized objects and missing authorized software that may indicate a security risk. Additional defects related to software asset management may be defined by the organization. Because of the high risk associated with unauthorized software installation, tools are available to block unauthorized software at first detection before the software is executed. Usually software blocking tools allow automatic blocking, or the user is asked whether to block or execute the software. In any case, after the comparison is complete, identified defects are scored and prioritized ${ }^{20}$ (using federal- and organization-defined criteria) so that the appropriate response action can be taken (i.e., so that higher risk problems are addressed first).

\subsection{SP 800-53 Control Items that Support SWAM}

Section 2.6 describes how control items that support SWAM were identified as well as the nomenclature used to clarify each control item's focus on software.

\subsubsection{Process for Identifying Needed Controls}

In Volume 1 of NISTIR 8011, Section 3.5.2, Tracing Security Control Items to Capabilities, describes the process used to determine the controls needed to support a capability. In short, the two steps are:

1. Use an automated keyword search of the control text to identify control items that might support the capability. See keyword rules used for SWAM in Appendix B.

2. Manually identify those that $d o$ support the capability (true positives) and ignore those that do not (false positives).

Completion of the above two steps produces three sets of controls:

1. Control items in the low, moderate, and high baselines that support the SWAM capability (listed individually in Section 3.3 on SWAM Control (Item) Security Assessment Plan Narrative Tables and Templates, and listed by security baseline in Section 3.4 on Control Allocation Tables).

2. Control items in the low, moderate, and high baselines selected by the keyword search, but manually determined to be false positives (listed in Appendix C).

\footnotetext{
${ }^{20}$ A risk scoring methodology is necessary to score and prioritize defects but risk scoring is out of scope for this publication.
} 
3. Control items not in a baseline, and not analyzed further after the keyword search, including:

a. Program management (PM) controls, because PM controls do not apply to individual systems;

b. Not selected controls - controls that are in SP 800-53 but are not assigned to (selected in) a baseline; and

c. Privacy controls.

The unanalyzed controls are listed in Appendix D, in case the organization wants to develop automated tests.

To implement whitelisting/blacklisting in general, and software whitelisting/blacklisting in particular, SWAM may rely on some other capabilities. The controls that support whitelisting and blacklisting are not included in SWAM if the supporting controls are more central to the other capability.

For example, configuration settings and/or user privilege lists are used to prevent anyone who is not a software manager from modifying the whitelists, graylists or blacklists. Moreover, the configuration settings and/or privileges are used to prevent the software managers from performing activities that could allow an outsider to misuse the software manager accounts to modify the desired state metadata. The same access controls are necessary to protect the actual state data. Assessment of such controls is left to the capabilities in which the control is central, rather than to the capability where applied (i.e., SWAM, in this case).

As a more specific example, controls supporting the PRIV capability are an important supplement to defect checks in all capabilities to ensure that only authorized persons can change the actual and desired state data, and the actual state of the system.

- For example, in SWAM, an attacker might try to change the trusted digital fingerprints of approved software files so that they may add or substitute malicious code. If the number of accounts authorized to make additions/substitutions is limited and only assigned to trusted persons with adequate separation of duties, such additions/substitutions are rendered more difficult.

- Also, if only a limited number of accounts are authorized to install software, it is harder for an attacker to find and exploit an account to inject malicious code.

Privileges to protect desired and actual state data are assessed in the PRIV capability, even though the privileges support SWAM and all other capabilities.

\subsubsection{Control Item Nomenclature}

Many control items that support the SWAM capability also support several other capabilities. For example, hardware, software products, software settings, and software patches may all benefit from configuration management controls. To clarify the scope of such control items as they relate to SWAM, expressions in the control item text are enclosed in curly brackets-for instance, \{installed software - - to denote that a particular control item, as it supports the SWAM capability, focuses on, and only on, what is inside the curly brackets. 


\subsection{SWAM Specific Roles and Responsibilities}

Table 5: Operational and Managerial Roles for SWAM, describes SWAM-specific roles and the corresponding responsibilities. Figure 5: Primary Roles in Automated Assessment of SWAM, shows how the roles integrate with the concept of operations. An organization implementing automated assessment can customize its approach by assigning (allocating) the responsibilities to persons in existing roles.

Table 5: Operational and Managerial Roles for SWAM

\begin{tabular}{|c|c|c|c|}
\hline $\begin{array}{l}\text { Role } \\
\text { Code }\end{array}$ & Role Title & Role Description & Role Type \\
\hline DM & $\begin{array}{l}\text { Device } \\
\text { Manager (DM) }\end{array}$ & $\begin{array}{l}\text { Assigned to a specific device or group of devices, device } \\
\text { managers are (for HWAM) responsible for adding/removing } \\
\text { devices from the network, and for configuring the hardware of } \\
\text { each device (adding and removing hardware components). The } \\
\text { device managers are specified in the desired state inventory } \\
\text { specification. The device manager may be a person or a group. } \\
\text { If a group, there is a group manager in charge. } \\
\text { In the absence of a Software Manager (SWMan), the DM may } \\
\text { be assigned the task of removing unauthorized software. }\end{array}$ & Operational \\
\hline Auth & Authorizers & $\begin{array}{l}\text { Authorizers have the responsibility of authorizing specific items } \\
\text { (e.g., devices, software, software installers, software locations, } \\
\text { or settings), and thereby define the desired state. In special } \\
\text { cases they authorize people to authorize other items. The } \\
\text { desired state manager oversees and organizes the activity of } \\
\text { authorization. }\end{array}$ & Operational \\
\hline DSM & $\begin{array}{l}\text { Desired State } \\
\text { Managers } \\
\text { (DSM) }\end{array}$ & $\begin{array}{l}\text { Desired State Managers are needed for both the ISCM Target } \\
\text { Network and each assessment object. The desired state } \\
\text { managers ensure that data specifying the desired state of the } \\
\text { relevant capability is entered into the ISCM system's desired } \\
\text { state data and is available to guide the actual state collection } \\
\text { subsystem and to identify defects. The DSM for the ISCM } \\
\text { Target Network also resolves any ambiguity about which system } \\
\text { authorization boundary has defects (if any). } \\
\text { Authorizers share some of the responsibilities by authorizing } \\
\text { specific items (e.g., devices, software, or settings), and thus } \\
\text { defining the desired state, as delegated by the DSM. The DSM } \\
\text { oversees and organizes this activity. }\end{array}$ & Operational \\
\hline $\begin{array}{l}\text { ISCM- } \\
\text { Ops }\end{array}$ & \begin{tabular}{|l} 
ISCM \\
Operators \\
(ISCM-Ops)
\end{tabular} & $\begin{array}{l}\text { ISCM operators are responsible for operating the ISCM system } \\
\text { (see ISCM-Sys). }\end{array}$ & Operational \\
\hline
\end{tabular}




\begin{tabular}{|c|c|c|c|}
\hline $\begin{array}{l}\text { Role } \\
\text { Code }\end{array}$ & Role Title & Role Description & Role Type \\
\hline $\begin{array}{l}\text { ISCM- } \\
\text { Sys }\end{array}$ & $\begin{array}{l}\text { The system that } \\
\text { collects, } \\
\text { analyzes and } \\
\text { displays ISCM } \\
\text { security-related } \\
\text { information }\end{array}$ & $\begin{array}{l}\text { The ISCM system: a) collects the desired state specification; b) } \\
\text { collects security-related information from sensors (e.g., } \\
\text { scanners, agents, training applications, etc.); and c) processes } \\
\text { that information into a useful form. } \\
\text { To support task c) the system conducts specified defect } \\
\text { check(s) and sends defect information to an ISCM dashboard } \\
\text { covering the relevant system(s). The ISCM system is } \\
\text { responsible for the assessment of most SP } 800-53 \text { security } \\
\text { controls. }\end{array}$ & Operational \\
\hline MAN & $\begin{array}{l}\text { Manual } \\
\text { Assessors }\end{array}$ & $\begin{array}{l}\text { Assessments not automated by the ISCM system are conducted } \\
\text { by human assessors using manual/procedural methods. } \\
\text { Manual/procedural assessments might also be conducted to } \\
\text { verify the automated security-related information collected by } \\
\text { the ISCM system-when there is a concern about data quality. }\end{array}$ & Operational \\
\hline RskEx & $\begin{array}{l}\text { Risk Executive, } \\
\text { System Owner, } \\
\text { and/or } \\
\text { Authorizing } \\
\text { Official (RskEx) }\end{array}$ & Defined in SPs $800-37$ and $800-39 .{ }^{21}$ & Managerial \\
\hline SWMan & $\begin{array}{l}\text { Software } \\
\text { Manager }\end{array}$ & $\begin{array}{l}\text { Assigned to specific devices and responsible for installing } \\
\text { and/or removing software from the device. The key aspects of } \\
\text { the Software Manager responsibility are to ONLY install } \\
\text { authorized software and to promptly remove ALL unauthorized } \\
\text { software found. The software manager is also responsible for } \\
\text { ensuring software media is available to support roll back of } \\
\text { changes and restoration of software to prior states. } \\
\text { This role might be performed by the DM (Device Manager) } \\
\text { and/or the PatMan (Patch Manager). } \\
\text { If users are authorized to install software, they are also } \\
\text { SWMans (Software Managers) for the relevant devices. }\end{array}$ & Operational \\
\hline TBD & $\begin{array}{l}\text { To be } \\
\text { determined by } \\
\text { the organization }\end{array}$ & Depends on specific use. TBD by the organization. & Unknown \\
\hline
\end{tabular}

${ }^{21}$ Joint Task Force Transformation Initiative, Risk Management Framework for Information Systems and Organizations, (2018), (National Institute of Standards and Technology, Gaithersburg, MD), NIST Special Publication (SP) 800-37, https://csrc.nist.gov/publications/detail/sp/800-37/rev-2/final;

Joint Task Force Transformation Initiative, Managing Information Security Risk: Organization, Mission, and Information System View (2011), (National Institute of Standards and Technology, Gaithersburg, MD), NIST Special Publication (SP) 800-39, https://doi.org/10.6028/NIST.SP.800-39. 


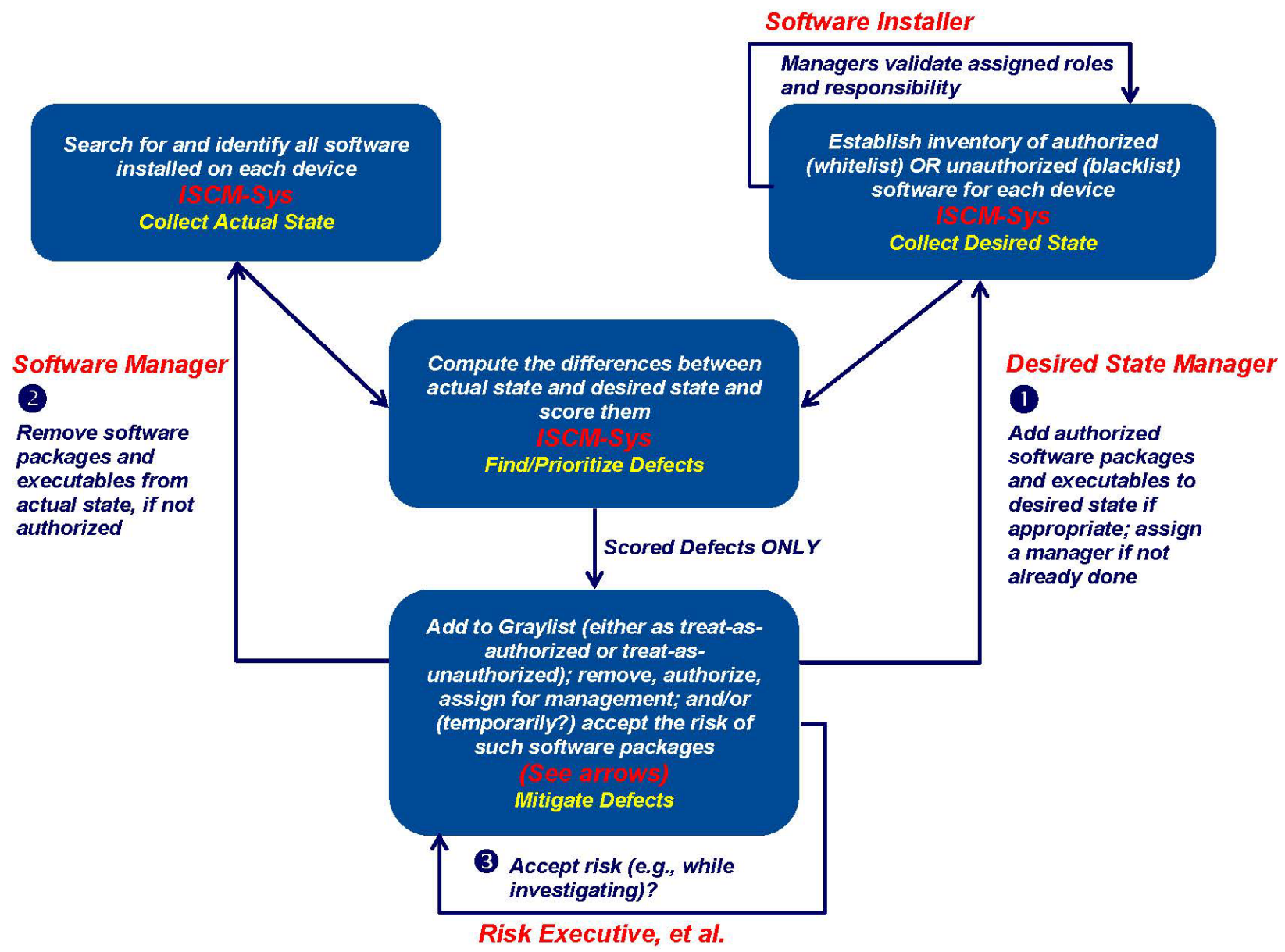

Figure 5: Primary Roles in Automated Assessment of SWAM

\subsection{SWAM Assessment Boundary}

The assessment boundary is ideally all software on an entire network of computers from the innermost enclave out to where the network either ends in an air-gap or interconnects to other network(s) - typically the Internet or the network(s) of a partner or partners. For SWAM, the boundary includes software on all devices inside the assessment boundary and associated components, including software on removable devices found at the time of the scan. For more detail and definitions of some of the terms applicable to the assessment boundary, see Section 4.3.2 in Volume 1 of this NISTIR.

\subsection{SWAM Actual State and Desired State Specification}

For information on the actual state and the desired state specification for SWAM, see the assessment criteria notes section of the defect check tables in Section 3.2. 
Note that many controls in SWAM refer to developing and updating an inventory of software on devices (or other inventories). Note also, that per the SP $800-53 \mathrm{~A}^{22}$ definition of test, testing of the SWAM controls implies the need for specification of both an actual state inventory and a desired state inventory, so that the test can compare the two inventories. The details of the comparison are described in the defect check tables in Section 3.2.

\subsection{SWAM Authorization Boundary and Inheritance}

See Section 4.3.1 of Volume 1 of this NISTIR for information on how authorization boundaries are addressed in automated assessment. In short, for SWAM, software on each device is assigned to one and only one authorization (system) boundary, per SP 800-53 CM-08(5), entitled "Information System Component Inventory | No Duplicate Accounting of Components." The ISCM dashboard can include a mechanism for recording the assignment of software to authorization boundaries, making sure all software are assigned to at least one authorization boundary, and that no software product is assigned to more than one authorization boundary.

For information on how inheritance of common controls is managed, see Section 4.3.3 of Volume 1 of this NISTIR. For SWAM, many utilities, database management software products, web server software objects, and parts of the operating system provide inheritable support and/or controls for other systems. The ISCM dashboard can include a mechanism to record information about inheritance and use it in assessing the system's overall risk.

\subsection{SWAM Assessment Criteria Recommended Scores and Risk-Acceptance Thresholds}

General guidance on options for risk scores ${ }^{23}$ to be used to set thresholds is outside the scope of this NISTIR and is being developed elsewhere. In any case, for SWAM, organizations are encouraged to use metrics that look at both average risk score and maximum risk score per device.

\subsection{SWAM Assessment Criteria Device Groupings to Consider}

To support automated assessment and ongoing authorization, software is clearly grouped by authorization boundary [see Control Items CM-8a and CM-8(5) in SP 800-53] and by the software managers responsible for software installation on specific devices ${ }^{24}$ [see Control Item CM-8(4) in SP 800-53]. In addition to these two important groupings, the organization may want to use other groupings for risk analysis, as discussed in Section 5.6 of Volume 1 of this NISTIR.

\footnotetext{
22 Joint Task Force Transformation Initiative (2014), Assessing Security and Privacy Controls in Federal Information Systems and Organizations (National Institute of Standards and Technology, Gaithersburg, MD), NIST Special Publication (SP) 800-53A, https://doi.org/10.6028/NIST.SP.800-53Ar4.

${ }^{23}$ A risk score, also called a defect score, in the context of SWAM, is a measure of how exploitable a defect is.

${ }^{24}$ The Software Manager (SWMan) role is responsible for installing on and removing software from the device, but the role might be performed by the device manager or other responsible party in a specific organization.
} 


\section{SWAM Security Assessment Plan Documentation Template}

\subsection{Introduction and Steps for Adapting This Plan}

This section provides templates for the security assessment plan in accordance with SP 800-37 and SP 800-53A. The documentation elements are described in Section 6 of Volume 1 of this NISTIR. Section 9 of the same volume specifically describes how the templates and documentation relate to the assessment tasks and work products defined in SP 800-37 and SP 800-53A. The following are suggested steps to adapt this plan to the organization's needs and implement automated monitoring.

Figure 6 shows the main steps in the adaptation process. The steps are expanded to more detail in the following three sections.

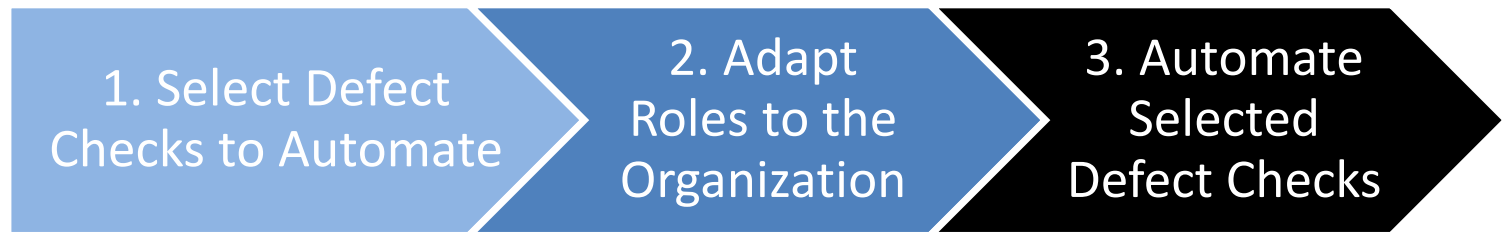

Figure 6: Main Steps in Adapting the Plan Template

\subsubsection{Select Defect Checks to Automate}

The main steps in selecting defect checks to automate are described in this section.
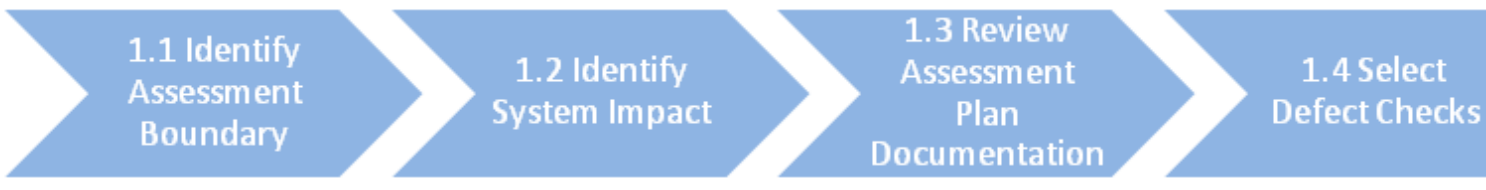

Figure 7: Sub-Steps to Select Defect Checks to Automate

Take the following steps to select which defect checks to automate:

(1) Identify Assessment Boundary: Identify the assessment boundary to be covered. (See Section 4.3 of Volume 1 of this NISTIR.) 
(2) Identify System Impact: Identify the Federal Information Processing Standard (FIPS) 199 impact level (high water mark) for the assessment boundary. ${ }^{25}$

Also see SP 800-60 and/or organizational categorization records. ${ }^{26}$

(3) Review Security Assessment Plan Documentation:

a. Review the defect checks documented in Section 3.2 to get an initial sense of the proposed items to be tested.

b. Review the security assessment plan narratives in Section 3.2 to understand how the defect checks apply to the controls that support Software Asset Management.

(4) Select Defect Checks:

a. Based on Steps (1) to (3) in this list and an understanding of the organization's risk tolerance, use Table 6: Mapping of Attack Steps to Security Sub-Capability, in Section 3.2.3 to identify the defect checks necessary to test the effectiveness of controls based on the impact level and risk tolerance.

b. Mark the defect checks necessary as selected in Section 3.2.2. The organization is not required to use automation, but automation of testing adds value to the extent that it:

(i) Produces assessment results accurately, completely, and timely enough to better defend against attacks; and/or

(ii) Reduces the cost of assessment over the long term.

\subsubsection{Adapt Roles to the Organization}

The main steps to adapt the roles to the organization are described in this section.

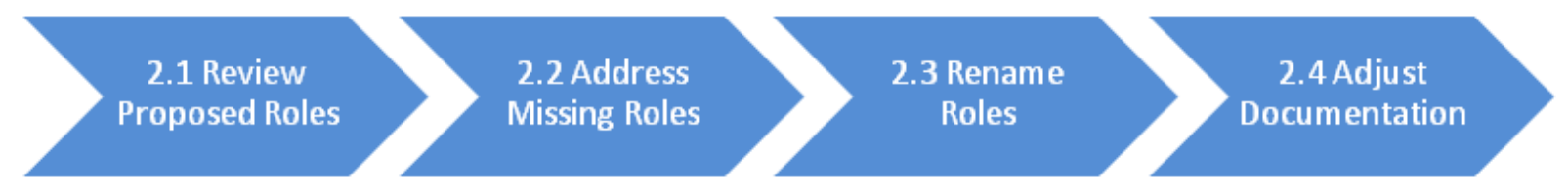

Figure 8: Sub-Steps to Adapt Roles to the Organization

(1) Review Proposed Roles: Proposed roles are described in Section 2.7, SWAM Specific Roles and Responsibilities (Illustrative).

(2) Address Missing Roles: Identify any required roles not currently assigned in the organization. Determine how to assign the unassigned roles.

(3) Rename Roles: Identify the organization-specific names that match each role. (Note that more than one proposed role might be performed by the same organizational role.)

\footnotetext{
${ }^{25}$ National Institute of Standards and Technology (2004), Standards for Security Categorization of Federal Information and Information Systems, Federal Information Processing Standard (FIPS) 199, https://doi.org/10.6028/NIST.FIPS.199.

${ }^{26}$ Stine K et al (2008), Guide for Mapping Types of Information and Information Systems to Security Categories (National Institute of Standards and Technology, Gaithersburg, MD), NIST Special Publication (SP) 800-60, https://doi.org/10.6028/NIST.SP.800-60v1r1.
} 
(4) Adjust Documentation: Map the organization-specific roles to the roles proposed herein, in one of two ways (either may be acceptable):

a. Add a column to the table in Section 2.7 for the organization-specific role and list it there; or

b. Use global replace to change the role names throughout the documentation from the names proposed here to the organization-specific names.

\subsubsection{Automate Selected Defect Checks}

The main steps to implement automation are described in this section.

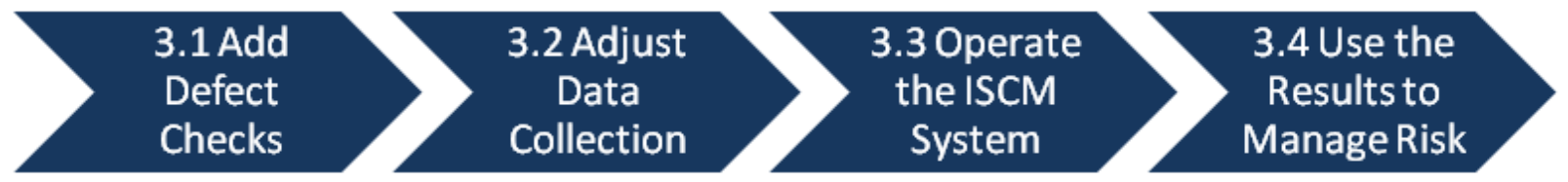

Figure 9: Sub-Steps to Automate Selected Defect Checks

(1) Add Defect Checks: Review the defect check definition and add checks as needed based on organizational risk tolerance and expected attack types. [Role: DSM (See Section 2.7.)]

(2) Adjust Data Collection:

a. Review the actual state information needed and configure automated sensors to collect the required information. [Role: ISCM-Sys (See Section 2.7)]

b. Review the matching desired state specification that was specified or add additional specifications to match the added actual state to be checked. Configure the collection system to receive and store this desired state specification in a form that can be automatically compared to the actual state data. [Role: ISCM-Sys (See Section 2.7.)]

(3) Operate the ISCM-System:

a. Operate the collection system to identify both security and data quality defects.

b. Configure the collection system to send security and data quality information to the defect management dashboard.

(4) Use the Results to Manage Risk: Use the results to respond to higher risk findings first and to measure potential residual risk to inform aggregate risk acceptance decisions. If risk is determined to be too great for acceptance, the results may also be used to help prioritize mitigation actions or as rationale for denial of continued authorization to operate. 


\subsection{SWAM Sub-Capabilities and Defect Check Tables and Templates}

This section documents the specific test templates that are proposed and considered adequate to assess the control items that support Software Asset Management. See Section 5 of Volume 1 of this NISTIR for an overview of defect checks and see Section 4.1 of Volume 1 for an overview of the actual state and desired state specifications discussed in the Assessment Criteria Notes for each defect check. Sections 3.2.1, 3.2.2, and 3.2.3 of this document describe the foundational, data quality, and local defect checks, respectively. The Supporting Control Item(s) data in sections 3.2.1, 3.2.2, and 3.2.3 specify which controls, when ineffective, might cause a particular defect check to fail. The association between control items and defect checks provides further documentation on why the check (test) might be needed. Refer to Section 3.1 for how to adapt the defect checks (and roles specified therein) to the organization.

Data found in this section can be used in both defect check selection and root cause analysis. Section 3.2.4 documents how each sub-capability (tested by a defect check) serves to support the overall capability by addressing certain example attack steps and/or data quality issues. Appendix G can also be used to support root cause analysis. The Defect Check Templates are organized as follows:

- In the section beginning "The purpose of this sub-capability...," the sub-capability being tested by the defect check is defined and assessment criteria described. How the subcapabilities block or delay certain example attack steps is described in Section 3.2.4.

- In the section beginning "The defect check to assess...," the defect check name and the assessment criteria to be used to assess whether the sub-capability is effective in achieving its purpose are described.

- In the section beginning "Example Responses," examples of potential responses when the check finds a defect, and what role is likely responsible are described. Potential responses (with example primary responsibility assignments) are common actions and are appropriate when defects are discovered in a given sub-capability. The example primary responsibility assignments do not change the overall management responsibilities defined in other NIST guidance. Moreover, the response actions and responsibilities can be customized by each organization to best adapt to local circumstances.

- Finally, in the section beginning "Supporting Control Items," the control items that work together to support the sub-capability are listed. Identification of the supporting control items is based on the mapping of defect checks to control items in Section 3.3. Each subcapability is supported by a set of control items. Thus, if any of the listed supporting controls fail, the defect check fails and overall risk is likely to increase.

As noted in Section 3.1, this material is designed to be customized and adapted to become part of an organization's security assessment plan. 


\subsubsection{Foundational Sub-Capabilities and Corresponding Defect Checks}

NISTIR 8011 Volume 3 proposes four foundational security-oriented defect checks for the SWAM capability. The foundational checks are designated SWAM-F01 through SWAM-F04.

The foundational defect checks were selected for their value for summary reporting. The Selected column indicates which of the checks are implemented by the organization. Defect checks may be computed for individual checks (e.g., foundational, data quality, or local), or summarized for various groupings of devices (e.g., device manager, device owner, system, etc.) out to the full assessment boundary.

Note for SWAM: SWAM defect checks F01, F02 and F03 provide alternate ways to detect the blocking or limiting of execution of unauthorized software from a mass storage device. Organizations select one or more of the defect check(s) F01, F02, and/or F03 based on organizational assurance needs and organization-specific control implementations. Organizations may determine that risk is sufficiently mitigated by applying defect check F01 only in specified locations associated with F03 and/or as installed by authorized installers associated with F02; however, SWAM defect check F04 is needed separately to detect malicious code in memory. 


\subsubsection{Prevent Unauthorized Software from Executing Sub-Capability and Defect Check SWAM-F01}

The purpose of this sub-capability is defined as follows:

\begin{tabular}{|c|c|}
\hline Sub-Capability Name & Sub-Capability Purpose \\
\hline Prevent unauthorized software from executing & Prevent or reduce the execution of unauthorized software (presumed malware). \\
\hline
\end{tabular}

The defect check to assess whether this sub-capability is operating effectively is defined as follows:

\begin{tabular}{|c|l|l|l|}
\hline $\begin{array}{c}\text { Defect } \\
\text { Check ID }\end{array}$ & Defect Check Name & \multicolumn{1}{|c|}{ Assessment Criteria Notes } & Selected \\
\hline SWAM-F01 & $\begin{array}{l}\text { Unauthorized } \\
\text { software executes }\end{array}$ & $\begin{array}{l}\text { 1) The actual state is the list (inventory) of all software files that the system has loaded (or } \\
\text { attempted to load) for execution, identified by digital fingerprints or equivalents, e.g., digitally } \\
\text { signed files or libraries. } \\
\text { 2) The desired state specification is a list of all software files authorized to be executed, identified } \\
\text { by digital fingerprints or equivalents. } \\
\text { 3) A defect is a software file that is executed (or attempted to be executed) that is not on the list of } \\
\text { files authorized to be executed. }\end{array}$ & $\begin{array}{l}\text { Yes } \\
\text { Note: F01 addresses distribution supply chain issues if the organization gets software file } \\
\text { message digests (encrypted and signed) from the software developer or other equally trusted } \\
\text { source. }\end{array}$ \\
\hline
\end{tabular}

\section{Example Responses:}

\begin{tabular}{|l|l|l|}
\hline Defect Check ID & \multicolumn{1}{|c|}{ Potential Response Action } & Primary Responsibility \\
\hline SWAM-F01 & Automatically block execution on detection & ISCM-Ops \\
\hline SWAM-F01 & Remove the software & SWMan \\
\hline SWAM-F01 & Authorize the software & Auth \\
\hline SWAM-F01 & Accept risk & RskEx \\
\hline SWAM-F01 & Oversee and coordinate response & DSM \\
\hline
\end{tabular}




\section{Supporting Control Items:}

\begin{tabular}{|l|l|l|}
\hline Defect Check ID & Baseline & SP 800-53 Control Item Code \\
\hline SWAM-F01 & Low & CM-7(b) \\
\hline SWAM-F01 & Low & CM-11(b) \\
\hline SWAM-F01 & Low & SI-3(b) \\
\hline SWAM-F01 & Low & SI-3(c) \\
\hline SWAM-F01 & Moderate & CM-7(1)(b) \\
\hline SWAM-F01 & Moderate & CM-7(2) \\
\hline SWAM-F01 & Moderate & CM-7(4)(a) \\
\hline SWAM-F01 & Moderate & CM-7(4)(b) \\
\hline SWAM-F01 & Moderate & MA-3(2) \\
\hline SWAM-F01 & Moderate & SC-18(a) \\
\hline SWAM-F01 & Moderate & SC-18(b) \\
\hline SWAM-F01 & Moderate & SC-18(c) \\
\hline SWAM-F01 & Moderate & SI-7 \\
\hline SWAM-F01 & High & CM-5(3) \\
\hline SWAM-F01 & High & CM-7(5)(a) \\
\hline SWAM-F01 & High & CM-7(5)(b) \\
\hline SWAM-F01 & High & SA-12 \\
\hline
\end{tabular}




\subsubsection{Prevent or Reduce Execution of Software from Unauthorized Installers Sub-Capability and Defect Check} SWAM-F02

The purpose of this sub-capability is defined as follows:

\begin{tabular}{|l|l|}
\hline \multicolumn{1}{|c|}{ Sub-Capability Name } & \multicolumn{1}{c|}{ Sub-Capability Purpose } \\
\hline $\begin{array}{l}\text { Prevent or reduce execution of software from } \\
\text { unauthorized installers }\end{array}$ & $\begin{array}{l}\text { Prevent or reduce the execution of software (presumed malware) installed by an } \\
\text { unauthorized installer. }\end{array}$ \\
\hline
\end{tabular}

The defect check to assess whether this sub-capability is operating effectively is defined as follows:

\begin{tabular}{|c|l|l|l|}
\hline $\begin{array}{c}\text { Defect } \\
\text { Check ID }\end{array}$ & Defect Check Name & \multicolumn{1}{c|}{ Assessment Criteria Notes } & Selected \\
\hline SWAM-F02 & $\begin{array}{l}\text { Unauthorized } \\
\text { software installer }\end{array}$ & $\begin{array}{l}\text { 1) The actual state is the list (inventory) of all software that is being executed or has been loaded } \\
\text { for execution over a specified period of time defined by the organization. } \\
\text { 2) The desired state specification is a list of all software installed by an authorized installer } \\
\text { account. } \\
\text { 3) A defect is software that is executed (or attempted to execute) that was not installed by an } \\
\text { authorized installer account. } \\
\text { Note: An alternate version of this defect check could operate on all installed software, rather than } \\
\text { executing software. The check could operate on both for defense in depth purposes. }\end{array}$ \\
\hline
\end{tabular}

\section{Example Responses:}

\begin{tabular}{|l|l|l|}
\hline Defect Check ID & \multicolumn{1}{|c|}{ Potential Response Action } & Primary Responsibility \\
\hline SWAM-F02 & Automatically block installation by unauthorized persons & ISCM-Ops \\
\hline SWAM-F02 & Automatically block execution on detection & ISCM-Ops \\
\hline SWAM-F02 & Remove the software & SWMan \\
\hline SWAM-F02 & Authorize the software/installer & Auth \\
\hline SWAM-F02 & Accept risk & RskEx \\
\hline SWAM-F02 & Oversee and coordinate response & DSM \\
\hline
\end{tabular}




\section{Supporting Control Items:}

\begin{tabular}{|l|l|l|}
\hline Defect Check ID & Baseline & SP $\mathbf{8 0 0 - 5 3 ~ C o n t r o l ~ I t e m ~ C o d e ~}$ \\
\hline SWAM-F02 & Low & CM-11(a) \\
\hline SWAM-F02 & Low & CM-11(b) \\
\hline SWAM-F02 & Moderate & CM-7(1)(b) \\
\hline SWAM-F02 & Moderate & CM-7(2) \\
\hline SWAM-F02 & Moderate & CM-7(4)(a) \\
\hline SWAM-F02 & Moderate & CM-7(4)(b) \\
\hline SWAM-F02 & Moderate & SI-3(1) \\
\hline SWAM-F02 & High & CM-7(5)(a) \\
\hline SWAM-F02 & High & CM-7(5)(b) \\
\hline
\end{tabular}




\subsubsection{Prevent or Reduce Software Execution from Unauthorized Location Sub-Capability and Defect Check SWAM-F03}

The purpose of this sub-capability is defined as follows:

\begin{tabular}{|l|l|}
\hline \multicolumn{1}{|c|}{ Sub-Capability Name } & \multicolumn{1}{c|}{ Sub-Capability Purpose } \\
\hline $\begin{array}{l}\text { Prevent or reduce software execution from } \\
\text { unauthorized location }\end{array}$ & $\begin{array}{l}\text { Prevent or reduce the execution of software (presumed malware) loaded from an } \\
\text { uncontrolled or unauthorized location. }\end{array}$ \\
\hline
\end{tabular}

The defect check to assess whether this sub-capability is operating effectively is defined as follows:

\begin{tabular}{|l|l|l|l|}
\hline $\begin{array}{l}\text { Defect } \\
\text { Check ID }\end{array}$ & Defect Check Name & \multicolumn{1}{|c|}{ Assessment Criteria Notes } \\
\hline $\begin{array}{l}\text { SWAM- } \\
\text { F03 }\end{array}$ & $\begin{array}{l}\text { Unauthorized software } \\
\text { directory/folder } \\
\text { location }\end{array}$ & $\begin{array}{l}\text { 1) The actual state is the list (inventory) of all software files (identified by the location from which } \\
\text { loaded, or equivalent) that are being executed or have been loaded for execution over a period of } \\
\text { time defined by the organization. (The actual value to be stored in the inventory is a tuple } \\
\text { consisting of the file and the location from which loaded.) } \\
\text { 2) The desired state specification is a list of all software files that exist in the authorized location. } \\
\text { (The actual value to be stored in the specification is one tuple for each authorized file and a } \\
\text { location from which it is permitted to be loaded.) } \\
\text { 3) A defect is a software file that is executed (or attempted to be executed) that is not loaded from } \\
\text { an authorized location. (The actual state tuple does not match a desired state tuple.) } \\
\text { Note: Authorized locations are to be restricted via access controls to be writable only by } \\
\text { authorized installer accounts. }\end{array}$ & Yand \\
\hline
\end{tabular}

\section{Example Responses:}

\begin{tabular}{|l|l|l|}
\hline Defect Check ID & \multicolumn{1}{|c|}{ Potential Response Action } & Primary Responsibility \\
\hline SWAM-F03 & Automatically block execution on detection of wrong location & ISCM-Ops \\
\hline SWAM-F03 & Remove the software & SWMan \\
\hline SWAM-F03 & Authorize the software/location for execution & Auth \\
\hline SWAM-F03 & Accept risk & RskEx \\
\hline SWAM-F03 & Oversee and coordinate response & DSM \\
\hline
\end{tabular}




\section{Supporting Control Items:}

\begin{tabular}{|l|l|l|}
\hline Defect Check ID & Baseline & SP 800-53 Control Item Code \\
\hline SWAM-F03 & Low & CM-7(b) \\
\hline SWAM-F03 & Low & CM-11(b) \\
\hline SWAM-F03 & Moderate & CM-7(1)(b) \\
\hline SWAM-F03 & Moderate & CM-7(2) \\
\hline SWAM-F03 & Moderate & CM-7(4)(a) \\
\hline SWAM-F03 & Moderate & CM-7(4)(b) \\
\hline SWAM-F03 & High & CM-7(5)(a) \\
\hline SWAM-F03 & High & CM-7(5)(b) \\
\hline
\end{tabular}




\subsubsection{Ensure or Increase Trust of System Software at Startup Sub-Capability and Defect Check SWAM-F04}

The purpose of this sub-capability is defined as follows:

\begin{tabular}{|l|l|}
\hline \multicolumn{1}{|c|}{ Sub-Capability Name } & \multicolumn{1}{c|}{ Sub-Capability Purpose } \\
\hline $\begin{array}{l}\text { Ensure or increase trust of system software at } \\
\text { startup }\end{array}$ & $\begin{array}{l}\text { Prevent or reduce the insertion of malware into key system components before or during } \\
\text { system startup. }\end{array}$ \\
\hline
\end{tabular}

The defect check to assess whether this sub-capability is operating effectively is defined as follows:

\begin{tabular}{|l|l|l|l|}
\hline $\begin{array}{c}\text { Defect } \\
\text { Check ID }\end{array}$ & $\begin{array}{l}\text { Defect Check } \\
\text { Name }\end{array}$ & \multicolumn{1}{|c|}{ Assessment Criteria Notes } & Selected \\
\hline $\begin{array}{l}\text { SWAM- } \\
\text { F04 }\end{array}$ & $\begin{array}{l}\text { Untrusted } \\
\text { core software }\end{array}$ & $\begin{array}{l}\text { 1) The actual state is data on the integrity of organizationally selected software components observed at } \\
\text { startup. At a minimum, core components are expected to include root operating system elements, } \\
\text { firmware, etc. Digital fingerprints are often used to identify components in the actual state. } \\
\text { 2) The desired state specification is a list of the approved version of each software element using the } \\
\text { same methods of identification (digital fingerprint, digital signature, etc.). } \\
\text { 3) A defect is software observed at startup that was not in the desired state specification. }\end{array}$ & Yes \\
\hline
\end{tabular}

\section{Example Responses:}

\begin{tabular}{|l|l|l|}
\hline Defect Check ID & \multicolumn{1}{|c|}{ Potential Response Action } & Primary Responsibility \\
\hline SWAM-F04 & Lock the system and block use & ISCM-Ops \\
\hline SWAM-F04 & Restore authorized state/software & SWMan \\
\hline SWAM-F04 & Authorize the new state & Auth \\
\hline SWAM-F04 & Accept risk & RskEx \\
\hline SWAM-F04 & Oversee and coordinate response & DSM \\
\hline
\end{tabular}




\section{Supporting Control Items:}

\begin{tabular}{|l|l|l|}
\hline Defect Check ID & Baseline & SP $\mathbf{8 0 0 - 5 3 ~ C o n t r o l ~ I t e m ~ C o d e ~}$ \\
\hline SWAM-F04 & Low & CM-11(b) \\
\hline SWAM-F04 & Low & SI-3(b) \\
\hline SWAM-F04 & Moderate & CM-7(1)(b) \\
\hline SWAM-F04 & Moderate & CM-7(4)(a) \\
\hline SWAM-F04 & Moderate & CM-7(4)(b) \\
\hline SWAM-F04 & Moderate & SI-7(1) \\
\hline SWAM-F04 & High & CM-5(3) \\
\hline SWAM-F04 & High & CM-7(5)(a) \\
\hline SWAM-F04 & High & CM-7(5)(b) \\
\hline
\end{tabular}




\subsubsection{Data Quality Sub-Capabilities and Corresponding Defect Checks}

NISTIR 8011 Volume 3 proposes four data quality defect checks, designated SWAM-Q01 through SWAM-Q04. The data quality defect checks are important because they provide the information necessary to determine how reliable the overall assessment automation process is, information which can be used to decide how much to trust the other defect check data (i.e., provide greater assurance about security control effectiveness). The data quality defect checks were selected for their value for summary reporting and are not associated with specific control items. The Selected column indicates which of the checks is implemented by the organization. Data quality checks are described more completely in NISTIR 8011, Volume 1, Overview, Section 5.5. Data Quality Measures. 


\subsubsection{Ensure Completeness of Device-Level Reporting Sub-Capability and Defect Check SWAM-Q01}

The purpose of this sub-capability is defined as follows:

\begin{tabular}{|l|l|}
\hline \multicolumn{1}{|c|}{ Sub-Capability Name } & \multicolumn{1}{c|}{ Sub-Capability Purpose } \\
\hline $\begin{array}{l}\text { Ensure completeness of device- } \\
\text { level reporting }\end{array}$ & $\begin{array}{l}\text { Ensure that devices are correctly reporting SWAM related information to the actual state inventory to } \\
\text { prevent SWAM defects from going undetected. }\end{array}$ \\
\hline
\end{tabular}

The defect check to assess whether this sub-capability is operating effectively is defined as follows:

\begin{tabular}{|l|l|l|l|}
\hline $\begin{array}{c}\text { Defect } \\
\text { Check ID }\end{array}$ & Defect Check Name & \multicolumn{1}{|c|}{ Assessment Criteria Notes } & Selected \\
\hline $\begin{array}{l}\text { SWAM- } \\
\text { Q01 }\end{array}$ & $\begin{array}{l}\text { Non-reporting of } \\
\text { device-level SWAM } \\
\text { information }\end{array}$ & $\begin{array}{l}\text { 1) The actual state is the list of devices connected to the assessment boundary. } \\
\text { 2) The desired state is that all the devices in the actual state are reporting SWAM information. } \\
\text { 3) A defect occurs when a device in the actual state has not reported its SWAM information as } \\
\text { recently as expected. } \\
\text { Criteria developed to define the threshold for "as recently as expected," for each device or device } \\
\text { type are based on the following considerations: } \\
\text { a. some devices (e. g., domain controllers, routers) must always be present. } \\
\text { b. endpoints may not report in a particular collection because they are turned off, network } \\
\text { connections are temporarily down, etc. But the endpoints should appear in the actual state at } \\
\text { least every n collections, where "n" is defined by "as recently as expected." } \\
\text { c. defining "as recently as expected" for devices such as laptops might require information on } \\
\text { what percent of the time the devices are expected to be connected to the network and powered } \\
\text { on. As that percent goes down, the length of "as recently as expected" goes up. } \\
\text { Time and experience are required to accurately define "as recently as expected" for each } \\
\text { device/device type in order to eliminate false positives while still finding true positives. }\end{array}$ & Yes \\
\hline
\end{tabular}




\section{Example Responses:}

\begin{tabular}{|l|l|l|}
\hline Defect Check ID & \multicolumn{1}{|c|}{ Potential Response Action } & Primary Responsibility \\
\hline SWAM-Q01 & Restore device reporting of software & ISCM-Ops \\
\hline SWAM-Q01 & Declare device missing (with software) & DM \\
\hline SWAM-Q01 & Accept risk & RskEx \\
\hline SWAM-Q01 & Oversee and coordinate response & ISCM-Ops \\
\hline
\end{tabular}

\section{Supporting Control Items:}

\begin{tabular}{|l|l|l|}
\hline Defect Check ID & Baseline & SP 800-53 Control Item Code \\
\hline SWAM-Q01 & Low & CM-8(a) \\
\hline
\end{tabular}




\subsubsection{Ensure Completeness of Defect-Check-Level Reporting Sub-Capability and Defect Check SWAM-Q02}

The purpose of this sub-capability is defined as follows:

\begin{tabular}{|l|l|}
\hline \multicolumn{1}{|c|}{ Sub-Capability Name } & \multicolumn{1}{c|}{ Sub-Capability Purpose } \\
\hline $\begin{array}{l}\text { Ensure completeness of defect-check- } \\
\text { level reporting }\end{array}$ & $\begin{array}{l}\text { Ensure that defect check information is correctly reported in the actual state inventory to prevent } \\
\text { systematic inability to check any defect on any device. }\end{array}$ \\
\hline
\end{tabular}

The defect check to assess whether this sub-capability is operating effectively is defined as follows:

\begin{tabular}{|l|l|l|l|}
\hline $\begin{array}{c}\text { Defect } \\
\text { Check ID }\end{array}$ & $\begin{array}{l}\text { Defect Check } \\
\text { Name }\end{array}$ & \multicolumn{1}{c|}{ Assessment Criteria Notes } & Selected \\
\hline $\begin{array}{l}\text { SWAM- } \\
\text { Q02 }\end{array}$ & $\begin{array}{l}\text { Non-reporting of } \\
\text { defect checks }\end{array}$ & $\begin{array}{l}\text { 1) The actual state is the set of SWAM data that was collected in each collection cycle to support all } \\
\text { implemented SWAM defect checks. } \\
\text { 2) The desired state is the set of SWAM data that must be collected in each collection cycle to support } \\
\text { all implemented SWAM defect checks. } \\
\text { 3) The defect is any set of data needed for a defect check where not all the data was collected for an } \\
\text { organizationally specified number of devices, indicating that the collection system is not providing } \\
\text { enough information to perform a sufficiently thorough assessment. }\end{array}$ & Yes \\
\hline
\end{tabular}

\section{Example Responses:}

\begin{tabular}{|l|l|l|}
\hline Defect Check ID & \multicolumn{1}{|c|}{ Potential Response Action } & Primary Responsibility \\
\hline SWAM-Q02 & Restore defect check reporting & ISCM-Ops \\
\hline SWAM-Q02 & Accept risk & RskEx \\
\hline SWAM-Q02 & Oversee and coordinate response & ISCM-Ops \\
\hline
\end{tabular}

\section{Supporting Control Items:}

\begin{tabular}{|l|l|l|}
\hline Defect Check ID & Baseline & SP 800-53 Control Item Code \\
\hline SWAM-Q02 & Low & CM-8(a) \\
\hline
\end{tabular}




\subsubsection{Increase Overall Reporting Completeness Sub-Capability and Defect Check SWAM-Q03}

The purpose of this sub-capability is defined as follows:

\begin{tabular}{|l|l|}
\hline \multicolumn{1}{|c|}{ Sub-Capability Name } & \multicolumn{1}{c|}{ Sub-Capability Purpose } \\
\hline $\begin{array}{l}\text { Increase overall reporting } \\
\text { completeness }\end{array}$ & $\begin{array}{l}\text { Ensure that data for as many defect checks as possible are correctly reported in the actual state inventory to } \\
\text { prevent defects from persisting undetected across the assessment boundary. }\end{array}$ \\
\hline
\end{tabular}

The defect check to assess whether this sub-capability is operating effectively is defined as follows:

\begin{tabular}{|c|c|c|c|}
\hline \begin{tabular}{|c|} 
Defect \\
Check ID
\end{tabular} & $\begin{array}{l}\text { Defect Check } \\
\text { Name }\end{array}$ & Assessment Criteria Notes & Selected \\
\hline \begin{tabular}{|l} 
SWAM- \\
Q03
\end{tabular} & $\begin{array}{l}\text { Low } \\
\text { completeness- } \\
\text { metric }\end{array}$ & $\begin{array}{l}\text { The completeness metric is not a device-level defect but is applied to any collection of devices - for } \\
\text { example, those in a system authorization boundary. The completeness metric is used in assessing the } \\
\text { accuracy of the collection system. } \\
\text { 1) The actual state is the number of specified defect checks provided by the collection system in a } \\
\text { reporting window. } \\
\text { 2) The desired state is the number of specified defect checks that should have been provided in that } \\
\text { same reporting window. } \\
\text { 3) Completeness is the metric defined as the actual state number divided by the desired state number - } \\
\text { that is, the completeness metric is the percentage of specified defect checks collected during the } \\
\text { reporting window. Completeness measures long term ability to collect all needed data. } \\
\text { 4) A defect is when completeness is too low (based on the defined threshold). This indicates risk } \\
\text { because, when completeness is too low, there is a higher risk of defects being undetected. An } \\
\text { acceptable level of completeness balances technical feasibility against the need for } 100 \% \\
\text { completeness. } \\
\text { Note on 1): A specific check-device combination may only be counted once in the required minimal } \\
\text { reporting period. For example, if checks are to be done every } 3 \text { days, a check done twice in that } \\
\text { timeframe would still count as } 1 \text { check. However, if there are } 30 \text { days in the reporting window, that } \\
\text { check-device combination could be counted for each of the ten } 3 \text {-day periods included. } \\
\text { Note on 2): For example, suppose that there are } 4 \text { devices and the organization requires that } 20 \\
\text { SWAM-specific defect checks be performed on each device, for a total of } 80 \text {. If only } 3 \text { devices are } \\
\text { checked but all } 20 \text { defects are checked on those } 3 \text { devices, then } 60 \text { out of } 80 \text { is the completeness } \\
\text { metric. If all four devices are checked and the number of defect checks performed on each device is } 5 \text {, } \\
10,15, \text { and } 20, \text { then } 50 \text { out of } 80 \text { is the completeness metric for the SWAM-specific defect checks. }\end{array}$ & Yes \\
\hline
\end{tabular}




\section{Example Responses:}

\begin{tabular}{|l|l|l|}
\hline Defect Check ID & Potential Response Action & Primary Responsibility \\
\hline SWAM-Q03 & Restore completeness & ISCM-Ops \\
\hline SWAM-Q03 & Accept risk & RskEx \\
\hline SWAM-Q03 & Oversee and coordinate response & ISCM-Ops \\
\hline
\end{tabular}

\section{Supporting Control Items:}

\begin{tabular}{|l|l|l|}
\hline Defect Check ID & Baseline & SP 800-53 Control Item Code \\
\hline SWAM-Q03 & Low & CM-8(a) \\
\hline
\end{tabular}




\subsubsection{Ensure Overall Reporting Timeliness Sub-Capability and Defect Check SWAM-Q04}

The purpose of this sub-capability is defined as follows:

\begin{tabular}{|l|l|}
\hline \multicolumn{1}{|c|}{$\begin{array}{c}\text { Sub-Capability } \\
\text { Name }\end{array}$} & \multicolumn{1}{c|}{ Sub-Capability Purpose } \\
\hline $\begin{array}{l}\text { Ensure overall } \\
\text { reporting timeliness }\end{array}$ & $\begin{array}{l}\text { Ensure that data for as many defect checks as possible are reported in a timely manner in the actual state inventory to } \\
\text { prevent defects from persisting undetected. To be effective, defects need to be found and mitigated considerably faster } \\
\text { than they can be exploited. }\end{array}$ \\
\hline
\end{tabular}

The defect check to assess whether this sub-capability is operating effectively is defined as follows:

\begin{tabular}{|l|l|l|l|}
\hline $\begin{array}{c}\text { Defect } \\
\text { Check ID }\end{array}$ & $\begin{array}{l}\text { Defect } \\
\text { Check Name }\end{array}$ & \multicolumn{1}{c|}{ Assessment Criteria Notes } & Selected \\
\hline SWAM- & $\begin{array}{l}\text { Poor } \\
\text { Qimeliness } \\
\text { metric }\end{array}$ & $\begin{array}{l}\text { The Timeliness metric is not a device-level defect, but can be applied to any collection of devices - for } \\
\text { example, those within a system (authorization boundary). It is used in computing the maturity of the } \\
\text { collection system. } \\
\text { 1) The actual state is the number of specified defect checks provided by the collection system in one } \\
\text { collection cycle - the period in which each defect should be checked once. } \\
\text { 2) The desired state is the number of specified defect checks that should have been provided in the } \\
\text { collection cycle. } \\
\text { 3) Timeliness is the metric defined as the actual state number divided by the desired state number - that } \\
\text { is, it is the percentage of specified defect checks collected in the reporting cycle. Thus it measures the } \\
\text { percentage of data that is currently timely (collected as recently as required). } \\
\text { 4) A defect is when "timeliness" is too poor (based on the defined threshold). This indicates risk because } \\
\text { when timeliness is poor there is a higher risk of defects not being detected quickly enough. } \\
\text { Note on 1): A specific check-device combination may only be counted once in the collection cycle. } \\
\text { Note on 2): Different devices may have different sets of specified checks, based on their role. }\end{array}$ & Yes \\
\hline
\end{tabular}




\section{Example Responses:}

\begin{tabular}{|l|l|l|}
\hline Defect Check ID & Potential Response Action & Primary Responsibility \\
\hline SWAM-Q04 & Restore frequency & ISCM-Ops \\
\hline SWAM-Q04 & Accept risk & RskEx \\
\hline SWAM-Q04 & Oversee and coordinate response & ISCM-Ops \\
\hline
\end{tabular}

\section{Supporting Control Items:}

\begin{tabular}{|l|l|l|}
\hline Defect Check ID & Baseline & SP 800-53 Control Item Code \\
\hline SWAM-Q04 & Low & CM-8(b) \\
\hline SWAM-Q04 & Low & CM-11(c) \\
\hline SWAM-Q04 & Moderate & CM-8(1) \\
\hline
\end{tabular}




\subsubsection{Local Sub-Capabilities and Corresponding Defect Checks}

This section includes local defect checks, as examples of what organizations may add to the foundational and data quality checks to provide more complete automated assessment of SP 80053 controls that support SWAM.

Organizations exercise authority to manage risk by choosing whether to select specific defect checks for implementation. In general, selecting more defect checks may lower risk (if there is capacity to address defects found) and provide greater assurance but may also increase cost of detection and mitigation. The organization selects defect checks for implementation (or not) to balance the benefits and costs and prioritize risk response actions by focusing first on the problems that pose greater risk (i.e., managing risk).

Note that each local defect check may also include options to make the defect check more or less rigorous, as the risk tolerance of the organization and impact level of the system indicates.

The "Selected" column is present to indicate which of the local defect checks the organization chooses to implement as documented or as modified by the organization. 


\subsubsection{Ensure or Increase Integrity of Software Authorizers Sub-Capability and Defect Check SWAM-L01}

The purpose of this sub-capability is defined as follows:

\begin{tabular}{|l|l|}
\hline \multicolumn{1}{|c|}{ Sub-Capability Name } & \multicolumn{1}{c|}{ Sub-Capability Purpose } \\
\hline $\begin{array}{l}\text { Ensure or increase integrity of software } \\
\text { authorizers }\end{array}$ & $\begin{array}{l}\text { Prevent or reduce the insertion of malware into the list of approved software by unauthorized } \\
\text { persons. }\end{array}$ \\
\hline
\end{tabular}

The defect check to assess whether this sub-capability is operating effectively is defined as follows:

\begin{tabular}{|l|l|l|l|}
\hline $\begin{array}{l}\text { Defect } \\
\text { Check ID }\end{array}$ & $\begin{array}{l}\text { Defect Check } \\
\text { Name }\end{array}$ & \multicolumn{1}{c|}{ Assessment Criteria Notes } & \multicolumn{1}{c|}{ Selected } \\
\hline $\begin{array}{l}\text { SWAM- } \\
\text { L01 }\end{array}$ & $\begin{array}{l}\text { Unapproved } \\
\text { authorizer }\end{array}$ & $\begin{array}{l}\text { 1) The actual state is the account which authorized the use of each instance of software. } \\
\text { 2) The desired state specification is a list of the approved accounts which can authorize software } \\
\text { 3) A defect is software that was authorized by an unapproved authorizer. } \\
\text { Note on 1): An instance of software authorized for use is specified at the level of granularity the } \\
\text { organization deems appropriate, based on the organization's business needs and risk tolerance. An } \\
\text { instance is likely a software product, but might be a software file, an Internet domain, or a } \\
\text { URL. Instances of software might be authorized for all devices, specific types of devices, or specific } \\
\text { individual devices. }\end{array}$ & organization \\
\hline
\end{tabular}

\section{Example Responses:}

\begin{tabular}{|l|l|l|}
\hline Defect Check ID & \multicolumn{1}{|c|}{ Potential Response Action } & Primary Responsibility \\
\hline SWAM-L01 & Block the software as unauthorized & ISCM-Ops \\
\hline SWAM-L01 & Remove the software & SWMan \\
\hline SWAM-L01 & Authorized person approves the software & Auth \\
\hline SWAM-L01 & Accept risk & RskEx \\
\hline SWAM-L01 & Oversee and coordinate response & DSM \\
\hline
\end{tabular}




\section{Supporting Control Items:}

\begin{tabular}{|l|l|l|}
\hline Defect Check ID & Baseline & SP 800-53 Control Item Code \\
\hline SWAM-L01 & Low & CM-4 \\
\hline SWAM-L01 & Moderate & SI-7 \\
\hline SWAM-L01 & High & SI-7(14)(b) \\
\hline
\end{tabular}




\subsubsection{Prevent or Reduce (Careless or Malicious) Software Approval Sub-Capability and Defect Check SWAM-L02}

The purpose of this sub-capability is defined as follows:

Sub-Capability Name

Prevent or reduce (careless or malicious) software approval

\section{Sub-Capability Purpose}

Ensure checks and balances are in place to prevent a single individual from carelessly or maliciously changing authorization of software installation.

Note 1: If the organization chooses to use access restrictions to enforce multiple approvals, effectiveness is assessed under the PRIV capability.

Note 2: See SWAM-L09 for authorization boundary.

The defect check to assess whether this sub-capability is operating effectively is defined as follows:

\begin{tabular}{|l|l|l|l|}
\hline $\begin{array}{c}\text { Defect } \\
\text { Check ID }\end{array}$ & \multicolumn{1}{|c|}{$\begin{array}{c}\text { Defect Check } \\
\text { Name }\end{array}$} & \multicolumn{1}{c|}{ Assessment Criteria Notes } \\
\hline $\begin{array}{l}\text { SWAM- } \\
\text { L02 }\end{array}$ & $\begin{array}{l}\text { Required } \\
\text { authorizations } \\
\text { missing }\end{array}$ & $\begin{array}{l}\text { 1) The actual state is the list of persons who authorized the change to the system, thus } \\
\text { allowing the software item to be executed. This would typically be recorded in the desired } \\
\text { state inventory as part of the configuration change control process. } \\
\text { 2) The desired state is the list of persons who are authorized to approve system changes and } \\
\text { allow software to be executed. This may include specifying first, second, etc., approver roles. } \\
\text { 3) A defect occurs when the software item is authorized } \\
\text { a. by fewer than the required number of distinct and authorized approvers; or } \\
\text { b. by persons not authorized to approve software. }\end{array}$ \\
$\begin{array}{l}\text { Note: An organization may wish to enhance this defect check by requiring different individuals } \\
\text { to verify different attributes of the software, such as supply chain strength, vendors' attention } \\
\text { to security, etc. }\end{array}$ \\
\hline
\end{tabular}




\section{Example Responses:}

\begin{tabular}{|l|l|l|}
\hline Defect Check ID & \multicolumn{1}{|c|}{ Potential Response Action } & Primary Responsibility \\
\hline SWAM-L02 & Block the software as unauthorized & ISCM-Ops \\
\hline SWAM-L02 & Remove the software & SWMan \\
\hline SWAM-L02 & Authorized person approves the software & Auth \\
\hline SWAM-L02 & Accept risk & RskEx \\
\hline SWAM-L02 & Oversee and coordinate response & DSM \\
\hline
\end{tabular}

\section{Supporting Control Items:}

\begin{tabular}{|l|l|l|}
\hline Defect Check ID & Baseline & SP 800-53 Control Item Code \\
\hline SWAM-L02 & Low & CM-4 \\
\hline SWAM-L02 & Moderate & SI-7 \\
\hline
\end{tabular}




\subsubsection{Promptly Determine and Address Needed Installation and Deinstallation of Software Sub-Capability and Defect Check SWAM-LO3}

The purpose of this sub-capability is defined as follows:

\begin{tabular}{|l|l|}
\hline \multicolumn{1}{|c|}{ Sub-Capability Name } & \multicolumn{1}{c|}{ Sub-Capability Purpose } \\
\hline $\begin{array}{l}\text { Promptly determine and address needed } \\
\text { installation and deinstallation of software }\end{array}$ & $\begin{array}{l}\text { Ensure that needed changes are addressed in a timely manner by flagging requested changes } \\
\text { not considered (approved and implemented; or disapproved) in a timely manner as risks. }\end{array}$ \\
\hline
\end{tabular}

The defect check to assess whether this sub-capability is operating effectively is defined as follows:

\begin{tabular}{|c|l|l|l|}
\hline $\begin{array}{c}\text { Defect } \\
\text { Check ID }\end{array}$ & \multicolumn{1}{|c|}{ Defect Check Name } & \multicolumn{1}{|c|}{ Assessment Criteria Notes } \\
\hline SWAM-L03 & $\begin{array}{l}\text { Expired actions on software } \\
\text { authorization/deauthorization requests }\end{array}$ & $\begin{array}{l}\text { 1) The actual state includes: } \\
\text { a. a list of proposed changes to the desired state. } \\
\text { b. a list of approved changes to the actual state, likely derived } \\
\text { from the desired state specification. } \\
\text { c. the date the change was proposed. } \\
\text { d. the date the change was implemented (if approved) or the } \\
\text { date the change was rejected. } \\
\text { 2) The desired state includes: } \\
\text { a. the timeframe within which proposed items are to be } \\
\text { approved or rejected. } \\
\text { b. the timeframe within which approved changes are to be } \\
\text { implemented in the actual state. } \\
\text { 3) A defect occurs when a device in the assessment } \\
\text { boundary: } \\
\text { a. includes a proposed change that has not been addressed } \\
\text { within the time allowed in 2(a); or } \\
\text { b. includes an approved change that has not been } \\
\text { implemented within the timeframe specified in 2(b). }\end{array}$ \\
\hline
\end{tabular}




\section{Example Responses:}

\begin{tabular}{|l|l|l|}
\hline Defect Check ID & \multicolumn{1}{|c|}{ Potential Response Action } & Primary Responsibility \\
\hline SWAM-L03 & Automatically block unapproved changes & ISCM-Ops \\
\hline SWAM-L03 & Automatically put into effect approved changes & SWMan \\
\hline SWAM-L03 & Manually remove unapproved changes promptly & SWMan \\
\hline SWAM-L03 & Manually implement approved changes promptly & SWMan \\
\hline SWAM-L03 & Change authorizations & Auth \\
\hline SWAM-L03 & Accept risk & RskEx \\
\hline SWAM-L03 & Oversee and coordinate response & DSM \\
\hline
\end{tabular}

\section{Supporting Control Items:}

\begin{tabular}{|l|l|l|}
\hline Defect Check ID & Baseline & SP 800-53 Control Item Code \\
\hline SWAM-L03 & Low & SI-3(d) \\
\hline SWAM-L03 & Moderate & SI-3(2) \\
\hline SWAM-L03 & High & CM-3(1)(c) \\
\hline
\end{tabular}




\subsubsection{Prevent or Reduce Exploitation of Software on Devices Moving into or out of Protective Boundaries Sub- Capability and Defect Check SWAM-LO4}

The purpose of this sub-capability is defined as follows:

\begin{tabular}{|l|l|}
\hline \multicolumn{1}{|c|}{ Sub-Capability Name } & \multicolumn{1}{c|}{ Sub-Capability Purpose } \\
\hline $\begin{array}{l}\text { Prevent or reduce exploitation } \\
\text { of software on devices moving } \\
\text { into or out of protective } \\
\text { boundaries }\end{array}$ & $\begin{array}{l}\text { Prevent exploitation of software on devices after removal, during use elsewhere, and after return (or other } \\
\text { mobile use) by a) appropriately hardening the device prior to removal; b) checking for organizational software } \\
\text { before removal; and c) sanitizing the device before introduction or reintroduction into the protective boundary. } \\
\text { Note: For more information on media sanitization, see Kissel, R. et al (2014), Guidelines for Media Sanitization } \\
\text { (National Institute of Standards and Technology, Gaithersburg, MD), NIST Special Publication (SP) 800-88, } \\
\text { https://csrc.nist.gov/publications/detail/sp/800-88/rev-1/final. }\end{array}$ \\
\hline
\end{tabular}


The defect check to assess whether this sub-capability is operating effectively is defined as follows:

\begin{tabular}{|c|c|c|c|}
\hline $\begin{array}{c}\text { Defect } \\
\text { Check ID }\end{array}$ & Defect Check Name & Assessment Criteria Notes & Selected \\
\hline $\begin{array}{l}\text { SWAM- } \\
\text { L04 }\end{array}$ & $\begin{array}{l}\text { Devices moving in/out of } \\
\text { protective boundaries not } \\
\text { in policy compliance }\end{array}$ & $\begin{array}{l}\text { 1) The actual state includes: } \\
\text { a. the actual installed software configuration on devices approved for travel (i.e., removal } \\
\text { and reintroduction). This typically consists of the presence or absence of specific } \\
\text { software. } \\
\text { b. data identifying devices about to be used in travel (and to where). } \\
\text { c. data identifying devices reentering protective boundaries (and where else the device } \\
\text { has been connected while outside of protective boundaries. The locations might be } \\
\text { validated from global positioning system (GPS) and internet protocol (IP) logging, if } \\
\text { appropriate). } \\
\text { 2) The desired state includes: } \\
\text { a. the list of devices authorized for travel. } \\
\text { b. the desired installed software strengthening (adding software protections and/or } \\
\text { removing sensitive software) and/or sanitization (restoring software and/or finding and } \\
\text { removing malicious software) for such devices, based on the location(s) to which } \\
\text { connected while removed, with respect to 1a and 1c above. } \\
\text { 3) A defect occurs when any of the following occur: } \\
\text { a. any device unauthorized for travel is either expected to be (or has actually been) } \\
\text { traveling, regardless of installed software configuration. } \\
\text { b. a device approved for travel does not have the desired installed software configuration } \\
\text { for the proposed uses. } \\
\text { c. a device approved for travel was connected to unapproved location(s) where its } \\
\text { installed software configuration was not appropriate (matching the desired state) for those } \\
\text { location(s). } \\
\text { d. a device approved and used for travel is not sanitized on its return based on the } \\
\text { location(s) to which connected while outside of protective boundaries, with respect to } \\
\text { items 1a and 1c above. }\end{array}$ & $\begin{array}{l}\text { TBD by } \\
\text { organization }\end{array}$ \\
\hline
\end{tabular}




\section{Example Responses:}

\begin{tabular}{|c|c|c|}
\hline Defect Check ID & Potential Response Action & Primary Responsibility \\
\hline SWAM-L04 & Correct configurations before allowing exit from boundary & SWMan \\
\hline SWAM-L04 & Correct configurations before allowing entry to boundary & SWMan \\
\hline SWAM-L04 & Authorize the new state & Auth \\
\hline SWAM-L04 & Accept risk & RskEx \\
\hline SWAM-L04 & Oversee and coordinate response & DSM \\
\hline
\end{tabular}

\section{Supporting Control Items:}

\begin{tabular}{|l|l|l|}
\hline Defect Check ID & Baseline & SP 800-53 Control Item Code \\
\hline SWAM-L04 & Low & CM-11(b) \\
\hline SWAM-L04 & Low & MP-6(a) \\
\hline SWAM-L04 & Low & MP-6(b) \\
\hline SWAM-L04 & Low & PS-4(d) \\
\hline SWAM-L04 & Low & SI-3(b) \\
\hline SWAM-L04 & Moderate & CM-2(7)(a) \\
\hline SWAM-L04 & Moderate & CM-2(7)(b) \\
\hline SWAM-L04 & Moderate & CM-7(1)(b) \\
\hline SWAM-L04 & Moderate & CM-7(4)(a) \\
\hline SWAM-L04 & Moderate & CM-7(4)(b) \\
\hline SWAM-L04 & Moderate & MA-3(1) \\
\hline SWAM-L04 & Moderate & MA-3(2) \\
\hline SWAM-L04 & High & CM-7(5)(a) \\
\hline SWAM-L04 & High & CM-7(5)(b) \\
\hline SWAM-L04 & High & MP-6(1) \\
\hline SWAM-L04 & High & MP-6(2) \\
\hline SWAM-L04 & High & MP-6(3) \\
\hline
\end{tabular}




\subsubsection{Enable Rollback and Recovery Sub-Capability and Defect Check SWAM-LO5}

The purpose of this sub-capability is defined as follows:

\begin{tabular}{|l|l|}
\hline Sub-Capability Name & \multicolumn{1}{c|}{ Sub-Capability Purpose } \\
\hline $\begin{array}{l}\text { Enable rollback and } \\
\text { recovery }\end{array}$ & $\begin{array}{l}\text { Require the maintenance of enough prior versions of software to ensure the ability to rollback and recover in the event } \\
\text { that issues are found with the newer software. }\end{array}$ \\
\hline
\end{tabular}

The defect check to assess whether this sub-capability is operating effectively is defined as follows:

\begin{tabular}{|c|l|l|l|}
\hline $\begin{array}{c}\text { Defect } \\
\text { Check ID }\end{array}$ & \multicolumn{1}{|c|}{ Defect Check Name } & \multicolumn{1}{|c|}{ Assessment Criteria Notes } \\
\hline SWAM-L05 & $\begin{array}{l}\text { Number of prior versions of } \\
\text { installed software inadequate }\end{array}$ & $\begin{array}{l}\text { 1) The actual state includes (for each device's software items): } \\
\text { a. the number of prior versions (replaced version) maintained. } \\
\text { b. the date each prior version was removed from the device. } \\
\text { c. the date the oldest version was put in service on that device. } \\
\text { 2) The desired state includes: } \\
\text { a. the minimum number (n) of prior versions to be maintained. } \\
\text { b. the minimum time (t) prior versions are to be maintained. } \\
\text { 3) A defect occurs when a device is connected to the assessment boundary } \\
\text { where less than the minimum number of prior versions of the software item have } \\
\text { been retained. } \\
\text { Note 1: The prior versions do not generally reside on the device itself, but typically } \\
\text { on some backup media. } \\
\text { Note 2: The number of required prior versions might be different for each software } \\
\text { product or class of software products, as specified by the organization. }\end{array}$ \\
\hline
\end{tabular}




\section{Example Responses:}

\begin{tabular}{|l|l|l|}
\hline Defect Check ID & \multicolumn{1}{|c|}{ Potential Response Action } & Primary Responsibility \\
\hline SWAM-L05 & Reconstruct backup version(s) & SWMan \\
\hline SWAM-L05 & Modify procedures to prevent future occurrences & RskEx \\
\hline SWAM-L05 & Change requirements & DSM \\
\hline SWAM-L05 & Accept risk & RskEx \\
\hline SWAM-L05 & Oversee and coordinate response & RskEx \\
\hline
\end{tabular}

\section{Supporting Control Items:}

\begin{tabular}{|l|l|l|}
\hline Defect Check ID & Baseline & SP 800-53 Control Item Code \\
\hline SWAM-L05 & Moderate & CM-2(3) \\
\hline
\end{tabular}




\subsubsection{Prevent or Reduce Software Defects Sub-Capability and Defect Check SWAM-L06}

The purpose of this sub-capability is defined as follows:

\begin{tabular}{|c|c|}
\hline Sub-Capability Name & Sub-Capability Purpose \\
\hline Prevent or reduce software defects & Prevent or reduce the installation of software which has not been tested and validated prior to approval. \\
\hline
\end{tabular}

The defect check to assess whether this sub-capability is operating effectively is defined as follows:

\begin{tabular}{|l|l|l|l|}
\hline $\begin{array}{l}\text { Defect } \\
\text { Check ID }\end{array}$ & Defect Check Name & \multicolumn{1}{|c|}{ Assessment Criteria Notes } & \multicolumn{1}{c|}{ Selected } \\
\hline $\begin{array}{l}\text { SWAM- } \\
\text { L06 }\end{array}$ & $\begin{array}{l}\text { Testing and } \\
\text { validation of software } \\
\text { inadequate }\end{array}$ & $\begin{array}{l}\text { 1) The actual state includes (for each software item on one or more devices): } \\
\text { a. the testing and validation steps conducted for that software. } \\
\text { b. the attributes of this software (used to determine the desired level of testing, see desired } \\
\text { state). } \\
\text { 2) The desired state includes: } \\
\text { a. the organization defined software item attributes used to determine the correct amount and } \\
\text { kind of testing and validation. } \\
\text { b. the specification of the correct amount and kind of testing and validation for each } \\
\text { combination of relevant attributes. } \\
\text { 3) A defect occurs when a device connected to the assessment boundary has installed } \\
\text { software where the amount and kind of testing and validation of the installed software is not at } \\
\text { least as complete as the desired state specification for the software item's combination of } \\
\text { relevant categories. }\end{array}$ & $\begin{array}{l}\text { TBD by } \\
\text { organization }\end{array}$ \\
\hline
\end{tabular}

\section{Example Responses:}

\begin{tabular}{|l|l|l|}
\hline Defect Check ID & \multicolumn{1}{|c|}{ Potential Response Action } & Primary Responsibility \\
\hline SWAM-L06 & Automatically block execution of software & ISCM-Ops \\
\hline SWAM-L06 & Remove the software & SWMan \\
\hline SWAM-L06 & Change testing and validation requirements & DSM \\
\hline SWAM-L06 & Accept risk & RskEx \\
\hline SWAM-L06 & Oversee and coordinate response & RskEx \\
\hline
\end{tabular}




\section{Supporting Control Items:}

\begin{tabular}{|l|l|l|}
\hline Defect Check ID & Baseline & SP 800-53 Control Item Code \\
\hline SWAM-L06 & Low & CM-4 \\
\hline SWAM-L06 & High & CM-4(1) \\
\hline
\end{tabular}




\subsubsection{Verify Ongoing Business Need for Software Sub-Capability and Defect Check SWAM-L07}

The purpose of this sub-capability is defined as follows:

\begin{tabular}{|l|l|}
\hline \multicolumn{1}{|c|}{ Sub-Capability Name } & \multicolumn{1}{c|}{ Sub-Capability Purpose } \\
\hline $\begin{array}{l}\text { Verify ongoing business } \\
\text { need for software }\end{array}$ & $\begin{array}{l}\text { Require periodic and/or event driven consideration of whether a software item is still needed for system functionality to } \\
\text { fulfill mission requirements in support of least functionality). }\end{array}$ \\
& $\begin{array}{l}\text { Note: Recommended practice is to require DMs to review devices for unauthorized, unneeded or unmanaged } \\
\text { software, and System Owners to review what software is needed in the authorization boundaries, compared to what is } \\
\text { present. }\end{array}$ \\
\hline
\end{tabular}

The defect check to assess whether this sub-capability is operating effectively is defined as follows:

\begin{tabular}{|c|l|l|l|}
\hline $\begin{array}{c}\text { Defect } \\
\text { Check ID }\end{array}$ & \multicolumn{1}{|c|}{ Defect Check Name } & \multicolumn{1}{|c|}{ Assessment Criteria Notes } \\
\hline SWAM-L07 & $\begin{array}{l}\text { Business need of software not } \\
\text { recently verified }\end{array}$ & $\begin{array}{l}\text { 1) The actual state includes (for each software item): } \\
\text { a. the date business need was last verified; and/or } \\
\text { b. whether or not a specified trigger event has occurred. } \\
\text { 2) The desired state includes: } \\
\text { a. the maximum time before re-verification is required for each software } \\
\text { item. } \\
\text { b. a software item sunset date and/or specific trigger events requiring } \\
\text { consideration of software item relevance, } \\
\text { i. by device type and/or software item role/attributes. } \\
\text { i. by device type and/or software item identity. } \\
\text { 3) A defect occurs when a device connected to the assessment boundary: } \\
\text { a. has a software item with an expired sunset date; or } \\
\text { b. has a software item nearing an expired sunset date (to provide warning to } \\
\text { desired state managers); or } \\
\text { c. a specified trigger event has occurred to this device or software item } \\
\text { without re-verification of business need. }\end{array}$ & $\begin{array}{l}\text { TBD by } \\
\text { organization }\end{array}$ \\
\end{tabular}




\section{Example Responses:}

\begin{tabular}{|l|l|l|}
\hline Defect Check ID & \multicolumn{1}{|c|}{ Potential Response Action } & Primary Responsibility \\
\hline SWAM-L07 & Verify business need & Auth \\
\hline SWAM-L07 & Automatically block execution of software & ISCM-Ops \\
\hline SWAM-L07 & Remove the software & SWMan \\
\hline SWAM-L07 & Change requirement for verification of business need & DSM \\
\hline SWAM-L07 & Accept risk & RskEx \\
\hline SWAM-L07 & Oversee and coordinate response & RskEx \\
\hline
\end{tabular}

\section{Supporting Control Items:}

\begin{tabular}{|l|l|l|}
\hline Defect Check ID & Baseline & SP 800-53 Control Item Code \\
\hline SWAM-L07 & Low & CM-4 \\
\hline SWAM-L07 & Low & CM-7(a) \\
\hline SWAM-L07 & Moderate & CM-7(1)(a) \\
\hline SWAM-L07 & Moderate & CM-7(4)(c) \\
\hline SWAM-L07 & High & CM-7(5)(c) \\
\hline
\end{tabular}




\subsubsection{Prevent or Reduce Unused (and thus Unneeded) Software Products Sub-Capability and Defect Check} SWAM-L08

The purpose of this sub-capability is defined as follows:

\begin{tabular}{|l|l|}
\hline \multicolumn{1}{|c|}{ Sub-Capability Name } & \multicolumn{1}{c|}{ Sub-Capability Purpose } \\
\hline $\begin{array}{l}\text { Prevent or reduce unused (and thus unneeded) } \\
\text { software products }\end{array}$ & $\begin{array}{l}\text { Prevent or reduce the presence of unused (and thus unneeded) software products as } \\
\text { determined by actual usage on a given device. }\end{array}$ \\
\hline
\end{tabular}

The defect check to assess whether this sub-capability is operating effectively is defined as follows:

\begin{tabular}{|l|l|l|l|}
\hline $\begin{array}{l}\text { Defect } \\
\text { Check ID }\end{array}$ & $\begin{array}{c}\text { Defect } \\
\text { Check } \\
\text { Name }\end{array}$ & \multicolumn{1}{|c|}{ Assessment Criteria Notes } \\
\hline $\begin{array}{l}\text { SWAM- } \\
\text { L08 }\end{array}$ & $\begin{array}{l}\text { Unused } \\
\text { software } \\
\text { present }\end{array}$ & $\begin{array}{l}\text { 1) The actual state includes (for each software product on one or more devices): } \\
\text { a. actual software product attributes (see note) used to determine how much it is expected to be used. } \\
\text { b. the last date of use. } \\
\text { c. the number of times used in an organizationally defined period. } \\
\text { 2) The desired state includes: } \\
\text { a. the software product attributes (see note) used to determine the expected amount of use. } \\
\text { b) the specification of the expected amount of use for each combination of relevant categories. } \\
\text { 3) A defect occurs when a device connected to the assessment boundary has installed software } \\
\text { products where any of the following are true: } \\
\text { a) the last use is older than expected. } \\
\text { b) the rate of use is less than expected. }\end{array}$ & $\begin{array}{l}\text { TBD by } \\
\text { organization }\end{array}$ \\
$\begin{array}{l}\text { Note for 1a and 2a: Different or variable timeframes/usage patterns for different types and classes of } \\
\text { software might be needed, since some software might be used at differing frequencies. For example, } \\
\text { some "quarterly report software" might only be expected to be used quarterly, while "annual report } \\
\text { software" might only be used annually. }\end{array}$ & \\
\hline
\end{tabular}




\section{Example Responses:}

\begin{tabular}{|l|l|l|}
\hline Defect Check ID & Potential Response Action & Primary Responsibility \\
\hline SWAM-L08 & Remove the software & SWMan \\
\hline SWAM-L08 & Change usage expectations & DSM \\
\hline SWAM-L08 & Accept risk & RskEx \\
\hline SWAM-L08 & Oversee and coordinate response & RskEx \\
\hline
\end{tabular}

\section{Supporting Control Items:}

\begin{tabular}{|l|l|l|}
\hline Defect Check ID & Baseline & SP 800-53 Control Item Code \\
\hline SWAM-L08 & Low & CM-4 \\
\hline SWAM-L08 & Low & CM-7(a) \\
\hline SWAM-L08 & Moderate & CM-7(1)(a) \\
\hline
\end{tabular}




\subsubsection{Ensure Software Is Required by a System Sub-Capability and Defect Check SWAM-LO9}

The purpose of this sub-capability is defined as follows:

\begin{tabular}{|l|l|}
\hline \multicolumn{1}{|c|}{ Sub-Capability Name } & \multicolumn{1}{c|}{ Sub-Capability Purpose } \\
\hline $\begin{array}{l}\text { Ensure device-software- } \\
\text { item level accountability }\end{array}$ & $\begin{array}{l}\text { Ensure each unique combination of a device and software item (device-software-item) has accountability. Reduce } \\
\text { duplication of effort by verifying that each unique combination of device and software-item is in one and only one } \\
\text { authorization boundary. }\end{array}$ \\
& Note: For this defect check, the relevant software item is more likely a software product than a software file. \\
\hline
\end{tabular}

The defect check to assess whether this sub-capability is operating effectively is defined as follows:

\begin{tabular}{|c|l|l|l|}
\hline $\begin{array}{c}\text { Defect } \\
\text { Check ID }\end{array}$ & \multicolumn{1}{|c|}{ Defect Check Name } & \multicolumn{1}{c|}{ Assessment Criteria Notes } & \multicolumn{1}{c|}{ Selected } \\
\hline SWAM-L09 & $\begin{array}{l}\text { Device-software-item assignment } \\
\text { to authorization boundary is not 1:1 }\end{array}$ & $\begin{array}{l}\text { 1) The actual state includes the authorization boundary(ies) to which the } \\
\text { device-software-item combination is assigned in the desired state. } \\
\text { 2) The desired state is that each device-software-item combination is in one } \\
\text { and only one authorization boundary, and thus has a clearly defined } \\
\text { management responsibility. } \\
\text { 3) A defect occurs when an actual state device-software-item combination is: } \\
\text { a. not listed in any authorization boundary; or } \\
\text { b. listed in more than one authorization boundary. }\end{array}$ & $\begin{array}{l}\text { TBD by } \\
\text { organization }\end{array}$ \\
& $\begin{array}{l}\text { Note: For guidance on defining authorization boundaries, see NIST SP 800- } \\
\text { 37. }\end{array}$ \\
\hline
\end{tabular}




\section{Example Responses:}

\begin{tabular}{|l|l|l|}
\hline Defect Check ID & \multicolumn{1}{|c|}{ Potential Response Action } & Primary Responsibility \\
\hline SWAM-L09 & Block the software & ISCM-Ops \\
\hline SWAM-L09 & Remove the software & SWMan \\
\hline SWAM-L09 & Adjust authorization boundary assignment & DSM \\
\hline SWAM-L09 & Accept risk & RskEx \\
\hline SWAM-L09 & Oversee and coordinate response & RskEx \\
\hline
\end{tabular}

\section{Supporting Control Items:}

\begin{tabular}{|l|l|l|}
\hline Defect Check ID & Baseline & SP 800-53 Control Item Code \\
\hline SWAM-L09 & Low & CM-11(b) \\
\hline SWAM-L09 & Moderate & CM-8(5) \\
\hline
\end{tabular}




\subsubsection{Ensure that Software Complies with License Agreements Sub-Capability and Defect Check SWAM-L10}

The purpose of this sub-capability is defined as follows:

\begin{tabular}{|c|c|}
\hline Sub-Capability Name & Sub-Capability Purpose \\
\hline Ensure that software complies with license agreements & Ensure that actual usage of software products complies with license agreements. \\
\hline
\end{tabular}

The defect check to assess whether this sub-capability is operating effectively is defined as follows:

\begin{tabular}{|l|l|l|l|}
\hline $\begin{array}{l}\text { Defect } \\
\text { Check ID }\end{array}$ & $\begin{array}{l}\text { Defect Check } \\
\text { Name }\end{array}$ & \multicolumn{1}{|c|}{ Assessment Criteria Notes } \\
\hline $\begin{array}{l}\text { SWAM- } \\
\text { L10 }\end{array}$ & $\begin{array}{l}\text { Unlicensed } \\
\text { software }\end{array}$ & $\begin{array}{l}\text { 1) The actual state includes } \\
\text { a) the inventory of each unique combination of a device and software product (device-software- } \\
\text { products) installed. } \\
\text { b) data (such as number installed, numbers concurrently used, amount of use, copies of installation } \\
\text { media, protection of media) to determine the extent of license compliance for each software } \\
\text { product. } \\
\text { 2) The desired state includes the criteria (such as number allowed to be installed, number } \\
\text { concurrently allowed to be used, limits to installation on specific devices, and amount of use) } \\
\text { needed to determine license compliance for each software product. } \\
\text { 3) A defect occurs when the actual state of a software-product is not in compliance with the desired } \\
\text { state. For example: } \\
\text { a. the criteria in 2) might be that } 80 \text { copies may be installed, but the actual state of 1.a) is that } 85 \\
\text { are installed } \\
\text { b) the criteria in 2) might limit concurrent users to 100, but the actual state in 1.b) might indicate that } \\
\text { there are periods with up to 125 concurrent users. } \\
\text { c) The criteria in 2) might limit hours of use to 1000, but the actual state in 1.b) might indicate that } \\
\text { 1010 hours were used. }\end{array}$ \\
organization \\
$\begin{array}{l}\text { Note 1: The criteria in 2) might limit the use of installation media to organizationally owned devices, } \\
\text { but 1) and 2) might be expanded to indicate that such media have been distributed to be used on } \\
\text { other devices. } \\
\text { Note 2: The object of assessment for SWAM-L10 is the software product and its licensed usage, not } \\
\text { individual devices or endpoints. }\end{array}$
\end{tabular}




\section{Example Responses:}

\begin{tabular}{|l|l|l|}
\hline Defect Check ID & Potential Response Action & Primary Responsibility \\
\hline SWAM-L10 & Block the software & ISCM-Ops \\
\hline SWAM-L10 & Remove the software & SWMan \\
\hline SWAM-L10 & Obtain/Renew the license & SWMan \\
\hline SWAM-L10 & Adjust usage & DSM \\
\hline SWAM-L10 & Accept risk & RskEx \\
\hline SWAM-L10 & Oversee and coordinate response & RskEx \\
\hline
\end{tabular}

\section{Supporting Control Items:}

\begin{tabular}{|l|l|l|}
\hline Defect Check ID & Baseline & SP 800-53 Control Item Code \\
\hline SWAM-L10 & Low & CM-4 \\
\hline SWAM-L10 & Low & CM-10(a) \\
\hline SWAM-L10 & Low & CM-10(b) \\
\hline SWAM-L10 & Low & CM-10(c) \\
\hline SWAM-L10 & Low & CM-11(b) \\
\hline
\end{tabular}




\subsubsection{Required Software Is Present Sub-Capability and Defect Check SWAM-L11}

The purpose of this sub-capability is defined as follows:

\begin{tabular}{|c|c|}
\hline Sub-Capability Name & Sub-Capability Purpose \\
\hline Required software is present & Avoid denial of service from missing required software. \\
\hline
\end{tabular}

The defect check to assess whether this sub-capability is operating effectively is defined as follows:

\begin{tabular}{|l|l|l|l|}
\hline $\begin{array}{c}\text { Defect Check } \\
\text { ID }\end{array}$ & \multicolumn{1}{|c|}{ Defect Check Name } & \multicolumn{1}{c|}{ Assessment Criteria Notes } & \multicolumn{1}{c|}{ Selected } \\
\hline SWAM-L11 & $\begin{array}{l}\text { Required software not } \\
\text { present }\end{array}$ & $\begin{array}{l}\text { 1) The actual state includes the inventory of software present on the } \\
\text { device(s). } \\
\text { 2) The desired state includes the list of required software for the device(s). } \\
\text { 3) A defect occurs when a software item is required and not present. }\end{array}$ & $\begin{array}{l}\text { TBD by } \\
\text { organization }\end{array}$ \\
\hline
\end{tabular}

\section{Example Responses:}

\begin{tabular}{|l|l|l|}
\hline Defect Check ID & \multicolumn{1}{|c|}{ Potential Response Action } & Primary Responsibility \\
\hline SWAM-L11 & Install missing required software & SWMan \\
\hline SWAM-L11 & Remove requirement & DSM \\
\hline SWAM-L11 & Accept risk & RskEx \\
\hline SWAM-L11 & Oversee and coordinate response & RskEx \\
\hline
\end{tabular}

\section{Supporting Control Items:}

\begin{tabular}{|l|l|l|}
\hline Defect Check ID & Baseline & SP 800-53 Control Item Code \\
\hline SWAM-L11 & Low & CM-2 \\
\hline SWAM-L11 & Low & CM-8(a) \\
\hline SWAM-L11 & Low & CM-8(b) \\
\hline SWAM-L11 & Moderate & CM-2(1)(a) \\
\hline SWAM-L11 & Moderate & CM-2(1)(b) \\
\hline SWAM-L11 & Moderate & CM-2(1)(c) \\
\hline SWAM-L11 & Moderate & CM-8(1) \\
\hline
\end{tabular}




\subsubsection{Ensure that Software is Managed Sub-Capability and Defect Check SWAM-L12}

The purpose of this sub-capability is defined as follows:

\begin{tabular}{|l|l|}
\hline $\begin{array}{l}\text { Sub-Capability } \\
\text { Name }\end{array}$ & \multicolumn{1}{c|}{ Sub-Capability Purpose } \\
\hline $\begin{array}{l}\text { Ensure that } \\
\text { software is } \\
\text { managed }\end{array}$ & $\begin{array}{l}\text { Ensure clear responsibility for software change implementation to facilitate the presence of only the authorized software for } \\
\text { the device. }\end{array}$ \\
& $\begin{array}{l}\text { Note: Patching can be done with a security purpose and/or a functional purpose. When a patch is applied for security } \\
\text { purposes, it is explicitly covered under the Vulnerability Management capability, because of the extra risk created by security } \\
\text { vulnerabilities. Patching for changes to functionality is addressed by SWAM-L12. }\end{array}$ \\
\hline
\end{tabular}

The defect check to assess whether this sub-capability is operating effectively is defined as follows:

\begin{tabular}{|c|l|l|l|}
\hline $\begin{array}{c}\text { Defect } \\
\text { Check ID }\end{array}$ & $\begin{array}{l}\text { Defect Check } \\
\text { Name }\end{array}$ & \multicolumn{1}{|c|}{ Assessment Criteria Notes } \\
\hline SWAM-L12 & $\begin{array}{l}\text { Unmanaged } \\
\text { software }\end{array}$ & $\begin{array}{l}\text { 1) The actual state is the list of software product installation managers assigned to manage } \\
\text { each installed software product (and/or to remove unauthorized products) on each device. } \\
\text { 2) The desired state specification the list of approved software product installation managers } \\
\text { for: } \\
\text { a. each software product type or product; and } \\
\text { b. each device type or device. } \\
\text { 3) A defect is an authorized installed software product where } \\
\text { a. no software product installation manager is specified, or } \\
\text { b. the specified software product installation manager is not authorized for that software } \\
\text { product (or type) on that device (or type). }\end{array}$ & $\begin{array}{l}\text { TBD by } \\
\text { organization }\end{array}$ \\
& $\begin{array}{l}\text { Note: The SWAM-F01, SWAM-F02, and SWAM-F03 status must be known to assess HWAM- } \\
\text { F02, in order to avoid requiring an installer account for unauthorized software. }\end{array}$ \\
\hline
\end{tabular}




\section{Example Responses:}

\begin{tabular}{|l|l|l|}
\hline Defect Check ID & \multicolumn{1}{|c|}{ Potential Response Action } & Primary Responsibility \\
\hline SWAM-L12 & Block the software & ISCM-Ops \\
\hline SWAM-L12 & Remove the software when no SWMan assigned & DM \\
\hline SWAM-L12 & Assign an appropriate SWMan & Auth \\
\hline SWAM-L12 & Accept risk & RskEx \\
\hline SWAM-L12 & Oversee and coordinate response & DSM \\
\hline
\end{tabular}

\section{Supporting Control Items:}

\begin{tabular}{|l|l|l|}
\hline Defect Check ID & Baseline & SP 800-53 Control Item Code \\
\hline SWAM-L12 & Low & CM-11(b) \\
\hline SWAM-L12 & High & CM-8(4) \\
\hline
\end{tabular}




\subsubsection{Increase Software Maintainability and Integrity Sub-Capability and Defect Check SWAM-L13}

The purpose of this sub-capability is defined as follows:

\begin{tabular}{|l|l|}
\hline \multicolumn{1}{|c|}{ Sub-Capability Name } & \multicolumn{1}{c|}{ Sub-Capability Purpose } \\
\hline $\begin{array}{l}\text { Increase software maintainability and } \\
\text { integrity }\end{array}$ & $\begin{array}{l}\text { Ensures that only software with warranty and/or source code is authorized so that it can be } \\
\text { maintained. }\end{array}$ \\
\hline
\end{tabular}

The defect check to assess whether this sub-capability is operating effectively is defined as follows:

\begin{tabular}{|l|l|l|l|}
\hline $\begin{array}{l}\text { Defect } \\
\text { Check ID }\end{array}$ & Defect Check Name & \multicolumn{1}{|c|}{ Assessment Criteria Notes } \\
\hline $\begin{array}{l}\text { SWAM- } \\
\text { L13 }\end{array}$ & $\begin{array}{l}\text { Software without } \\
\text { warranty and/or } \\
\text { source code }\end{array}$ & $\begin{array}{l}\text { 1) The actual state includes, for each software product installed on at least one device in the } \\
\text { assessment boundary the availability of (based on having such items under configuration } \\
\text { management): } \\
\text { a. source code for the product. } \\
\text { b. a general warranty for the product. } \\
\text { c. a commitment to find and fix security defects for the product } \\
\text { and information about the software product necessary to determine which of the preceding } \\
\text { items is required for that product (e.g., whether software is commercial-off-the-shelf (COTS), } \\
\text { government-off-the-shelf (GOTS), or custom software). } \\
\text { 2) The desired state includes: } \\
\text { the criteria (needed to determine whether source code and/or specific warranty terms are } \\
\text { required for a software product. } \\
\text { 3) A defect occurs when a software-product's nature requires the organization to have } \\
\text { source code and or specific warranty terms, which the software product does not provide. }\end{array}$ \\
\hline
\end{tabular}




\section{Example Responses:}

\begin{tabular}{|l|l|l|}
\hline Defect Check ID & \multicolumn{1}{|c|}{ Potential Response Action } & Primary Responsibility \\
\hline SWAM-L13 & Automatically block execution of software & ISCM-Ops \\
\hline SWAM-L13 & Manually remove the software & SWMan \\
\hline SWAM-L13 & Obtain the missing warranty, documentation, etc. & RskEx \\
\hline SWAM-L13 & Accept risk & RskEx \\
\hline SWAM-L13 & Oversee and coordinate response & DSM \\
\hline
\end{tabular}

\section{Supporting Control Items:}

\begin{tabular}{|l|l|l|}
\hline Defect Check ID & Baseline & SP 800-53 Control Item Code \\
\hline SWAM-L13 & Low & CM-4 \\
\hline SWAM-L13 & Low & CM-11(b) \\
\hline SWAM-L13 & High & SI-7(14)(a) \\
\hline
\end{tabular}




\subsubsection{Prevent or Reduce Malware Sub-Capability and Defect Check SWAM-L14}

The purpose of this sub-capability is defined as follows:

\begin{tabular}{|l|l|}
\hline \multicolumn{1}{|c|}{$\begin{array}{c}\text { Sub-Capability } \\
\text { Name }\end{array}$} & \multicolumn{1}{c|}{ Sub-Capability Purpose } \\
\hline $\begin{array}{l}\text { Prevent or reduce } \\
\text { malware }\end{array}$ & $\begin{array}{l}\text { Ensures that black-listing methods such as anti-virus protection and spam filters are in place to block the most obvious } \\
\text { sources of malware, as judged needed by the organization. }\end{array}$ \\
\hline
\end{tabular}

The defect check to assess whether this sub-capability is operating effectively is defined as follows:

\begin{tabular}{|l|l|l|l|}
\hline $\begin{array}{l}\text { Defect Check } \\
\text { ID }\end{array}$ & \multicolumn{1}{|c|}{ Defect Check Name } & \multicolumn{1}{|c|}{ Assessment Criteria Notes } \\
\hline SWAM-L14 & $\begin{array}{l}\text { Poor anti-virus (AV) } \\
\text { protection }\end{array}$ & $\begin{array}{l}\text { 1) The actual state is the: } \\
\text { a. list of software blacklisting products or mechanisms operating. } \\
\text { b. the kinds of operations they are doing. } \\
\text { c. the date the blacklist was last updated. } \\
\text { 2) The desired state specification the list of approved software product } \\
\text { installation managers for: } \\
\text { a. list of software blacklisting products or mechanisms expected to be operating. } \\
\text { b. the kinds of operations they are expected to be doing. } \\
\text { c. the expected frequency with which they are to be updated. } \\
\text { 3) A defect is a blacklisting product or mechanism: } \\
\text { a. expected to be present, but which is not; or } \\
\text { b. not performing its expected operations; or } \\
\text { c. not last updated within the expected frequency. }\end{array}$ \\
\hline
\end{tabular}

\section{Example Responses:}

\begin{tabular}{|l|l|l|}
\hline Defect Check ID & \multicolumn{1}{|c|}{ Potential Response Action } & Primary Responsibility \\
\hline SWAM-L14 & Install Blacklisting solutions where missing & SWMan \\
\hline SWAM-L14 & Remove the requirement & DSM \\
\hline SWAM-L14 & Accept risk & RskEx \\
\hline SWAM-L14 & Oversee and coordinate response & RskEx \\
\hline
\end{tabular}




\section{Supporting Control Items:}

\begin{tabular}{|l|l|l|}
\hline Defect Check ID & Baseline & SP 800-53 Control Item Code \\
\hline SWAM-L14 & Low & CM-4 \\
\hline SWAM-L14 & Low & SI-3(a) \\
\hline SWAM-L14 & Low & SI-3(b) \\
\hline SWAM-L14 & Low & SI-3(c) \\
\hline
\end{tabular}




\subsubsection{Security Impact of Each Sub-Capability on an Attack Step Model}

Table 6 shows the primary ways the defect checks derived from the SP 800-53 security controls contribute to blocking attacks/events as described in Figure 1: SWAM Impact on an Attack Step Model.

Table 6: Mapping of Attack Steps to Security Sub-Capability

\begin{tabular}{|c|c|c|c|}
\hline Attack Step & Attack Step Description & $\begin{array}{c}\text { Sub-Capability ID } \\
\text { and Name }\end{array}$ & Sub-Capability Purpose \\
\hline $\begin{array}{l}\text { 1) Gain Internal } \\
\text { Entry }\end{array}$ & $\begin{array}{l}\text { The attacker is outside the target boundaries and } \\
\text { seeks entry. } \\
\text { Examples include: spear phishing email sent; } \\
\text { DDoS attack against .gov initiated. Unauthorized } \\
\text { person attempts to gain physical access to } \\
\text { restricted facility. }\end{array}$ & $\begin{array}{l}\text { SWAM-L04: Prevent } \\
\text { or reduce exploitation } \\
\text { of software on } \\
\text { devices moving into } \\
\text { or out of protective } \\
\text { boundaries }\end{array}$ & $\begin{array}{l}\text { Prevent exploitation of software on devices after } \\
\text { removal, during use elsewhere, and after return } \\
\text { (or other mobile use) by a) appropriately } \\
\text { hardening the device prior to removal; b) checking } \\
\text { for organizational software before removal; and c) } \\
\text { sanitizing the device before introduction or } \\
\text { reintroduction into the protective boundary. } \\
\text { Note: For more information on sanitization, see } \\
\text { NIST SP 800-88, Guidelines for Media } \\
\text { Sanitization. }\end{array}$ \\
\hline $\begin{array}{l}\text { 1) Gain Internal } \\
\text { Entry }\end{array}$ & $\begin{array}{l}\text { The attacker is outside the target boundaries and } \\
\text { seeks entry. } \\
\text { Examples include: spear phishing email sent; } \\
\text { DDoS attack against .gov initiated. Unauthorized } \\
\text { person attempts to gain physical access to } \\
\text { restricted facility. }\end{array}$ & $\begin{array}{l}\text { SWAM-L06: Prevent } \\
\text { or reduce software } \\
\text { defects }\end{array}$ & $\begin{array}{l}\text { Prevent or reduce the installation of software } \\
\text { which has not been tested and validated prior to } \\
\text { approval. }\end{array}$ \\
\hline $\begin{array}{l}\text { 1) Gain Internal } \\
\text { Entry }\end{array}$ & $\begin{array}{l}\text { The attacker is outside the target boundaries and } \\
\text { seeks entry. } \\
\text { Examples include: spear phishing email sent; } \\
\text { DDoS attack against .gov initiated. Unauthorized } \\
\text { person attempts to gain physical access to } \\
\text { restricted facility. }\end{array}$ & $\begin{array}{l}\text { SWAM-L12: Ensure } \\
\text { that software is } \\
\text { managed }\end{array}$ & $\begin{array}{l}\text { Ensure clear responsibility for software change } \\
\text { implementation to facilitate the presence of only } \\
\text { the authorized software for the device. }\end{array}$ \\
\hline
\end{tabular}




\begin{tabular}{|c|c|c|c|}
\hline Attack Step & Attack Step Description & $\begin{array}{l}\text { Sub-Capability ID } \\
\text { and Name }\end{array}$ & Sub-Capability Purpose \\
\hline 3) Gain Foothold & $\begin{array}{l}\text { The attacker has gained entry to the assessment } \\
\text { object and achieves enough compromise to gain } \\
\text { a foothold, but without persistence. } \\
\text { Examples include: Unauthorized user successfully } \\
\text { logs in with authorized credentials; browser } \\
\text { exploit code successfully executed in memory and } \\
\text { initiates call back; person gains unauthorized } \\
\text { access to server room. }\end{array}$ & $\begin{array}{l}\text { SWAM-F01: Prevent } \\
\text { unauthorized } \\
\text { software from } \\
\text { executing }\end{array}$ & $\begin{array}{l}\text { Prevent or reduce the execution of unauthorized } \\
\text { software (presumed malware). }\end{array}$ \\
\hline 3) Gain Foothold & $\begin{array}{l}\text { The attacker has gained entry to the assessment } \\
\text { object and achieves enough compromise to gain } \\
\text { a foothold, but without persistence. } \\
\text { Examples include: Unauthorized user successfully } \\
\text { logs in with authorized credentials; browser } \\
\text { exploit code successfully executed in memory and } \\
\text { initiates call back; person gains unauthorized } \\
\text { access to server room. }\end{array}$ & $\begin{array}{l}\text { SWAM-F02: Prevent } \\
\text { or reduce execution } \\
\text { of software from } \\
\text { unauthorized } \\
\text { installers }\end{array}$ & $\begin{array}{l}\text { Prevent or reduce the execution of software } \\
\text { (presumed malware) installed by an unauthorized } \\
\text { installer. }\end{array}$ \\
\hline 3) Gain Foothold & $\begin{array}{l}\text { The attacker has gained entry to the assessment } \\
\text { object and achieves enough compromise to gain } \\
\text { a foothold, but without persistence. } \\
\text { Examples include: Unauthorized user successfully } \\
\text { logs in with authorized credentials; browser } \\
\text { exploit code successfully executed in memory and } \\
\text { initiates call back; person gains unauthorized } \\
\text { access to server room. }\end{array}$ & $\begin{array}{l}\text { SWAM-L01: Ensure } \\
\text { or increase integrity } \\
\text { of software } \\
\text { authorizers }\end{array}$ & $\begin{array}{l}\text { Prevent or reduce the insertion of malware into } \\
\text { the list of approved software by unauthorized } \\
\text { persons. }\end{array}$ \\
\hline 3) Gain Foothold & $\begin{array}{l}\text { The attacker has gained entry to the assessment } \\
\text { object and achieves enough compromise to gain } \\
\text { a foothold, but without persistence. } \\
\text { Examples include: Unauthorized user successfully } \\
\text { logs in with authorized credentials; browser } \\
\text { exploit code successfully executed in memory and } \\
\text { initiates call back; person gains unauthorized } \\
\text { access to server room. }\end{array}$ & $\begin{array}{l}\text { SWAM-L02: Prevent } \\
\text { or reduce (careless } \\
\text { or malicious) } \\
\text { software approval }\end{array}$ & $\begin{array}{l}\text { Ensure checks and balances are in place to } \\
\text { prevent a single individual from carelessly or } \\
\text { maliciously changing authorization of software } \\
\text { installation. } \\
\text { Note 1: If the organization chooses to use access } \\
\text { restrictions to enforce multiple approvals, } \\
\text { effectiveness is assessed under the PRIV } \\
\text { capability. } \\
\text { Note 2: See SWAM-L09 for authorization } \\
\text { boundary. }\end{array}$ \\
\hline
\end{tabular}




\begin{tabular}{|c|c|c|c|}
\hline Attack Step & Attack Step Description & $\begin{array}{c}\text { Sub-Capability ID } \\
\text { and Name }\end{array}$ & Sub-Capability Purpose \\
\hline 3) Gain Foothold & $\begin{array}{l}\text { The attacker has gained entry to the assessment } \\
\text { object and achieves enough compromise to gain } \\
\text { a foothold, but without persistence. } \\
\text { Examples include: Unauthorized user successfully } \\
\text { logs in with authorized credentials; browser } \\
\text { exploit code successfully executed in memory and } \\
\text { initiates call back; person gains unauthorized } \\
\text { access to server room. }\end{array}$ & $\begin{array}{l}\text { SWAM-L06: Prevent } \\
\text { or reduce software } \\
\text { defects }\end{array}$ & $\begin{array}{l}\text { Prevent or reduce the installation of software } \\
\text { which has not been tested and validated prior to } \\
\text { approval. }\end{array}$ \\
\hline 3) Gain Foothold & $\begin{array}{l}\text { The attacker has gained entry to the assessment } \\
\text { object and achieves enough compromise to gain } \\
\text { a foothold, but without persistence. } \\
\text { Examples include: Unauthorized user successfully } \\
\text { logs in with authorized credentials; browser } \\
\text { exploit code successfully executed in memory and } \\
\text { initiates call back; person gains unauthorized } \\
\text { access to server room. }\end{array}$ & $\begin{array}{l}\text { SWAM-L07: Verify } \\
\text { ongoing business } \\
\text { need for software }\end{array}$ & $\begin{array}{l}\text { Require periodic and/or event driven } \\
\text { consideration of whether a software item is still } \\
\text { needed for system functionality to fulfill mission } \\
\text { requirements in support of least functionality). } \\
\text { Note: Recommended practice is to require DMs to } \\
\text { review devices for unauthorized, unneeded or } \\
\text { unmanaged software, and System Owners to } \\
\text { review what software is needed in the } \\
\text { authorization boundaries, compared to what is } \\
\text { present. }\end{array}$ \\
\hline 3) Gain Foothold & $\begin{array}{l}\text { The attacker has gained entry to the assessment } \\
\text { object and achieves enough compromise to gain } \\
\text { a foothold, but without persistence. } \\
\text { Examples include: Unauthorized user successfully } \\
\text { logs in with authorized credentials; browser } \\
\text { exploit code successfully executed in memory and } \\
\text { initiates call back; person gains unauthorized } \\
\text { access to server room. }\end{array}$ & $\begin{array}{l}\text { SWAM-L08: Prevent } \\
\text { or reduce unused } \\
\text { (and thus unneeded) } \\
\text { software products }\end{array}$ & $\begin{array}{l}\text { Prevent or reduce the presence of unused (and } \\
\text { thus unneeded) software products as determined } \\
\text { by actual usage on a given device. }\end{array}$ \\
\hline 3) Gain Foothold & $\begin{array}{l}\text { The attacker has gained entry to the assessment } \\
\text { object and achieves enough compromise to gain } \\
\text { a foothold, but without persistence. } \\
\text { Examples include: Unauthorized user successfully } \\
\text { logs in with authorized credentials; browser } \\
\text { exploit code successfully executed in memory and } \\
\text { initiates call back; person gains unauthorized } \\
\text { access to server room. }\end{array}$ & $\begin{array}{l}\text { SWAM-L13: Increase } \\
\text { software } \\
\text { maintainability and } \\
\text { integrity }\end{array}$ & $\begin{array}{l}\text { Ensures that only software with warranty and/or } \\
\text { source code is authorized so that it can be } \\
\text { maintained. }\end{array}$ \\
\hline
\end{tabular}




\begin{tabular}{|c|c|c|c|}
\hline Attack Step & Attack Step Description & $\begin{array}{c}\text { Sub-Capability ID } \\
\text { and Name }\end{array}$ & Sub-Capability Purpose \\
\hline 4) Gain Persistence & $\begin{array}{l}\text { The attack has gained a foothold on the object } \\
\text { and now achieves persistence. } \\
\text { Examples include: Malware installed on host that } \\
\text { survives reboot or log off; BIOS or kernel } \\
\text { modified; new/privileged account created for } \\
\text { unauthorized user; unauthorized person issued } \\
\text { credentials/allowed access; unauthorized } \\
\text { personnel added to access control list (ACL) for } \\
\text { server room. }\end{array}$ & $\begin{array}{l}\text { SWAM-F02: Prevent } \\
\text { or reduce execution } \\
\text { of software from } \\
\text { unauthorized } \\
\text { installers }\end{array}$ & $\begin{array}{l}\text { Prevent or reduce the execution of software } \\
\text { (presumed malware) installed by an unauthorized } \\
\text { installer. }\end{array}$ \\
\hline 4) Gain Persistence & $\begin{array}{l}\text { The attack has gained a foothold on the object } \\
\text { and now achieves persistence. } \\
\text { Examples include: Malware installed on host that } \\
\text { survives reboot or log off; BIOS or kernel } \\
\text { modified; new/privileged account created for } \\
\text { unauthorized user; unauthorized person issued } \\
\text { credentials/allowed access; unauthorized } \\
\text { personnel added to access control list (ACL) for } \\
\text { server room. }\end{array}$ & $\begin{array}{l}\text { SWAM-F03: Prevent } \\
\text { or reduce software } \\
\text { execution from } \\
\text { unauthorized location }\end{array}$ & $\begin{array}{l}\text { Prevent or reduce the execution of software } \\
\text { (presumed malware) loaded from an uncontrolled } \\
\text { or unauthorized location. }\end{array}$ \\
\hline 4) Gain Persistence & $\begin{array}{l}\text { The attack has gained a foothold on the object } \\
\text { and now achieves persistence. } \\
\text { Examples include: Malware installed on host that } \\
\text { survives reboot or log off; BIOS or kernel } \\
\text { modified; new/privileged account created for } \\
\text { unauthorized user; unauthorized person issued } \\
\text { credentials/allowed access; unauthorized } \\
\text { personnel added to access control list (ACL) for } \\
\text { server room. }\end{array}$ & $\begin{array}{l}\text { SWAM-F04: Ensure } \\
\text { or increase trust of } \\
\text { system software at } \\
\text { startup }\end{array}$ & $\begin{array}{l}\text { Prevent or reduce the insertion of malware into } \\
\text { key system components before or during system } \\
\text { startup. }\end{array}$ \\
\hline 4) Gain Persistence & $\begin{array}{l}\text { The attack has gained a foothold on the object } \\
\text { and now achieves persistence. } \\
\text { Examples include: Malware installed on host that } \\
\text { survives reboot or log off; BIOS or kernel } \\
\text { modified; new/privileged account created for } \\
\text { unauthorized user; unauthorized person issued } \\
\text { credentials/allowed access; unauthorized } \\
\text { personnel added to access control list (ACL) for } \\
\text { server room. }\end{array}$ & $\begin{array}{l}\text { SWAM-L01: Ensure } \\
\text { or increase integrity } \\
\text { of software } \\
\text { authorizers }\end{array}$ & $\begin{array}{l}\text { Prevent or reduce the insertion of malware into } \\
\text { the list of approved software by unauthorized } \\
\text { persons. }\end{array}$ \\
\hline
\end{tabular}




\begin{tabular}{|c|c|c|c|}
\hline Attack Step & Attack Step Description & $\begin{array}{c}\text { Sub-Capability ID } \\
\text { and Name }\end{array}$ & Sub-Capability Purpose \\
\hline 4) Gain Persistence & $\begin{array}{l}\text { The attack has gained a foothold on the object } \\
\text { and now achieves persistence. } \\
\text { Examples include: Malware installed on host that } \\
\text { survives reboot or log off; BIOS or kernel } \\
\text { modified; new/privileged account created for } \\
\text { unauthorized user; unauthorized person issued } \\
\text { credentials/allowed access; unauthorized } \\
\text { personnel added to access control list (ACL) for } \\
\text { server room. }\end{array}$ & $\begin{array}{l}\text { SWAM-L02: Prevent } \\
\text { or reduce (careless } \\
\text { or malicious) } \\
\text { software approval }\end{array}$ & $\begin{array}{l}\text { Ensure checks and balances are in place to } \\
\text { prevent a single individual from carelessly or } \\
\text { maliciously changing authorization of software } \\
\text { installation. } \\
\text { Note 1: If the organization chooses to use access } \\
\text { restrictions to enforce multiple approvals, } \\
\text { effectiveness is assessed under the PRIV } \\
\text { capability. } \\
\text { Note 2: See SWAM-L09 for authorization } \\
\text { boundary. }\end{array}$ \\
\hline 4) Gain Persistence & $\begin{array}{l}\text { The attack has gained a foothold on the object } \\
\text { and now achieves persistence. } \\
\text { Examples include: Malware installed on host that } \\
\text { survives reboot or log off; BIOS or kernel } \\
\text { modified; new/privileged account created for } \\
\text { unauthorized user; unauthorized person issued } \\
\text { credentials/allowed access; unauthorized } \\
\text { personnel added to access control list (ACL) for } \\
\text { server room. }\end{array}$ & $\begin{array}{l}\text { SWAM-L03: } \\
\text { Promptly determine } \\
\text { and address needed } \\
\text { installation and } \\
\text { deinstallation of } \\
\text { software }\end{array}$ & $\begin{array}{l}\text { Ensure that needed changes are addressed in a } \\
\text { timely manner by flagging requested changes not } \\
\text { considered (approved and implemented; or } \\
\text { disapproved) in a timely manner as risks. }\end{array}$ \\
\hline 4) Gain Persistence & $\begin{array}{l}\text { The attack has gained a foothold on the object } \\
\text { and now achieves persistence. } \\
\text { Examples include: Malware installed on host that } \\
\text { survives reboot or log off; BIOS or kernel } \\
\text { modified; new/privileged account created for } \\
\text { unauthorized user; unauthorized person issued } \\
\text { credentials/allowed access; unauthorized } \\
\text { personnel added to access control list (ACL) for } \\
\text { server room. }\end{array}$ & $\begin{array}{l}\text { SWAM-L07: Verify } \\
\text { ongoing business } \\
\text { need for software }\end{array}$ & $\begin{array}{l}\text { Require periodic and/or event driven } \\
\text { consideration of whether a software item is still } \\
\text { needed for system functionality to fulfill mission } \\
\text { requirements in support of least functionality). } \\
\text { Note: Recommended practice is to require DMs to } \\
\text { review devices for unauthorized, unneeded or } \\
\text { unmanaged software, and System Owners to } \\
\text { review what software is needed in the } \\
\text { authorization boundaries, compared to what is } \\
\text { present. }\end{array}$ \\
\hline
\end{tabular}




\begin{tabular}{|c|c|c|c|}
\hline Attack Step & Attack Step Description & $\begin{array}{l}\text { Sub-Capability ID } \\
\text { and Name }\end{array}$ & Sub-Capability Purpose \\
\hline 4) Gain Persistence & $\begin{array}{l}\text { The attack has gained a foothold on the object } \\
\text { and now achieves persistence. } \\
\text { Examples include: Malware installed on host that } \\
\text { survives reboot or log off; BIOS or kernel } \\
\text { modified; new/privileged account created for } \\
\text { unauthorized user; unauthorized person issued } \\
\text { credentials/allowed access; unauthorized } \\
\text { personnel added to access control list (ACL) for } \\
\text { server room. }\end{array}$ & $\begin{array}{l}\text { SWAM-L08: Prevent } \\
\text { or reduce unused } \\
\text { (and thus unneeded) } \\
\text { software products }\end{array}$ & $\begin{array}{l}\text { Prevent or reduce the presence of unused (and } \\
\text { thus unneeded) software products as determined } \\
\text { by actual usage on a given device. }\end{array}$ \\
\hline 4) Gain Persistence & $\begin{array}{l}\text { The attack has gained a foothold on the object } \\
\text { and now achieves persistence. } \\
\text { Examples include: Malware installed on host that } \\
\text { survives reboot or log off; BIOS or kernel } \\
\text { modified; new/privileged account created for } \\
\text { unauthorized user; unauthorized person issued } \\
\text { credentials/allowed access; unauthorized } \\
\text { personnel added to access control list (ACL) for } \\
\text { server room. }\end{array}$ & $\begin{array}{l}\text { SWAM-L09: Ensure } \\
\text { device-software-item } \\
\text { level accountability }\end{array}$ & $\begin{array}{l}\text { Ensure each unique combination of a device and } \\
\text { software item (device-software-item) has } \\
\text { accountability. Reduce duplication of effort by } \\
\text { verifying that each unique combination of device } \\
\text { and software-item is in one and only one } \\
\text { authorization boundary. } \\
\text { Note: For this defect check, the relevant software } \\
\text { item is more likely a software product than a } \\
\text { software file. }\end{array}$ \\
\hline 4) Gain Persistence & $\begin{array}{l}\text { The attack has gained a foothold on the object } \\
\text { and now achieves persistence. } \\
\text { Examples include: Malware installed on host that } \\
\text { survives reboot or log off; BIOS or kernel } \\
\text { modified; new/privileged account created for } \\
\text { unauthorized user; unauthorized person issued } \\
\text { credentials/allowed access; unauthorized } \\
\text { personnel added to access control list (ACL) for } \\
\text { server room. }\end{array}$ & $\begin{array}{l}\text { SWAM-L10: Ensure } \\
\text { that software } \\
\text { complies with license } \\
\text { agreements }\end{array}$ & $\begin{array}{l}\text { Ensure that actual usage of software products } \\
\text { complies with license agreements. }\end{array}$ \\
\hline
\end{tabular}




\begin{tabular}{|c|c|c|c|}
\hline Attack Step & Attack Step Description & $\begin{array}{l}\text { Sub-Capability ID } \\
\text { and Name }\end{array}$ & Sub-Capability Purpose \\
\hline 4) Gain Persistence & $\begin{array}{l}\text { The attack has gained a foothold on the object } \\
\text { and now achieves persistence. } \\
\text { Examples include: Malware installed on host that } \\
\text { survives reboot or log off; BIOS or kernel } \\
\text { modified; new/privileged account created for } \\
\text { unauthorized user; unauthorized person issued } \\
\text { credentials/allowed access; unauthorized } \\
\text { personnel added to access control list (ACL) for } \\
\text { server room. }\end{array}$ & $\begin{array}{l}\text { SWAM-L12: Ensure } \\
\text { that software is } \\
\text { managed }\end{array}$ & $\begin{array}{l}\text { Ensure clear responsibility for software change } \\
\text { implementation to facilitate the presence of only } \\
\text { the authorized software for the device. }\end{array}$ \\
\hline 4) Gain Persistence & $\begin{array}{l}\text { The attack has gained a foothold on the object } \\
\text { and now achieves persistence. } \\
\text { Examples include: Malware installed on host that } \\
\text { survives reboot or log off; BIOS or kernel } \\
\text { modified; new/privileged account created for } \\
\text { unauthorized user; unauthorized person issued } \\
\text { credentials/allowed access; unauthorized } \\
\text { personnel added to access control list (ACL) for } \\
\text { server room. }\end{array}$ & $\begin{array}{l}\text { SWAM-L13: Increase } \\
\text { software } \\
\text { maintainability and } \\
\text { integrity }\end{array}$ & $\begin{array}{l}\text { Ensures that only software with warranty and/or } \\
\text { source code is authorized so that it can be } \\
\text { maintained. }\end{array}$ \\
\hline 4) Gain Persistence & $\begin{array}{l}\text { The attack has gained a foothold on the object } \\
\text { and now achieves persistence. } \\
\text { Examples include: Malware installed on host that } \\
\text { survives reboot or log off; BIOS or kernel } \\
\text { modified; new/privileged account created for } \\
\text { unauthorized user; unauthorized person issued } \\
\text { credentials/allowed access; unauthorized } \\
\text { personnel added to access control list (ACL) for } \\
\text { server room. }\end{array}$ & $\begin{array}{l}\text { SWAM-L14: Prevent } \\
\text { or reduce malware }\end{array}$ & $\begin{array}{l}\text { Ensures that black-listing methods such as anti- } \\
\text { virus protection and spam filters are in place to } \\
\text { block the most obvious sources of malware, as } \\
\text { judged needed by the organization. }\end{array}$ \\
\hline $\begin{array}{l}\text { 6) Achieve Attack } \\
\text { Objective }\end{array}$ & $\begin{array}{l}\text { The attacker achieves an objective. Loss of } \\
\text { confidentiality, integrity, or availability of data or } \\
\text { system capability. } \\
\text { Examples include: Exfiltration of files; modification } \\
\text { of database entries; deletion of file or application; } \\
\text { denial of service; disclosure of PII. }\end{array}$ & $\begin{array}{l}\text { SWAM-L05: Enable } \\
\text { rollback and recovery }\end{array}$ & $\begin{array}{l}\text { Require the maintenance of enough prior versions } \\
\text { of software to ensure the ability to rollback and } \\
\text { recover in the event that issues are found with the } \\
\text { newer software. }\end{array}$ \\
\hline
\end{tabular}




\begin{tabular}{|c|c|c|c|}
\hline Attack Step & Attack Step Description & $\begin{array}{l}\text { Sub-Capability ID } \\
\text { and Name }\end{array}$ & Sub-Capability Purpose \\
\hline $\begin{array}{l}\text { 6) Achieve Attack } \\
\text { Objective }\end{array}$ & $\begin{array}{l}\text { The attacker achieves an objective. Loss of } \\
\text { confidentiality, integrity, or availability of data or } \\
\text { system capability. } \\
\text { Examples include: Exfiltration of files; modification } \\
\text { of database entries; deletion of file or application; } \\
\text { denial of service; disclosure of PII. }\end{array}$ & $\begin{array}{l}\text { SWAM-L10: Ensure } \\
\text { that software } \\
\text { complies with license } \\
\text { agreements }\end{array}$ & $\begin{array}{l}\text { Ensure that actual usage of software products } \\
\text { complies with license agreements. }\end{array}$ \\
\hline $\begin{array}{l}\text { 6) Achieve Attack } \\
\text { Objective }\end{array}$ & $\begin{array}{l}\text { The attacker achieves an objective. Loss of } \\
\text { confidentiality, integrity, or availability of data or } \\
\text { system capability. } \\
\text { Examples include: Exfiltration of files; modification } \\
\text { of database entries; deletion of file or application; } \\
\text { denial of service; disclosure of PII. }\end{array}$ & $\begin{array}{l}\text { SWAM-L11: } \\
\text { Required software is } \\
\text { present }\end{array}$ & $\begin{array}{l}\text { Avoid self-denial of service from missing required } \\
\text { software. }\end{array}$ \\
\hline
\end{tabular}




\subsection{SWAM Control (Item) Security Assessment Plan Narrative Tables and Templates}

The security assessment plan narratives in this section are designed to provide the core of an assessment plan for the automated assessment, as described in Section 6 of Volume 1 of this NISTIR. The narratives are supplemented by the other material in this section, including defect check tables (defining the tests to be used) and are summarized in the Control Allocation Tables in Section 3.4.

The roles referenced in the narratives match the roles defined by NIST in relevant special publications (SP 800-37, etc.) and/or the SWAM-specific roles defined in Section 2.7. The roles can be adapted and/or customized to the organization as described in the introduction to Section 3.

The determination statements listed here have been derived from the relevant control item language, specifically modified by the following adjustments:

(1) The phrase \{software has been added where necessary for control items that apply to more areas than just SWAM. This language tailors the control item to remain within SWAM. In this case, the same control item is likely to appear in other capabilities with the relevant scoping for that capability. For example, most Configuration Management (CM) family controls apply not only to hardware CM, but also to software CM. Only the software CM aspect is relevant to the SWAM capability, so that is what is covered in this volume.

(2) The phrases \{actual state or \{desired state specification $\}$ have been added to determination statements where both actual and desired state are needed for automated testing but where this was implicit in the original statement of the control. For example, CM-8a has two determination statements that are identical except that determination statement CM-8a(1) applies to the actual state, and determination statement $\mathrm{CM}-8 \mathrm{a}(2)$ applies to the desired state specification.

(3) Where a control item includes inherently different actions that are best assessed by different defect checks (typically, because the assessment criteria are different), the control item may be divided into multiple SWAM-applicable determination statements.

(4) Part of a control item may not apply to SWAM, while another part does. To address this issue, the determination statements in this volume include only the portion of the control item applicable to the SWAM capability. The portion of the control item that does not apply is documented by a note under the control item and included with other capabilities, as appropriate. 


\subsubsection{Outline Followed for Each Control Item}

The literal text of the control item follows the heading Control Item Text.

There may be one or more determination statements for each control item. Each determination statement is documented in a table, noting the:

- determination statement ID (Control Item ID concatenated with the Determination Statement Number, where Determination Number is enclosed in curly brackets);

- determination statement text;

- implemented by (responsibility);

- assessment boundary;

- assessment responsibility;

- assessment method;

- selected column (TBD by the organization);

- rationale for risk acceptance (thresholds) (TBD by the organization);

- frequency of assessment; ${ }^{27}$ and

- impact of not implementing the defect check (TBD by the organization).

The determination statement details are followed by a table showing the defect checks (and related sub-capability) that might be caused to fail if the control being tested fails.

The resulting text provides a template for the organization to edit, as described in Section 3.1.

\subsubsection{Outline Organized by Baselines}

This section includes security control items selected in the SP 800-53 Low, Moderate, and High baselines and that support the SWAM capability. For convenience, the control items are presented in three sections as follows:

(1) Low Baseline Control Items (Section 3.3.3). Security control items in the low baseline, which are required for all systems.

(2) Moderate Baseline Control Items (Section 3.3.4). Security control items in the moderate baseline, which are also required for the high baseline.

(3) High Baseline Control Items (Section 3.3.5). Security control items that are required only for the high baseline.

Table 7 illustrates the applicability of the security control items to each baseline.

\footnotetext{
27 While automated tools may be able to assess as frequently as every 3 to 4 days, organizations determine the appropriate assessment frequency in accordance with the ISCM strategy.
} 
Table 7: Applicability of Control Items

\begin{tabular}{|l|l|l|l|}
\hline $\begin{array}{l}\text { FIPS-199a } \\
\text { (SP 800-60) } \\
\text { Impact Level }\end{array}$ & $\begin{array}{l}\text { (1) Low Control Items } \\
\text { (Section 3.3.3) }\end{array}$ & $\begin{array}{l}\text { (2) Moderate Control } \\
\text { Items (Section 3.3.4) }\end{array}$ & $\begin{array}{l}\text { (3) High Control Items } \\
\text { (Section 3.3.5) }\end{array}$ \\
\hline Low & Applicable & & \\
\hline Moderate & Applicable & Applicable & \\
\hline High & Applicable & Applicable & Applicable \\
\hline
\end{tabular}

a FIPS-199 defines Low, Moderate, and High overall potential impact designations.

${ }^{\mathrm{b}}$ See SP 800-60, Section 3.2. 


\subsubsection{Low Baseline Security Control Item Narratives}

\subsubsection{Control Item CM-2: BASELINE CONFIGURATION}

\section{Control Item Text}

Control: The organization develops, documents, and maintains under configuration control, a current baseline configuration of the information system.

\section{Determination Statement 1}

\begin{tabular}{|l|l|}
\hline \multicolumn{1}{|c|}{$\begin{array}{c}\text { Determination } \\
\text { Statement ID }\end{array}$} & \multicolumn{1}{c|}{ Determination Statement Text } \\
\hline $\mathrm{CM}-2\{1\}$ & $\begin{array}{l}\text { Determine if the organization: develops, documents, and maintains under configuration control, a current baseline } \\
\text { configuration of the information system. }\end{array}$ \\
\hline
\end{tabular}

Roles and Assessment Methods

\begin{tabular}{|c|c|c|c|c|c|c|c|c|}
\hline $\begin{array}{l}\text { Determination } \\
\text { Statement ID }\end{array}$ & $\begin{array}{c}\text { Implemented } \\
\text { By }\end{array}$ & $\begin{array}{l}\text { Assessment } \\
\text { Boundary }\end{array}$ & $\begin{array}{l}\text { Assessment } \\
\text { Responsibility }\end{array}$ & $\begin{array}{c}\text { Assessment } \\
\text { Methods }\end{array}$ & Selected & $\begin{array}{c}\text { Rationale for } \\
\text { Risk } \\
\text { Acceptance }\end{array}$ & $\begin{array}{c}\text { Frequency of } \\
\text { Assessment }\end{array}$ & $\begin{array}{l}\text { Impact of Not } \\
\text { Implementing }\end{array}$ \\
\hline $\mathrm{CM}-2\{1\}$ & DSM & ISCM-TN & ISCM-Sys & Test & & & & \\
\hline
\end{tabular}




\section{Defect Check Rationale Table}

A failure in effectiveness of this control item results in a defect in one or more of the following defect checks:

\begin{tabular}{|l|l|l|l|}
\hline $\begin{array}{c}\text { Determination } \\
\text { Statement ID }\end{array}$ & $\begin{array}{c}\text { Defect } \\
\text { Check ID }\end{array}$ & $\begin{array}{c}\text { Defect Check } \\
\text { Name }\end{array}$ & $\begin{array}{c}\text { Rationale } \\
\text { If an [organization-defined measure] for this defect check is above [the organization-defined } \\
\text { threshold], then defects in developing, documenting, and maintaining under configuration } \\
\text { control a current baseline configuration of the information system related to this control } \\
\text { item might be the cause of the defect, i.e.,... }\end{array}$ \\
\hline CM-2\{1\} & $\begin{array}{l}\text { SWAM- } \\
\text { L11 }\end{array}$ & $\begin{array}{l}\text { Required } \\
\text { software not } \\
\text { present }\end{array}$ & absence of required software. \\
\hline
\end{tabular}




\subsubsection{Control Item CM-4: SECURITY IMPACT ANALYSIS}

\section{Control Item Text}

Control: The organization analyzes changes to the information system to determine potential security impacts prior to change implementation.

\section{Determination Statement 1}

\begin{tabular}{|l|l|}
\hline $\begin{array}{c}\text { Determination } \\
\text { Statement ID }\end{array}$ & \multicolumn{1}{c|}{ Determination Statement Text } \\
\hline $\mathrm{CM}-4\{1\}$ & $\begin{array}{l}\text { Determine if the organization: analyzes changes to the information system } \text { software }\} \text { to determine potential security } \\
\text { impacts prior to change implementation. }\end{array}$ \\
\hline
\end{tabular}

Roles and Assessment Methods

\begin{tabular}{|c|c|c|c|c|c|c|c|c|}
\hline $\begin{array}{l}\text { Determination } \\
\text { Statement ID }\end{array}$ & $\begin{array}{c}\text { Implemented } \\
\text { By }\end{array}$ & $\begin{array}{l}\text { Assessment } \\
\text { Boundary }\end{array}$ & $\begin{array}{l}\text { Assessment } \\
\text { Responsibility }\end{array}$ & $\begin{array}{c}\text { Assessment } \\
\text { Methods }\end{array}$ & Selected & $\begin{array}{c}\text { Rationale for } \\
\text { Risk } \\
\text { Acceptance }\end{array}$ & $\begin{array}{l}\text { Frequency of } \\
\text { Assessment }\end{array}$ & $\begin{array}{l}\text { Impact of Not } \\
\text { Implementing }\end{array}$ \\
\hline $\mathrm{CM}-4\{1\}$ & DSM & ISCM-TN & ISCM-Sys & Test & & & & \\
\hline
\end{tabular}




\section{Defect Check Rationale Table}

A failure in effectiveness of this control item results in a defect in one or more of the following defect checks:

\begin{tabular}{|c|c|c|c|}
\hline $\begin{array}{l}\text { Determination } \\
\text { Statement ID }\end{array}$ & $\begin{array}{l}\text { Defect } \\
\text { Check ID }\end{array}$ & Defect Check Name & $\begin{array}{l}\text { Rationale } \\
\text { If an [organization-defined measure] for this defect check is above [the organization- } \\
\text { defined threshold], then defects in analyzing changes to the information system } \\
\text { \{software\} to determine potential security impacts prior to change implementation } \\
\text { related to this control item might be the cause of the defect, i.e., ... }\end{array}$ \\
\hline $\mathrm{CM}-4\{1\}$ & $\begin{array}{l}\text { SWAM- } \\
\text { L01 }\end{array}$ & $\begin{array}{l}\text { Unapproved } \\
\text { authorizer }\end{array}$ & lack of verification that software was authorized by approved accounts (persons). \\
\hline CM-4\{1\} & $\begin{array}{l}\text { SWAM- } \\
\text { L02 }\end{array}$ & $\begin{array}{l}\text { Required } \\
\text { authorizations } \\
\text { missing }\end{array}$ & careless or malicious authorization of software. \\
\hline $\mathrm{CM}-4\{1\}$ & $\begin{array}{l}\text { SWAM- } \\
\text { L06 }\end{array}$ & $\begin{array}{l}\text { Testing and } \\
\text { validation of software } \\
\text { inadequate }\end{array}$ & lack of adequate testing and validation. \\
\hline $\mathrm{CM}-4\{1\}$ & $\begin{array}{l}\text { SWAM- } \\
\text { L07 }\end{array}$ & $\begin{array}{l}\text { Business need of } \\
\text { software not recently } \\
\text { verified }\end{array}$ & $\begin{array}{l}\text { the presence of software without a recently verified need, resulting in an increase in the } \\
\text { attack surface without associated organizational value. }\end{array}$ \\
\hline CM-4\{1\} & $\begin{array}{l}\text { SWAM- } \\
\text { L08 }\end{array}$ & $\begin{array}{l}\text { Unused software } \\
\text { present }\end{array}$ & the presence of unneeded software, resulting in an increase in the attack surface. \\
\hline $\mathrm{CM}-4\{1\}$ & $\begin{array}{l}\text { SWAM- } \\
\text { L10 }\end{array}$ & Unlicensed software & $\begin{array}{l}\text { use of software not in compliance with quantity licenses, contract agreements, or } \\
\text { copyright laws. }\end{array}$ \\
\hline $\mathrm{CM}-4\{1\}$ & $\begin{array}{l}\text { SWAM- } \\
\text { L13 }\end{array}$ & $\begin{array}{l}\text { Software without } \\
\text { warranty and/or } \\
\text { source code }\end{array}$ & the presence of software without warranty and/or source code. \\
\hline $\mathrm{CM}-4\{1\}$ & $\begin{array}{l}\text { SWAM- } \\
\text { L14 }\end{array}$ & Poor AV protection & absence of methods to block malware. \\
\hline
\end{tabular}




\subsubsection{Control Item CM-7(a): LEAST FUNCTIONALITY}

\section{Control Item Text}

Control: The organization:

a. Configures the information system to provide only essential capabilities.

\section{Determination Statement 1}

\begin{tabular}{|l|l|}
\hline Determination Statement ID & Determination Statement Text \\
\hline CM-7 (a) $\{1\}$ & Determine if the organization: configures the system \{installed software\} to provide only essential capabilities. \\
\hline
\end{tabular}

Roles and Assessment Methods

\begin{tabular}{|c|c|c|c|c|c|c|c|c|}
\hline $\begin{array}{l}\text { Determination } \\
\text { Statement ID }\end{array}$ & $\begin{array}{c}\text { Implemented } \\
\text { By }\end{array}$ & $\begin{array}{c}\text { Assessment } \\
\text { Boundary }\end{array}$ & $\begin{array}{c}\text { Assessment } \\
\text { Responsibility }\end{array}$ & $\begin{array}{l}\text { Assessment } \\
\text { Methods }\end{array}$ & Selected & $\begin{array}{l}\text { Rationale for } \\
\text { Risk } \\
\text { Acceptance }\end{array}$ & $\begin{array}{l}\text { Frequency of } \\
\text { Assessment }\end{array}$ & $\begin{array}{l}\text { Impact of Not } \\
\text { Implementing }\end{array}$ \\
\hline CM-7(a) $\{1\}$ & DSM & ISCM-TN & ISCM-Sys & Test & & & & \\
\hline
\end{tabular}

\section{Defect Check Rationale Table}

A failure in effectiveness of this control item results in a defect in one or more of the following defect checks:

\begin{tabular}{|l|l|l|l|}
\hline $\begin{array}{c}\text { Determination } \\
\text { Statement ID }\end{array}$ & $\begin{array}{c}\text { Defect } \\
\text { Check ID }\end{array}$ & $\begin{array}{c}\text { Defect Check } \\
\text { Name }\end{array}$ & $\begin{array}{r}\text { Rationale } \\
\text { If an [organization-defined measure] for this defect check is above [the organization- } \\
\text { defined threshold], then defects in configuring the system } \begin{array}{c}\text { [installed software\} to } \\
\text { provide only essential capabilities related to this control item might be the cause of the } \\
\text { defect, i.e.,... }\end{array}\end{array}$ \\
\hline CM-7 (a)\{1\} & $\begin{array}{l}\text { SWAM- } \\
\text { L07 }\end{array}$ & $\begin{array}{l}\text { Business need of } \\
\text { software not } \\
\text { recently verified }\end{array}$ & $\begin{array}{l}\text { the presence of software without a recently verified need, resulting in an increase in the } \\
\text { attack surface without associated organizational value. }\end{array}$ \\
\hline CM-7(a)\{1\} & $\begin{array}{l}\text { Unused software } \\
\text { present }\end{array}$ & the presence of unneeded software, resulting in an increase in the attack surface. \\
\hline
\end{tabular}




\subsubsection{Control Item CM-7(b): LEAST FUNCTIONALITY}

\section{Control Item Text}

Control: The organization:

b. Prohibits or restricts the use of the following functions, ports, protocols, and/or services: [Assignment: organizationdefined prohibited or restricted functions, ports, protocols, and/or services].

\section{Determination Statement 1}

\begin{tabular}{|l|l|}
\hline $\begin{array}{c}\text { Determination } \\
\text { Statement ID }\end{array}$ & \multicolumn{1}{c|}{ Determination Statement Text } \\
\hline $\mathrm{CM}-7(\mathrm{~b})\{1\}$ & $\begin{array}{l}\text { Determine if the organization: prohibits or restricts the use of the following \{installed software }\} \text { functions and/or services: } \\
\text { [Assignment: organization-defined prohibited or restricted functions and/or services]. }\end{array}$ \\
\hline
\end{tabular}

\section{Roles and Assessment Methods}

\begin{tabular}{|c|c|c|c|c|c|c|c|c|}
\hline $\begin{array}{l}\text { Determination } \\
\text { Statement ID }\end{array}$ & $\begin{array}{c}\text { Implemented } \\
\text { By }\end{array}$ & $\begin{array}{l}\text { Assessment } \\
\text { Boundary }\end{array}$ & $\begin{array}{c}\text { Assessment } \\
\text { Responsibility }\end{array}$ & $\begin{array}{l}\text { Assessment } \\
\text { Methods }\end{array}$ & Selected & $\begin{array}{c}\text { Rationale for } \\
\text { Risk } \\
\text { Acceptance }\end{array}$ & $\begin{array}{l}\text { Frequency of } \\
\text { Assessment }\end{array}$ & $\begin{array}{l}\text { Impact of Not } \\
\text { Implementing }\end{array}$ \\
\hline CM-7(b) $\{1\}$ & DSM & ISCM-TN & ISCM-Sys & Test & & & & \\
\hline
\end{tabular}

\section{Defect Check Rationale Table}

A failure in effectiveness of this control item results in a defect in one or more of the following defect checks:

\begin{tabular}{|c|c|c|c|}
\hline $\begin{array}{l}\text { Determination } \\
\text { Statement ID }\end{array}$ & $\begin{array}{c}\text { Defect } \\
\text { Check ID }\end{array}$ & Defect Check Name & $\begin{array}{l}\text { Rationale } \\
\text { If an [organization-defined measure] for this defect check is above [the organization- } \\
\text { defined threshold], then defects in prohibiting or restricting the use of specified } \\
\text { \{installed software\} functions and/or services related to this control item might be } \\
\text { the cause of the defect, i.e., ... }\end{array}$ \\
\hline $\mathrm{CM}-7(\mathrm{~b})\{1\}$ & $\begin{array}{l}\text { SWAM- } \\
\text { F01 }\end{array}$ & $\begin{array}{l}\text { Unauthorized software } \\
\text { executes }\end{array}$ & the execution of unauthorized software. \\
\hline CM-7(b)\{1\} & $\begin{array}{l}\text { SWAM- } \\
\text { F03 }\end{array}$ & $\begin{array}{l}\text { Unauthorized software } \\
\text { directory/folder location }\end{array}$ & the execution of software not loaded from an approved directory/folder location. \\
\hline
\end{tabular}




\subsubsection{Control Item CM-8(a): INFORMATION SYSTEM COMPONENT INVENTORY}

\section{Control Item Text}

Control: The organization:

a. Develops and documents an inventory of information system components that:

1. Accurately reflects the current information system;

2. Includes all components within the authorization boundary of the information system;

3. Is at the level of granularity deemed necessary for tracking and reporting; and

4. Includes [Assignment: organization-defined information deemed necessary to achieve effective information system component accountability].

\section{Determination Statement 1}

\begin{tabular}{|l|l|}
\hline $\begin{array}{c}\text { Determination } \\
\text { Statement ID }\end{array}$ & \multicolumn{1}{c|}{ Determination Statement Text } \\
\hline $\mathrm{CM}-8(\mathrm{a})\{1\}$ & $\begin{array}{l}\text { Determine if the organization: develops and documents an inventory of system components ffor software }\} \text { that: (1) } \\
\text { accurately reflects the current system; and (2) includes all components within the authorization boundary of the system. }\end{array}$ \\
\hline
\end{tabular}

\section{Roles and Assessment Methods}

\begin{tabular}{|c|c|c|c|c|c|c|c|c|}
\hline $\begin{array}{l}\text { Determination } \\
\text { Statement ID }\end{array}$ & $\begin{array}{c}\text { Implemented } \\
\text { By }\end{array}$ & $\begin{array}{l}\text { Assessment } \\
\text { Boundary }\end{array}$ & $\begin{array}{l}\text { Assessment } \\
\text { Responsibility }\end{array}$ & $\begin{array}{c}\text { Assessment } \\
\text { Methods }\end{array}$ & Selected & $\begin{array}{c}\text { Rationale for } \\
\text { Risk } \\
\text { Acceptance }\end{array}$ & $\begin{array}{l}\text { Frequency of } \\
\text { Assessment }\end{array}$ & $\begin{array}{l}\text { Impact of Not } \\
\text { Implementing }\end{array}$ \\
\hline CM-8(a)\{1\} & DSM & ISCM-TN & ISCM-Sys & Test & & & & \\
\hline
\end{tabular}




\section{Defect Check Rationale Table}

A failure in effectiveness of this control item results in a defect in one or more of the following defect checks:

\begin{tabular}{|l|l|l|l|}
\hline $\begin{array}{c}\text { Determination } \\
\text { Statement ID }\end{array}$ & $\begin{array}{l}\text { Defect } \\
\text { Check ID }\end{array}$ & Defect Check Name & $\begin{array}{c}\text { Rationale } \\
\text { If an [organization-defined measure] for this defect check is above [the organization- } \\
\text { defined threshold], then defects in developing and documenting an inventory of } \\
\text { system components which is accurate, complete, detailed, and has specified } \\
\text { information related to this control item might be the cause of the defect, i.e., ... }\end{array}$ \\
\hline CM-8(a) $\{1\}$ & $\begin{array}{l}\text { SWAM- } \\
\text { L11 }\end{array}$ & $\begin{array}{l}\text { Required software not } \\
\text { present }\end{array}$ & $\begin{array}{l}\text { absence of required software. } \\
\text { CM-8(a) }\{1\}\end{array}$ \\
$\begin{array}{l}\text { SWAM- } \\
\text { Q01 }\end{array}$ & $\begin{array}{l}\text { Non-reporting of } \\
\text { device-level SWAM } \\
\text { information }\end{array}$ & a device failing to report within the specified time frame. \\
\hline CM-8(a) $\{1\}$ & $\begin{array}{l}\text { SWAM- } \\
\text { Q02 }\end{array}$ & $\begin{array}{l}\text { Non-reporting of } \\
\text { defect checks }\end{array}$ & specific defect checks failing to report. \\
\hline CM-8(a) $\{1\}$ & $\begin{array}{l}\text { SWAM- } \\
\text { Q03 }\end{array}$ & $\begin{array}{l}\text { Low completeness- } \\
\text { metric }\end{array}$ & completeness of overall ISCM reporting not meeting the threshold. \\
\hline
\end{tabular}

\section{Determination Statement 2}

\begin{tabular}{|l|l|}
\hline $\begin{array}{c}\text { Determination } \\
\text { Statement ID }\end{array}$ & \multicolumn{1}{c|}{ Determination Statement Text } \\
\hline CM-8(a)\{2\} & $\begin{array}{l}\text { Determine if the organization: develops and documents an inventory of system components \{for software }\} \text { that is at the } \\
\text { level of granularity deemed necessary for tracking and reporting [by the organization]. }\end{array}$ \\
\hline
\end{tabular}

\section{Roles and Assessment Methods}

\begin{tabular}{|l|l|l|l|l|l|l|l|l|}
\hline $\begin{array}{c}\text { Determination } \\
\text { Statement ID }\end{array}$ & $\begin{array}{c}\text { Implemented } \\
\text { By }\end{array}$ & $\begin{array}{c}\text { Assessment } \\
\text { Boundary }\end{array}$ & $\begin{array}{c}\text { Assessment } \\
\text { Responsibility }\end{array}$ & $\begin{array}{c}\text { Assessment } \\
\text { Methods }\end{array}$ & Selected & $\begin{array}{c}\text { Rationale for } \\
\text { Risk } \\
\text { Acceptance }\end{array}$ & $\begin{array}{c}\text { Frequency of } \\
\text { Assessment }\end{array}$ & $\begin{array}{c}\text { Impact of Not } \\
\text { Implementing }\end{array}$ \\
\hline CM- $8(a)\{2\}$ & ISCM-Sys & ISCM-TN & ISCM-Sys & Test & & & \\
\hline
\end{tabular}




\section{Defect Check Rationale Table}

A failure in effectiveness of this control item results in a defect in one or more of the following defect checks:

\begin{tabular}{|l|l|l|l|}
\hline $\begin{array}{c}\text { Determination } \\
\text { Statement ID }\end{array}$ & $\begin{array}{c}\text { Defect } \\
\text { Check ID }\end{array}$ & $\begin{array}{r}\text { Rationale } \\
\text { If an [organization-defined measure] for this defect check is above [the organization- } \\
\text { defined threshold], then defects in developing and documenting the inventory of } \\
\text { system components } \\
\text { organization for tracking and reporting related to this control item might be the cause of } \\
\text { the defect, i.e., ... }\end{array}$ \\
\hline CM-8(a) $\{2\}$ & $\begin{array}{l}\text { SWAM- } \\
\text { L11 }\end{array}$ & $\begin{array}{l}\text { Required software not } \\
\text { present }\end{array}$ & absence of required software. \\
\hline CM-8(a) $\{2\}$ & $\begin{array}{l}\text { SWAM- } \\
\text { Q01 }\end{array}$ & $\begin{array}{l}\text { Non-reporting of } \\
\text { device-level SWAM } \\
\text { information }\end{array}$ & a device failing to report within the specified time frame. \\
\hline CM-8(a) $\{2\}$ & $\begin{array}{l}\text { SWAM- } \\
\text { Q02 }\end{array}$ & $\begin{array}{l}\text { Non-reporting of } \\
\text { defect checks }\end{array}$ & specific defect checks failing to report. \\
\hline CM-8(a) $\{2\}$ & $\begin{array}{l}\text { SWAM- } \\
\text { Q03 }\end{array}$ & $\begin{array}{l}\text { Low completeness- } \\
\text { metric }\end{array}$ & completeness of overall ISCM reporting not meeting the threshold. \\
\hline
\end{tabular}




\subsubsection{Control Item CM-8(b): INFORMATION SYSTEM COMPONENT INVENTORY}

\section{Control Item Text}

Control: The organization:

b. Reviews and updates the information system component inventory [Assignment: organization-defined frequency].

\section{Determination Statement 1}

\begin{tabular}{|l|l|}
\hline \multicolumn{1}{|c|}{ IDetermination Statement } & \multicolumn{1}{c|}{ Determination Statement Text } \\
\hline $\mathrm{CM}-8(\mathrm{~b})\{1\}$ & $\begin{array}{l}\text { Determine if the organization: updates the system component inventory \{for software }[\text { [Assignment: organization- } \\
\text { defined frequency]. }\end{array}$ \\
\hline
\end{tabular}

\section{Roles and Assessment Methods}

\begin{tabular}{|c|c|c|c|c|c|c|c|c|}
\hline $\begin{array}{c}\text { Determination } \\
\text { Statement ID }\end{array}$ & $\begin{array}{c}\text { Implemented } \\
\text { By }\end{array}$ & $\begin{array}{c}\text { Assessment } \\
\text { Boundary }\end{array}$ & $\begin{array}{c}\text { Assessment } \\
\text { Responsibility }\end{array}$ & $\begin{array}{l}\text { Assessment } \\
\text { Methods }\end{array}$ & Selected & $\begin{array}{l}\text { Rationale for } \\
\text { Risk } \\
\text { Acceptance }\end{array}$ & $\begin{array}{l}\text { Frequency of } \\
\text { Assessment }\end{array}$ & $\begin{array}{l}\text { Impact of Not } \\
\text { Implementing }\end{array}$ \\
\hline CM-8(b) $\{1\}$ & ISCM-Sys & ISCM-TN & ISCM-Sys & Test & & & & \\
\hline
\end{tabular}

\section{Defect Check Rationale Table}

A failure in effectiveness of this control item results in a defect in one or more of the following defect checks:

\begin{tabular}{|l|l|l|l|}
\hline $\begin{array}{c}\text { Determination } \\
\text { Statement ID }\end{array}$ & $\begin{array}{c}\text { Defect } \\
\text { Check ID }\end{array}$ & $\begin{array}{l}\text { Defect Check } \\
\text { Name }\end{array}$ & $\begin{array}{c}\text { Rationale } \\
\text { If an [organization-defined measure] for this defect check is above [the organization-defined } \\
\text { threshold], then defects in updating the system \{installed software\} component inventory } \\
\text { with the organization-defined frequency related to this control item might be the cause of the } \\
\text { defect, i.e.,... }\end{array}$ \\
\hline CM-8(b)\{1\} & $\begin{array}{l}\text { SWAM- } \\
\text { L11 }\end{array}$ & $\begin{array}{l}\text { Required } \\
\text { software not } \\
\text { present }\end{array}$ & absence of required software. \\
\hline CM-8(b)\{1\} & $\begin{array}{l}\text { SWAM- } \\
\text { Q04 }\end{array}$ & $\begin{array}{l}\text { Poor timeliness } \\
\text { metric }\end{array}$ & poor timeliness of overall ISCM reporting. \\
\hline
\end{tabular}




\section{Determination Statement 2}

\begin{tabular}{|l|l|}
\hline $\begin{array}{l}\text { Determination Statement } \\
\text { ID }\end{array}$ & \multicolumn{1}{c|}{ Determination Statement Text } \\
\hline CM-8(b)\{2\} & $\begin{array}{l}\text { Determine if the organization: reviews the system component inventory \{for software\} [Assignment: organization- } \\
\text { defined frequency]. }\end{array}$ \\
\hline
\end{tabular}

\section{Roles and Assessment Methods}

\begin{tabular}{|l|l|l|l|l|l|l|l|l|}
\hline $\begin{array}{c}\text { Determination } \\
\text { Statement ID }\end{array}$ & $\begin{array}{c}\text { Implemented } \\
\text { By }\end{array}$ & $\begin{array}{c}\text { Assessment } \\
\text { Boundary }\end{array}$ & $\begin{array}{c}\text { Assessment } \\
\text { Responsibility }\end{array}$ & $\begin{array}{c}\text { Assessment } \\
\text { Methods }\end{array}$ & Selected & $\begin{array}{c}\text { Rationale for } \\
\text { Risk } \\
\text { Acceptance }\end{array}$ & $\begin{array}{c}\text { Frequency of } \\
\text { Assessment }\end{array}$ & $\begin{array}{c}\text { Impact of Not } \\
\text { Implementing }\end{array}$ \\
\hline $\mathrm{CM}-8(\mathrm{~b})\{2\}$ & $\mathrm{DSM}$ & ISCM-TN & ISCM-Sys & Test & & & & \\
\hline
\end{tabular}

\section{Defect Check Rationale Table}

A failure in effectiveness of this control item results in a defect in one or more of the following defect checks:

\begin{tabular}{|l|l|l|l|}
\hline $\begin{array}{c}\text { Determination } \\
\text { Statement ID }\end{array}$ & $\begin{array}{c}\text { Defect } \\
\text { Check ID }\end{array}$ & $\begin{array}{l}\text { Refect Check } \\
\text { Name }\end{array}$ & $\begin{array}{l}\text { Rationale } \\
\text { If an [organization-defined measure] for this defect check is above [the organization-defined } \\
\text { threshold], then defects in reviewing the system component } \begin{array}{c}\text { [software\} inventory with the } \\
\text { organization-defined frequency related to this control item might be the cause of the defect, } \\
\text { i.e., ... }\end{array}\end{array}$ \\
\hline CM-8(b)\{2\} & $\begin{array}{l}\text { SWAM- } \\
\text { L11 }\end{array}$ & $\begin{array}{l}\text { Required } \\
\text { software not } \\
\text { present }\end{array}$ & absence of required software. \\
\hline CM-8(b)\{2\} & $\begin{array}{l}\text { SWAM- } \\
\text { Q04 }\end{array}$ & $\begin{array}{l}\text { Poor timeliness } \\
\text { metric }\end{array}$ & poor timeliness of overall ISCM reporting. \\
\hline
\end{tabular}




\subsubsection{Control Item CM-10(a): SOFTWARE USAGE RESTRICTIONS}

\section{Control Item Text}

Control: The organization:

a. Uses software and associated documentation in accordance with contract agreements and copyright laws.

\section{Determination Statement 1}

\begin{tabular}{|l|l|}
\hline $\begin{array}{l}\text { Determination Statement } \\
\text { ID }\end{array}$ & \multicolumn{1}{c|}{ Determination Statement Text } \\
\hline $\mathrm{CM}-10(\mathrm{a})\{1\}$ & $\begin{array}{l}\text { Determine if the organization: uses software and associated documentation in accordance with contract agreements } \\
\text { and copyright laws. }\end{array}$ \\
\hline
\end{tabular}

\section{Roles and Assessment Methods}

\begin{tabular}{|c|c|c|c|c|c|c|c|c|}
\hline $\begin{array}{c}\text { Determination } \\
\text { Statement ID }\end{array}$ & $\begin{array}{c}\text { Implemented } \\
\text { By }\end{array}$ & $\begin{array}{c}\text { Assessment } \\
\text { Boundary }\end{array}$ & $\begin{array}{c}\text { Assessment } \\
\text { Responsibility }\end{array}$ & $\begin{array}{l}\text { Assessment } \\
\text { Methods }\end{array}$ & Selected & $\begin{array}{l}\text { Rationale for } \\
\text { Risk } \\
\text { Acceptance }\end{array}$ & $\begin{array}{l}\text { Frequency of } \\
\text { Assessment }\end{array}$ & $\begin{array}{l}\text { Impact of Not } \\
\text { Implementing }\end{array}$ \\
\hline CM-10(a) $\{1\}$ & DSM & ISCM-TN & ISCM-Sys & Test & & & & \\
\hline
\end{tabular}

\section{Defect Check Rationale Table}

A failure in effectiveness of this control item results in a defect in one or more of the following defect checks:

\begin{tabular}{|l|l|l|l|}
\hline $\begin{array}{c}\text { Determination } \\
\text { Statement ID }\end{array}$ & $\begin{array}{c}\text { Defect } \\
\text { Check ID }\end{array}$ & $\begin{array}{c}\text { Rationale } \\
\text { Defect } \\
\text { Check Name }\end{array}$ & $\begin{array}{c}\text { If an [organization-defined measure] for this defect check is above [the organization-defined } \\
\text { threshold], then defects in using software and associated documentation in accordance with } \\
\text { contract agreements and copyright laws related to this control item might be the cause of the } \\
\text { defect, i.e., ... }\end{array}$ \\
\hline $\mathrm{CM}-10(\mathrm{a})\{1\}$ & $\begin{array}{l}\text { SWAM- } \\
\text { L10 }\end{array}$ & $\begin{array}{l}\text { Unlicensed } \\
\text { software }\end{array}$ & use of software not in compliance with quantity licenses, contract agreements, or copyright laws. \\
\hline
\end{tabular}




\subsubsection{Control Item CM-10(b): SOFTWARE USAGE RESTRICTIONS}

\section{Control Item Text}

Control: The organization:

b. Tracks the use of software and associated documentation protected by quantity licenses to control copying and distribution.

\section{Determination Statement 1}

\begin{tabular}{|l|l|}
\hline \multicolumn{1}{|c|}{$\begin{array}{l}\text { Determination Statement } \\
\text { ID }\end{array}$} & \multicolumn{1}{c|}{ Determination Statement Text } \\
\hline $\mathrm{CM}-10(\mathrm{~b})\{1\}$ & $\begin{array}{l}\text { Determine if the organization: tracks the use of software protected by quantity licenses to control copying and } \\
\text { distribution. }\end{array}$ \\
\hline
\end{tabular}

\section{Roles and Assessment Methods}

\begin{tabular}{|c|c|c|c|c|c|c|c|c|}
\hline $\begin{array}{l}\text { Determination } \\
\text { Statement ID }\end{array}$ & $\begin{array}{c}\text { Implemented } \\
\text { By }\end{array}$ & $\begin{array}{l}\text { Assessment } \\
\text { Boundary }\end{array}$ & $\begin{array}{l}\text { Assessment } \\
\text { Responsibility }\end{array}$ & $\begin{array}{c}\text { Assessment } \\
\text { Methods }\end{array}$ & Selected & $\begin{array}{c}\text { Rationale for } \\
\text { Risk } \\
\text { Acceptance }\end{array}$ & $\begin{array}{l}\text { Frequency of } \\
\text { Assessment }\end{array}$ & $\begin{array}{l}\text { Impact of Not } \\
\text { Implementing }\end{array}$ \\
\hline CM-10(b)\{1\} & ISCM-Sys & ISCM-TN & ISCM-Sys & Test & & & & \\
\hline
\end{tabular}

\section{Defect Check Rationale Table}

A failure in effectiveness of this control item results in a defect in one or more of the following defect checks:

\begin{tabular}{|l|l|l|l|}
\hline $\begin{array}{c}\text { Determination } \\
\text { Statement ID }\end{array}$ & $\begin{array}{c}\text { Defect } \\
\text { Check ID }\end{array}$ & $\begin{array}{c}\text { Refect } \\
\text { Check Name }\end{array}$ & $\begin{array}{c}\text { Rationale } \\
\text { If an [organization-defined measure] for this defect check is above [the organization-defined } \\
\text { threshold], then defects in tracking the use of software protected by quantity licenses to } \\
\text { control copying and distribution related to this control item might be the cause of the defect, } \\
\text { i.e., ... }\end{array}$ \\
\hline $\mathrm{CM}-10(\mathrm{~b})\{1\}$ & $\begin{array}{l}\text { SWAM- } \\
\text { L10 }\end{array}$ & $\begin{array}{l}\text { Unlicensed } \\
\text { software }\end{array}$ & use of software not in compliance with quantity licenses, contract agreements, or copyright laws. \\
\hline
\end{tabular}




\section{Determination Statement 2}

\begin{tabular}{|l|l|}
\hline $\begin{array}{c}\text { Determination } \\
\text { Statement ID }\end{array}$ & \multicolumn{1}{c|}{ Determination Statement Text } \\
\hline $\mathrm{CM}-10(\mathrm{~b})\{2\}$ & $\begin{array}{l}\text { Determine if the organization: tracks the use of software associated documentation protected by quantity licenses to } \\
\text { control copying and distribution. }\end{array}$ \\
\hline
\end{tabular}

\section{Roles and Assessment Methods}

\begin{tabular}{|c|c|c|c|c|c|c|c|c|}
\hline $\begin{array}{l}\text { Determination } \\
\text { Statement ID }\end{array}$ & $\begin{array}{c}\text { Implemented } \\
\text { By }\end{array}$ & $\begin{array}{l}\text { Assessment } \\
\text { Boundary }\end{array}$ & $\begin{array}{l}\text { Assessment } \\
\text { Responsibility }\end{array}$ & $\begin{array}{l}\text { Assessment } \\
\text { Methods }\end{array}$ & Selected & $\begin{array}{l}\text { Rationale for } \\
\text { Risk } \\
\text { Acceptance }\end{array}$ & $\begin{array}{l}\text { Frequency of } \\
\text { Assessment }\end{array}$ & $\begin{array}{l}\text { Impact of Not } \\
\text { Implementing }\end{array}$ \\
\hline CM-10(b) $\{2\}$ & DSM & ISCM-TN & MAN & TBD & & & & \\
\hline
\end{tabular}

\section{Defect Check Rationale Table}

A failure in effectiveness of this control item results in a defect in one or more of the following defect checks:

Not applicable because tested manually. 


\subsubsection{Control Item CM-10(c): SOFTWARE USAGE RESTRICTIONS}

\section{Control Item Text}

Control: The organization:

c. Controls and documents the use of peer-to-peer file sharing technology to ensure that this capability is not used for the unauthorized distribution, display, performance, or reproduction of copyrighted work.

\section{Determination Statement 1}

\begin{tabular}{|l|l|}
\hline $\begin{array}{c}\text { Determination } \\
\text { Statement ID }\end{array}$ & \multicolumn{1}{c|}{ Determination Statement Text } \\
\hline $\mathrm{CM}-10(\mathrm{c})\{1\}$ & $\begin{array}{l}\text { Determine if the organization: controls and documents the use of peer-to-peer file sharing technology to ensure that this } \\
\text { capability is not used for the unauthorized distribution, display, performance, or reproduction of copyrighted work. }\end{array}$ \\
\hline
\end{tabular}

\section{Roles and Assessment Methods}

\begin{tabular}{|c|c|c|c|c|c|c|c|c|}
\hline $\begin{array}{l}\text { Determination } \\
\text { Statement ID }\end{array}$ & $\begin{array}{c}\text { Implemented } \\
\text { By }\end{array}$ & $\begin{array}{l}\text { Assessment } \\
\text { Boundary }\end{array}$ & $\begin{array}{l}\text { Assessment } \\
\text { Responsibility }\end{array}$ & $\begin{array}{c}\text { Assessment } \\
\text { Methods }\end{array}$ & Selected & $\begin{array}{c}\text { Rationale for } \\
\text { Risk } \\
\text { Acceptance }\end{array}$ & $\begin{array}{l}\text { Frequency of } \\
\text { Assessment }\end{array}$ & $\begin{array}{l}\text { Impact of Not } \\
\text { Implementing }\end{array}$ \\
\hline CM-10(c) $\{1\}$ & ISCM-Ops & ISCM-TN & ISCM-Sys & Test & & & & \\
\hline
\end{tabular}

\section{Defect Check Rationale Table}

A failure in effectiveness of this control item results in a defect in one or more of the following defect checks:

\begin{tabular}{|l|l|l|l|}
\hline $\begin{array}{c}\text { Determination } \\
\text { Statement ID }\end{array}$ & $\begin{array}{c}\text { Defect } \\
\text { Check ID }\end{array}$ & $\begin{array}{c}\text { Refect Check } \\
\text { Name }\end{array}$ & $\begin{array}{c}\text { Rationale } \\
\text { If an [organization-defined measure] for this defect check is above [the organization-defined } \\
\text { threshold], then defects in controlling and documenting the use of peer-to-peer file sharing } \\
\text { technology related to this control item might be the cause of the defect, i.e., ... }\end{array}$ \\
\hline CM-10(c) $\{1\}$ & $\begin{array}{l}\text { SWAM- } \\
\text { L10 }\end{array}$ & $\begin{array}{l}\text { Unlicensed } \\
\text { software }\end{array}$ & $\begin{array}{l}\text { use of software not in compliance with quantity licenses, contract agreements, or copyright } \\
\text { laws. }\end{array}$ \\
\hline
\end{tabular}




\subsubsection{Control Item CM-11(a): USER-INSTALLED SOFTWARE}

\section{Control Item Text}

Control: The organization:

a. Establishes [Assignment: organization-defined policies] governing the installation of software by users.

\section{Determination Statement 1}

\begin{tabular}{|l|l|}
\hline $\begin{array}{l}\text { Determination Statement } \\
\text { ID }\end{array}$ & \multicolumn{1}{c|}{ Determination Statement Text } \\
\hline $\mathrm{CM}-11(\mathrm{a})\{1\}$ & $\begin{array}{l}\text { Determine if the organization: establishes [Assignment: organization-defined policies] governing the installation of } \\
\text { software by users. }\end{array}$ \\
\hline
\end{tabular}

\section{Roles and Assessment Methods}

\begin{tabular}{|c|c|c|c|c|c|c|c|c|}
\hline $\begin{array}{c}\text { Determination } \\
\text { Statement ID }\end{array}$ & $\begin{array}{c}\text { Implemented } \\
\text { By }\end{array}$ & $\begin{array}{c}\text { Assessment } \\
\text { Boundary }\end{array}$ & $\begin{array}{c}\text { Assessment } \\
\text { Responsibility }\end{array}$ & $\begin{array}{l}\text { Assessment } \\
\text { Methods }\end{array}$ & Selected & $\begin{array}{l}\text { Rationale for } \\
\text { Risk } \\
\text { Acceptance }\end{array}$ & $\begin{array}{l}\text { Frequency of } \\
\text { Assessment }\end{array}$ & $\begin{array}{l}\text { Impact of Not } \\
\text { Implementing }\end{array}$ \\
\hline CM-11(a) $\{1\}$ & RskEx & ISCM-TN & ISCM-Sys & Test & & & & \\
\hline
\end{tabular}

\section{Defect Check Rationale Table}

A failure in effectiveness of this control item results in a defect in one or more of the following defect checks:

\begin{tabular}{|l|l|l|l|}
\hline $\begin{array}{c}\text { Determination } \\
\text { Statement ID }\end{array}$ & $\begin{array}{c}\text { Defect } \\
\text { Check ID }\end{array}$ & $\begin{array}{c}\text { Defect Check } \\
\text { Name }\end{array}$ & $\begin{array}{c}\text { Rationale } \\
\text { If an [organization-defined measure] for this defect check is above [the organization-defined } \\
\text { threshold], then defects in establishing policies governing the installation of software } \\
\text { by users related to this control item might be the cause of the defect, i.e.,... }\end{array}$ \\
\hline CM-11(a)\{1\} & $\begin{array}{l}\text { SWAM- } \\
\text { F02 }\end{array}$ & $\begin{array}{l}\text { Unauthorized } \\
\text { software installer }\end{array}$ & the execution of software not installed by an authorized installer. \\
\hline
\end{tabular}




\subsubsection{Control Item CM-11(b): USER-INSTALLED SOFTWARE}

\section{Control Item Text}

Control: The organization:

b. Enforces software installation policies through [Assignment: organization-defined methods].

\section{Determination Statement 1}

\begin{tabular}{|l|l|}
\hline $\begin{array}{l}\text { Determination Statement } \\
\text { ID }\end{array}$ & \multicolumn{1}{c|}{ Determination Statement Text } \\
\hline $\mathrm{CM}-11(\mathrm{~b})\{1\}$ & $\begin{array}{l}\text { Determine if the organization: enforces software installation policies through [Assignment: organization-defined } \\
\text { methods]. }\end{array}$ \\
\hline
\end{tabular}

\section{Roles and Assessment Methods}

\begin{tabular}{|c|c|c|c|c|c|c|c|c|}
\hline $\begin{array}{l}\text { Determination } \\
\text { Statement ID }\end{array}$ & $\begin{array}{c}\text { Implemented } \\
\text { By }\end{array}$ & $\begin{array}{l}\text { Assessment } \\
\text { Boundary }\end{array}$ & $\begin{array}{c}\text { Assessment } \\
\text { Responsibility }\end{array}$ & $\begin{array}{l}\text { Assessment } \\
\text { Methods }\end{array}$ & Selected & $\begin{array}{l}\text { Rationale for } \\
\text { Risk } \\
\text { Acceptance }\end{array}$ & $\begin{array}{l}\text { Frequency of } \\
\text { Assessment }\end{array}$ & $\begin{array}{l}\text { Impact of Not } \\
\text { Implementing }\end{array}$ \\
\hline $\mathrm{CM}-11(\mathrm{~b})\{1\}$ & ISCM-Ops & ISCM-TN & ISCM-Sys & Test & & & & \\
\hline
\end{tabular}




\section{Defect Check Rationale Table}

A failure in effectiveness of this control item results in a defect in one or more of the following defect checks:

\begin{tabular}{|l|l|l|l|}
\hline $\begin{array}{c}\text { Determination } \\
\text { Statement ID }\end{array}$ & $\begin{array}{c}\text { Defect } \\
\text { Check ID }\end{array}$ & \multicolumn{1}{|c|}{ Defect Check Name } & $\begin{array}{r}\text { Rationale } \\
\text { If an [organization-defined measure] for this defect check is above [the } \\
\text { organization-defined threshold], then defects in enforcing software installation } \\
\text { policies through specified methods related to this control item might be the } \\
\text { cause of the defect, i.e., ... }\end{array}$ \\
\hline CM-11(b)\{1\} & $\begin{array}{l}\text { SWAM- } \\
\text { F01 }\end{array}$ & $\begin{array}{l}\text { Unauthorized software } \\
\text { executes }\end{array}$ & the execution of unauthorized software. \\
\hline CM-11(b)\{1\} & $\begin{array}{l}\text { SWAM- } \\
\text { F02 }\end{array}$ & $\begin{array}{l}\text { Unauthorized software } \\
\text { installer }\end{array}$ & the execution of software not installed by an authorized installer. \\
\hline CM-11(b)\{1\} & $\begin{array}{l}\text { SWAM- } \\
\text { F03 }\end{array}$ & $\begin{array}{l}\text { Unauthorized software } \\
\text { directory/folder location }\end{array}$ & the execution of software not loaded from an approved directory/folder location. \\
\hline CM-11(b)\{1\} & $\begin{array}{l}\text { SWAM- } \\
\text { F04 }\end{array}$ & Untrusted core software & lack of core software integrity at start-up. \\
\hline CM-11(b)\{1\} & $\begin{array}{l}\text { SWAM- } \\
\text { L04 }\end{array}$ & $\begin{array}{l}\text { Devices moving in/out of } \\
\text { protective boundaries not in } \\
\text { policy compliance }\end{array}$ & $\begin{array}{l}\text { devices' software not being adequately strengthened and/or sanitized for } \\
\text { movement into or out of protective boundaries. }\end{array}$ \\
\hline CM-11(b)\{1\} & $\begin{array}{l}\text { SWAM- } \\
\text { L09 }\end{array}$ & $\begin{array}{l}\text { Device-software-item } \\
\text { assignment to authorization } \\
\text { boundary is not 1:1 }\end{array}$ & unclear management responsibility that could lead to unmanaged components. \\
\hline CM-11(b)\{1\} & $\begin{array}{l}\text { SWAM- } \\
\text { L10 }\end{array}$ & Unlicensed software & $\begin{array}{l}\text { use of software not in compliance with quantity licenses, contract agreements, or } \\
\text { copyright laws. }\end{array}$ \\
\hline CM-11(b) $)\{1\}$ & $\begin{array}{l}\text { SWAM- } \\
\text { L12 }\end{array}$ & Unmanaged software & the presence of unmanaged software. \\
\hline CM-11(b)\{1\} & $\begin{array}{l}\text { SWAM- } \\
\text { L13 }\end{array}$ & $\begin{array}{l}\text { Software without warranty } \\
\text { and/or source code }\end{array}$ & the presence of software without warranty and/or source code. \\
\hline
\end{tabular}




\subsubsection{Control Item CM-11(c): USER-INSTALLED SOFTWARE}

\section{Control Item Text}

Control: The organization:

c. Monitors policy compliance at [Assignment: organization-defined frequency].

\section{Determination Statement 1}

\begin{tabular}{|l|l|}
\hline $\begin{array}{c}\text { Determination Statement } \\
\text { ID }\end{array}$ & \multicolumn{1}{c|}{ Determination Statement Text } \\
\hline $\mathrm{CM}-11(\mathrm{c})\{1\}$ & $\begin{array}{l}\text { Determine if the organization: monitors policy compliance for \{installed software\} at [Assignment: organization- } \\
\text { defined frequency]. }\end{array}$ \\
\hline
\end{tabular}

\section{Roles and Assessment Methods}

\begin{tabular}{|c|c|c|c|c|c|c|c|c|}
\hline $\begin{array}{l}\text { Determination } \\
\text { Statement ID }\end{array}$ & $\begin{array}{c}\text { Implemented } \\
\text { By }\end{array}$ & $\begin{array}{l}\text { Assessment } \\
\text { Boundary }\end{array}$ & $\begin{array}{c}\text { Assessment } \\
\text { Responsibility }\end{array}$ & $\begin{array}{l}\text { Assessment } \\
\text { Methods }\end{array}$ & Selected & $\begin{array}{l}\text { Rationale for } \\
\text { Risk } \\
\text { Acceptance }\end{array}$ & $\begin{array}{l}\text { Frequency of } \\
\text { Assessment }\end{array}$ & $\begin{array}{l}\text { Impact of Not } \\
\text { Implementing }\end{array}$ \\
\hline CM-11(c) $\{1\}$ & ISCM-Ops & ISCM-TN & ISCM-Sys & Test & & & & \\
\hline
\end{tabular}

\section{Defect Check Rationale Table}

A failure in effectiveness of this control item results in a defect in one or more of the following defect checks:

\begin{tabular}{|l|l|l|l|}
\hline $\begin{array}{c}\text { Determination } \\
\text { Statement ID }\end{array}$ & $\begin{array}{c}\text { Defect } \\
\text { Check ID }\end{array}$ & $\begin{array}{c}\text { Defect } \\
\text { Check Name }\end{array}$ & $\begin{array}{c}\text { Rationale } \\
\text { If an [organization-defined measure] for this defect check is above [the organization-defined } \\
\text { threshold], then defects in monitoring policy compliance for }\{\text { installed software\} at the } \\
\text { specified frequency related to this control item might be the cause of the defect, i.e., ... }\end{array}$ \\
\hline CM-11(c) $\{1\}$ & $\begin{array}{l}\text { SWAM- } \\
\text { Q04 }\end{array}$ & $\begin{array}{l}\text { Poor } \\
\text { timeliness } \\
\text { metric }\end{array}$ & poor timeliness of overall ISCM reporting. \\
\hline
\end{tabular}




\subsubsection{Control Item MP-6(a): MEDIA SANITIZATION}

\section{Control Item Text}

Control: The organization:

a. Sanitizes [Assignment: organization-defined information system media] prior to disposal, release out of organizational control, or release for reuse using [Assignment: organization-defined sanitization techniques and procedures] in accordance with applicable federal and organizational standards and policies.

\section{Determination Statement 1}

\begin{tabular}{|l|l|}
\hline $\begin{array}{c}\text { Determination } \\
\text { Statement ID }\end{array}$ & \multicolumn{1}{c|}{ Determination Statement Text } \\
\hline MP-6(a)\{1\} & $\begin{array}{l}\text { Determine if the organization: sanitizes \{to remove software\} [Assignment: organization-defined information system media] } \\
\text { prior to disposal, release out of organizational control, or release for reuse using [Assignment: organization-defined } \\
\text { sanitization techniques and procedures] in accordance with applicable federal and organizational standards and policies. }\end{array}$ \\
\hline
\end{tabular}

\section{Roles and Assessment Methods}

\begin{tabular}{|c|c|c|c|c|c|c|c|c|}
\hline $\begin{array}{l}\text { Determination } \\
\text { Statement ID }\end{array}$ & $\begin{array}{c}\text { Implemented } \\
\text { By }\end{array}$ & $\begin{array}{l}\text { Assessment } \\
\text { Boundary }\end{array}$ & $\begin{array}{l}\text { Assessment } \\
\text { Responsibility }\end{array}$ & $\begin{array}{l}\text { Assessment } \\
\text { Methods }\end{array}$ & Selected & $\begin{array}{l}\text { Rationale for } \\
\text { Risk } \\
\text { Acceptance }\end{array}$ & $\begin{array}{l}\text { Frequency of } \\
\text { Assessment }\end{array}$ & $\begin{array}{l}\text { Impact of Not } \\
\text { Implementing }\end{array}$ \\
\hline MP-6(a)\{1\} & SWMan & ISCM-TN & ISCM-Sys & Test & & & & \\
\hline
\end{tabular}

\section{Defect Check Rationale Table}

A failure in effectiveness of this control item results in a defect in one or more of the following defect checks:

\begin{tabular}{|l|l|l|l|}
\hline $\begin{array}{c}\text { Determination } \\
\text { Statement ID }\end{array}$ & $\begin{array}{c}\text { Defect } \\
\text { Check ID }\end{array}$ & \multicolumn{1}{|c|}{ Defect Check Name } & $\begin{array}{c}\text { Rationale } \\
\text { If an [organization-defined measure] for this defect check is above [the organization- } \\
\text { defined threshold], then defects in sanitizing \{to remove software\} media before } \\
\text { moving to high risk areas, as required, using approved methods related to this } \\
\text { control item might be the cause of the defect, i.e.,.... }\end{array}$ \\
\hline MP-6(a)\{1\} & $\begin{array}{l}\text { SWAM- } \\
\text { L04 }\end{array}$ & $\begin{array}{l}\text { Devices moving in/out of } \\
\text { protective boundaries not } \\
\text { in policy compliance }\end{array}$ & $\begin{array}{l}\text { devices' software not being adequately strengthened and/or sanitized for movement } \\
\text { into or out of protective boundaries. }\end{array}$ \\
\hline
\end{tabular}




\subsubsection{Control Item MP-6(b): MEDIA SANITIZATION}

\section{Control Item Text}

Control: The organization:

b. Employs sanitization mechanisms with the strength and integrity commensurate with the security category or classification of the information.

\section{Determination Statement 1}

\begin{tabular}{|l|l|}
\hline $\begin{array}{c}\text { Determination } \\
\text { Statement ID }\end{array}$ & \multicolumn{1}{c|}{ Determination Statement Text } \\
\hline MP-6(b) $\{1\}$ & $\begin{array}{l}\text { Determine if the organization: employs sanitization mechanisms } \text { to remove software }\} \text { with the strength and integrity } \\
\text { commensurate with the security category or classification of the information. }\end{array}$ \\
\hline
\end{tabular}

\section{Roles and Assessment Methods}

\begin{tabular}{|c|c|c|c|c|c|c|c|c|}
\hline $\begin{array}{l}\text { Determination } \\
\text { Statement ID }\end{array}$ & $\begin{array}{c}\text { Implemented } \\
\text { By }\end{array}$ & $\begin{array}{l}\text { Assessment } \\
\text { Boundary }\end{array}$ & $\begin{array}{c}\text { Assessment } \\
\text { Responsibility }\end{array}$ & $\begin{array}{c}\text { Assessment } \\
\text { Methods }\end{array}$ & Selected & $\begin{array}{c}\text { Rationale for } \\
\text { Risk } \\
\text { Acceptance }\end{array}$ & $\begin{array}{l}\text { Frequency of } \\
\text { Assessment }\end{array}$ & $\begin{array}{l}\text { Impact of Not } \\
\text { Implementing }\end{array}$ \\
\hline MP-6(b) $\{1\}$ & SWMan & ISCM-TN & ISCM-Sys & Test & & & & \\
\hline
\end{tabular}

\section{Defect Check Rationale Table}

A failure in effectiveness of this control item results in a defect in one or more of the following defect checks:

\begin{tabular}{|l|l|l|l|}
\hline $\begin{array}{c}\text { Determination } \\
\text { Statement ID }\end{array}$ & $\begin{array}{c}\text { Defect } \\
\text { Check ID }\end{array}$ & $\begin{array}{c}\text { Rationale } \\
\text { Defect Check Name }\end{array}$ & $\begin{array}{c}\text { If an [organization-defined measure] for this defect check is above [the organization- } \\
\text { defined threshold], then defects in employing sanitization mechanisms } \begin{array}{c}\text { \{to remove } \\
\text { software\} with the strength and integrity commensurate with the security category } \\
\text { or classification of the information related to this control item might be the cause of } \\
\text { the defect, i.e., ... }\end{array}\end{array}$ \\
\hline MP-6(b)\{1\} & $\begin{array}{l}\text { SWAM- } \\
\text { L04 }\end{array}$ & $\begin{array}{l}\text { Devices moving in/out } \\
\text { of protective boundaries } \\
\text { not in policy compliance }\end{array}$ & $\begin{array}{l}\text { devices' software not being adequately strengthened and/or sanitized for movement into } \\
\text { or outective boundaries. }\end{array}$ \\
\hline
\end{tabular}




\subsubsection{Control Item PS-4(d): PERSONNEL TERMINATION}

\section{Control Item Text}

Control: The organization, upon termination of individual employment:

d. Retrieves all security-related organizational information system-related property.

\section{Determination Statement 1}

\begin{tabular}{|l|l|}
\hline \multicolumn{1}{|c|}{ Determination Statement } & \multicolumn{1}{c|}{ Determination Statement Text } \\
\hline PS-4(d)\{1\} & $\begin{array}{l}\text { Determine if the organization: retrieves all security-related organizational system-related } \\
\text { media\} property. }\end{array}$ \\
\hline
\end{tabular}

\section{Roles and Assessment Methods}

\begin{tabular}{|c|c|c|c|c|c|c|c|c|}
\hline $\begin{array}{c}\text { Determination } \\
\text { Statement ID }\end{array}$ & $\begin{array}{c}\text { Implemented } \\
\text { By }\end{array}$ & $\begin{array}{c}\text { Assessment } \\
\text { Boundary }\end{array}$ & $\begin{array}{c}\text { Assessment } \\
\text { Responsibility }\end{array}$ & $\begin{array}{l}\text { Assessment } \\
\text { Methods }\end{array}$ & Selected & $\begin{array}{l}\text { Rationale for } \\
\text { Risk } \\
\text { Acceptance }\end{array}$ & $\begin{array}{l}\text { Frequency of } \\
\text { Assessment }\end{array}$ & $\begin{array}{l}\text { Impact of Not } \\
\text { Implementing }\end{array}$ \\
\hline PS-4(d) $\{1\}$ & SWMan & ISCM-TN & ISCM-Sys & Test & & & & \\
\hline
\end{tabular}

\section{Defect Check Rationale Table}

A failure in effectiveness of this control item results in a defect in one or more of the following defect checks:

\begin{tabular}{|l|l|l|l|}
\hline $\begin{array}{c}\text { Determination } \\
\text { Statement ID }\end{array}$ & $\begin{array}{c}\text { Defect } \\
\text { Check ID }\end{array}$ & \multicolumn{1}{|c|}{$\begin{array}{c}\text { Rationale } \\
\text { Defect Check Name }\end{array}$} & $\begin{array}{l}\text { If an [organization-defined measure] for this defect check is above [the organization- } \\
\text { defined threshold], then defects in retrieving all security-related organizational } \\
\text { system-related } \begin{array}{c}\text { \{software and software media\} property related to this control } \\
\text { item might be the cause of the defect, i.e., ... }\end{array}\end{array}$ \\
\hline PS-4(d)\{1\} & $\begin{array}{l}\text { SWAM- } \\
\text { L04 }\end{array}$ & $\begin{array}{l}\text { Devices moving in/out of } \\
\text { protective boundaries not } \\
\text { in policy compliance }\end{array}$ & $\begin{array}{l}\text { devices' software not being adequately strengthened and/or sanitized for movement } \\
\text { into or out of protective boundaries. }\end{array}$ \\
\hline
\end{tabular}




\subsubsection{Control Item SI-3(a): MALICIOUS CODE PROTECTION}

\section{Control Item Text}

Control: The organization:

a. Employs malicious code protection mechanisms at information system entry and exit points to detect and eradicate malicious code.

\section{Determination Statement 1}

\begin{tabular}{|l|l|}
\hline $\begin{array}{c}\text { Determination } \\
\text { Statement ID }\end{array}$ & \multicolumn{1}{c|}{ Determination Statement Text } \\
\hline SI-3(a)\{1\} & $\begin{array}{l}\text { Determine if the organization: employs malicious code protection mechanisms at system entry and exit points to } \\
\text { detect and eradicate malicious code. }\end{array}$ \\
\hline
\end{tabular}

\section{Roles and Assessment Methods}

\begin{tabular}{|c|c|c|c|c|c|c|c|c|}
\hline $\begin{array}{l}\text { Determination } \\
\text { Statement ID }\end{array}$ & $\begin{array}{c}\text { Implemented } \\
\text { By }\end{array}$ & $\begin{array}{l}\text { Assessment } \\
\text { Boundary }\end{array}$ & $\begin{array}{l}\text { Assessment } \\
\text { Responsibility }\end{array}$ & $\begin{array}{c}\text { Assessment } \\
\text { Methods }\end{array}$ & Selected & $\begin{array}{c}\text { Rationale for } \\
\text { Risk } \\
\text { Acceptance }\end{array}$ & $\begin{array}{l}\text { Frequency of } \\
\text { Assessment }\end{array}$ & $\begin{array}{l}\text { Impact of Not } \\
\text { Implementing }\end{array}$ \\
\hline SI-3(a) $\{1\}$ & ISCM-Ops & ISCM-TN & ISCM-Sys & Test & & & & \\
\hline
\end{tabular}

\section{Defect Check Rationale Table}

A failure in effectiveness of this control item results in a defect in one or more of the following defect checks:

\begin{tabular}{|l|l|l|l|}
\hline $\begin{array}{c}\text { Determination } \\
\text { Statement ID }\end{array}$ & $\begin{array}{c}\text { Defect } \\
\text { Check ID }\end{array}$ & $\begin{array}{r}\text { Rationale } \\
\text { Defect } \\
\text { Check } \\
\text { Name }\end{array}$ & $\begin{array}{c}\text { Ran an [organization-defined measure] for this defect check is above [the organization-defined } \\
\text { threshold], then defects in employing malicious code protection mechanisms at system entry } \\
\text { and exit points to detect and eradicate malicious code related to this control item might be the } \\
\text { cause of the defect, i.e.,... }\end{array}$ \\
\hline SI-3(a)\{1\} & $\begin{array}{l}\text { SWAM- } \\
\text { L14 }\end{array}$ & $\begin{array}{l}\text { Poor AV } \\
\text { protection }\end{array}$ & absence of methods to block malware. \\
\hline
\end{tabular}




\subsubsection{Control Item SI-3(b): MALICIOUS CODE PROTECTION}

\section{Control Item Text}

Control: The organization:

b. Updates malicious code protection mechanisms whenever new releases are available in accordance with organizational configuration management policy and procedures.

\section{Determination Statement 1}

\begin{tabular}{|l|l|}
\hline $\begin{array}{c}\text { Determination } \\
\text { Statement ID }\end{array}$ & \multicolumn{1}{c|}{ Determination Statement Text } \\
\hline SI-3(b)\{1\} & $\begin{array}{l}\text { Determine if the organization: updates malicious code protection mechanisms whenever new releases are available in } \\
\text { accordance with organizational configuration management policy and procedures. }\end{array}$ \\
\hline
\end{tabular}

\section{Roles and Assessment Methods}

\begin{tabular}{|c|c|c|c|c|c|c|c|c|}
\hline $\begin{array}{l}\text { Determination } \\
\text { Statement ID }\end{array}$ & $\begin{array}{c}\text { Implemented } \\
\text { By }\end{array}$ & $\begin{array}{l}\text { Assessment } \\
\text { Boundary }\end{array}$ & $\begin{array}{l}\text { Assessment } \\
\text { Responsibility }\end{array}$ & $\begin{array}{c}\text { Assessment } \\
\text { Methods }\end{array}$ & Selected & $\begin{array}{c}\text { Rationale for } \\
\text { Risk } \\
\text { Acceptance }\end{array}$ & $\begin{array}{l}\text { Frequency of } \\
\text { Assessment }\end{array}$ & $\begin{array}{l}\text { Impact of Not } \\
\text { Implementing }\end{array}$ \\
\hline SI-3(b) $\{1\}$ & ISCM-Ops & ISCM-TN & ISCM-Sys & Test & & & & \\
\hline
\end{tabular}




\section{Defect Check Rationale Table}

A failure in effectiveness of this control item results in a defect in one or more of the following defect checks:

\begin{tabular}{|c|c|c|c|}
\hline $\begin{array}{l}\text { Determination } \\
\text { Statement ID }\end{array}$ & $\begin{array}{l}\text { Defect } \\
\text { Check ID }\end{array}$ & Defect Check Name & $\begin{array}{l}\text { Rationale } \\
\text { If an [organization-defined measure] for this defect check is above [the organization- } \\
\text { defined threshold], then defects in updating malicious code protection mechanisms } \\
\text { whenever new releases are available in accordance with organizational } \\
\text { configuration management policy and procedures related to this control item might } \\
\text { be the cause of the defect, i.e., ... }\end{array}$ \\
\hline SI-3(b) $\{1\}$ & $\begin{array}{l}\text { SWAM- } \\
\text { F01 }\end{array}$ & $\begin{array}{l}\text { Unauthorized software } \\
\text { executes }\end{array}$ & the execution of unauthorized software. \\
\hline SI-3(b) $\{1\}$ & $\begin{array}{l}\text { SWAM- } \\
\text { F04 }\end{array}$ & Untrusted core software & lack of core software integrity at start-up. \\
\hline SI-3(b) $\{1\}$ & $\begin{array}{l}\text { SWAM- } \\
\text { L04 }\end{array}$ & $\begin{array}{l}\text { Devices moving in/out of } \\
\text { protective boundaries not } \\
\text { in policy compliance }\end{array}$ & $\begin{array}{l}\text { devices' software not being adequately strengthened and/or sanitized for movement } \\
\text { into or out of protective boundaries. }\end{array}$ \\
\hline SI-3(b) $\{1\}$ & $\begin{array}{l}\text { SWAM- } \\
\text { L14 }\end{array}$ & Poor AV protection & absence of methods to block malware. \\
\hline
\end{tabular}




\subsubsection{Control Item SI-3(c): MALICIOUS CODE PROTECTION}

\section{Control Item Text}

Control: The organization:

c. Configures malicious code protection mechanisms to:

1. Perform periodic scans of the information system [Assignment: organization-defined frequency] and real-time scans of files from external sources at [Selection (one or more); endpoint; network entry/exit points] as the files are downloaded, opened, or executed in accordance with organizational security policy; and

2. [Selection (one or more): block malicious code; quarantine malicious code; send alert to administrator; [Assignment: organization-defined action]] in response to malicious code detection.

\section{Determination Statement 1}

\begin{tabular}{|l|l|}
\hline $\begin{array}{c}\text { Determination } \\
\text { Statement ID }\end{array}$ & \multicolumn{1}{c|}{ Determination Statement Text } \\
\hline SI-3(c)\{1\} & $\begin{array}{l}\text { Determine if the organization: configures malicious code protection mechanisms to perform periodic scans of [software } \\
\text { and files that might include hidden software] at an [Assignment: organization-defined frequency] on [devices]. }\end{array}$ \\
\hline
\end{tabular}

\section{Roles and Assessment Methods}

\begin{tabular}{|c|c|c|c|c|c|c|c|c|}
\hline $\begin{array}{l}\text { Determination } \\
\text { Statement ID }\end{array}$ & $\begin{array}{c}\text { Implemented } \\
\text { By }\end{array}$ & $\begin{array}{c}\text { Assessment } \\
\text { Boundary }\end{array}$ & $\begin{array}{c}\text { Assessment } \\
\text { Responsibility }\end{array}$ & $\begin{array}{l}\text { Assessment } \\
\text { Methods }\end{array}$ & Selected & $\begin{array}{l}\text { Rationale for } \\
\text { Risk } \\
\text { Acceptance }\end{array}$ & $\begin{array}{l}\text { Frequency of } \\
\text { Assessment }\end{array}$ & $\begin{array}{l}\text { Impact of Not } \\
\text { Implementing }\end{array}$ \\
\hline SI-3(c) $\{1\}$ & ISCM-Ops & ISCM-TN & ISCM-Sys & Test & & & & \\
\hline
\end{tabular}




\section{Defect Check Rationale Table}

A failure in effectiveness of this control item results in a defect in one or more of the following defect checks:

\begin{tabular}{|l|l|l|r|}
\hline $\begin{array}{c}\text { Determination } \\
\text { Statement ID }\end{array}$ & $\begin{array}{c}\text { Defect } \\
\text { Check ID }\end{array}$ & $\begin{array}{c}\text { Defect } \\
\text { Check } \\
\text { Name }\end{array}$ & $\begin{array}{c}\text { Rationale } \\
\text { If an [organization-defined measure] for this defect check is above [the organization-defined } \\
\text { threshold], then defects in configuring malicious code protection mechanisms to perform } \\
\text { periodic scans of } \begin{array}{c}\text { \{software and files\} on mass storage, as specified related to this control } \\
\text { item might be the cause of the defect, i.e.,.... }\end{array}\end{array}$ \\
\hline SI-3(c) $\{1\}$ & $\begin{array}{l}\text { SWAM- } \\
\text { L14 }\end{array}$ & $\begin{array}{l}\text { Poor AV } \\
\text { protection }\end{array}$ & absence of methods to block malware. \\
\hline
\end{tabular}

\section{Determination Statement 2}

\begin{tabular}{|l|l|}
\hline $\begin{array}{c}\text { Determination } \\
\text { Statement ID }\end{array}$ & Determination Statement Text \\
\hline SI-3(c) $\{2\}$ & $\begin{array}{l}\text { Determine if the organization: configures malicious code protection mechanisms to perform scans of software and files } \\
\text { that might include hidden software at network entry/exit points as the files are downloaded. }\end{array}$ \\
\hline
\end{tabular}

\section{Roles and Assessment Methods}

\begin{tabular}{|c|c|c|c|c|c|c|c|c|}
\hline $\begin{array}{l}\text { Determination } \\
\text { Statement ID }\end{array}$ & $\begin{array}{c}\text { Implemented } \\
\text { By }\end{array}$ & $\begin{array}{c}\text { Assessment } \\
\text { Boundary }\end{array}$ & $\begin{array}{c}\text { Assessment } \\
\text { Responsibility }\end{array}$ & $\begin{array}{l}\text { Assessment } \\
\text { Methods }\end{array}$ & Selected & $\begin{array}{l}\text { Rationale for } \\
\text { Risk } \\
\text { Acceptance }\end{array}$ & $\begin{array}{l}\text { Frequency of } \\
\text { Assessment }\end{array}$ & $\begin{array}{l}\text { Impact of Not } \\
\text { Implementing }\end{array}$ \\
\hline SI-3(c)\{2\} & ISCM-Ops & ISCM-TN & ISCM-Sys & Test & & & & \\
\hline
\end{tabular}

\section{Defect Check Rationale Table}

A failure in effectiveness of this control item results in a defect in one or more of the following defect checks:

\begin{tabular}{|l|l|l|l|}
\hline $\begin{array}{c}\text { Determination } \\
\text { Statement ID }\end{array}$ & $\begin{array}{c}\text { Defect } \\
\text { Check ID }\end{array}$ & $\begin{array}{c}\text { Defect } \\
\text { Check } \\
\text { Name }\end{array}$ & $\begin{array}{c}\text { Rationale } \\
\text { If an [organization-defined measure] for this defect check is above [the organization-defined } \\
\text { threshold], then defects in configuring malicious code protection mechanisms to perform } \\
\text { periodic scans of } \begin{array}{c}\text { \{software and files\} at entry and exit points related to this control item might } \\
\text { be the cause of the defect, i.e.,... }\end{array}\end{array}$ \\
\hline SI-3(c) $\{2\}$ & $\begin{array}{l}\text { SWAM- } \\
\text { L14 }\end{array}$ & $\begin{array}{l}\text { Poor AV } \\
\text { protection }\end{array}$ & absence of methods to block malware. \\
\hline
\end{tabular}




\section{Determination Statement 3}

\begin{tabular}{|l|l|}
\hline $\begin{array}{c}\text { Determination } \\
\text { Statement ID }\end{array}$ & \multicolumn{1}{c|}{ Determination Statement Text } \\
\hline SI-3(c) $\{3\}$ & $\begin{array}{l}\text { Determine if the organization: configures malicious code protection mechanisms to perform scans of [software and files } \\
\text { that might include hidden software] when opened or executed. }\end{array}$ \\
\hline
\end{tabular}

\section{Roles and Assessment Methods}

\begin{tabular}{|c|c|c|c|c|c|c|c|c|}
\hline $\begin{array}{c}\text { Determination } \\
\text { Statement ID }\end{array}$ & $\begin{array}{c}\text { Implemented } \\
\text { By }\end{array}$ & $\begin{array}{c}\text { Assessment } \\
\text { Boundary }\end{array}$ & $\begin{array}{l}\text { Assessment } \\
\text { Responsibility }\end{array}$ & $\begin{array}{l}\text { Assessment } \\
\text { Methods }\end{array}$ & Selected & $\begin{array}{l}\text { Rationale for } \\
\text { Risk } \\
\text { Acceptance }\end{array}$ & $\begin{array}{l}\text { Frequency of } \\
\text { Assessment }\end{array}$ & $\begin{array}{l}\text { Impact of Not } \\
\text { Implementing }\end{array}$ \\
\hline SI-3(c) $\{3\}$ & ISCM-Ops & ISCM-TN & ISCM-Sys & Test & & & & \\
\hline
\end{tabular}

\section{Defect Check Rationale Table}

A failure in effectiveness of this control item results in a defect in one or more of the following defect checks:

\begin{tabular}{|l|l|l|l|}
\hline $\begin{array}{c}\text { Determination } \\
\text { Statement ID }\end{array}$ & $\begin{array}{c}\text { Defect } \\
\text { Check ID }\end{array}$ & $\begin{array}{c}\text { Refect Check } \\
\text { Name }\end{array}$ & $\begin{array}{c}\text { Rationale } \\
\text { If an [organization-defined measure] for this defect check is above [the organization-defined } \\
\text { threshold], then defects in configuring malicious code protection mechanisms to } \\
\text { perform periodic scans of } \begin{array}{r}\text { [software and files\} when opened or executed related to this } \\
\text { control item might be the cause of the defect, i.e., ... }\end{array}\end{array}$ \\
\hline SI-3(c)\{3\} & $\begin{array}{l}\text { SWAM- } \\
\text { F01 }\end{array}$ & $\begin{array}{l}\text { Unauthorized } \\
\text { software executes }\end{array}$ & the execution of unauthorized software. \\
\hline SI-3(c) $\{3\}$ & SWAM- & $\begin{array}{l}\text { Poor AV } \\
\text { protection }\end{array}$ & absence of methods to block malware. \\
\hline
\end{tabular}




\section{Determination Statement 4}

\begin{tabular}{|l|l|}
\hline $\begin{array}{c}\text { Determination } \\
\text { Statement ID }\end{array}$ & \multicolumn{1}{c|}{ Determination Statement Text } \\
\hline SI-3(c)\{4\} & $\begin{array}{l}\text { Determine if the organization: configures malicious code protection mechanisms to take one or more of the following } \\
\text { action(s) when malicious software is detected: [Selection (one or more): block malicious code; quarantine malicious code; } \\
\text { send alert to administrator]. }\end{array}$ \\
\hline
\end{tabular}

\section{Roles and Assessment Methods}

\begin{tabular}{|c|c|c|c|c|c|c|c|c|}
\hline $\begin{array}{l}\text { Determination } \\
\text { Statement ID }\end{array}$ & $\begin{array}{c}\text { Implemented } \\
\text { By }\end{array}$ & $\begin{array}{l}\text { Assessment } \\
\text { Boundary }\end{array}$ & $\begin{array}{c}\text { Assessment } \\
\text { Responsibility }\end{array}$ & $\begin{array}{l}\text { Assessment } \\
\text { Methods }\end{array}$ & Selected & $\begin{array}{l}\text { Rationale for } \\
\text { Risk } \\
\text { Acceptance }\end{array}$ & $\begin{array}{l}\text { Frequency of } \\
\text { Assessment }\end{array}$ & $\begin{array}{l}\text { Impact of Not } \\
\text { Implementing }\end{array}$ \\
\hline SI-3(c) $\{4\}$ & ISCM-Ops & ISCM-TN & ISCM-Sys & Test & & & & \\
\hline
\end{tabular}

\section{Defect Check Rationale Table}

A failure in effectiveness of this control item results in a defect in one or more of the following defect checks:

\begin{tabular}{|l|l|l|l|}
\hline $\begin{array}{c}\text { Determination } \\
\text { Statement ID }\end{array}$ & $\begin{array}{c}\text { Defect } \\
\text { Check ID }\end{array}$ & $\begin{array}{c}\text { Defect Check } \\
\text { Name }\end{array}$ & $\begin{array}{c}\text { Rationale } \\
\text { If an [organization-defined measure] for this defect check is above [the organization-defined } \\
\text { threshold], then defects in configuring malicious code protection mechanisms to take } \\
\text { specific protective actions when malicious software is detected related to this control } \\
\text { item might be the cause of the defect, i.e., ... }\end{array}$ \\
\hline SI-3(c) $\{4\}$ & $\begin{array}{l}\text { SWAM- } \\
\text { F01 }\end{array}$ & $\begin{array}{l}\text { Unauthorized } \\
\text { software executes }\end{array}$ & the execution of unauthorized software. \\
\hline SI-3(c) $\{4\}$ & $\begin{array}{l}\text { SWAM- } \\
\text { L14 }\end{array}$ & $\begin{array}{l}\text { Poor AV } \\
\text { protection }\end{array}$ & absence of methods to block malware. \\
\hline
\end{tabular}




\subsubsection{Control Item SI-3(d): MALICIOUS CODE PROTECTION}

\section{Control Item Text}

Control: The organization:

d. Addresses the receipt of false positives during malicious code detection and eradication and the resulting potential impact on the availability of the information system.

\section{Determination Statement 1}

\begin{tabular}{|l|l|}
\hline $\begin{array}{c}\text { Determination } \\
\text { Statement ID }\end{array}$ & \multicolumn{1}{c|}{ Determination Statement Text } \\
\hline $\mathrm{SI}-3(\mathrm{~d})\{1\}$ & $\begin{array}{l}\text { Determine if the organization: addresses the receipt of false positives during malicious code detection and eradication } \\
\text { and the resulting potential impact on the availability of the system. }\end{array}$ \\
\hline
\end{tabular}

\section{Roles and Assessment Methods}

\begin{tabular}{|c|c|c|c|c|c|c|c|c|}
\hline $\begin{array}{l}\text { Determination } \\
\text { Statement ID }\end{array}$ & $\begin{array}{c}\text { Implemented } \\
\text { By }\end{array}$ & $\begin{array}{l}\text { Assessment } \\
\text { Boundary }\end{array}$ & $\begin{array}{l}\text { Assessment } \\
\text { Responsibility }\end{array}$ & $\begin{array}{c}\text { Assessment } \\
\text { Methods }\end{array}$ & Selected & $\begin{array}{c}\text { Rationale for } \\
\text { Risk } \\
\text { Acceptance }\end{array}$ & $\begin{array}{l}\text { Frequency of } \\
\text { Assessment }\end{array}$ & $\begin{array}{l}\text { Impact of Not } \\
\text { Implementing }\end{array}$ \\
\hline SI-3(d)\{1\} & ISCM-Ops & ISCM-TN & ISCM-Sys & Test & & & & \\
\hline
\end{tabular}

\section{Defect Check Rationale Table}

A failure in effectiveness of this control item results in a defect in one or more of the following defect checks:

\begin{tabular}{|l|l|l|l|}
\hline $\begin{array}{c}\text { Determination } \\
\text { Statement ID }\end{array}$ & $\begin{array}{c}\text { Defect } \\
\text { Check } \\
\text { ID }\end{array}$ & \multicolumn{1}{|c|}{$\begin{array}{c}\text { Rationale } \\
\text { Defect Check Name }\end{array}$} & $\begin{array}{c}\text { If an [organization-defined measure] for this defect check is above [the } \\
\text { organization-defined threshold], then defects in addressing the receipt of } \\
\text { false positives during malicious code detection and eradication and the } \\
\text { resulting potential impact on the availability of the system related to this } \\
\text { control item might be the cause of the defect, i.e., ... }\end{array}$ \\
\hline SI-3(d)\{1\} & $\begin{array}{l}\text { SWAM- } \\
\text { L03 }\end{array}$ & $\begin{array}{l}\text { Expired actions on software } \\
\text { authorization/deauthorization } \\
\text { requests }\end{array}$ & requested changes not being addressed in a timely manner. \\
\hline
\end{tabular}




\subsubsection{Moderate Baseline Security Control Item Narratives}

\subsubsection{Control Item CM-2(1)(a): BASELINE CONFIGURATION | REVIEWS AND UPDATES}

\section{Control Item Text}

The organization reviews and updates the baseline configuration of the information system:

(a) [Assignment: organization-defined frequency].

Determination Statement 1

\begin{tabular}{|l|l|}
\hline Determination Statement ID & \multicolumn{1}{c|}{ Determination Statement Text } \\
\hline CM-2(1)(a)\{1\} & $\begin{array}{l}\text { Determine if the organization: reviews and updates the baseline configuration of the information system: } \\
\text { (a) [Assignment: organization-defined frequency]. }\end{array}$ \\
\hline
\end{tabular}

Roles and Assessment Methods

\begin{tabular}{|c|c|c|c|c|c|c|c|c|}
\hline $\begin{array}{l}\text { Determination } \\
\text { Statement ID }\end{array}$ & $\begin{array}{c}\text { Implemented } \\
\text { By }\end{array}$ & $\begin{array}{l}\text { Assessment } \\
\text { Boundary }\end{array}$ & $\begin{array}{l}\text { Assessment } \\
\text { Responsibility }\end{array}$ & $\begin{array}{l}\text { Assessment } \\
\text { Methods }\end{array}$ & Selected & $\begin{array}{l}\text { Rationale for } \\
\text { Risk } \\
\text { Acceptance }\end{array}$ & $\begin{array}{l}\text { Frequency of } \\
\text { Assessment }\end{array}$ & $\begin{array}{l}\text { Impact of Not } \\
\text { Implementing }\end{array}$ \\
\hline CM-2(1)(a)\{1\} & DSM & ISCM-TN & ISCM-Sys & Test & & & & \\
\hline
\end{tabular}




\section{Defect Check Rationale Table}

A failure in effectiveness of this control item results in a defect in one or more of the following defect checks:

\begin{tabular}{|l|l|l|l|}
\hline $\begin{array}{c}\text { Determination } \\
\text { Statement ID }\end{array}$ & $\begin{array}{c}\text { Defect } \\
\text { Check ID }\end{array}$ & $\begin{array}{r}\text { Defect Check } \\
\text { Name }\end{array}$ & $\begin{array}{r}\text { Rationale } \\
\text { If an [organization-defined measure] for this defect check is above [the organization-defined } \\
\text { threshold], then defects in reviewing and updating the baseline configuration of the } \\
\text { information system: [assignment: organization-defined frequency] related to this control item } \\
\text { might be the cause of the defect, i.e.,... }\end{array}$ \\
\hline CM-2(1)(a)\{1\} & $\begin{array}{l}\text { SWAM- } \\
\text { L11 }\end{array}$ & $\begin{array}{l}\text { Required } \\
\text { software not } \\
\text { present }\end{array}$ & absence of required software. \\
\hline
\end{tabular}




\subsubsection{Control Item CM-2(1)(b): BASELINE CONFIGURATION | REVIEWS AND UPDATES}

\section{Control Item Text}

The organization reviews and updates the baseline configuration of the information system:

(b) When required due to [Assignment organization-defined circumstances].

\section{Determination Statement 1}

\begin{tabular}{|l|l|}
\hline Determination Statement ID & \multicolumn{1}{c}{ Determination Statement Text } \\
\hline $\mathrm{CM}-2(1)(\mathrm{b})\{1\}$ & $\begin{array}{l}\text { Determine if the organization: reviews and updates the baseline configuration of the information system: } \\
\text { (b) When required due to [Assignment organization-defined circumstances]. }\end{array}$
\end{tabular}

Roles and Assessment Methods

\begin{tabular}{|c|c|c|c|c|c|c|c|c|}
\hline $\begin{array}{l}\text { Determination } \\
\text { Statement ID }\end{array}$ & $\begin{array}{c}\text { Implemented } \\
\text { By }\end{array}$ & $\begin{array}{l}\text { Assessment } \\
\text { Boundary }\end{array}$ & $\begin{array}{l}\text { Assessment } \\
\text { Responsibility }\end{array}$ & $\begin{array}{l}\text { Assessment } \\
\text { Methods }\end{array}$ & Selected & $\begin{array}{c}\text { Rationale for } \\
\text { Risk } \\
\text { Acceptance }\end{array}$ & $\begin{array}{l}\text { Frequency of } \\
\text { Assessment }\end{array}$ & $\begin{array}{l}\text { Impact of Not } \\
\text { Implementing }\end{array}$ \\
\hline CM-2(1)(b)\{1\} & DSM & ISCM-TN & ISCM-Sys & Test & & & & \\
\hline
\end{tabular}

Defect Check Rationale Table

A failure in effectiveness of this control item results in a defect in one or more of the following defect checks:

\begin{tabular}{|l|l|l|l|}
\hline $\begin{array}{c}\text { Determination } \\
\text { Statement ID }\end{array}$ & $\begin{array}{c}\text { Defect } \\
\text { Check ID }\end{array}$ & $\begin{array}{r}\text { Defect Check } \\
\text { Name }\end{array}$ & $\begin{array}{r}\text { Rationale } \\
\text { If an [organization-defined measure] for this defect check is above [the organization-defined } \\
\text { threshold], then defects in reviewing and updating the baseline configuration of the } \\
\text { information system when required due to [Assignment organization-defined circumstances] } \\
\text { related to this control item might be the cause of the defect, i.e., ... }\end{array}$ \\
\hline $\mathrm{CM}-2(1)(\mathrm{b})\{1\}$ & $\begin{array}{l}\text { SWAM- } \\
\text { L11 }\end{array}$ & $\begin{array}{l}\text { Required } \\
\text { software not } \\
\text { present }\end{array}$ & absence of required software. \\
\hline
\end{tabular}




\subsubsection{Control Item CM-2(1)(c): BASELINE CONFIGURATION | REVIEWS AND UPDATES}

\section{Control Item Text}

The organization reviews and updates the baseline configuration of the information system:

(c) As an integral part of information system component installations and upgrades.

\section{Determination Statement 1}

\begin{tabular}{|l|l|}
\hline Determination Statement ID & \multicolumn{1}{c}{ Determination Statement Text } \\
\hline $\mathrm{CM}-2(1)(\mathrm{c})\{1\}$ & $\begin{array}{l}\text { Determine if the organization: reviews and updates the baseline configuration of the information system: } \\
\text { (c) As an integral part of information system component installations and upgrades. }\end{array}$
\end{tabular}

Roles and Assessment Methods

\begin{tabular}{|l|l|l|l|l|l|l|l|}
\hline $\begin{array}{c}\text { Determination } \\
\text { Statement ID }\end{array}$ & $\begin{array}{c}\text { Implemented } \\
\text { By }\end{array}$ & $\begin{array}{c}\text { Assessment } \\
\text { Boundary }\end{array}$ & $\begin{array}{c}\text { Assessment } \\
\text { Responsibility }\end{array}$ & $\begin{array}{c}\text { Assessment } \\
\text { Methods }\end{array}$ & $\begin{array}{c}\text { Selected } \\
\text { Rationale for } \\
\text { Risk } \\
\text { Acceptance }\end{array}$ & $\begin{array}{c}\text { Frequency of } \\
\text { Assessment }\end{array}$ & $\begin{array}{c}\text { Impact of Not } \\
\text { Implementing }\end{array}$ \\
\hline CM-2(1)(c)\{1\} & DSM & ISCM-TN & ISCM-Sys & Test & & & \\
\hline
\end{tabular}

Defect Check Rationale Table

A failure in effectiveness of this control item results in a defect in one or more of the following defect checks:

\begin{tabular}{|l|l|l|l|}
\hline $\begin{array}{c}\text { Determination } \\
\text { Statement ID }\end{array}$ & $\begin{array}{c}\text { Defect } \\
\text { Check ID }\end{array}$ & $\begin{array}{c}\text { Defect Check } \\
\text { Name }\end{array}$ & $\begin{array}{r}\text { Rationale } \\
\text { If an [organization-defined measure] for this defect check is above [the organization-defined } \\
\text { threshold], then defects in reviewing and updating the baseline configuration of the } \\
\text { information system as an integral part of information system component installations and } \\
\text { upgrades related to this control item might be the cause of the defect, i.e., ... }\end{array}$ \\
\hline CM-2(1)(c)\{1\} & $\begin{array}{l}\text { SWAM- } \\
\text { L11 }\end{array}$ & $\begin{array}{l}\text { Required } \\
\text { software not } \\
\text { present }\end{array}$ & absence of required software. \\
\hline
\end{tabular}




\subsubsection{Control Item CM-2(3): BASELINE CONFIGURATION | RETENTION OF PREVIOUS CONFIGURATIONS}

\section{Control Item Text}

The organization retains [Assignment: organization-defined previous versions of baseline configurations of the information system] to support rollback.

\section{Determination Statement 1}

\begin{tabular}{|l|l|}
\hline $\begin{array}{c}\text { Determination } \\
\text { Statement ID }\end{array}$ & \multicolumn{1}{c|}{ Determination Statement Text } \\
\hline $\mathrm{CM}-2(3)\{1\}$ & $\begin{array}{l}\text { Determine if the organization: retains [Assignment: organization-defined previous versions of baseline configurations of } \\
\text { the information system] to support rollback. }\end{array}$ \\
\hline
\end{tabular}

Roles and Assessment Methods

\begin{tabular}{|c|c|c|c|c|c|c|c|c|}
\hline $\begin{array}{l}\text { Determination } \\
\text { Statement ID }\end{array}$ & $\begin{array}{c}\text { Implemented } \\
\text { By }\end{array}$ & $\begin{array}{l}\text { Assessment } \\
\text { Boundary }\end{array}$ & $\begin{array}{l}\text { Assessment } \\
\text { Responsibility }\end{array}$ & $\begin{array}{l}\text { Assessment } \\
\text { Methods }\end{array}$ & Selected & $\begin{array}{c}\text { Rationale for } \\
\text { Risk } \\
\text { Acceptance }\end{array}$ & $\begin{array}{l}\text { Frequency of } \\
\text { Assessment }\end{array}$ & $\begin{array}{l}\text { Impact of Not } \\
\text { Implementing }\end{array}$ \\
\hline CM-2(3) $\{1\}$ & SWMan & ISCM-TN & ISCM-Sys & Test & & & & \\
\hline
\end{tabular}

\section{Defect Check Rationale Table}

A failure in effectiveness of this control item results in a defect in one or more of the following defect checks:

\begin{tabular}{|l|l|l|l|}
\hline $\begin{array}{c}\text { Determination } \\
\text { Statement ID }\end{array}$ & $\begin{array}{c}\text { Defect } \\
\text { Check ID }\end{array}$ & $\begin{array}{r}\text { Rationale } \\
\text { If an [organization-defined measure] for this defect check is above [the organization- } \\
\text { defined threshold], then defects in maintaining an adequate number of prior software } \\
\text { baseline versions to support rollback related to this control item might be the cause of } \\
\text { the defect, i.e.,... }\end{array}$ \\
\hline CM-2(3)\{1\} & $\begin{array}{l}\text { SWAM- } \\
\text { L05 }\end{array}$ & $\begin{array}{l}\text { Number of prior } \\
\text { versions of installed } \\
\text { software inadequate }\end{array}$ & lack of prior versions of installed software to enable rollback and recovery. \\
\hline
\end{tabular}




\subsubsection{Control Item CM-2(7)(a): BASELINE CONFIGURATION | CONFIGURE SYSTEMS, COMPONENTS, OR DEVICES FOR HIGH-RISK AREAS}

\section{Control Item Text}

The organization:

(a) Issues [Assignment: organization-defined information systems, system components, or devices] with [Assignment: organization-defined configurations] to individuals traveling to locations that the organization deems to be of significant risk.

\section{Determination Statement 1}

\begin{tabular}{|l|l|}
\hline $\begin{array}{c}\text { Determination } \\
\text { Statement ID }\end{array}$ & \multicolumn{1}{c|}{ Determination Statement Text } \\
\hline $\mathrm{CM}-2(7)(\mathrm{a})\{1\}$ & $\begin{array}{l}\text { Determine if the organization: issues [Assignment: organization-defined information systems, system components, or } \\
\text { devices] with [Assignment: organization-defined configurations] to individuals traveling to locations that the organization } \\
\text { deems to be of significant risk. }\end{array}$ \\
\hline
\end{tabular}

\section{Roles and Assessment Methods}

\begin{tabular}{|c|c|c|c|c|c|c|c|c|}
\hline $\begin{array}{l}\text { Determination } \\
\text { Statement ID }\end{array}$ & $\begin{array}{c}\text { Implemented } \\
\text { By }\end{array}$ & $\begin{array}{c}\text { Assessment } \\
\text { Boundary }\end{array}$ & $\begin{array}{l}\text { Assessment } \\
\text { Responsibility }\end{array}$ & $\begin{array}{c}\text { Assessment } \\
\text { Methods }\end{array}$ & Selected & $\begin{array}{c}\text { Rationale for } \\
\text { Risk } \\
\text { Acceptance }\end{array}$ & $\begin{array}{l}\text { Frequency of } \\
\text { Assessment }\end{array}$ & $\begin{array}{l}\text { Impact of Not } \\
\text { Implementing }\end{array}$ \\
\hline CM-2(7)(a)\{1\} & SWMan & ISCM-TN & ISCM-Sys & Test & & & & \\
\hline
\end{tabular}




\section{Defect Check Rationale Table}

A failure in effectiveness of this control item results in a defect in one or more of the following defect checks:

\begin{tabular}{|l|l|l|l|}
\hline $\begin{array}{c}\text { Determination } \\
\text { Statement ID }\end{array}$ & $\begin{array}{c}\text { Defect } \\
\text { Check ID }\end{array}$ & $\begin{array}{c}\text { Rationale } \\
\text { If an [organization-defined measure] for this defect check is above [the organization- } \\
\text { defined threshold], then defects in issuing [Assignment: organization-defined } \\
\text { information systems, system components, or devices] with [Assignment: } \\
\text { organization-defined configurations] to individuals traveling to locations that the } \\
\text { organization deems to be of significant risk related to this control item might be the } \\
\text { cause of the defect, i.e., ... }\end{array}$ \\
\hline CM-2(7)(a)\{1\} & $\begin{array}{l}\text { SWAM- } \\
\text { L04 }\end{array}$ & $\begin{array}{l}\text { Devices moving in/out } \\
\text { of protective boundaries } \\
\text { not in policy compliance }\end{array}$ & $\begin{array}{l}\text { devices' software not being adequately strengthened and/or sanitized for movement into } \\
\text { or out of protective boundaries. }\end{array}$ \\
\hline
\end{tabular}




\subsubsection{Control Item CM-2(7)(b): BASELINE CONFIGURATION | CONFIGURE SYSTEMS, COMPONENTS, OR DEVICES FOR HIGH-RISK AREAS}

\section{Control Item Text}

The organization:

(b) Applies [Assignment: organization-defined security safeguards] to the devices when the individuals return.

\section{Determination Statement 1}

\begin{tabular}{|l|l|}
\hline $\begin{array}{l}\text { Determination Statement } \\
\text { ID }\end{array}$ & \multicolumn{1}{c|}{ Determination Statement Text } \\
\hline $\mathrm{CM}-2(7)(\mathrm{b})\{1\}$ & $\begin{array}{l}\text { Determine if the organization: applies [Assignment: organization-defined security safeguards] to the devices when } \\
\text { the individuals return. }\end{array}$ \\
\hline
\end{tabular}

Roles and Assessment Methods

\begin{tabular}{|l|l|l|l|l|l|l|l|l|}
\hline $\begin{array}{c}\text { Determination } \\
\text { Statement ID }\end{array}$ & $\begin{array}{c}\text { Implemented } \\
\text { By }\end{array}$ & $\begin{array}{c}\text { Assessment } \\
\text { Boundary }\end{array}$ & $\begin{array}{c}\text { Assessment } \\
\text { Responsibility }\end{array}$ & $\begin{array}{c}\text { Assessment } \\
\text { Methods }\end{array}$ & Selected & $\begin{array}{c}\text { Rationale for } \\
\text { Risk } \\
\text { Acceptance }\end{array}$ & $\begin{array}{c}\text { Frequency of } \\
\text { Assessment }\end{array}$ & $\begin{array}{c}\text { Impact of Not } \\
\text { Implementing }\end{array}$ \\
\hline CM-2(7)(b)\{1\} & SWMan & ISCM-TN & ISCM-Sys & Test & & & & \\
\hline
\end{tabular}

\section{Defect Check Rationale Table}

A failure in effectiveness of this control item results in a defect in one or more of the following defect checks:

\begin{tabular}{|l|l|l|l|}
\hline $\begin{array}{c}\text { Determination } \\
\text { Statement ID }\end{array}$ & $\begin{array}{c}\text { Defect } \\
\text { Check ID }\end{array}$ & Defect Check Name & $\begin{array}{c}\text { Rationale } \\
\text { If an [organization-defined measure] for this defect check is above [the organization- } \\
\text { defined threshold], then defects in applying [Assignment: organization-defined } \\
\text { security safeguards] to the devices when the individuals return related to this } \\
\text { control item might be the cause of the defect, i.e.,... }\end{array}$ \\
\hline CM-2(7)(b)\{1\} & $\begin{array}{l}\text { SWAM- } \\
\text { L04 }\end{array}$ & $\begin{array}{l}\text { Devices moving in/out of } \\
\text { protective boundaries not } \\
\text { in policy compliance }\end{array}$ & $\begin{array}{l}\text { devices' software not being adequately strengthened and/or sanitized for movement } \\
\text { into or out of protective boundaries. }\end{array}$ \\
\hline
\end{tabular}




\subsubsection{Control Item CM-7(1)(a): LEAST FUNCTIONALITY | PERIODIC REVIEW}

\section{Control Item Text}

The organization:

(a) Reviews the information system [Assignment: organization-defined frequency] to identify unnecessary and/or nonsecure functions, ports, protocols, and services.

\section{Determination Statement 1}

\begin{tabular}{|l|l|}
\hline $\begin{array}{c}\text { Determination } \\
\text { Statement ID }\end{array}$ & Determination Statement Text \\
\hline $\mathrm{CM}-7(1)(\mathrm{a})\{1\}$ & $\begin{array}{l}\text { Determine if the organization: reviews the system } \text { installed software } \text { [Assignment: organization-defined frequency] to } \\
\text { identify unnecessary and/or nonsecure functions and services. }\end{array}$ \\
\hline
\end{tabular}

\section{Roles and Assessment Methods}

\begin{tabular}{|c|c|c|c|c|c|c|c|c|}
\hline $\begin{array}{l}\text { Determination } \\
\text { Statement ID }\end{array}$ & $\begin{array}{c}\text { Implemented } \\
\text { By }\end{array}$ & $\begin{array}{l}\text { Assessment } \\
\text { Boundary }\end{array}$ & $\begin{array}{l}\text { Assessment } \\
\text { Responsibility }\end{array}$ & $\begin{array}{l}\text { Assessment } \\
\text { Methods }\end{array}$ & Selected & $\begin{array}{c}\text { Rationale for } \\
\text { Risk } \\
\text { Acceptance }\end{array}$ & $\begin{array}{l}\text { Frequency of } \\
\text { Assessment }\end{array}$ & $\begin{array}{l}\text { Impact of Not } \\
\text { Implementing }\end{array}$ \\
\hline CM-7(1)(a)\{1\} & ISCM-Ops & ISCM-TN & ISCM-Sys & Test & & & & \\
\hline
\end{tabular}




\section{Defect Check Rationale Table}

A failure in effectiveness of this control item results in a defect in one or more of the following defect checks:

\begin{tabular}{|l|l|l|l|}
\hline $\begin{array}{c}\text { Determination } \\
\text { Statement ID }\end{array}$ & $\begin{array}{c}\text { Defect } \\
\text { Check ID }\end{array}$ & $\begin{array}{c}\text { Defect Check } \\
\text { Name }\end{array}$ & $\begin{array}{c}\text { Rationale } \\
\text { If an [organization-defined measure] for this defect check is above [the organization-defined } \\
\text { threshold], then defects in reviewing the system } \text { [installed software\} often enough to } \\
\text { identify unnecessary and/or nonsecure functions and services related to this control item } \\
\text { might be the cause of the defect, i.e., ... }\end{array}$ \\
\hline CM-7(1)(a)\{1\} & $\begin{array}{l}\text { SWAM- } \\
\text { L07 }\end{array}$ & $\begin{array}{l}\text { Business need of } \\
\text { software not } \\
\text { recently verified }\end{array}$ & $\begin{array}{l}\text { the presence of software without a recently verified need, resulting in an increase in the attack } \\
\text { surface without associated organizational value. }\end{array}$ \\
\hline CM-7(1)(a)\{1\} & $\begin{array}{l}\text { SWAM- } \\
\text { L08 }\end{array}$ & $\begin{array}{l}\text { Unused software } \\
\text { present }\end{array}$ & the presence of unneeded software, resulting in an increase in the attack surface. \\
\hline
\end{tabular}




\subsubsection{Control Item CM-7(1)(b): LEAST FUNCTIONALITY | PERIODIC REVIEW}

\section{Control Item Text}

The organization:

(b) Disables [Assignment: organization-defined functions, ports, protocols, and services within the information system deemed to be unnecessary and/or nonsecure].

\section{Determination Statement 1}

\begin{tabular}{|l|l|}
\hline $\begin{array}{c}\text { Determination } \\
\text { Statement ID }\end{array}$ & \multicolumn{1}{c|}{ Determination Statement Text } \\
\hline CM-7(1)(b)\{1\} & $\begin{array}{l}\text { Determine if the organization: disables [Assignment: organization-defined \{installed software\} functions and services } \\
\text { within the system deemed to be unnecessary and/or nonsecure]. }\end{array}$ \\
\hline
\end{tabular}

\section{Roles and Assessment Methods}

\begin{tabular}{|c|c|c|c|c|c|c|c|c|}
\hline $\begin{array}{c}\text { Determination } \\
\text { Statement ID }\end{array}$ & $\begin{array}{c}\text { Implemented } \\
\text { By }\end{array}$ & $\begin{array}{l}\text { Assessment } \\
\text { Boundary }\end{array}$ & $\begin{array}{c}\text { Assessment } \\
\text { Responsibility }\end{array}$ & $\begin{array}{l}\text { Assessment } \\
\text { Methods }\end{array}$ & Selected & $\begin{array}{c}\text { Rationale for } \\
\text { Risk } \\
\text { Acceptance }\end{array}$ & $\begin{array}{l}\text { Frequency of } \\
\text { Assessment }\end{array}$ & $\begin{array}{l}\text { Impact of Not } \\
\text { Implementing }\end{array}$ \\
\hline CM-7(1)(b)\{1\} & DSM & ISCM-TN & ISCM-Sys & Test & & & & \\
\hline
\end{tabular}




\section{Defect Check Rationale Table}

A failure in effectiveness of this control item results in a defect in one or more of the following defect checks:

\begin{tabular}{|c|c|c|c|}
\hline $\begin{array}{l}\text { Determination } \\
\text { Statement ID }\end{array}$ & $\begin{array}{c}\text { Defect } \\
\text { Check ID }\end{array}$ & Defect Check Name & $\begin{array}{l}\text { Rationale } \\
\text { If an [organization-defined measure] for this defect check is above [the organization- } \\
\text { defined threshold], then defects in disabling specified functions and services } \\
\text { within the system deemed to be unnecessary and/or nonsecure related to this } \\
\text { control item might be the cause of the defect, i.e., ... }\end{array}$ \\
\hline $\mathrm{CM}-7(1)(\mathrm{b})\{1\}$ & $\begin{array}{l}\text { SWAM- } \\
\text { F01 }\end{array}$ & $\begin{array}{l}\text { Unauthorized software } \\
\text { executes }\end{array}$ & the execution of unauthorized software. \\
\hline CM-7(1)(b)\{1\} & $\begin{array}{l}\text { SWAM- } \\
\text { F02 }\end{array}$ & $\begin{array}{l}\text { Unauthorized software } \\
\text { installer }\end{array}$ & the execution of software not installed by an authorized installer. \\
\hline $\mathrm{CM}-7(1)(\mathrm{b})\{1\}$ & $\begin{array}{l}\text { SWAM- } \\
\text { F03 }\end{array}$ & $\begin{array}{l}\text { Unauthorized software } \\
\text { directory/folder location }\end{array}$ & the execution of software not loaded from an approved directory/folder location. \\
\hline CM-7(1)(b)\{1\} & $\begin{array}{l}\text { SWAM- } \\
\text { F04 }\end{array}$ & Untrusted core software & lack of core software integrity at start-up. \\
\hline CM-7(1)(b)\{1\} & $\begin{array}{l}\text { SWAM- } \\
\text { L04 }\end{array}$ & $\begin{array}{l}\text { Devices moving in/out of } \\
\text { protective boundaries not in } \\
\text { policy compliance }\end{array}$ & $\begin{array}{l}\text { devices' software not being adequately strengthened and/or sanitized for movement } \\
\text { into or out of protective boundaries. }\end{array}$ \\
\hline
\end{tabular}




\subsubsection{Control Item CM-7(2): LEAST FUNCTIONALITY | PREVENT PROGRAM EXECUTION}

\section{Control Item Text}

The information system prevents program execution in accordance with [Selection (one or more): [Assignment: organization-defined policies regarding software program usage and restrictions]; rules authorizing the terms and conditions of software program usage].

\section{Determination Statement 1}

\begin{tabular}{|l|l|}
\hline $\begin{array}{c}\text { Determination } \\
\text { Statement ID }\end{array}$ & \multicolumn{1}{c|}{ Determination Statement Text } \\
\hline $\mathrm{CM}-7(2)\{1\}$ & $\begin{array}{l}\text { Determine if the organization: prevents \{installed software\} program execution in accordance with [Selection (one or more): } \\
\text { [Assignment: organization-defined policies regarding software program usage and restrictions]; rules authorizing the terms } \\
\text { and conditions of software program usage]. }\end{array}$ \\
\hline
\end{tabular}

\section{Roles and Assessment Methods}

\begin{tabular}{|c|c|c|c|c|c|c|c|c|}
\hline $\begin{array}{c}\text { Determination } \\
\text { Statement ID }\end{array}$ & $\begin{array}{c}\text { Implemented } \\
\text { By }\end{array}$ & $\begin{array}{l}\text { Assessment } \\
\text { Boundary }\end{array}$ & $\begin{array}{l}\text { Assessment } \\
\text { Responsibility }\end{array}$ & $\begin{array}{c}\text { Assessment } \\
\text { Methods }\end{array}$ & Selected & $\begin{array}{c}\text { Rationale for } \\
\text { Risk } \\
\text { Acceptance }\end{array}$ & $\begin{array}{l}\text { Frequency of } \\
\text { Assessment }\end{array}$ & $\begin{array}{l}\text { Impact of Not } \\
\text { Implementing }\end{array}$ \\
\hline CM-7(2)\{1\} & ISCM-Ops & ISCM-TN & ISCM-Sys & Test & & & & \\
\hline
\end{tabular}




\section{Defect Check Rationale Table}

A failure in effectiveness of this control item results in a defect in one or more of the following defect checks:

\begin{tabular}{|l|l|l|l|}
\hline $\begin{array}{c}\text { Determination } \\
\text { Statement ID }\end{array}$ & $\begin{array}{c}\text { Defect } \\
\text { Check ID }\end{array}$ & Defect Check Name & $\begin{array}{c}\text { Rationale } \\
\text { If an [organization-defined measure] for this defect check is above [the organization- } \\
\text { defined threshold], then defects in preventing finstalled software\} program } \\
\text { execution as specified related to this control item might be the cause of the defect, } \\
\text { i.e.,... }\end{array}$ \\
\hline CM-7(2)\{1\} & $\begin{array}{l}\text { SWAM- } \\
\text { F01 }\end{array}$ & $\begin{array}{l}\text { Unauthorized software } \\
\text { executes }\end{array}$ & the execution of unauthorized software. \\
\hline CM-7(2)\{1\} & $\begin{array}{l}\text { SWAM- } \\
\text { F02 }\end{array}$ & $\begin{array}{l}\text { Unauthorized software } \\
\text { installer }\end{array}$ & the execution of software not installed by an authorized installer. \\
\hline CM-7(2)\{1\} & $\begin{array}{l}\text { SWAM- } \\
\text { F03 }\end{array}$ & $\begin{array}{l}\text { Unauthorized software } \\
\text { directory/folder location }\end{array}$ & the execution of software not loaded from an approved directory/folder location. \\
\hline
\end{tabular}




\subsubsection{Control Item CM-7(4)(a): LEAST FUNCTIONALITY | UNAUTHORIZED SOFTWARE / BLACKLISTING}

\section{Control Item Text}

The organization:

(a) Identifies [Assignment: organization-defined software programs not authorized to execute on the information system].

\section{Determination Statement 1}

\begin{tabular}{|l|l|}
\hline $\begin{array}{l}\text { Determination Statement } \\
\text { ID }\end{array}$ & \multicolumn{1}{c|}{ Determination Statement Text } \\
\hline $\mathrm{CM}-7(4)(\mathrm{a})\{1\}$ & $\begin{array}{l}\text { Determine if the organization: identifies [Assignment: organization-defined software programs not authorized to } \\
\text { execute on the system]. }\end{array}$ \\
\hline
\end{tabular}

\section{Roles and Assessment Methods}

\begin{tabular}{|c|c|c|c|c|c|c|c|c|}
\hline $\begin{array}{c}\text { Determination } \\
\text { Statement ID }\end{array}$ & $\begin{array}{c}\text { Implemented } \\
\text { By }\end{array}$ & $\begin{array}{c}\text { Assessment } \\
\text { Boundary }\end{array}$ & $\begin{array}{l}\text { Assessment } \\
\text { Responsibility }\end{array}$ & $\begin{array}{c}\text { Assessment } \\
\text { Methods }\end{array}$ & Selected & $\begin{array}{c}\text { Rationale for } \\
\text { Risk } \\
\text { Acceptance }\end{array}$ & $\begin{array}{l}\text { Frequency of } \\
\text { Assessment }\end{array}$ & $\begin{array}{l}\text { Impact of Not } \\
\text { Implementing }\end{array}$ \\
\hline CM-7(4)(a)\{1\} & ISCM-Ops & ISCM-TN & ISCM-Sys & Test & & & & \\
\hline
\end{tabular}




\section{Defect Check Rationale Table}

A failure in effectiveness of this control item results in a defect in one or more of the following defect checks:

\begin{tabular}{|l|l|l|l|}
\hline $\begin{array}{c}\text { Determination } \\
\text { Statement ID }\end{array}$ & $\begin{array}{l}\text { Defect } \\
\text { Check ID }\end{array}$ & \multicolumn{1}{|c|}{ Defect Check Name } & $\begin{array}{c}\text { Rationale } \\
\text { If an [organization-defined measure] for this defect check is above [the } \\
\text { organization-defined threshold], then defects in identifying specified software } \\
\text { programs not authorized to execute related to this control item might be the } \\
\text { cause of the defect, i.e., ... }\end{array}$ \\
\hline CM-7(4)(a)\{1\} & $\begin{array}{l}\text { SWAM- } \\
\text { F01 }\end{array}$ & $\begin{array}{l}\text { Unauthorized software } \\
\text { executes }\end{array}$ & the execution of unauthorized software. \\
\hline CM-7(4)(a)\{1\} & $\begin{array}{l}\text { SWAM- } \\
\text { F02 }\end{array}$ & $\begin{array}{l}\text { Unauthorized software } \\
\text { installer }\end{array}$ & the execution of software not installed by an authorized installer. \\
\hline CM-7(4)(a)\{1\} & $\begin{array}{l}\text { SWAM- } \\
\text { F03 }\end{array}$ & $\begin{array}{l}\text { Unauthorized software } \\
\text { directory/folder location }\end{array}$ & the execution of software not loaded from an approved directory/folder location. \\
\hline CM-7(4)(a)\{1\} & $\begin{array}{l}\text { SWAM- } \\
\text { F04 }\end{array}$ & Untrusted core software & lack of core software integrity at start-up. \\
\hline CM-7(4)(a)\{1\} & $\begin{array}{l}\text { SWAM- } \\
\text { L04 }\end{array}$ & $\begin{array}{l}\text { Devices moving in/out of } \\
\text { protective boundaries not in } \\
\text { policy compliance }\end{array}$ & $\begin{array}{l}\text { devices' software not being adequately strengthened and/or sanitized for } \\
\text { movement into or out of protective boundaries. }\end{array}$ \\
\hline
\end{tabular}




\subsubsection{Control Item CM-7(4)(b): LEAST FUNCTIONALITY | UNAUTHORIZED SOFTWARE / BLACKLISTING}

\section{Control Item Text}

The organization:

(b) Employs an allow-all, deny-by-exception policy to prohibit the execution of unauthorized software programs on the information system.

\section{Determination Statement 1}

\begin{tabular}{|l|l|}
\hline $\begin{array}{c}\text { Determination } \\
\text { Statement ID }\end{array}$ & \multicolumn{1}{c|}{ Determination Statement Text } \\
\hline $\mathrm{CM}-7(4)(\mathrm{b})\{1\}$ & $\begin{array}{l}\text { Determine if the organization: employs an allow-all, deny-by-exception policy to prohibit the execution of unauthorized } \\
\text { software programs on the system. }\end{array}$ \\
\hline
\end{tabular}

\section{Roles and Assessment Methods}

\begin{tabular}{|c|c|c|c|c|c|c|c|c|}
\hline $\begin{array}{l}\text { Determination } \\
\text { Statement ID }\end{array}$ & $\begin{array}{c}\text { Implemented } \\
\text { By }\end{array}$ & $\begin{array}{c}\text { Assessment } \\
\text { Boundary }\end{array}$ & $\begin{array}{l}\text { Assessment } \\
\text { Responsibility }\end{array}$ & $\begin{array}{c}\text { Assessment } \\
\text { Methods }\end{array}$ & Selected & $\begin{array}{c}\text { Rationale for } \\
\text { Risk } \\
\text { Acceptance }\end{array}$ & $\begin{array}{l}\text { Frequency of } \\
\text { Assessment }\end{array}$ & $\begin{array}{l}\text { Impact of Not } \\
\text { Implementing }\end{array}$ \\
\hline CM-7(4)(b)\{1\} & RskEx & ISCM-TN & ISCM-Sys & Test & & & & \\
\hline
\end{tabular}




\section{Defect Check Rationale Table}

A failure in effectiveness of this control item results in a defect in one or more of the following defect checks:

\begin{tabular}{|l|l|l|l|}
\hline $\begin{array}{c}\text { Determination } \\
\text { Statement ID }\end{array}$ & $\begin{array}{l}\text { Defect } \\
\text { Check ID }\end{array}$ & \multicolumn{1}{|c|}{ Defect Check Name } & $\begin{array}{l}\text { Rationale } \\
\text { If an [organization-defined measure] for this defect check is above [the organization- } \\
\text { defined threshold], then defects in employing an allow-all, deny-by-exception } \\
\text { policy to prohibit the execution of unauthorized software programs } \\
\text { (blacklisting) related to this control item might be the cause of the defect, i.e., ... }\end{array}$ \\
\hline CM-7(4)(b)\{1\} & $\begin{array}{l}\text { SWAM- } \\
\text { F01 }\end{array}$ & $\begin{array}{l}\text { Unauthorized software } \\
\text { executes }\end{array}$ & the execution of unauthorized software. \\
\hline CM-7(4)(b)\{1\} & $\begin{array}{l}\text { SWAM- } \\
\text { F02 }\end{array}$ & $\begin{array}{l}\text { Unauthorized software } \\
\text { installer }\end{array}$ & the execution of software not installed by an authorized installer. \\
\hline $\mathrm{CM}-7(4)(\mathrm{b})\{1\}$ & $\begin{array}{l}\text { SWAM- } \\
\text { F03 }\end{array}$ & $\begin{array}{l}\text { Unauthorized software } \\
\text { directory/folder location }\end{array}$ & the execution of software not loaded from an approved directory/folder location. \\
\hline $\mathrm{CM}-7(4)(b)\{1\}$ & $\begin{array}{l}\text { SWAM- } \\
\text { F04 }\end{array}$ & Untrusted core software & lack of core software integrity at start-up. \\
\hline $\mathrm{CM}-7(4)(\mathrm{b})\{1\}$ & $\begin{array}{l}\text { SWAM- } \\
\text { L04 }\end{array}$ & $\begin{array}{l}\text { Devices moving in/out of } \\
\text { protective boundaries not in } \\
\text { policy compliance }\end{array}$ & $\begin{array}{l}\text { devices' software not being adequately strengthened and/or sanitized for movement } \\
\text { into or out of protective boundaries. }\end{array}$ \\
\hline
\end{tabular}




\subsubsection{Control Item CM-7(4)(c): LEAST FUNCTIONALITY | UNAUTHORIZED SOFTWARE / BLACKLISTING}

\section{Control Item Text}

The organization:

(c) Reviews and updates the list of unauthorized software programs [Assignment: organization-defined frequency].

\section{Determination Statement 1}

\begin{tabular}{|l|l|}
\hline $\begin{array}{c}\text { Determination Statement } \\
\text { ID }\end{array}$ & \multicolumn{1}{c|}{ Determination Statement Text } \\
\hline $\mathrm{CM}-7(4)(\mathrm{c})\{1\}$ & $\begin{array}{l}\text { Determine if the organization: reviews and updates the list of unauthorized software programs [Assignment: } \\
\text { organization-defined frequency]. }\end{array}$ \\
\hline
\end{tabular}

\section{Roles and Assessment Methods}

\begin{tabular}{|l|l|l|l|l|l|l|l|l|}
\hline $\begin{array}{c}\text { Determination } \\
\text { Statement ID }\end{array}$ & $\begin{array}{c}\text { Implemented } \\
\text { By }\end{array}$ & $\begin{array}{c}\text { Assessment } \\
\text { Boundary }\end{array}$ & $\begin{array}{c}\text { Assessment } \\
\text { Responsibility }\end{array}$ & $\begin{array}{c}\text { Assessment } \\
\text { Methods }\end{array}$ & Selected & $\begin{array}{c}\text { Rationale for } \\
\text { Risk } \\
\text { Acceptance }\end{array}$ & $\begin{array}{c}\text { Frequency of } \\
\text { Assessment }\end{array}$ & $\begin{array}{c}\text { Impact of Not } \\
\text { Implementing }\end{array}$ \\
\hline CM-7(4)(c) $\{1\}$ & DSM & ISCM-TN & ISCM-Sys & Test & & & & \\
\hline
\end{tabular}

\section{Defect Check Rationale Table}

A failure in effectiveness of this control item results in a defect in one or more of the following defect checks:

\begin{tabular}{|l|l|l|l|}
\hline $\begin{array}{c}\text { Determination } \\
\text { Statement ID }\end{array}$ & $\begin{array}{c}\text { Defect } \\
\text { Check ID }\end{array}$ & $\begin{array}{c}\text { Defect Check } \\
\text { Name }\end{array}$ & $\begin{array}{c}\text { Rationale } \\
\text { If an [organization-defined measure] for this defect check is above [the organization-defined } \\
\text { threshold], then defects in reviewing and updating the list of unauthorized software } \\
\text { programs frequently enough related to this control item might be the cause of the defect, } \\
\text { i.e.,.... }\end{array}$ \\
\hline CM-7(4)(c)\{1\} & $\begin{array}{l}\text { SWAM- } \\
\text { L07 }\end{array}$ & $\begin{array}{l}\text { Business need of } \\
\text { software not } \\
\text { recently verified }\end{array}$ & $\begin{array}{l}\text { the presence of software without a recently verified need, resulting in an increase in the } \\
\text { attack surface without associated organizational value. }\end{array}$ \\
\hline
\end{tabular}




\subsubsection{Control Item CM-8(1): INFORMATION SYSTEM COMPONENT INVENTORY | UPDATES DURING} INSTALLATIONS / REMOVALS

\section{Control Item Text}

The organization updates the inventory of information system components as an integral part of component installations, removals, and information system updates.

\section{Determination Statement 1}

\begin{tabular}{|l|l|}
\hline $\begin{array}{c}\text { Determination } \\
\text { Statement ID }\end{array}$ & \multicolumn{1}{c|}{ Determination Statement Text } \\
\hline $\mathrm{CM}-8(1)\{1\}$ & $\begin{array}{l}\text { Determine if the organization: updates the inventory of system } \text { installed software }\} \text { components as an integral part of } \\
\text { component installations, removals, and system updates. }\end{array}$ \\
\hline
\end{tabular}

\section{Roles and Assessment Methods}

\begin{tabular}{|c|c|c|c|c|c|c|c|c|}
\hline $\begin{array}{l}\text { Determination } \\
\text { Statement ID }\end{array}$ & $\begin{array}{c}\text { Implemented } \\
\text { By }\end{array}$ & $\begin{array}{l}\text { Assessment } \\
\text { Boundary }\end{array}$ & $\begin{array}{l}\text { Assessment } \\
\text { Responsibility }\end{array}$ & $\begin{array}{l}\text { Assessment } \\
\text { Methods }\end{array}$ & Selected & $\begin{array}{c}\text { Rationale for } \\
\text { Risk } \\
\text { Acceptance }\end{array}$ & $\begin{array}{l}\text { Frequency of } \\
\text { Assessment }\end{array}$ & $\begin{array}{l}\text { Impact of Not } \\
\text { Implementing }\end{array}$ \\
\hline $\mathrm{CM}-8(1)\{1\}$ & ISCM-Sys & ISCM-TN & ISCM-Sys & Test & & & & \\
\hline
\end{tabular}




\section{Defect Check Rationale Table}

A failure in effectiveness of this control item results in a defect in one or more of the following defect checks:

\begin{tabular}{|c|c|c|c|}
\hline $\begin{array}{l}\text { Determination } \\
\text { Statement ID }\end{array}$ & $\begin{array}{c}\text { Defect } \\
\text { Check ID }\end{array}$ & $\begin{array}{l}\text { Defect Check } \\
\text { Name }\end{array}$ & $\begin{array}{l}\text { Rationale } \\
\text { If an [organization-defined measure] for this defect check is above [the organization-defined } \\
\text { threshold], then defects in updating the inventory of system \{installed software\} components } \\
\text { as an integral part of component installations, removals, and system updates related to this } \\
\text { control item might be the cause of the defect, i.e., ... }\end{array}$ \\
\hline CM-8(1)\{1\} & $\begin{array}{l}\text { SWAM- } \\
\text { L11 }\end{array}$ & \begin{tabular}{|l|} 
Required \\
software not \\
present
\end{tabular} & absence of required software. \\
\hline CM-8(1)\{1\} & $\begin{array}{l}\text { SWAM- } \\
\text { Q04 }\end{array}$ & $\begin{array}{l}\text { Poor } \\
\text { timeliness } \\
\text { metric }\end{array}$ & poor timeliness of overall ISCM reporting. \\
\hline
\end{tabular}




\subsubsection{Control Item CM-8(5): INFORMATION SYSTEM COMPONENT INVENTORY | NO DUPLICATE ACCOUNTING OF COMPONENTS}

\section{Control Item Text}

The organization verifies that all components within the authorization boundary of the information system are not duplicated in other information system inventories.

\section{Determination Statement 1}

\begin{tabular}{|l|l|}
\hline $\begin{array}{c}\text { Determination } \\
\text { Statement ID }\end{array}$ & \multicolumn{1}{c|}{ Determination Statement Text } \\
\hline $\mathrm{CM}-8(5)\{1\}$ & $\begin{array}{l}\text { Determine if the organization: verifies that all }\{\text { installed software }\} \text { components within the authorization boundary of the } \\
\text { system are not duplicated in other system inventories. }\end{array}$ \\
\hline
\end{tabular}

\section{Roles and Assessment Methods}

\begin{tabular}{|c|c|c|c|c|c|c|c|c|}
\hline $\begin{array}{l}\text { Determination } \\
\text { Statement ID }\end{array}$ & $\begin{array}{c}\text { Implemented } \\
\text { By }\end{array}$ & $\begin{array}{l}\text { Assessment } \\
\text { Boundary }\end{array}$ & $\begin{array}{l}\text { Assessment } \\
\text { Responsibility }\end{array}$ & $\begin{array}{l}\text { Assessment } \\
\text { Methods }\end{array}$ & Selected & $\begin{array}{c}\text { Rationale for } \\
\text { Risk } \\
\text { Acceptance }\end{array}$ & $\begin{array}{l}\text { Frequency of } \\
\text { Assessment }\end{array}$ & $\begin{array}{l}\text { Impact of Not } \\
\text { Implementing }\end{array}$ \\
\hline CM-8(5)\{1\} & ISCM-Sys & ISCM-TN & ISCM-Sys & Test & & & & \\
\hline
\end{tabular}

\section{Defect Check Rationale Table}

A failure in effectiveness of this control item results in a defect in one or more of the following defect checks:

\begin{tabular}{|l|l|l|l|}
\hline $\begin{array}{c}\text { Determination } \\
\text { Statement ID }\end{array}$ & $\begin{array}{c}\text { Defect } \\
\text { Check ID }\end{array}$ & $\begin{array}{c}\text { Rationale } \\
\text { Defect Check Name } \\
\text { If an [organization-defined measure] for this defect check is above [the organization- } \\
\text { defined threshold], then defects in verifying that all \{installed software\} components } \\
\text { within the authorization boundary of the system are not duplicated in other } \\
\text { system inventories related to this control item might be the cause of the defect, i.e.,... }\end{array}$ \\
\hline CM-8(5)\{1\} & $\begin{array}{l}\text { SWAM- } \\
\text { L09 }\end{array}$ & $\begin{array}{l}\text { Device-software-item } \\
\text { assignment to } \\
\text { authorization boundary is } \\
\text { not 1:1 }\end{array}$ & unclear management responsibility that could lead to unmanaged components. \\
\hline
\end{tabular}




\subsubsection{Control Item MA-3(1): MAINTENANCE TOOLS | INSPECT TOOLS}

\section{Control Item Text}

The organization inspects the maintenance tools carried into a facility by maintenance personnel for improper or unauthorized modifications.

\section{Determination Statement 1}

\begin{tabular}{|l|l|}
\hline $\begin{array}{c}\text { Determination } \\
\text { Statement ID }\end{array}$ & \multicolumn{1}{c|}{ Determination Statement Text } \\
\hline MA-3(1)\{1\} & $\begin{array}{l}\text { Determine if the organization: inspects the maintenance tools with } \text { installed software } \text { carried into a facility by } \\
\text { maintenance personnel for improper or unauthorized modifications to the }\{\text { installed software\}. }\end{array}$ \\
\hline
\end{tabular}

\section{Roles and Assessment Methods}

\begin{tabular}{|c|c|c|c|c|c|c|c|c|}
\hline $\begin{array}{c}\text { Determination } \\
\text { Statement ID }\end{array}$ & $\begin{array}{c}\text { Implemented } \\
\text { By }\end{array}$ & $\begin{array}{c}\text { Assessment } \\
\text { Boundary }\end{array}$ & $\begin{array}{l}\text { Assessment } \\
\text { Responsibility }\end{array}$ & $\begin{array}{l}\text { Assessment } \\
\text { Methods }\end{array}$ & Selected & $\begin{array}{c}\text { Rationale for } \\
\text { Risk } \\
\text { Acceptance }\end{array}$ & $\begin{array}{l}\text { Frequency of } \\
\text { Assessment }\end{array}$ & $\begin{array}{l}\text { Impact of Not } \\
\text { Implementing }\end{array}$ \\
\hline MA-3(1)\{1\} & SWMan & ISCM-TN & ISCM-Sys & Test & & & & \\
\hline
\end{tabular}

\section{Defect Check Rationale Table}

A failure in effectiveness of this control item results in a defect in one or more of the following defect checks:

\begin{tabular}{|l|l|l|l|}
\hline $\begin{array}{c}\text { Determination } \\
\text { Statement ID }\end{array}$ & $\begin{array}{c}\text { Defect } \\
\text { Check ID }\end{array}$ & $\begin{array}{c}\text { Rationale } \\
\text { Defect Check Name } \\
\text { If an [organization-defined measure] for this defect check is above [the organization- } \\
\text { defined threshold], then defects in inspecting the maintenance tools with \{installed } \\
\text { software\} carried into a facility by maintenance personnel for improper or } \\
\text { unauthorized modifications to the \{installed software\} related to this control item } \\
\text { might be the cause of the defect, i.e., ... }\end{array}$ \\
\hline MA-3(1)\{1\} & $\begin{array}{l}\text { SWAM- } \\
\text { L04 }\end{array}$ & $\begin{array}{l}\text { Devices moving in/out of } \\
\text { protective boundaries } \\
\text { not in policy compliance }\end{array}$ & $\begin{array}{l}\text { devices' software not being adequately strengthened and/or sanitized for movement into } \\
\text { or out of protective boundaries. }\end{array}$ \\
\hline
\end{tabular}




\subsubsection{Control Item MA-3(2): MAINTENANCE TOOLS | INSPECT MEDIA}

\section{Control Item Text}

The organization checks media containing diagnostic and test programs for malicious code before the media are used in the information system.

\section{Determination Statement 1}

\begin{tabular}{|l|l|}
\hline $\begin{array}{c}\text { Determination } \\
\text { Statement ID }\end{array}$ & \multicolumn{1}{c|}{ Determination Statement Text } \\
\hline MA-3(2)\{1\} & $\begin{array}{l}\text { Determine if the organization: checks media containing diagnostic and test programs for malicious code before the } \\
\text { media are used in the system. }\end{array}$ \\
\hline
\end{tabular}

\section{Roles and Assessment Methods}

\begin{tabular}{|c|c|c|c|c|c|c|c|c|}
\hline $\begin{array}{l}\text { Determination } \\
\text { Statement ID }\end{array}$ & $\begin{array}{c}\text { Implemented } \\
\text { By }\end{array}$ & $\begin{array}{l}\text { Assessment } \\
\text { Boundary }\end{array}$ & $\begin{array}{l}\text { Assessment } \\
\text { Responsibility }\end{array}$ & $\begin{array}{l}\text { Assessment } \\
\text { Methods }\end{array}$ & Selected & $\begin{array}{c}\text { Rationale for } \\
\text { Risk } \\
\text { Acceptance }\end{array}$ & $\begin{array}{l}\text { Frequency of } \\
\text { Assessment }\end{array}$ & $\begin{array}{l}\text { Impact of Not } \\
\text { Implementing }\end{array}$ \\
\hline MA-3(2) $\{1\}$ & SWMan & ISCM-TN & ISCM-Sys & Test & & & & \\
\hline
\end{tabular}

\section{Defect Check Rationale Table}

A failure in effectiveness of this control item results in a defect in one or more of the following defect checks:

\begin{tabular}{|l|l|l|l|}
\hline $\begin{array}{c}\text { Determination } \\
\text { Statement ID }\end{array}$ & $\begin{array}{c}\text { Defect } \\
\text { Check ID }\end{array}$ & \multicolumn{1}{|c|}{$\begin{array}{c}\text { Rationale } \\
\text { Defect Check Name } \\
\text { If an [organization-defined measure] for this defect check is above [the organization- } \\
\text { defined threshold], then defects in checking media containing diagnostic and test } \\
\text { programs for malicious code before the media are used in the system related to } \\
\text { this control item might be the cause of the defect, i.e., ... }\end{array}$} \\
\hline MA-3(2)\{1\} & $\begin{array}{l}\text { SWAM- } \\
\text { F01 }\end{array}$ & $\begin{array}{l}\text { Unauthorized software } \\
\text { executes }\end{array}$ & the execution of unauthorized software. \\
\hline MA-3(2)\{1\} & $\begin{array}{l}\text { SWAM- } \\
\text { L04 }\end{array}$ & $\begin{array}{l}\text { Devices moving in/out of } \\
\text { protective boundaries not } \\
\text { in policy compliance }\end{array}$ & $\begin{array}{l}\text { devices' software not being adequately strengthened and/or sanitized for movement } \\
\text { into or out of protective boundaries. }\end{array}$ \\
\hline
\end{tabular}




\subsubsection{Control Item SC-18(a): MOBILE CODE}

\section{Control Item Text}

Control: The organization:

a. Defines acceptable and unacceptable mobile code and mobile code technologies.

\section{Determination Statement 1}

\begin{tabular}{|l|l|}
\hline Determination Statement ID & Determination Statement Text \\
\hline SC-18(a)\{1\} & Determine if the organization: defines acceptable and unacceptable mobile code and mobile code technologies. \\
\hline
\end{tabular}

\section{Roles and Assessment Methods}

\begin{tabular}{|c|c|c|c|c|c|c|c|c|}
\hline $\begin{array}{l}\text { Determination } \\
\text { Statement ID }\end{array}$ & $\begin{array}{c}\text { Implemented } \\
\text { By }\end{array}$ & $\begin{array}{l}\text { Assessment } \\
\text { Boundary }\end{array}$ & $\begin{array}{l}\text { Assessment } \\
\text { Responsibility }\end{array}$ & $\begin{array}{l}\text { Assessment } \\
\text { Methods }\end{array}$ & Selected & $\begin{array}{l}\text { Rationale for } \\
\text { Risk } \\
\text { Acceptance }\end{array}$ & $\begin{array}{l}\text { Frequency of } \\
\text { Assessment }\end{array}$ & $\begin{array}{l}\text { Impact of Not } \\
\text { Implementing }\end{array}$ \\
\hline SC-18(a) $\{1\}$ & DSM & ISCM-TN & ISCM-Sys & Test & & & & \\
\hline
\end{tabular}

\section{Defect Check Rationale Table}

A failure in effectiveness of this control item results in a defect in one or more of the following defect checks:

\begin{tabular}{|l|l|l|l|}
\hline $\begin{array}{c}\text { Determination } \\
\text { Statement ID }\end{array}$ & $\begin{array}{c}\text { Defect } \\
\text { Check ID }\end{array}$ & $\begin{array}{c}\text { Refect Check } \\
\text { Name }\end{array}$ & $\begin{array}{c}\text { Rationale } \\
\text { If an [organization-defined measure] for this defect check is above [the organization-defined } \\
\text { threshold], then defects in defining acceptable and unacceptable mobile code and } \\
\text { mobile code technologies related to this control item might be the cause of the defect, i.e., } \\
\ldots\end{array}$ \\
\hline SC-18(a)\{1\} & $\begin{array}{l}\text { SWAM- } \\
\text { F01 }\end{array}$ & $\begin{array}{l}\text { Unauthorized } \\
\text { software executes }\end{array}$ & the execution of unauthorized software. \\
\hline
\end{tabular}




\subsubsection{Control Item SC-18(b): MOBILE CODE}

\section{Control Item Text}

Control: The organization:

b. Establishes usage restrictions and implementation guidance for acceptable mobile code and mobile code technologies.

\section{Determination Statement 1}

\begin{tabular}{|l|l|}
\hline $\begin{array}{c}\text { Determination } \\
\text { Statement ID }\end{array}$ & \multicolumn{1}{c|}{ Determination Statement Text } \\
\hline SC-18(b)\{1\} & $\begin{array}{l}\text { Determine if the organization: establishes usage restrictions and implementation guidance for acceptable mobile code } \\
\text { and mobile code technologies. }\end{array}$ \\
\hline
\end{tabular}

\section{Roles and Assessment Methods}

\begin{tabular}{|c|c|c|c|c|c|c|c|c|}
\hline $\begin{array}{l}\text { Determination } \\
\text { Statement ID }\end{array}$ & $\begin{array}{c}\text { Implemented } \\
\text { By }\end{array}$ & $\begin{array}{l}\text { Assessment } \\
\text { Boundary }\end{array}$ & $\begin{array}{c}\text { Assessment } \\
\text { Responsibility }\end{array}$ & $\begin{array}{c}\text { Assessment } \\
\text { Methods }\end{array}$ & Selected & $\begin{array}{c}\text { Rationale for } \\
\text { Risk } \\
\text { Acceptance }\end{array}$ & $\begin{array}{l}\text { Frequency of } \\
\text { Assessment }\end{array}$ & $\begin{array}{l}\text { Impact of Not } \\
\text { Implementing }\end{array}$ \\
\hline SC-18(b)\{1\} & DSM & ISCM-TN & ISCM-Sys & Test & & & & \\
\hline
\end{tabular}

\section{Defect Check Rationale Table}

A failure in effectiveness of this control item results in a defect in one or more of the following defect checks:

\begin{tabular}{|l|l|l|l|}
\hline $\begin{array}{c}\text { Determination } \\
\text { Statement ID }\end{array}$ & $\begin{array}{c}\text { Defect } \\
\text { Check ID }\end{array}$ & $\begin{array}{c}\text { Rationale } \\
\text { Defect Check } \\
\text { Name }\end{array}$ & $\begin{array}{c}\text { If an [organization-defined measure] for this defect check is above [the organization-defined } \\
\text { threshold], then defects in establishing usage restrictions and implementation guidance } \\
\text { for acceptable mobile code and mobile code technologies related to this control item might } \\
\text { be the cause of the defect, i.e., ... }\end{array}$ \\
\hline SC-18(b)\{1\} & $\begin{array}{l}\text { SWAM- } \\
\text { F01 }\end{array}$ & $\begin{array}{l}\text { Unauthorized } \\
\text { software executes }\end{array}$ & the execution of unauthorized software. \\
\hline
\end{tabular}




\subsubsection{Control Item SC-18(c): MOBILE CODE}

\section{Control Item Text}

Control: The organization:

c. Authorizes, monitors, and controls the use of mobile code within the information system.

\section{Determination Statement 1}

\begin{tabular}{|l|l|}
\hline Determination Statement ID & \multicolumn{1}{c|}{ Determination Statement Text } \\
\hline SC-18(c) $\{1\}$ & Determine if the organization: authorizes, monitors, and controls the use of mobile code within the system. \\
\hline
\end{tabular}

Roles and Assessment Methods

\begin{tabular}{|c|c|c|c|c|c|c|c|c|}
\hline $\begin{array}{l}\text { Determination } \\
\text { Statement ID }\end{array}$ & $\begin{array}{c}\text { Implemented } \\
\text { By }\end{array}$ & $\begin{array}{c}\text { Assessment } \\
\text { Boundary }\end{array}$ & $\begin{array}{l}\text { Assessment } \\
\text { Responsibility }\end{array}$ & $\begin{array}{l}\text { Assessment } \\
\text { Methods }\end{array}$ & Selected & $\begin{array}{l}\text { Rationale for } \\
\text { Risk } \\
\text { Acceptance }\end{array}$ & $\begin{array}{l}\text { Frequency of } \\
\text { Assessment }\end{array}$ & $\begin{array}{l}\text { Impact of Not } \\
\text { Implementing }\end{array}$ \\
\hline SC-18(c) $\{1\}$ & ISCM-Ops & ISCM-TN & ISCM-Sys & Test & & & & \\
\hline
\end{tabular}

\section{Defect Check Rationale Table}

A failure in effectiveness of this control item results in a defect in one or more of the following defect checks:

\begin{tabular}{|l|l|l|l|}
\hline $\begin{array}{c}\text { Determination } \\
\text { Statement ID }\end{array}$ & $\begin{array}{c}\text { Defect } \\
\text { Check ID }\end{array}$ & $\begin{array}{c}\text { Defect Check } \\
\text { Name }\end{array}$ & $\begin{array}{c}\text { Rationale } \\
\text { If an [organization-defined measure] for this defect check is above [the organization-defined } \\
\text { threshold], then defects in authorizing, monitoring, and controlling the use of mobile } \\
\text { code within the system related to this control item might be the cause of the defect, i.e., ... }\end{array}$ \\
\hline SC-18(c)\{1\} & $\begin{array}{l}\text { SWAM- } \\
\text { F01 }\end{array}$ & $\begin{array}{l}\text { Unauthorized } \\
\text { software executes }\end{array}$ & the execution of unauthorized software. \\
\hline
\end{tabular}




\subsubsection{Control Item SI-3(1): MALICIOUS CODE PROTECTION | CENTRAL MANAGEMENT}

\section{Control Item Text}

The organization centrally manages malicious code protection mechanisms.

\section{Determination Statement 1}

\begin{tabular}{|l|c|}
\hline Determination Statement ID & Determination Statement Text \\
\hline SI-3(1)\{1\} & Determine if the organization: centrally manages malicious code protection mechanisms. \\
\hline
\end{tabular}

Roles and Assessment Methods

\begin{tabular}{|l|l|l|l|l|l|l|l|l|}
\hline $\begin{array}{c}\text { Determination } \\
\text { Statement ID }\end{array}$ & $\begin{array}{c}\text { Implemented } \\
\text { By }\end{array}$ & $\begin{array}{c}\text { Assessment } \\
\text { Boundary }\end{array}$ & $\begin{array}{c}\text { Assessment } \\
\text { Responsibility }\end{array}$ & $\begin{array}{c}\text { Assessment } \\
\text { Methods }\end{array}$ & Selected & $\begin{array}{c}\text { Rationale for } \\
\text { Risk } \\
\text { Acceptance }\end{array}$ & $\begin{array}{c}\text { Frequency of } \\
\text { Assessment }\end{array}$ & $\begin{array}{c}\text { Impact of Not } \\
\text { Implementing }\end{array}$ \\
\hline SI-3(1)\{1\} & ISCM-Ops & ISCM-TN & ISCM-Sys & Test & & & & \\
\hline
\end{tabular}

\section{Defect Check Rationale Table}

A failure in effectiveness of this control item results in a defect in one or more of the following defect checks:

\begin{tabular}{|l|l|l|r|}
\hline $\begin{array}{c}\text { Determination } \\
\text { Statement ID }\end{array}$ & $\begin{array}{c}\text { Defect } \\
\text { Check ID }\end{array}$ & $\begin{array}{c}\text { Defect Check } \\
\text { Name }\end{array}$ & $\begin{array}{c}\text { Rationale } \\
\text { If an [organization-defined measure] for this defect check is above [the organization-defined } \\
\text { threshold], then defects in centrally managing malicious code protection mechanisms } \\
\text { related to this control item might be the cause of the defect, i.e., ... }\end{array}$ \\
\hline SI-3(1)\{1\} & $\begin{array}{l}\text { SWAM- } \\
\text { F02 }\end{array}$ & $\begin{array}{l}\text { Unauthorized } \\
\text { software installer }\end{array}$ & the execution of software not installed by an authorized installer. \\
\hline
\end{tabular}




\subsubsection{Control Item SI-3(2): MALICIOUS CODE PROTECTION | AUTOMATIC UPDATES}

\section{Control Item Text}

The information system automatically updates malicious code protection mechanisms.

\section{Determination Statement 1}

\begin{tabular}{|l|l|}
\hline Determination Statement ID & Determination Statement Text \\
\hline $\mathrm{SI}-3(2)\{1\}$ & Determine if the organization: automatically updates malicious code protection mechanisms. \\
\hline
\end{tabular}

Roles and Assessment Methods

\begin{tabular}{|l|l|l|l|l|l|l|l|l|}
\hline $\begin{array}{c}\text { Determination } \\
\text { Statement ID }\end{array}$ & $\begin{array}{c}\text { Implemented } \\
\text { By }\end{array}$ & $\begin{array}{c}\text { Assessment } \\
\text { Boundary }\end{array}$ & $\begin{array}{c}\text { Assessment } \\
\text { Responsibility }\end{array}$ & $\begin{array}{c}\text { Assessment } \\
\text { Methods }\end{array}$ & Selected & $\begin{array}{c}\text { Rationale for } \\
\text { Risk } \\
\text { Acceptance }\end{array}$ & $\begin{array}{c}\text { Frequency of } \\
\text { Assessment }\end{array}$ & $\begin{array}{c}\text { Impact of Not } \\
\text { Implementing }\end{array}$ \\
\hline SI-3(2)\{1\} & ISCM-Ops & ISCM-TN & ISCM-Sys & Test & & & & \\
\hline
\end{tabular}

\section{Defect Check Rationale Table}

A failure in effectiveness of this control item results in a defect in one or more of the following defect checks:

\begin{tabular}{|l|l|l|l|}
\hline $\begin{array}{c}\text { Determination } \\
\text { Statement ID }\end{array}$ & $\begin{array}{c}\text { Defect } \\
\text { Check ID }\end{array}$ & \multicolumn{1}{c|}{$\begin{array}{c}\text { Rationale } \\
\text { Defect Check Name }\end{array}$} & $\begin{array}{c}\text { If an [organization-defined measure] for this defect check is above [the } \\
\text { organization-defined threshold], then defects in automatically updating } \\
\text { malicious code protection mechanisms related to this control item might } \\
\text { be the cause of the defect, i.e.,.... }\end{array}$ \\
\hline SI-3(2)\{1\} & $\begin{array}{l}\text { SWAM- } \\
\text { L03 }\end{array}$ & $\begin{array}{l}\text { Expired actions on software } \\
\text { authorization/deauthorization requests }\end{array}$ & requested changes not being addressed in a timely manner. \\
\hline
\end{tabular}




\subsubsection{Control Item SI-7: SOFTWARE, FIRMWARE, AND INFORMATION INTEGRITY}

\section{Control Item Text}

Control: The organization employs integrity verification tools to detect unauthorized changes to [Assignment:

organization-defined software, firmware, and information].

\section{Determination Statement 1}

\begin{tabular}{|l|l|}
\hline $\begin{array}{c}\text { Determination } \\
\text { Statement ID }\end{array}$ & \multicolumn{1}{c|}{ Determination Statement Text } \\
\hline SI-7\{1\} & $\begin{array}{l}\text { Determine if the organization: employs integrity verification tools to detect unauthorized changes to [Assignment: an } \\
\text { organization-defined subset of software, firmware, and information]. }\end{array}$ \\
\hline
\end{tabular}

\section{Roles and Assessment Methods}

\begin{tabular}{|c|c|c|c|c|c|c|c|c|}
\hline $\begin{array}{l}\text { Determination } \\
\text { Statement ID }\end{array}$ & $\begin{array}{c}\text { Implemented } \\
\text { By }\end{array}$ & $\begin{array}{l}\text { Assessment } \\
\text { Boundary }\end{array}$ & $\begin{array}{l}\text { Assessment } \\
\text { Responsibility }\end{array}$ & $\begin{array}{l}\text { Assessment } \\
\text { Methods }\end{array}$ & Selected & $\begin{array}{c}\text { Rationale for } \\
\text { Risk } \\
\text { Acceptance }\end{array}$ & $\begin{array}{l}\text { Frequency of } \\
\text { Assessment }\end{array}$ & $\begin{array}{l}\text { Impact of Not } \\
\text { Implementing }\end{array}$ \\
\hline SI-7\{1\} & ISCM-Ops & ISCM-TN & ISCM-Sys & Test & & & & \\
\hline
\end{tabular}




\section{Defect Check Rationale Table}

A failure in effectiveness of this control item results in a defect in one or more of the following defect checks:

\begin{tabular}{|l|l|l|l|}
\hline $\begin{array}{c}\text { Determination } \\
\text { Statement ID }\end{array}$ & $\begin{array}{c}\text { Defect } \\
\text { Check ID }\end{array}$ & $\begin{array}{c}\text { Defect Check } \\
\text { Name }\end{array}$ & $\begin{array}{c}\text { Rationale } \\
\text { If an [organization-defined measure] for this defect check is above [the organization-defined } \\
\text { threshold], then defects in employing integrity verification tools to detect unauthorized } \\
\text { changes to specified software related to this control item might be the cause of the defect, } \\
\text { i.e.,.... }\end{array}$ \\
\hline SI-7\{1\} & $\begin{array}{l}\text { SWAM- } \\
\text { F01 }\end{array}$ & $\begin{array}{l}\text { Unauthorized } \\
\text { software executes }\end{array}$ & the execution of unauthorized software. \\
\hline SI-7\{1\} & $\begin{array}{l}\text { SWAM- } \\
\text { L01 }\end{array}$ & $\begin{array}{l}\text { Unapproved } \\
\text { authorizer }\end{array}$ & lack of verification that software was authorized by approved accounts (persons). \\
\hline SI-7\{1\} & $\begin{array}{l}\text { SWAM- } \\
\text { L02 }\end{array}$ & $\begin{array}{l}\text { Required } \\
\text { authorizations } \\
\text { missing }\end{array}$ & careless or malicious authorization of software. \\
\hline
\end{tabular}




\subsubsection{Control Item SI-7(1): SOFTWARE, FIRMWARE, AND INFORMATION INTEGRITY | INTEGRITY CHECKS}

\section{Control Item Text}

The information system performs an integrity check of [Assignment: organization-defined software, firmware, and information] [Selection (one or more): at startup; at [Assignment: organization-defined transitional states or securityrelevant events]; [Assignment: organization-defined frequency]].

\section{Determination Statement 1}

\begin{tabular}{|l|l|}
\hline $\begin{array}{c}\text { Determination } \\
\text { Statement ID }\end{array}$ & \multicolumn{1}{c|}{ Determination Statement Text } \\
\hline SI-7(1)\{1\} & $\begin{array}{l}\text { Determine if the organization: performs an integrity check of [Assignment: organization-defined software, firmware, and } \\
\text { information] [Selection (one or more): at startup; at [Assignment: organization-defined transitional states or security-relevant } \\
\text { events]; [Assignment: organization-defined frequency]]. }\end{array}$ \\
\hline
\end{tabular}

\section{Roles and Assessment Methods}

\begin{tabular}{|c|c|c|c|c|c|c|c|c|}
\hline $\begin{array}{c}\text { Determination } \\
\text { Statement ID }\end{array}$ & $\begin{array}{c}\text { Implemented } \\
\text { By }\end{array}$ & $\begin{array}{l}\text { Assessment } \\
\text { Boundary }\end{array}$ & $\begin{array}{l}\text { Assessment } \\
\text { Responsibility }\end{array}$ & $\begin{array}{l}\text { Assessment } \\
\text { Methods }\end{array}$ & Selected & $\begin{array}{c}\text { Rationale for } \\
\text { Risk } \\
\text { Acceptance }\end{array}$ & $\begin{array}{l}\text { Frequency of } \\
\text { Assessment }\end{array}$ & $\begin{array}{l}\text { Impact of Not } \\
\text { Implementing }\end{array}$ \\
\hline SI-7(1)\{1\} & ISCM-Ops & ISCM-TN & ISCM-Sys & Test & & & & \\
\hline
\end{tabular}

\section{Defect Check Rationale Table}

A failure in effectiveness of this control item results in a defect in one or more of the following defect checks:

\begin{tabular}{|c|c|c|c|}
\hline $\begin{array}{l}\text { Determination } \\
\text { Statement ID }\end{array}$ & $\begin{array}{c}\text { Defect } \\
\text { Check ID }\end{array}$ & $\begin{array}{c}\text { Defect Check } \\
\text { Name }\end{array}$ & $\begin{array}{l}\text { Rationale } \\
\text { If an [organization-defined measure] for this defect check is above [the organization-defined } \\
\text { threshold], then defects in performing an integrity check of specified software at specified } \\
\text { times related to this control item might be the cause of the defect, i.e.,... }\end{array}$ \\
\hline SI-7(1)\{1\} & $\begin{array}{l}\text { SWAM- } \\
\text { F04 }\end{array}$ & $\begin{array}{l}\text { Untrusted } \\
\text { core software }\end{array}$ & lack of core software integrity at start-up. \\
\hline
\end{tabular}




\subsubsection{Control Item SI-16: MEMORY PROTECTION}

\section{Control Item Text}

Control: The information system implements [Assignment: organization-defined security safeguards] to protect its memory from unauthorized code execution.

\section{Determination Statement 1}

\begin{tabular}{|l|l|}
\hline $\begin{array}{c}\text { Determination } \\
\text { Statement ID }\end{array}$ & \multicolumn{1}{c|}{ Determination Statement Text } \\
\hline SI-16\{1\} & $\begin{array}{l}\text { Determine if the organization: implements [Assignment: organization-defined security safeguards] to protect its } \\
\text { memory from unauthorized code execution. }\end{array}$ \\
\hline
\end{tabular}

\section{Roles and Assessment Methods}

\begin{tabular}{|c|c|c|c|c|c|c|c|c|}
\hline $\begin{array}{l}\text { Determination } \\
\text { Statement ID }\end{array}$ & $\begin{array}{c}\text { Implemented } \\
\text { By }\end{array}$ & $\begin{array}{l}\text { Assessment } \\
\text { Boundary }\end{array}$ & $\begin{array}{l}\text { Assessment } \\
\text { Responsibility }\end{array}$ & $\begin{array}{l}\text { Assessment } \\
\text { Methods }\end{array}$ & Selected & $\begin{array}{c}\text { Rationale for } \\
\text { Risk } \\
\text { Acceptance }\end{array}$ & $\begin{array}{l}\text { Frequency of } \\
\text { Assessment }\end{array}$ & $\begin{array}{l}\text { Impact of Not } \\
\text { Implementing }\end{array}$ \\
\hline SI-16 $\{1\}$ & TBD & ISCM-TN & MAN & TBD & & & & \\
\hline
\end{tabular}

\section{Defect Check Rationale Table}

A failure in effectiveness of this control item results in a defect in one or more of the following defect checks:

Not applicable because tested manually. 


\subsubsection{High Baseline Security Control Item Narratives}

\subsubsection{Control Item CM-3(1)(c): CONFIGURATION CHANGE CONTROL | AUTOMATED DOCUMENT I NOTIFICATION / PROHIBITION OF CHANGES}

\section{Control Item Text}

The organization employs automated mechanisms to:

(c) Highlight proposed changes to the information system that have not been approved or disapproved by [Assignment: organization-defined time period].

\section{Determination Statement 1}

\begin{tabular}{|c|c|}
\hline $\begin{array}{l}\text { Determination } \\
\text { Statement ID }\end{array}$ & Determination Statement Text \\
\hline $\mathrm{CM}-3(1)(\mathrm{c})\{1\}$ & $\begin{array}{l}\text { Determine if the organization: employs automated mechanisms to highlight proposed changes to the system }\{\text { installed } \\
\text { software\} that have not been approved or disapproved by [Assignment: organization-defined time period]. }\end{array}$ \\
\hline
\end{tabular}

\section{Roles and Assessment Methods}

\begin{tabular}{|c|c|c|c|c|c|c|c|c|}
\hline $\begin{array}{l}\text { Determination } \\
\text { Statement ID }\end{array}$ & $\begin{array}{c}\text { Implemented } \\
\text { By }\end{array}$ & $\begin{array}{l}\text { Assessment } \\
\text { Boundary }\end{array}$ & $\begin{array}{l}\text { Assessment } \\
\text { Responsibility }\end{array}$ & $\begin{array}{l}\text { Assessment } \\
\text { Methods }\end{array}$ & Selected & $\begin{array}{c}\text { Rationale for } \\
\text { Risk } \\
\text { Acceptance }\end{array}$ & $\begin{array}{l}\text { Frequency of } \\
\text { Assessment }\end{array}$ & $\begin{array}{l}\text { Impact of Not } \\
\text { Implementing }\end{array}$ \\
\hline CM-3(1)(c) $\{1\}$ & ISCM-Sys & ISCM-TN & ISCM-Sys & Test & & & & \\
\hline
\end{tabular}




\section{Defect Check Rationale Table}

A failure in effectiveness of this control item results in a defect in one or more of the following defect checks:

\begin{tabular}{|l|l|l|l|}
\hline $\begin{array}{c}\text { Determination } \\
\text { Statement ID }\end{array}$ & $\begin{array}{c}\text { Defect } \\
\text { Check } \\
\text { ID }\end{array}$ & \multicolumn{1}{|c|}{$\begin{array}{c}\text { Rationale } \\
\text { Defect Check Name }\end{array}$} & $\begin{array}{r}\text { If an [organization-defined measure] for this defect check is above [the } \\
\text { organization-defined threshold], then defects in employing automated } \\
\text { mechanisms to highlight proposed changes to the system } \text { [installed } \\
\text { software\} that have not been approved or disapproved by [Assignment: } \\
\text { organization-defined time period] related to this control item might be the } \\
\text { cause of the defect, i.e.,... }\end{array}$ \\
\hline CM-3(1)(c)\{1\} & $\begin{array}{l}\text { SWAM- } \\
\text { L03 }\end{array}$ & $\begin{array}{l}\text { Expired actions on software } \\
\text { authorization/deauthorization } \\
\text { requests }\end{array}$ & requested changes not being addressed in a timely manner. \\
\hline
\end{tabular}




\subsubsection{Control Item CM-4: SECURITY IMPACT ANALYSIS | SEPARATE TEST ENVIRONMENTS}

\section{Control Item Text}

The organization analyzes changes to the information system in a separate test environment before implementation in an operational environment, looking for security impacts due to flaws, weaknesses, incompatibility, or intentional malice.

\section{Determination Statement 1}

\begin{tabular}{|l|l|}
\hline $\begin{array}{c}\text { Determination } \\
\text { Statement ID }\end{array}$ & \multicolumn{1}{c|}{ Determination Statement Text } \\
\hline $\mathrm{CM}-4(1)\{1\}$ & $\begin{array}{l}\text { Determine if the organization: analyzes changes to the information system } \text { \{software\} in a separate test environment before } \\
\text { implementation in an operational environment, looking for security impacts due to flaws, weaknesses, incompatibility, or } \\
\text { intentional malice. }\end{array}$ \\
\hline
\end{tabular}

Roles and Assessment Methods

\begin{tabular}{|c|c|c|c|c|c|c|c|c|}
\hline $\begin{array}{l}\text { Determination } \\
\text { Statement ID }\end{array}$ & $\begin{array}{c}\text { Implemented } \\
\text { By }\end{array}$ & $\begin{array}{c}\text { Assessment } \\
\text { Boundary }\end{array}$ & $\begin{array}{l}\text { Assessment } \\
\text { Responsibility }\end{array}$ & $\begin{array}{c}\text { Assessment } \\
\text { Methods }\end{array}$ & Selected & $\begin{array}{c}\text { Rationale for } \\
\text { Risk } \\
\text { Acceptance }\end{array}$ & $\begin{array}{l}\text { Frequency of } \\
\text { Assessment }\end{array}$ & $\begin{array}{l}\text { Impact of Not } \\
\text { Implementing }\end{array}$ \\
\hline $\mathrm{CM}-4(1)\{1\}$ & DSM & ISCM-TN & ISCM-Sys & Test & & & & \\
\hline
\end{tabular}

\section{Defect Check Rationale Table}

A failure in effectiveness of this control item results in a defect in one or more of the following defect checks:

\begin{tabular}{|l|l|l|l|}
\hline $\begin{array}{c}\text { Determination } \\
\text { Statement ID }\end{array}$ & $\begin{array}{c}\text { Defect } \\
\text { Check ID }\end{array}$ & $\begin{array}{c}\text { Defect Check } \\
\text { Name }\end{array}$ & $\begin{array}{c}\text { Rationale } \\
\text { If an [organization-defined measure] for this defect check is above [the organization-defined } \\
\text { threshold], then defects in analyzing changes to the information system \{software\}, } \\
\text { looking for security impacts due to flaws, weaknesses, incompatibility, or intentional } \\
\text { malice related to this control item might be the cause of the defect, i.e.,... }\end{array}$ \\
\hline CM-4(1)\{1\} & $\begin{array}{l}\text { SWAM- } \\
\text { L06 }\end{array}$ & $\begin{array}{l}\text { Testing and } \\
\text { validation of } \\
\text { software } \\
\text { inadequate }\end{array}$ & \begin{tabular}{l} 
lack of adequate testing and validation. \\
\hline
\end{tabular} \\
\hline
\end{tabular}




\subsubsection{Control Item CM-5(3): ACCESS RESTRICTIONS FOR CHANGE | SIGNED COMPONENTS}

\section{Control Item Text}

The information system prevents the installation of [Assignment: organization-defined software and firmware components] without verification that the component has been digitally signed using a certificate that is recognized and approved by the organization.

\section{Determination Statement 1}

\begin{tabular}{|l|l|}
\hline $\begin{array}{c}\text { Determination } \\
\text { Statement ID }\end{array}$ & \multicolumn{1}{c|}{ Determination Statement Text } \\
\hline $\mathrm{CM}-5(3)\{1\}$ & $\begin{array}{l}\text { Determine if the organization: verifies that the \{software\} component has been digitally signed using a certificate that is } \\
\text { recognized and approved by the organization before installation of [Assignment: organization-defined software and } \\
\text { firmware components]. }\end{array}$ \\
\hline
\end{tabular}

\section{Roles and Assessment Methods}

\begin{tabular}{|c|c|c|c|c|c|c|c|c|}
\hline $\begin{array}{c}\text { Determination } \\
\text { Statement ID }\end{array}$ & $\begin{array}{c}\text { Implemented } \\
\text { By }\end{array}$ & $\begin{array}{l}\text { Assessment } \\
\text { Boundary }\end{array}$ & $\begin{array}{l}\text { Assessment } \\
\text { Responsibility }\end{array}$ & $\begin{array}{l}\text { Assessment } \\
\text { Methods }\end{array}$ & Selected & $\begin{array}{c}\text { Rationale for } \\
\text { Risk } \\
\text { Acceptance }\end{array}$ & $\begin{array}{l}\text { Frequency of } \\
\text { Assessment }\end{array}$ & $\begin{array}{l}\text { Impact of Not } \\
\text { Implementing }\end{array}$ \\
\hline CM-5(3)\{1\} & SWMan & ISCM-TN & ISCM-Sys & Test & & & & \\
\hline
\end{tabular}




\section{Defect Check Rationale Table}

A failure in effectiveness of this control item results in a defect in one or more of the following defect checks:

\begin{tabular}{|l|l|l|l|}
\hline $\begin{array}{c}\text { Determination } \\
\text { Statement ID }\end{array}$ & $\begin{array}{c}\text { Defect } \\
\text { Check ID }\end{array}$ & $\begin{array}{c}\text { Refect Check } \\
\text { Name }\end{array}$ & $\begin{array}{c}\text { Rationale } \\
\text { If an [organization-defined measure] for this defect check is above [the organization-defined } \\
\text { threshold], then defects in verifying that the \{software\} component has been digitally } \\
\text { signed using a certificate that is recognized and approved by the organization before } \\
\text { installation of specific components related to this control item might be the cause of the } \\
\text { defect, i.e.,... }\end{array}$ \\
\hline CM-5(3)\{1\} & $\begin{array}{l}\text { SWAM- } \\
\text { F01 }\end{array}$ & $\begin{array}{l}\text { Unauthorized } \\
\text { software } \\
\text { executes }\end{array}$ & the execution of unauthorized software. \\
\hline CM-5(3)\{1\} & $\begin{array}{l}\text { SWAM- } \\
\text { F04 }\end{array}$ & $\begin{array}{l}\text { Untrusted core } \\
\text { software }\end{array}$ & lack of core software integrity at start-up. \\
\hline
\end{tabular}




\subsubsection{Control Item CM-7(5)(a): LEAST FUNCTIONALITY | AUTHORIZED SOFTWARE / WHITELISTING}

\section{Control Item Text}

The organization:

(a) Identifies [Assignment: organization-defined software programs authorized to execute on the information system].

\section{Determination Statement 1}

\begin{tabular}{|l|l|}
\hline $\begin{array}{l}\text { Determination Statement } \\
\text { ID }\end{array}$ & \multicolumn{1}{c|}{ Determination Statement Text } \\
\hline $\mathrm{CM}-7(5)(\mathrm{a})\{1\}$ & $\begin{array}{l}\text { Determine if the organization: identifies [Assignment: organization-defined software programs authorized to execute } \\
\text { on the system]. }\end{array}$ \\
\hline
\end{tabular}

\section{Roles and Assessment Methods}

\begin{tabular}{|l|l|l|l|l|l|l|l|l|}
\hline $\begin{array}{c}\text { Determination } \\
\text { Statement ID }\end{array}$ & $\begin{array}{c}\text { Implemented } \\
\text { By }\end{array}$ & $\begin{array}{c}\text { Assessment } \\
\text { Boundary }\end{array}$ & $\begin{array}{c}\text { Assessment } \\
\text { Responsibility }\end{array}$ & $\begin{array}{c}\text { Assessment } \\
\text { Methods }\end{array}$ & Selected & $\begin{array}{c}\text { Rationale for } \\
\text { Risk } \\
\text { Acceptance }\end{array}$ & $\begin{array}{c}\text { Frequency of } \\
\text { Assessment }\end{array}$ & $\begin{array}{l}\text { Impact of Not } \\
\text { Implementing }\end{array}$ \\
\hline CM-7(5)(a)\{1\} & DSM & ISCM-TN & ISCM-Sys & Test & & & & \\
\hline
\end{tabular}




\section{Defect Check Rationale Table}

A failure in effectiveness of this control item results in a defect in one or more of the following defect checks:

\begin{tabular}{|l|l|l|l|}
\hline $\begin{array}{c}\text { Determination } \\
\text { Statement ID }\end{array}$ & $\begin{array}{l}\text { Defect } \\
\text { Check ID }\end{array}$ & \multicolumn{1}{|c|}{ Defect Check Name } & $\begin{array}{c}\text { Rationale } \\
\text { If an [organization-defined measure] for this defect check is above [the } \\
\text { organization-defined threshold], then defects in identifying specific software } \\
\text { programs authorized to execute on the system related to this control item might } \\
\text { be the cause of the defect, i.e., ... }\end{array}$ \\
\hline CM-7(5)(a)\{1\} & $\begin{array}{l}\text { SWAM- } \\
\text { F01 }\end{array}$ & $\begin{array}{l}\text { Unauthorized software } \\
\text { executes }\end{array}$ & the execution of unauthorized software. \\
\hline CM-7(5)(a) $\{1\}$ & $\begin{array}{l}\text { SWAM- } \\
\text { F02 }\end{array}$ & $\begin{array}{l}\text { Unauthorized software } \\
\text { installer }\end{array}$ & the execution of software not installed by an authorized installer. \\
\hline CM-7(5)(a)\{1\} & $\begin{array}{l}\text { SWAM- } \\
\text { F03 }\end{array}$ & $\begin{array}{l}\text { Unauthorized software } \\
\text { directory/folder location }\end{array}$ & the execution of software not loaded from an approved directory/folder location. \\
\hline CM-7(5)(a)\{1\} & $\begin{array}{l}\text { SWAM- } \\
\text { F04 }\end{array}$ & Untrusted core software & lack of core software integrity at start-up. \\
\hline CM-7(5)(a) $\{1\}$ & $\begin{array}{l}\text { SWAM- } \\
\text { L04 }\end{array}$ & $\begin{array}{l}\text { Devices moving in/out of } \\
\text { protective boundaries not in } \\
\text { policy compliance }\end{array}$ & $\begin{array}{l}\text { devices' software not being adequately strengthened and/or sanitized for } \\
\text { movement into or out of protective boundaries. }\end{array}$ \\
\hline
\end{tabular}




\subsubsection{Control Item CM-7(5)(b): LEAST FUNCTIONALITY | AUTHORIZED SOFTWARE / WHITELISTING}

\section{Control Item Text}

The organization:

(b) Employs a deny-all, permit-by-exception policy to allow the execution of authorized software programs on the information system.

\section{Determination Statement 1}

\begin{tabular}{|c|l|}
\hline $\begin{array}{c}\text { Determination } \\
\text { Statement ID }\end{array}$ & \multicolumn{1}{c|}{ Determination Statement Text } \\
\hline $\mathrm{CM}-7(5)(\mathrm{b})\{1\}$ & $\begin{array}{l}\text { Determine if the organization: employs a deny-all, permit-by-exception policy to allow the execution of authorized } \\
\text { software programs on the system. }\end{array}$ \\
\hline
\end{tabular}

\section{Roles and Assessment Methods}

\begin{tabular}{|c|c|c|c|c|c|c|c|c|}
\hline $\begin{array}{c}\text { Determination } \\
\text { Statement ID }\end{array}$ & $\begin{array}{c}\text { Implemented } \\
\text { By }\end{array}$ & $\begin{array}{c}\text { Assessment } \\
\text { Boundary }\end{array}$ & $\begin{array}{l}\text { Assessment } \\
\text { Responsibility }\end{array}$ & $\begin{array}{c}\text { Assessment } \\
\text { Methods }\end{array}$ & Selected & $\begin{array}{c}\text { Rationale for } \\
\text { Risk } \\
\text { Acceptance }\end{array}$ & $\begin{array}{l}\text { Frequency of } \\
\text { Assessment }\end{array}$ & $\begin{array}{l}\text { Impact of Not } \\
\text { Implementing }\end{array}$ \\
\hline CM-7(5)(b)\{1\} & RskEx & ISCM-TN & ISCM-Sys & Test & & & & \\
\hline
\end{tabular}




\section{Defect Check Rationale Table}

A failure in effectiveness of this control item results in a defect in one or more of the following defect checks:

\begin{tabular}{|c|c|c|c|}
\hline $\begin{array}{l}\text { Determination } \\
\text { Statement ID }\end{array}$ & $\begin{array}{c}\text { Defect } \\
\text { Check ID }\end{array}$ & Defect Check Name & $\begin{array}{l}\text { Rationale } \\
\text { If an [organization-defined measure] for this defect check is above [the organization- } \\
\text { defined threshold], then defects in employing a deny-all, permit-by-exception } \\
\text { policy to allow the execution of authorized software programs (whitelisting) } \\
\text { related to this control item might be the cause of the defect, i.e., ... }\end{array}$ \\
\hline CM-7(5)(b)\{1\} & $\begin{array}{l}\text { SWAM- } \\
\text { F01 }\end{array}$ & $\begin{array}{l}\text { Unauthorized software } \\
\text { executes }\end{array}$ & the execution of unauthorized software. \\
\hline CM-7(5)(b)\{1\} & $\begin{array}{l}\text { SWAM- } \\
\text { F02 }\end{array}$ & $\begin{array}{l}\text { Unauthorized software } \\
\text { installer }\end{array}$ & the execution of software not installed by an authorized installer. \\
\hline $\mathrm{CM}-7(5)(\mathrm{b})\{1\}$ & $\begin{array}{l}\text { SWAM- } \\
\text { F03 }\end{array}$ & $\begin{array}{l}\text { Unauthorized software } \\
\text { directory/folder location }\end{array}$ & the execution of software not loaded from an approved directory/folder location. \\
\hline CM-7(5)(b)\{1\} & $\begin{array}{l}\text { SWAM- } \\
\text { F04 }\end{array}$ & Untrusted core software & lack of core software integrity at start-up. \\
\hline CM-7(5)(b)\{1\} & $\begin{array}{l}\text { SWAM- } \\
\text { L04 }\end{array}$ & $\begin{array}{l}\text { Devices moving in/out of } \\
\text { protective boundaries not in } \\
\text { policy compliance }\end{array}$ & $\begin{array}{l}\text { devices' software not being adequately strengthened and/or sanitized for movement } \\
\text { into or out of protective boundaries. }\end{array}$ \\
\hline
\end{tabular}




\subsubsection{Control Item CM-7(5)(c): LEAST FUNCTIONALITY | AUTHORIZED SOFTWARE / WHITELISTING}

\section{Control Item Text}

The organization:

(c) Reviews and updates the list of authorized software programs [Assignment: organization-defined frequency].

\section{Determination Statement 1}

\begin{tabular}{|l|l|}
\hline $\begin{array}{c}\text { Determination Statement } \\
\text { ID }\end{array}$ & \multicolumn{1}{c|}{ Determination Statement Text } \\
\hline $\mathrm{CM}-7(5)(\mathrm{c})\{1\}$ & $\begin{array}{l}\text { Determine if the organization: reviews and updates the list of authorized software programs [Assignment: } \\
\text { organization-defined frequency]. }\end{array}$ \\
\hline
\end{tabular}

\section{Roles and Assessment Methods}

\begin{tabular}{|l|l|l|l|l|l|l|l|l|}
\hline $\begin{array}{c}\text { Determination } \\
\text { Statement ID }\end{array}$ & $\begin{array}{c}\text { Implemented } \\
\text { By }\end{array}$ & $\begin{array}{c}\text { Assessment } \\
\text { Boundary }\end{array}$ & $\begin{array}{c}\text { Assessment } \\
\text { Responsibility }\end{array}$ & $\begin{array}{c}\text { Assessment } \\
\text { Methods }\end{array}$ & Selected & $\begin{array}{c}\text { Rationale for } \\
\text { Risk } \\
\text { Acceptance }\end{array}$ & $\begin{array}{c}\text { Frequency of } \\
\text { Assessment }\end{array}$ & $\begin{array}{c}\text { Impact of Not } \\
\text { Implementing }\end{array}$ \\
\hline $\mathrm{CM}-7(5)(\mathrm{c})\{1\}$ & $\mathrm{DSM}$ & ISCM-TN & ISCM-Sys & Test & & & & \\
\hline
\end{tabular}

\section{Defect Check Rationale Table}

A failure in effectiveness of this control item results in a defect in one or more of the following defect checks:

\begin{tabular}{|l|l|l|l|}
\hline $\begin{array}{c}\text { Determination } \\
\text { Statement ID }\end{array}$ & $\begin{array}{c}\text { Defect } \\
\text { Check ID }\end{array}$ & $\begin{array}{c}\text { Defect Check } \\
\text { Name }\end{array}$ & $\begin{array}{c}\text { Rationale } \\
\text { If an [organization-defined measure] for this defect check is above [the organization-defined } \\
\text { threshold], then defects in reviewing and updating the list of authorized software } \\
\text { programs at the required frequency related to this control item might be the cause of the } \\
\text { defect, i.e., ... }\end{array}$ \\
\hline CM-7(5)(c)\{1\} & $\begin{array}{l}\text { SWAM- } \\
\text { L07 }\end{array}$ & $\begin{array}{l}\text { Business need of } \\
\text { software not } \\
\text { recently verified }\end{array}$ & $\begin{array}{l}\text { the presence of software without a recently verified need, resulting in an increase in the } \\
\text { attack surface without associated organizational value. }\end{array}$ \\
\hline
\end{tabular}




\subsubsection{Control Item CM-8(4): INFORMATION SYSTEM COMPONENT INVENTORY | ACCOUNTABILITY INFORMATION}

\section{Control Item Text}

The organization includes in the information system component inventory information, a means for identifying by [Selection (one or more): name; position; role], individuals responsible/accountable for administering those components.

\section{Determination Statement 1}

\begin{tabular}{|l|l|}
\hline $\begin{array}{c}\text { Determination } \\
\text { Statement ID }\end{array}$ & \multicolumn{1}{c|}{ Determination Statement Text } \\
\hline $\mathrm{CM}-8(4)\{1\}$ & $\begin{array}{l}\text { Determine if the organization: includes in the \{installed software\} system component inventory information, a means for } \\
\text { identifying by [Selection (one or more): name; position; role], individuals responsible/accountable for administering those } \\
\text { components. }\end{array}$ \\
\hline
\end{tabular}

\section{Roles and Assessment Methods}

\begin{tabular}{|c|c|c|c|c|c|c|c|c|}
\hline $\begin{array}{l}\text { Determination } \\
\text { Statement ID }\end{array}$ & $\begin{array}{c}\text { Implemented } \\
\text { By }\end{array}$ & $\begin{array}{l}\text { Assessment } \\
\text { Boundary }\end{array}$ & $\begin{array}{l}\text { Assessment } \\
\text { Responsibility }\end{array}$ & $\begin{array}{l}\text { Assessment } \\
\text { Methods }\end{array}$ & Selected & $\begin{array}{c}\text { Rationale for } \\
\text { Risk } \\
\text { Acceptance }\end{array}$ & $\begin{array}{l}\text { Frequency of } \\
\text { Assessment }\end{array}$ & $\begin{array}{l}\text { Impact of Not } \\
\text { Implementing }\end{array}$ \\
\hline CM-8(4)\{1\} & DSM & ISCM-TN & ISCM-Sys & Test & & & & \\
\hline
\end{tabular}

\section{Defect Check Rationale Table}

A failure in effectiveness of this control item results in a defect in one or more of the following defect checks:

\begin{tabular}{|l|l|l|l|}
\hline $\begin{array}{c}\text { Determination } \\
\text { Statement ID }\end{array}$ & $\begin{array}{c}\text { Defect } \\
\text { Check ID }\end{array}$ & $\begin{array}{r}\text { Rationale } \\
\text { Defect Check } \\
\text { Name }\end{array}$ & $\begin{array}{r}\text { If an [organization-defined measure] for this defect check is above [the organization-defined } \\
\text { threshold], then defects in including in the \{installed software\} system component inventory } \\
\text { information a means for identifying individuals responsible or accountable for } \\
\text { administering those components related to this control item might be the cause of the defect, } \\
\text { i.e.,... }\end{array}$ \\
\hline $\mathrm{CM}-8(4)\{1\}$ & $\begin{array}{l}\text { SWAM- } \\
\text { L12 }\end{array}$ & $\begin{array}{l}\text { Unmanaged } \\
\text { software }\end{array}$ & the presence of unmanaged software. \\
\hline
\end{tabular}




\subsubsection{Control Item MP-6(1): MEDIA SANITIZATION | REVIEW / APPROVE / TRACK / DOCUMENT / VERIFY}

\section{Control Item Text}

The organization reviews, approves, tracks, documents, and verifies media sanitization and disposal actions.

\section{Determination Statement 1}

\begin{tabular}{|l|l|}
\hline \multicolumn{1}{|c|}{ IDetermination Statement } & \multicolumn{1}{c|}{ Determination Statement Text } \\
\hline MP-6(1)\{1\} & $\begin{array}{l}\text { Determine if the organization: reviews, approves, tracks, documents, and verifies media sanitization and disposal } \\
\text { actions \{to remove software\}. }\end{array}$ \\
\hline
\end{tabular}

\section{Roles and Assessment Methods}

\begin{tabular}{|l|l|l|l|l|l|l|l|l|}
\hline $\begin{array}{c}\text { Determination } \\
\text { Statement ID }\end{array}$ & $\begin{array}{c}\text { Implemented } \\
\text { By }\end{array}$ & $\begin{array}{c}\text { Assessment } \\
\text { Boundary }\end{array}$ & $\begin{array}{c}\text { Assessment } \\
\text { Responsibility }\end{array}$ & $\begin{array}{c}\text { Assessment } \\
\text { Methods }\end{array}$ & Selected & $\begin{array}{c}\text { Rationale for } \\
\text { Risk } \\
\text { Acceptance }\end{array}$ & $\begin{array}{c}\text { Frequency of } \\
\text { Assessment }\end{array}$ & $\begin{array}{l}\text { Impact of Not } \\
\text { Implementing }\end{array}$ \\
\hline MP-6(1)\{1\} & SWMan & ISCM-TN & ISCM-Sys & Test & & & & \\
\hline
\end{tabular}

\section{Defect Check Rationale Table}

A failure in effectiveness of this control item results in a defect in one or more of the following defect checks:

\begin{tabular}{|l|l|l|r|}
\hline $\begin{array}{c}\text { Determination } \\
\text { Statement ID }\end{array}$ & $\begin{array}{c}\text { Defect } \\
\text { Check ID }\end{array}$ & Defect Check Name & $\begin{array}{c}\text { Rationale } \\
\text { If an [organization-defined measure] for this defect check is above [the organization- } \\
\text { defined threshold], then defects in reviewing, approving, tracking, documenting, } \\
\text { and verifying media sanitization and disposal actions } \text { \{to remove software\} } \\
\text { related to this control item might be the cause of the defect, i.e., ... }\end{array}$ \\
\hline MP-6(1)\{1\} & $\begin{array}{l}\text { SWAM- } \\
\text { L04 }\end{array}$ & $\begin{array}{l}\text { Devices moving in/out of } \\
\text { protective boundaries not } \\
\text { in policy compliance }\end{array}$ & $\begin{array}{l}\text { devices' software not being adequately strengthened and/or sanitized for movement } \\
\text { into or out of protective boundaries. }\end{array}$ \\
\hline
\end{tabular}




\subsubsection{Control Item MP-6(2): MEDIA SANITIZATION | EQUIPMENT TESTING}

\section{Control Item Text}

The organization tests sanitization equipment and procedures [Assignment: organization-defined frequency] to verify that the intended sanitization is being achieved.

\section{Determination Statement 1}

\begin{tabular}{|l|l|}
\hline $\begin{array}{c}\text { Determination } \\
\text { Statement ID }\end{array}$ & \multicolumn{1}{c|}{ Determination Statement Text } \\
\hline MP-6(2)\{1\} & $\begin{array}{l}\text { Determine if the organization: tests sanitization equipment and procedures [Assignment: organization-defined frequency] } \\
\text { to verify that the intended sanitization \{to remove software }\} \text { is being achieved. }\end{array}$ \\
\hline
\end{tabular}

\section{Roles and Assessment Methods}

\begin{tabular}{|c|c|c|c|c|c|c|c|c|}
\hline $\begin{array}{c}\text { Determination } \\
\text { Statement ID }\end{array}$ & $\begin{array}{c}\text { Implemented } \\
\text { By }\end{array}$ & $\begin{array}{c}\text { Assessment } \\
\text { Boundary }\end{array}$ & $\begin{array}{l}\text { Assessment } \\
\text { Responsibility }\end{array}$ & $\begin{array}{l}\text { Assessment } \\
\text { Methods }\end{array}$ & Selected & $\begin{array}{c}\text { Rationale for } \\
\text { Risk } \\
\text { Acceptance }\end{array}$ & $\begin{array}{l}\text { Frequency of } \\
\text { Assessment }\end{array}$ & $\begin{array}{l}\text { Impact of Not } \\
\text { Implementing }\end{array}$ \\
\hline MP-6(2)\{1\} & SWMan & ISCM-TN & ISCM-Sys & Test & & & & \\
\hline
\end{tabular}

\section{Defect Check Rationale Table}

A failure in effectiveness of this control item results in a defect in one or more of the following defect checks:

\begin{tabular}{|l|l|l|l|}
\hline $\begin{array}{c}\text { Determination } \\
\text { Statement ID }\end{array}$ & $\begin{array}{c}\text { Defect } \\
\text { Check ID }\end{array}$ & $\begin{array}{c}\text { Rationale } \\
\text { Defect Check Name }\end{array}$ & $\begin{array}{c}\text { If an [organization-defined measure] for this defect check is above [the organization- } \\
\text { defined threshold], then defects in testing sanitization equipment and procedures } \\
\text { [Assignment: organization-defined frequency] to verify that the intended } \\
\text { sanitization } \text { \{to remove software\} is being achieved related to this control item might } \\
\text { be the cause of the defect, i.e., ... }\end{array}$ \\
\hline MP-6(2)\{1\} & $\begin{array}{l}\text { SWAM- } \\
\text { L04 }\end{array}$ & $\begin{array}{l}\text { Devices moving in/out of } \\
\text { protective boundaries } \\
\text { not in policy compliance }\end{array}$ & $\begin{array}{l}\text { devices' software not being adequately strengthened and/or sanitized for movement into } \\
\text { or out of protective boundaries. }\end{array}$ \\
\hline
\end{tabular}




\subsubsection{Control Item MP-6(3): MEDIA SANITIZATION | NONDESTRUCTIVE TECHNIQUES}

\section{Control Item Text}

The organization applies nondestructive sanitization techniques to portable storage devices prior to connecting such devices to the information system under the following circumstances: [Assignment: organization-defined circumstances requiring sanitization of portable storage devices].

\section{Determination Statement 1}

\begin{tabular}{|l|l|}
\hline $\begin{array}{c}\text { Determination } \\
\text { Statement ID }\end{array}$ & Determination Statement Text \\
\hline MP-6(3)\{1\} & $\begin{array}{l}\text { Determine if the organization: applies nondestructive sanitization techniques }\{\text { to remove software }\} \text { to portable storage } \\
\text { devices prior to connecting such devices to the information system under the following circumstances: }[\text { Assignment: } \\
\text { organization-defined circumstances requiring sanitization of portable storage devices]. }\end{array}$ \\
\hline
\end{tabular}

\section{Roles and Assessment Methods}

\begin{tabular}{|c|c|c|c|c|c|c|c|c|}
\hline $\begin{array}{c}\text { Determination } \\
\text { Statement ID }\end{array}$ & $\begin{array}{c}\text { Implemented } \\
\text { By }\end{array}$ & $\begin{array}{l}\text { Assessment } \\
\text { Boundary }\end{array}$ & $\begin{array}{l}\text { Assessment } \\
\text { Responsibility }\end{array}$ & $\begin{array}{l}\text { Assessment } \\
\text { Methods }\end{array}$ & Selected & $\begin{array}{c}\text { Rationale for } \\
\text { Risk } \\
\text { Acceptance }\end{array}$ & $\begin{array}{l}\text { Frequency of } \\
\text { Assessment }\end{array}$ & $\begin{array}{l}\text { Impact of Not } \\
\text { Implementing }\end{array}$ \\
\hline MP-6(3)\{1\} & SWMan & ISCM-TN & ISCM-Sys & Test & & & & \\
\hline
\end{tabular}

\section{Defect Check Rationale Table}

A failure in effectiveness of this control item results in a defect in one or more of the following defect checks:

\begin{tabular}{|l|l|l|l|}
\hline $\begin{array}{c}\text { Determination } \\
\text { Statement ID }\end{array}$ & $\begin{array}{c}\text { Defect } \\
\text { Check ID }\end{array}$ & $\begin{array}{c}\text { Rationale } \\
\text { If an [organization-defined measure] for this defect check is above [the organization- } \\
\text { defined threshold], then defects in applying nondestructive sanitization techniques } \text { \{to } \\
\text { remove software\} to portable storage devices prior to connecting such devices to } \\
\text { the information system when moved from high risk areas related to this control item } \\
\text { might be the cause of the defect, i.e.,.... }\end{array}$ \\
\hline MP-6(3)\{1\} & $\begin{array}{l}\text { SWAM- } \\
\text { L04 }\end{array}$ & $\begin{array}{l}\text { Devices moving in/out } \\
\text { of protective boundaries } \\
\text { not in policy compliance }\end{array}$ & $\begin{array}{l}\text { devices' software not being adequately strengthened and/or sanitized for movement into } \\
\text { or out of protective boundaries. }\end{array}$ \\
\hline
\end{tabular}




\subsubsection{Control Item SA-12: SUPPLY CHAIN PROTECTION}

\section{Control Item Text}

Control: The organization protects against supply chain threats to the information system, system component, or information system service by employing [Assignment: organization-defined security safeguards] as part of a comprehensive, defense-in-breadth information security strategy.

\section{Determination Statement 1}

\begin{tabular}{|l|l|}
\hline $\begin{array}{c}\text { Determination } \\
\text { Statement ID }\end{array}$ & \multicolumn{1}{c|}{ Determination Statement Text } \\
\hline SA-12\{1\} & $\begin{array}{l}\text { Determine if the organization: protects against supply chain threats to the system \{installed software }\} \text { by employing } \\
\text { [Assignment: organization-defined security safeguards] as part of a comprehensive, defense-in-breadth information } \\
\text { security strategy. }\end{array}$ \\
\hline
\end{tabular}

\section{Roles and Assessment Methods}

\begin{tabular}{|c|c|c|c|c|c|c|c|c|}
\hline $\begin{array}{c}\text { Determination } \\
\text { Statement ID }\end{array}$ & $\begin{array}{c}\text { Implemented } \\
\text { By }\end{array}$ & $\begin{array}{l}\text { Assessment } \\
\text { Boundary }\end{array}$ & $\begin{array}{l}\text { Assessment } \\
\text { Responsibility }\end{array}$ & $\begin{array}{l}\text { Assessment } \\
\text { Methods }\end{array}$ & Selected & $\begin{array}{c}\text { Rationale for } \\
\text { Risk } \\
\text { Acceptance }\end{array}$ & $\begin{array}{l}\text { Frequency of } \\
\text { Assessment }\end{array}$ & $\begin{array}{l}\text { Impact of Not } \\
\text { Implementing }\end{array}$ \\
\hline SA-12\{1\} & DSM & ISCM-TN & ISCM-Sys & Test & & & & \\
\hline
\end{tabular}

\section{Defect Check Rationale Table}

A failure in effectiveness of this control item results in a defect in one or more of the following defect checks:

\begin{tabular}{|l|l|l|l|}
\hline $\begin{array}{c}\text { Determination } \\
\text { Statement ID }\end{array}$ & $\begin{array}{c}\text { Defect } \\
\text { Check ID }\end{array}$ & $\begin{array}{c}\text { Defect Check } \\
\text { Name }\end{array}$ & $\begin{array}{c}\text { Rationale } \\
\text { If an [organization-defined measure] for this defect check is above [the organization-defined } \\
\text { threshold], then defects in protecting against supply chain threats to the system as } \\
\text { specified related to this control item might be the cause of the defect, i.e., ... }\end{array}$ \\
\hline SA-12\{1\} & $\begin{array}{l}\text { SWAM- } \\
\text { F01 }\end{array}$ & $\begin{array}{l}\text { Unauthorized } \\
\text { software executes }\end{array}$ & the execution of unauthorized software. \\
\hline
\end{tabular}




\subsubsection{Control Item SI-7(14)(a): SOFTWARE, FIRMWARE, AND INFORMATION INTEGRITY | BINARY OR MACHINE EXECUTABLE CODE}

\section{Control Item Text}

The organization:

(a) Prohibits the use of binary or machine-executable code from sources with limited or no warranty and without the provision of source code.

\section{Determination Statement 1}

\begin{tabular}{|l|l|}
\hline $\begin{array}{c}\text { Determination } \\
\text { Statement ID }\end{array}$ & \multicolumn{1}{c|}{ Determination Statement Text } \\
\hline $\mathrm{SI}-7(14)(\mathrm{a})\{1\}$ & $\begin{array}{l}\text { Determine if the organization: prohibits the use of binary or machine-executable code from sources with limited or no } \\
\text { warranty and/or without the provision of source code. }\end{array}$ \\
\hline
\end{tabular}

Roles and Assessment Methods

\begin{tabular}{|l|l|l|l|l|l|l|l|l|}
\hline $\begin{array}{c}\text { Determination } \\
\text { Statement ID }\end{array}$ & $\begin{array}{c}\text { Implemented } \\
\text { By }\end{array}$ & $\begin{array}{c}\text { Assessment } \\
\text { Boundary }\end{array}$ & $\begin{array}{c}\text { Assessment } \\
\text { Responsibility }\end{array}$ & $\begin{array}{c}\text { Assessment } \\
\text { Methods }\end{array}$ & Selected & $\begin{array}{c}\text { Rationale for } \\
\text { Risk } \\
\text { Acceptance }\end{array}$ & $\begin{array}{c}\text { Frequency of } \\
\text { Assessment }\end{array}$ & $\begin{array}{c}\text { Impact of Not } \\
\text { Implementing }\end{array}$ \\
\hline SI-7(14)(a) $\{1\}$ & RskEx & ISCM-TN & ISCM-Sys & Test & & & & \\
\hline
\end{tabular}

\section{Defect Check Rationale Table}

A failure in effectiveness of this control item results in a defect in one or more of the following defect checks:

\begin{tabular}{|c|c|c|c|}
\hline $\begin{array}{l}\text { Determination } \\
\text { Statement ID }\end{array}$ & $\begin{array}{c}\text { Defect } \\
\text { Check ID }\end{array}$ & $\begin{array}{c}\text { Defect Check } \\
\text { Name }\end{array}$ & $\begin{array}{l}\text { Rationale } \\
\text { If an [organization-defined measure] for this defect check is above [the organization-defined } \\
\text { threshold], then defects in prohibiting the use of binary or machine-executable code from } \\
\text { sources with limited or no warranty and/or without the provision of source code related } \\
\text { to this control item might be the cause of the defect, i.e.,... }\end{array}$ \\
\hline SI-7(14)(a)\{1\} & $\begin{array}{l}\text { SWAM- } \\
\text { L13 }\end{array}$ & $\begin{array}{l}\text { Software without } \\
\text { warranty and/or } \\
\text { source code }\end{array}$ & the presence of software without warranty and/or source code. \\
\hline
\end{tabular}




\subsubsection{Control Item SI-7(14)(b): SOFTWARE, FIRMWARE, AND INFORMATION INTEGRITY | BINARY OR MACHINE EXECUTABLE CODE}

\section{Control Item Text}

The organization:

(b) Provides exceptions to the source code requirement only for compelling mission/operational requirements and with the approval of the authorizing official.

\section{Determination Statement 1}

\begin{tabular}{|l|l|}
\hline $\begin{array}{c}\text { Determination } \\
\text { Statement ID }\end{array}$ & \multicolumn{1}{c|}{ Determination Statement Text } \\
\hline SI-7(14)(b)\{1\} & $\begin{array}{l}\text { Determine if the organization: provides exceptions to the source code requirement only for compelling } \\
\text { mission/operational requirements and with the approval of the authorizing official. }\end{array}$ \\
\hline
\end{tabular}

Roles and Assessment Methods

\begin{tabular}{|c|c|c|c|c|c|c|c|c|}
\hline $\begin{array}{l}\text { Determination } \\
\text { Statement ID }\end{array}$ & $\begin{array}{c}\text { Implemented } \\
\text { By }\end{array}$ & $\begin{array}{l}\text { Assessment } \\
\text { Boundary }\end{array}$ & $\begin{array}{c}\text { Assessment } \\
\text { Responsibility }\end{array}$ & $\begin{array}{c}\text { Assessment } \\
\text { Methods }\end{array}$ & Selected & $\begin{array}{c}\text { Rationale for } \\
\text { Risk } \\
\text { Acceptance }\end{array}$ & $\begin{array}{l}\text { Frequency of } \\
\text { Assessment }\end{array}$ & $\begin{array}{l}\text { Impact of Not } \\
\text { Implementing }\end{array}$ \\
\hline SI-7(14)(b)\{1\} & RskEx & ISCM-TN & ISCM-Sys & Test & & & & \\
\hline
\end{tabular}

\section{Defect Check Rationale Table}

A failure in effectiveness of this control item results in a defect in one or more of the following defect checks:

\begin{tabular}{|l|l|l|l|}
\hline $\begin{array}{c}\text { Determination } \\
\text { Statement ID }\end{array}$ & $\begin{array}{c}\text { Defect } \\
\text { Check ID }\end{array}$ & $\begin{array}{c}\text { Refect Check } \\
\text { Name }\end{array}$ & $\begin{array}{c}\text { Rationale } \\
\text { If an [organization-defined measure] for this defect check is above [the organization-defined } \\
\text { threshold], then defects in providing exceptions to the source code requirement only for } \\
\text { compelling mission/operational requirements and with the approval of the authorizing } \\
\text { official related to this control item might be the cause of the defect, i.e., ... }\end{array}$ \\
\hline SI-7(14)(b)\{1\} & $\begin{array}{l}\text { SWAM- } \\
\text { L01 }\end{array}$ & $\begin{array}{l}\text { Unapproved } \\
\text { authorizer }\end{array}$ & lack of verification that software was authorized by approved accounts (persons). \\
\hline
\end{tabular}




\subsection{Control Allocation Tables (CATs)}

Table 8: Low Baseline Control (Item) Allocation Table, Table 9: Moderate Baseline Control (Item) Allocation Table, and Table 10: High Baseline Control (Item) Allocation Table, provide the low, moderate, and high baseline control allocations, respectively. The following is a summary of the material in the security plan assessment narrative for each determination statement in Section 3.3. It provides a concise summary of the assessment plan. 


\subsubsection{Low Baseline Control Allocation Table}

Table 8: Low Baseline Control (Item) Allocation Table

\begin{tabular}{|c|c|c|c|c|c|c|c|c|}
\hline $\begin{array}{l}\text { Determination } \\
\text { Statement ID }\end{array}$ & $\underset{\text { By }}{\text { Implemented }}$ & $\begin{array}{l}\text { Assessment } \\
\text { Boundary }\end{array}$ & $\begin{array}{c}\text { Assessment } \\
\text { Responsibility }\end{array}$ & $\begin{array}{l}\text { Assessment } \\
\text { Methods }\end{array}$ & Selected & $\begin{array}{c}\text { Rationale for Risk } \\
\text { Acceptance }\end{array}$ & $\begin{array}{c}\text { Frequency } \\
\text { of } \\
\text { Assessment }\end{array}$ & $\begin{array}{l}\text { Impact of Not } \\
\text { Implementing }\end{array}$ \\
\hline CM-2 $\{1\}$ & DSM & ISCM-TN & ISCM-Sys & Test & & & & \\
\hline CM-4\{1\} & DSM & ISCM-TN & ISCM-Sys & Test & & & & \\
\hline CM-7(a) $\{1\}$ & DSM & ISCM-TN & ISCM-Sys & Test & & & & \\
\hline CM-7(b) $\{1\}$ & DSM & ISCM-TN & ISCM-Sys & Test & & & & \\
\hline CM-8(a) $\{1\}$ & DSM & ISCM-TN & ISCM-Sys & Test & & & & \\
\hline CM-8(a)\{2\} & ISCM-Sys & ISCM-TN & ISCM-Sys & Test & & & & \\
\hline CM-8(b) $\{1\}$ & ISCM-Sys & ISCM-TN & ISCM-Sys & Test & & & & \\
\hline CM-8(b) $\{2\}$ & DSM & ISCM-TN & ISCM-Sys & Test & & & & \\
\hline CM-10(a) $\{1\}$ & DSM & ISCM-TN & ISCM-Sys & Test & & & & \\
\hline CM-10(b) $\{1\}$ & ISCM-Sys & ISCM-TN & ISCM-Sys & Test & & & & \\
\hline CM-10(b) $\{2\}$ & DSM & ISCM-TN & MAN & TBD & & & & \\
\hline CM-10(c) $\{1\}$ & ISCM-Ops & ISCM-TN & ISCM-Sys & Test & & & & \\
\hline CM-11(a) $\{1\}$ & RskEx & ISCM-TN & ISCM-Sys & Test & & & & \\
\hline CM-11(b) $\{1\}$ & ISCM-Ops & ISCM-TN & ISCM-Sys & Test & & & & \\
\hline CM-11(c)\{1\} & ISCM-Ops & ISCM-TN & ISCM-Sys & Test & & & & \\
\hline MP-6(a)\{1\} & SWMan & ISCM-TN & ISCM-Sys & Test & & & & \\
\hline MP-6(b) $\{1\}$ & SWMan & ISCM-TN & ISCM-Sys & Test & & & & \\
\hline PS-4(d)\{1\} & SWMan & ISCM-TN & ISCM-Sys & Test & & & & \\
\hline SI-3(a) $\{1\}$ & ISCM-Ops & ISCM-TN & ISCM-Sys & Test & & & & \\
\hline SI-3(b) $\{1\}$ & ISCM-Ops & ISCM-TN & ISCM-Sys & Test & & & & \\
\hline SI-3(c) $\{1\}$ & ISCM-Ops & ISCM-TN & ISCM-Sys & Test & & & & \\
\hline SI-3(c) $\{2\}$ & ISCM-Ops & ISCM-TN & ISCM-Sys & Test & & & & \\
\hline SI-3(c) $\{3\}$ & ISCM-Ops & ISCM-TN & ISCM-Sys & Test & & & & \\
\hline
\end{tabular}




\begin{tabular}{|c|c|c|c|c|c|c|c|c|}
\hline $\begin{array}{c}\text { Determination } \\
\text { Statement ID }\end{array}$ & $\begin{array}{c}\text { Implemented } \\
\text { By }\end{array}$ & $\begin{array}{c}\text { Assessment } \\
\text { Boundary }\end{array}$ & $\begin{array}{c}\text { Assessment } \\
\text { Responsibility }\end{array}$ & $\begin{array}{l}\text { Assessment } \\
\text { Methods }\end{array}$ & Selected & $\begin{array}{l}\text { Rationale for Risk } \\
\text { Acceptance }\end{array}$ & \begin{tabular}{|c|}
$\begin{array}{c}\text { Frequency } \\
\text { of } \\
\text { Assessment }\end{array}$ \\
\end{tabular} & $\begin{array}{l}\text { Impact of Not } \\
\text { Implementing }\end{array}$ \\
\hline SI-3(c) $\{4\}$ & ISCM-Ops & ISCM-TN & ISCM-Sys & Test & & & & \\
\hline SI-3(d) $\{1\}$ & ISCM-Ops & ISCM-TN & ISCM-Sys & Test & & & & \\
\hline
\end{tabular}




\subsubsection{Moderate Baseline Control Allocation Table}

Table 9: Moderate Baseline Control (Item) Allocation Table

\begin{tabular}{|c|c|c|c|c|c|c|c|c|}
\hline $\begin{array}{l}\text { Determination } \\
\text { Statement ID }\end{array}$ & $\begin{array}{c}\text { Implemented } \\
\text { By }\end{array}$ & $\begin{array}{l}\text { Assessment } \\
\text { Boundary }\end{array}$ & $\begin{array}{c}\text { Assessment } \\
\text { Responsibility }\end{array}$ & $\begin{array}{l}\text { Assessment } \\
\text { Methods }\end{array}$ & Selected & $\begin{array}{l}\text { Rationale for Risk } \\
\text { Acceptance }\end{array}$ & $\begin{array}{c}\begin{array}{c}\text { Frequency } \\
\text { of } \\
\text { Assessment }\end{array} \\
\end{array}$ & $\begin{array}{l}\text { Impact of Not } \\
\text { Implementing }\end{array}$ \\
\hline CM-2(1)(a)\{1\} & DSM & ISCM-TN & ISCM-Sys & Test & & & & \\
\hline CM-2(1)(b)\{1\} & DSM & ISCM-TN & ISCM-Sys & Test & & & & \\
\hline CM-2(1)(c)\{1\} & DSM & ISCM-TN & ISCM-Sys & Test & & & & \\
\hline CM-2(3)\{1\} & SWMan & ISCM-TN & ISCM-Sys & Test & & & & \\
\hline CM-2(7)(a)\{1\} & SWMan & ISCM-TN & ISCM-Sys & Test & & & & \\
\hline CM-2(7)(b)\{1\} & SWMan & ISCM-TN & ISCM-Sys & Test & & & & \\
\hline CM-7(1)(a)\{1\} & ISCM-Ops & ISCM-TN & ISCM-Sys & Test & & & & \\
\hline CM-7(1)(b)\{1\} & DSM & ISCM-TN & ISCM-Sys & Test & & & & \\
\hline CM-7(2)\{1\} & ISCM-Ops & ISCM-TN & ISCM-Sys & Test & & & & \\
\hline CM-7(4)(a)\{1\} & ISCM-Ops & ISCM-TN & ISCM-Sys & Test & & & & \\
\hline CM-7(4)(b)\{1\} & RskEx & ISCM-TN & ISCM-Sys & Test & & & & \\
\hline CM-7(4)(c)\{1\} & DSM & ISCM-TN & ISCM-Sys & Test & & & & \\
\hline CM-8(1)\{1\} & ISCM-Sys & ISCM-TN & ISCM-Sys & Test & & & & \\
\hline CM-8(5)\{1\} & ISCM-Sys & ISCM-TN & ISCM-Sys & Test & & & & \\
\hline MA-3(1)\{1\} & SWMan & ISCM-TN & ISCM-Sys & Test & & & & \\
\hline MA-3(2)\{1\} & SWMan & ISCM-TN & ISCM-Sys & Test & & & & \\
\hline SC-18(a)\{1\} & DSM & ISCM-TN & ISCM-Sys & Test & & & & \\
\hline SC-18(b)\{1\} & DSM & ISCM-TN & ISCM-Sys & Test & & & & \\
\hline SC-18(c) $\{1\}$ & ISCM-Ops & ISCM-TN & ISCM-Sys & Test & & & & \\
\hline SI-3(1)\{1\} & ISCM-Ops & ISCM-TN & ISCM-Sys & Test & & & & \\
\hline SI-3(2)\{1\} & ISCM-Ops & ISCM-TN & ISCM-Sys & Test & & & & \\
\hline SI-7\{1\} & ISCM-Ops & ISCM-TN & ISCM-Sys & Test & & & & \\
\hline SI-7(1)\{1\} & ISCM-Ops & ISCM-TN & ISCM-Sys & Test & & & & \\
\hline SI-16 $\{1\}$ & TBD & ISCM-TN & MAN & TBD & & & & \\
\hline
\end{tabular}




\subsubsection{High Baseline Control Allocation Table}

Table 10: High Baseline Control (Item) Allocation Table

\begin{tabular}{|c|c|c|c|c|c|c|c|c|}
\hline $\begin{array}{l}\text { Determination } \\
\text { Statement ID }\end{array}$ & $\underset{\mathrm{By}}{\text { Implemented }}$ & $\begin{array}{c}\text { Assessment } \\
\text { Boundary }\end{array}$ & $\begin{array}{l}\text { Assessment } \\
\text { Responsibility }\end{array}$ & $\begin{array}{c}\text { Assessment } \\
\text { Methods }\end{array}$ & Selected & $\begin{array}{l}\text { Rationale for Risk } \\
\text { Acceptance }\end{array}$ & $\begin{array}{c}\text { Frequency } \\
\text { of } \\
\text { Assessment }\end{array}$ & $\begin{array}{l}\text { Impact of Not } \\
\text { Implementing }\end{array}$ \\
\hline CM-3(1)(c)\{1\} & ISCM-Sys & ISCM-TN & ISCM-Sys & Test & & & & \\
\hline CM-4(1)\{1\} & DSM & ISCM-TN & ISCM-Sys & Test & & & & \\
\hline CM-5(3)\{1\} & SWMan & ISCM-TN & ISCM-Sys & Test & & & & \\
\hline CM-7(5)(a)\{1\} & DSM & ISCM-TN & ISCM-Sys & Test & & & & \\
\hline CM-7(5)(b)\{1\} & RskEx & ISCM-TN & ISCM-Sys & Test & & & & \\
\hline CM-7(5)(c)\{1\} & DSM & ISCM-TN & ISCM-Sys & Test & & & & \\
\hline CM-8(4)\{1\} & DSM & ISCM-TN & ISCM-Sys & Test & & & & \\
\hline MP-6(1)\{1\} & SWMan & ISCM-TN & ISCM-Sys & Test & & & & \\
\hline MP-6(2)\{1\} & SWMan & ISCM-TN & ISCM-Sys & Test & & & & \\
\hline MP-6(3)\{1\} & SWMan & ISCM-TN & ISCM-Sys & Test & & & & \\
\hline SA-12\{1\} & DSM & ISCM-TN & ISCM-Sys & Test & & & & \\
\hline SI-7(14)(a)\{1\} & RskEx & ISCM-TN & ISCM-Sys & Test & & & & \\
\hline SI-7(14)(b)\{1\} & RskEx & ISCM-TN & ISCM-Sys & Test & & & & \\
\hline
\end{tabular}




\section{Appendix A. Traceability of SWAM Control Items to Example Attack Steps}

Note: This Appendix includes only those control items that can be assessed (at least in part) via automation.

\begin{tabular}{|c|c|}
\hline Example Attack Step & SP 800-53 Control Item Code \\
\hline 1) Gain Internal Entry & CM-2(7)(a) \\
\hline 1) Gain Internal Entry & CM-2(7)(b) \\
\hline 1) Gain Internal Entry & CM-4 \\
\hline 1) Gain Internal Entry & CM-4(1) \\
\hline 1) Gain Internal Entry & CM-7(1)(b) \\
\hline 1) Gain Internal Entry & CM-7(4)(a) \\
\hline 1) Gain Internal Entry & CM-7(4)(b) \\
\hline 1) Gain Internal Entry & CM-7(5)(a) \\
\hline 1) Gain Internal Entry & CM-7(5)(b) \\
\hline 1) Gain Internal Entry & CM-8(4) \\
\hline 1) Gain Internal Entry & CM-11(b) \\
\hline 1) Gain Internal Entry & MA-3(1) \\
\hline 1) Gain Internal Entry & MA-3(2) \\
\hline 1) Gain Internal Entry & MP-6(a) \\
\hline 1) Gain Internal Entry & MP-6(b) \\
\hline 1) Gain Internal Entry & MP-6(1) \\
\hline 1) Gain Internal Entry & MP-6(2) \\
\hline 1) Gain Internal Entry & MP-6(3) \\
\hline 1) Gain Internal Entry & PS-4(d) \\
\hline 1) Gain Internal Entry & SI-3(b) \\
\hline 3) Gain Foothold & CM-4 \\
\hline 3) Gain Foothold & CM-4(1) \\
\hline 3) Gain Foothold & CM-5(3) \\
\hline 3) Gain Foothold & CM-7(a) \\
\hline 3) Gain Foothold & CM-7(b) \\
\hline 3) Gain Foothold & CM-7(1)(a) \\
\hline 3) Gain Foothold & CM-7(1)(b) \\
\hline 3) Gain Foothold & CM-7(2) \\
\hline 3) Gain Foothold & CM-7(4)(a) \\
\hline 3) Gain Foothold & CM-7(4)(b) \\
\hline 3) Gain Foothold & CM-7(4)(c) \\
\hline 3) Gain Foothold & CM-7(5)(a) \\
\hline 3) Gain Foothold & CM-7(5)(b) \\
\hline 3) Gain Foothold & CM-7(5)(c) \\
\hline
\end{tabular}




\begin{tabular}{|c|c|}
\hline Example Attack Step & SP 800-53 Control Item Code \\
\hline 3) Gain Foothold & CM-11(a) \\
\hline 3) Gain Foothold & CM-11(b) \\
\hline 3) Gain Foothold & MA-3(2) \\
\hline 3) Gain Foothold & SA-12 \\
\hline 3) Gain Foothold & SC-18(a) \\
\hline 3) Gain Foothold & SC-18(b) \\
\hline 3) Gain Foothold & SC-18(c) \\
\hline 3) Gain Foothold & SI-3(b) \\
\hline 3) Gain Foothold & SI-3(c) \\
\hline 3) Gain Foothold & $\mathrm{SI}-3(1)$ \\
\hline 3) Gain Foothold & SI-7 \\
\hline 3) Gain Foothold & SI-7(14)(a) \\
\hline 3) Gain Foothold & SI-7(14)(b) \\
\hline 4) Gain Persistence & CM-3(1)(c) \\
\hline 4) Gain Persistence & CM-4 \\
\hline 4) Gain Persistence & CM-5(3) \\
\hline 4) Gain Persistence & CM-7(a) \\
\hline 4) Gain Persistence & CM-7(b) \\
\hline 4) Gain Persistence & CM-7(1)(a) \\
\hline 4) Gain Persistence & CM-7(1)(b) \\
\hline 4) Gain Persistence & CM-7(2) \\
\hline 4) Gain Persistence & CM-7(4)(a) \\
\hline 4) Gain Persistence & CM-7(4)(b) \\
\hline 4) Gain Persistence & CM-7(4)(c) \\
\hline 4) Gain Persistence & CM-7(5)(a) \\
\hline 4) Gain Persistence & CM-7(5)(b) \\
\hline 4) Gain Persistence & CM-7(5)(c) \\
\hline 4) Gain Persistence & CM-8(4) \\
\hline 4) Gain Persistence & CM-8(5) \\
\hline 4) Gain Persistence & CM-10(a) \\
\hline 4) Gain Persistence & CM-10(b) \\
\hline 4) Gain Persistence & CM-10(c) \\
\hline 4) Gain Persistence & CM-11(a) \\
\hline 4) Gain Persistence & CM-11(b) \\
\hline 4) Gain Persistence & SI-3(a) \\
\hline 4) Gain Persistence & SI-3(b) \\
\hline 4) Gain Persistence & SI-3(c) \\
\hline 4) Gain Persistence & SI-3(d) \\
\hline 4) Gain Persistence & $\mathrm{SI}-3(1)$ \\
\hline
\end{tabular}




\begin{tabular}{|l|l|}
\hline \multicolumn{1}{|c|}{ Example Attack Step } & \multicolumn{1}{c|}{ SP 800-53 Control Item Code } \\
\hline 4) Gain Persistence & SI-3(2) \\
\hline 4) Gain Persistence & SI-7 \\
\hline 4) Gain Persistence & SI-7(1) \\
\hline 4) Gain Persistence & SI-7(14)(a) \\
\hline 4) Gain Persistence & SI-7(14)(b) \\
\hline 6) Achieve Attack Objective & CM-2 \\
\hline 6) Achieve Attack Objective & CM-2(1)(a) \\
\hline 6) Achieve Attack Objective & CM-2(1)(b) \\
\hline 6) Achieve Attack Objective & CM-2(1)(c) \\
\hline 6) Achieve Attack Objective & CM-2(3) \\
\hline 6) Achieve Attack Objective & CM-4 \\
\hline 6) Achieve Attack Objective & CM-8(a) \\
\hline 6) Achieve Attack Objective & CM-8(b) \\
\hline 6) Achieve Attack Objective & CM-8(1) \\
\hline 6) Achieve Attack Objective & CM-10(a) \\
\hline 6) Achieve Attack Objective & CM-10(b) \\
\hline 6) Achieve Attack Objective & CM-10(c) \\
\hline 6) Achieve Attack Objective & CM-11(b) \\
\hline
\end{tabular}




\section{Appendix B. Keyword Rules Used to Identify Controls that Support SWAM}

Automated keyword searches were employed to identify candidate control items in SP 800-53 that might support the SWAM capability. After candidate controls were returned by the keyword searches, the language content of each control item was examined manually, to separate those that do support the SWAM capability (true positives) from those that do not (false positives). The control items for the low, moderate, and high baselines are listed in Tables, 8, 9, and 10, respectively. The specific keyword rules used to identify SWAM controls appear in the table below.

\begin{tabular}{|c|c|}
\hline Keywords to Match in SP $800-53$ & Rationale \\
\hline *anti-counterfeit ${ }^{*}$ & Applies to counterfeit software. \\
\hline *authorized software* & $\begin{array}{l}\text { The organization authorizes software using either a deny-by- } \\
\text { exception or allow-by-exception strategy. }\end{array}$ \\
\hline *automatic* AND *execution* & $\begin{array}{l}\text { Reduce the chance that newly inserted unapproved software } \\
\text { will execute. }\end{array}$ \\
\hline "change control $^{*}$ & $\begin{array}{l}\text { The organization needs a change control process to determine } \\
\text { authorized software. }\end{array}$ \\
\hline *flaw remediation* & $\begin{array}{l}\text { CVEs and CWEs (whether flaws have been remediated) should } \\
\text { be considered when approving software initially and on an } \\
\text { ongoing basis. }\end{array}$ \\
\hline *function isolation* & $\begin{array}{l}\text { CVEs and CWEs related to function isolation should be } \\
\text { considered when approving software initially and on an ongoing } \\
\text { basis. }\end{array}$ \\
\hline${ }^{*}$ heterogen* & $\begin{array}{l}\text { Using heterogeneous software is a strategy to make a system } \\
\text { less attackable. }\end{array}$ \\
\hline *high-risk areas* & $\begin{array}{l}\text { Types and instances of software are more controlled in high risk } \\
\text { areas. When returning from a high-risk area, the software is } \\
\text { suspect, as it may have been modified. }\end{array}$ \\
\hline *inventory* & $\begin{array}{l}\text { The organization must know its current inventory, to compare to } \\
\text { the authorized inventory. }\end{array}$ \\
\hline "least func* NOT *software program* & $\begin{array}{l}\text { Unneeded software and software functions should be removed } \\
\text { or disabled. }\end{array}$ \\
\hline${ }^{*}$ malicious code* OR *malware* & Reduce the chance that unapproved software will execute. \\
\hline${ }^{*}$ mobile code* & Mobile code requires extra and/or different protections. \\
\hline *non-persisten* OR *persisten* & $\begin{array}{l}\text { Reduce the chance that unapproved software will execute } \\
\text { and/or persist }\end{array}$ \\
\hline $\begin{array}{l}\text { *operating system-independent } \\
\text { application* OR *platform-independent } \\
\text { application* }\end{array}$ & $\begin{array}{l}\text { OS- and platform-independent software is often attacked more } \\
\text { frequently as it is present on more devices. }\end{array}$ \\
\hline *peer-to-peer* & $\begin{array}{l}\text { Managing peer-to-peer software helps address copyright } \\
\text { issues; however, peer-to-peer software may also introduce } \\
\text { security vulnerabilities. }\end{array}$ \\
\hline
\end{tabular}




\begin{tabular}{|c|c|}
\hline Keywords to Match in SP $800-53$ & Rationale \\
\hline "process isolation* & $\begin{array}{l}\text { The degree of process isolation present, e.g., whether inter- } \\
\text { process communication is allowed, is a consideration when } \\
\text { authorizing software. }\end{array}$ \\
\hline *property* & $\begin{array}{l}\text { Licensed software needs control as property to avoid licensing } \\
\text { violations, which could lead to non-patching and other issues. }\end{array}$ \\
\hline *supply chain* NOT *monitoring* & $\begin{array}{l}\text { Only software from an approved supply chain should be } \\
\text { authorized (and present) }\end{array}$ \\
\hline "software* AND *restrict* & $\begin{array}{l}\text { Only authorized software should be present on the target } \\
\text { network }\end{array}$ \\
\hline $\begin{array}{l}\text { *software usage restriction* NOT * peer- } \\
\text { to-peer* }\end{array}$ & $\begin{array}{l}\text { Only authorized software should be present on the target } \\
\text { network }\end{array}$ \\
\hline *tamper resistance* & $\begin{array}{l}\text { Only software from an approved supply chain should be } \\
\text { authorized (and present) to ensure software integrity and resist } \\
\text { tampering. }\end{array}$ \\
\hline *unsupport* AND *system* & Unsupported software becomes increasingly vulnerable. \\
\hline *user* AND *software* AND *install* & Only authorized installers should be able to install software. \\
\hline "user* AND *software* AND *govern* & $\begin{array}{l}\text { A process is needed to authorize and manage installed } \\
\text { software. }\end{array}$ \\
\hline "user* AND *software* AND *polic* & Policy is needed to authorize and manage installed software. \\
\hline
\end{tabular}




\section{Appendix C. Control Items in the Low-High Baseline that were Selected by the Keyword Search for Controls that Support SWAM, but were Manually Determined to be False Positives}

\begin{tabular}{|c|c|c|c|}
\hline $\begin{array}{l}\text { SP } 800-53 \\
\text { Control } \\
\text { Item }\end{array}$ & Control Text & Level & Rationale for Calling a False Positive \\
\hline AC-6 (1) & $\begin{array}{l}\text { LEAST PRIVILEGE I AUTHORIZE ACCESS TO SECURITY FUNCTIONS } \\
\text { The organization explicitly authorizes access to [Assignment: } \\
\text { organization-defined security functions (deployed in hardware, software, } \\
\text { and firmware) and security-relevant information]. }\end{array}$ & Moderate & Relates to privileges and accounts \\
\hline SA-11 & $\begin{array}{l}\text { DEVELOPER SECURITY TESTING AND EVALUATION } \\
\text { Control: The organization requires the developer of the information } \\
\text { system, system component, or information system service to: } \\
\text { d. Implement a verifiable flaw remediation process. }\end{array}$ & Moderate & $\begin{array}{l}\text { Relates to flaw remediation (VULN) } \\
\text { rather than software asset management } \\
\text { (SWAM) }\end{array}$ \\
\hline SC-39 & $\begin{array}{l}\text { PROCESS ISOLATION } \\
\text { Control: The information system maintains a separate execution domain } \\
\text { for each executing process. }\end{array}$ & Low & $\begin{array}{l}\text { Relates to separation of processes } \\
\text { (internal boundaries - BOUND), rather } \\
\text { than to SWAM }\end{array}$ \\
\hline $\mathrm{SI}-2$ & $\begin{array}{l}\text { FLAW REMEDIATION } \\
\text { Control: The organization: } \\
\text { b. Tests software and firmware updates related to flaw remediation for } \\
\text { effectiveness and potential side effects before installation. }\end{array}$ & Low & $\begin{array}{l}\text { Relates to flaw remediation (VULN) } \\
\text { rather than to SWAM }\end{array}$ \\
\hline SI-2 (1) & $\begin{array}{l}\text { FLAW REMEDIATION | CENTRAL MANAGEMENT } \\
\text { The organization centrally manages the flaw remediation process. }\end{array}$ & High & $\begin{array}{l}\text { Relates to flaw remediation (VULN) } \\
\text { rather than to SWAM }\end{array}$ \\
\hline SI-2 (2) & $\begin{array}{l}\text { FLAW REMEDIATION | AUTOMATED FLAW REMEDIATION STATUS } \\
\text { The organization employs automated mechanisms [Assignment: } \\
\text { organization-defined frequency] to determine the state of information } \\
\text { system components with regard to flaw remediation. }\end{array}$ & Moderate & $\begin{array}{l}\text { Relates to flaw remediation (VULN) } \\
\text { rather than to SWAM }\end{array}$ \\
\hline SI-7 (2) & $\begin{array}{l}\text { SOFTWARE, FIRMWARE, AND INFORMATION INTEGRITY | } \\
\text { AUTOMATED NOTIFICATIONS OF INTEGRITY VIOLATIONS } \\
\text { The organization employs automated tools that provide notification to } \\
\text { [Assignment: organization-defined personnel or roles] upon discovering } \\
\text { discrepancies during integrity verification. }\end{array}$ & High & $\begin{array}{l}\text { Relates to behavioral expectations } \\
\text { (BEHAVE) rather than SWAM }\end{array}$ \\
\hline
\end{tabular}




\begin{tabular}{|l|l|l|l|}
\hline $\begin{array}{c}\text { SP } \mathbf{8 0 0 - 5 3} \\
\text { Control } \\
\text { Item }\end{array}$ & \multicolumn{1}{|c|}{ Control Text } & Level & Rationale for Calling a False Positive \\
\hline SI-7 (5) & $\begin{array}{l}\text { SOFTWARE, FIRMWARE, AND INFORMATION INTEGRITY } \\
\text { AUTOMATED RESPONSE TO INTEGRITY VIOLATIONS } \\
\text { The information system automatically [Selection (one or more): shuts the } \\
\text { information system down; restarts the information system; implements } \\
\text { [Assignment: organization-defined security safeguards]] when integrity } \\
\text { violations are discovered. }\end{array}$ & High & $\begin{array}{l}\text { Focus is on detect incidents and } \\
\text { contingencies (DETECT) and respond to } \\
\text { incidents and contingencies } \\
\text { (RESPOND) rather than SWAM }\end{array}$ \\
\hline SI-7 (7) & $\begin{array}{l}\text { SOFTWARE, FIRMWARE, AND INFORMATION INTEGRITY I } \\
\text { INTEGRATION OF DETECTION AND RESPONSE } \\
\text { The organization incorporates the detection of unauthorized [Assignment: } \\
\text { organization-defined security-relevant changes to the information system] } \\
\text { into the organizational incident response capability. }\end{array}$ & Moderate & $\begin{array}{l}\text { Relates to preparation for events } \\
\text { (PREPARE) rather than SWAM }\end{array}$ \\
\hline
\end{tabular}




\section{Appendix D. Control Items Not in the Low, Moderate, or High Baselines}

The following security controls items are not included in an SP 800-53 baseline and thus were not analyzed further after the keyword search:

- the Program Management (PM) Family, because the PM controls do not apply to individual systems;

- control items selected by the SWAM keywords (as specified in Appendix B) but that are not assigned to an SP 800-53 baseline; and

- the Privacy Controls.

The control items matching the criteria in the bulleted list above are provided in this appendix in case an organization wants to develop its own automated tests.

\begin{tabular}{|l|l|}
\hline \multicolumn{1}{|c|}{ SP 800-53 Control Item } & \multicolumn{1}{c|}{ Control Text } \\
\hline AT-3(4) & $\begin{array}{l}\text { SECURITY TRAINING | SUSPICIOUS COMMUNICATIONS AND ANOMALOUS SYSTEM BEHAVIOR } \\
\text { The organization provides training to its personnel on [Assignment: organization-defined indicators of } \\
\text { malicious code] to recognize suspicious communications and anomalous behavior in organizational } \\
\text { information systems. }\end{array}$ \\
\hline CM-3(3) & $\begin{array}{l}\text { CONFIGURATION CHANGE CONTROL | AUTOMATED CHANGE IMPLEMENTATION } \\
\text { The organization employs automated mechanisms to implement changes to the current information system } \\
\text { baseline and deploys the updated baseline across the installed base. }\end{array}$ \\
\hline CM-3(4) & $\begin{array}{l}\text { CONFIGURATION CHANGE CONTROL | SECURITY REPRESENTATIVE } \\
\text { The organization requires an information security representative to be a member of the [Assignment: } \\
\text { organization-defined configuration change control element]. }\end{array}$ \\
\hline CM-3(5) & $\begin{array}{l}\text { CONFIGURATION CHANGE CONTROL | AUTOMATED SECURITY RESPONSE } \\
\text { The information system implements [Assignment: organization-defined security responses] automatically if } \\
\text { baseline configurations are changed in an unauthorized manner. }\end{array}$ \\
\hline CM-3(6) & $\begin{array}{l}\text { CONFIGURATION CHANGE CONTROL | CRYPTOGRAPHY MANAGEMENT } \\
\text { The organization ensures that cryptographic mechanisms used to provide [Assignment: organization-defined } \\
\text { security safeguards] are under configuration management. }\end{array}$ \\
\hline
\end{tabular}




\begin{tabular}{|c|c|}
\hline SP $800-53$ Control Item & Control Text \\
\hline CM-5(6) & $\begin{array}{l}\text { ACCESS RESTRICTIONS FOR CHANGE I LIMIT LIBRARY PRIVILEGES } \\
\text { The organization limits privileges to change software resident within software libraries. }\end{array}$ \\
\hline CM-7(3) & $\begin{array}{l}\text { LEAST FUNCTIONALITY | REGISTRATION COMPLIANCE } \\
\text { The organization ensures compliance with [Assignment: organization-defined registration requirements for } \\
\text { functions, ports, protocols, and services]. }\end{array}$ \\
\hline CM-8(6) & $\begin{array}{l}\text { INFORMATION SYSTEM COMPONENT INVENTORY | ASSESSED CONFIGURATIONS / APPROVED } \\
\text { DEVIATIONS } \\
\text { The organization includes assessed component configurations and any approved deviations to current } \\
\text { deployed configurations in the information system component inventory. }\end{array}$ \\
\hline CM-8(7) & $\begin{array}{l}\text { INFORMATION SYSTEM COMPONENT INVENTORY I CENTRALIZED REPOSITORY } \\
\text { The organization provides a centralized repository for the inventory of information system components. }\end{array}$ \\
\hline CM-8(8) & $\begin{array}{l}\text { INFORMATION SYSTEM COMPONENT INVENTORY | AUTOMATED LOCATION TRACKING } \\
\text { The organization employs automated mechanisms to support tracking of information system components by } \\
\text { geographic location. }\end{array}$ \\
\hline CM-8(9)(a) & $\begin{array}{l}\text { INFORMATION SYSTEM COMPONENT INVENTORY | ASSIGNMENT OF COMPONENTS TO SYSTEMS } \\
\text { The organization: } \\
\text { (a) Assigns [Assignment: organization-defined acquired information system components] to an information } \\
\text { system. }\end{array}$ \\
\hline CM-8(9)(b) & $\begin{array}{l}\text { INFORMATION SYSTEM COMPONENT INVENTORY | ASSIGNMENT OF COMPONENTS TO SYSTEMS } \\
\text { The organization: } \\
\text { (b) Receives an acknowledgement from the information system owner of this assignment. }\end{array}$ \\
\hline CM-10(1) & $\begin{array}{l}\text { SOFTWARE USAGE RESTRICTIONS I OPEN SOURCE SOFTWARE } \\
\text { The organization establishes the following restrictions on the use of open source software: [Assignment: } \\
\text { organization-defined restrictions]. }\end{array}$ \\
\hline CM-11(1) & $\begin{array}{l}\text { USER-INSTALLED SOFTWARE I ALERTS FOR UNAUTHORIZED INSTALLATIONS } \\
\text { The information system alerts [Assignment: organization-defined personnel or roles] when the unauthorized } \\
\text { installation of software is detected. }\end{array}$ \\
\hline CM-11(2) & $\begin{array}{l}\text { USER-INSTALLED SOFTWARE I PROHIBIT INSTALLATION WITHOUT PRIVILEGED STATUS } \\
\text { The information system prohibits user installation of software without explicit privileged status. }\end{array}$ \\
\hline CP-10(6) & $\begin{array}{l}\text { INFORMATION SYSTEM RECOVERY AND RECONSTITUTION | COMPONENT PROTECTION } \\
\text { The organization protects backup and restoration hardware, firmware, and software. }\end{array}$ \\
\hline
\end{tabular}




\begin{tabular}{|c|c|}
\hline SP $800-53$ Control Item & Control Text \\
\hline IR-4(10) & $\begin{array}{l}\text { INCIDENT HANDLING | SUPPLY CHAIN COORDINATION } \\
\text { The organization coordinates incident handling activities involving supply chain events with other } \\
\text { organizations involved in the supply chain. }\end{array}$ \\
\hline IR-6(3) & $\begin{array}{l}\text { INCIDENT REPORTING I COORDINATION WITH SUPPLY CHAIN } \\
\text { The organization provides security incident information to other organizations involved in the supply chain for } \\
\text { information systems or information system components related to the incident. }\end{array}$ \\
\hline IR-10 & $\begin{array}{l}\text { INTEGRATED INFORMATION SECURITY ANALYSIS TEAM } \\
\text { Control: The organization establishes an integrated team of forensic/malicious code analysts, tool } \\
\text { developers, and real-time operations personnel. }\end{array}$ \\
\hline PM-5 & $\begin{array}{l}\text { INFORMATION SYSTEM INVENTORY } \\
\text { Control: The organization develops and maintains an inventory of its information systems. }\end{array}$ \\
\hline SA-10(1) & $\begin{array}{l}\text { DEVELOPER CONFIGURATION MANAGEMENT I SOFTWARE / FIRMWARE INTEGRITY VERIFICATION } \\
\text { The organization requires the developer of the information system, system component, or information system } \\
\text { service to enable integrity verification of software and firmware components. }\end{array}$ \\
\hline SA-10(4) & $\begin{array}{l}\text { DEVELOPER CONFIGURATION MANAGEMENT I TRUSTED GENERATION } \\
\text { The organization requires the developer of the information system, system component, or information system } \\
\text { service to employ tools for comparing newly generated versions of security-relevant hardware descriptions } \\
\text { and software/firmware source and object code with previous versions. }\end{array}$ \\
\hline SA-10(5) & $\begin{array}{l}\text { DEVELOPER CONFIGURATION MANAGEMENT I MAPPING INTEGRITY FOR VERSION CONTROL } \\
\text { The organization requires the developer of the information system, system component, or information system } \\
\text { service to maintain the integrity of the mapping between the master build data (hardware drawings and } \\
\text { software/firmware code) describing the current version of security-relevant hardware, software, and firmware } \\
\text { and the on-site master copy of the data for the current version. }\end{array}$ \\
\hline SA-10(6) & $\begin{array}{l}\text { DEVELOPER CONFIGURATION MANAGEMENT I TRUSTED DISTRIBUTION } \\
\text { The organization requires the developer of the information system, system component, or information system } \\
\text { service to execute procedures for ensuring that security-relevant hardware, software, and firmware updates } \\
\text { distributed to the organization are exactly as specified by the master copies. }\end{array}$ \\
\hline SA-12(1) & $\begin{array}{l}\text { SUPPLY CHAIN PROTECTION | ACQUISITION STRATEGIES / TOOLS / METHODS } \\
\text { The organization employs [Assignment: organization-defined tailored acquisition strategies, contract tools, } \\
\text { and procurement methods] for the purchase of the information system, system component, or information } \\
\text { system service from suppliers. }\end{array}$ \\
\hline
\end{tabular}




\begin{tabular}{|c|c|}
\hline SP 800-53 Control Item & Control Text \\
\hline SA-12(2) & $\begin{array}{l}\text { SUPPLY CHAIN PROTECTION I SUPPLIER REVIEWS } \\
\text { The organization conducts a supplier review prior to entering into a contractual agreement to acquire the } \\
\text { information system, system component, or information system service }\end{array}$ \\
\hline SA-12(5) & $\begin{array}{l}\text { SUPPLY CHAIN PROTECTION I LIMITATION OF HARM } \\
\text { The organization employs [Assignment: organization-defined security safeguards] to limit harm from potential } \\
\text { adversaries identifying and targeting the organizational supply chain. }\end{array}$ \\
\hline SA-12(7) & $\begin{array}{l}\text { SUPPLY CHAIN PROTECTION | ASSESSMENTS PRIOR TO SELECTION / ACCEPTANCE / UPDATE } \\
\text { The organization conducts an assessment of the information system, system component, or information } \\
\text { system service prior to selection, acceptance, or update. }\end{array}$ \\
\hline SA-12(8) & $\begin{array}{l}\text { SUPPLY CHAIN PROTECTION I USE OF ALL-SOURCE INTELLIGENCE } \\
\text { The organization uses all-source intelligence analysis of suppliers and potential suppliers of the information } \\
\text { system, system component, or information system service. }\end{array}$ \\
\hline SA-12(9) & $\begin{array}{l}\text { SUPPLY CHAIN PROTECTION I OPERATIONS SECURITY } \\
\text { The organization employs [Assignment: organization-defined Operations Security (OPSEC) safeguards] in } \\
\text { accordance with classification guides to protect supply chain-related information for the information system, } \\
\text { system component, or information system service. }\end{array}$ \\
\hline SA-12(10) & $\begin{array}{l}\text { SUPPLY CHAIN PROTECTION I VALIDATE AS GENUINE AND NOT ALTERED } \\
\text { The organization employs [Assignment: organization-defined security safeguards] to validate that the } \\
\text { information system or system component received is genuine and has not been altered. }\end{array}$ \\
\hline SA-12(11) & $\begin{array}{l}\text { SUPPLY CHAIN PROTECTION I PENETRATION TESTING / ANALYSIS OF ELEMENTS, PROCESSES, } \\
\text { AND ACTORS } \\
\text { The organization employs [Selection (one or more): organizational analysis, independent third-party analysis, } \\
\text { organizational penetration testing, independent third-party penetration testing] of [Assignment: organization- } \\
\text { defined supply chain elements, processes, and actors] associated with the information system, system } \\
\text { component, or information system service. }\end{array}$ \\
\hline SA-12(12) & $\begin{array}{l}\text { SUPPLY CHAIN PROTECTION | INTER-ORGANIZATIONAL AGREEMENTS } \\
\text { The organization establishes inter-organizational agreements and procedures with entities involved in the } \\
\text { supply chain for the information system, system component, or information system service. }\end{array}$ \\
\hline SA-12(13) & $\begin{array}{l}\text { SUPPLY CHAIN PROTECTION | CRITICAL INFORMATION SYSTEM COMPONENTS } \\
\text { The organization employs [Assignment: organization-defined security safeguards] to ensure an adequate } \\
\text { supply of [Assignment: organization-defined critical information system components]. }\end{array}$ \\
\hline
\end{tabular}




\begin{tabular}{|c|c|}
\hline SP $800-53$ Control Item & Control Text \\
\hline SA-12(14) & $\begin{array}{l}\text { SUPPLY CHAIN PROTECTION | IDENTITY AND TRACEABILITY } \\
\text { The organization establishes and retains unique identification of [Assignment: organization-defined supply } \\
\text { chain elements, processes, and actors] for the information system, system component, or information system } \\
\text { service. }\end{array}$ \\
\hline SA-12(15) & $\begin{array}{l}\text { SUPPLY CHAIN PROTECTION | PROCESSES TO ADDRESS WEAKNESSES OR DEFICIENCIES } \\
\text { The organization establishes a process to address weaknesses or deficiencies in supply chain elements } \\
\text { identified during independent or organizational assessments of such elements. }\end{array}$ \\
\hline SA-17(2)(a) & $\begin{array}{l}\text { DEVELOPER SECURITY ARCHITECTURE AND DESIGN I SECURITY-RELEVANT COMPONENTS } \\
\text { The organization requires the developer of the information system, system component, or information system } \\
\text { service to: } \\
\text { (a) Define security-relevant hardware, software, and firmware. }\end{array}$ \\
\hline SA-17(2)(b) & $\begin{array}{l}\text { DEVELOPER SECURITY ARCHITECTURE AND DESIGN I SECURITY-RELEVANT COMPONENTS } \\
\text { The organization requires the developer of the information system, system component, or information system } \\
\text { service to: } \\
\text { (b) Provide a rationale that the definition for security-relevant hardware, software, and firmware is complete. }\end{array}$ \\
\hline SA-17(3)(a) & $\begin{array}{l}\text { DEVELOPER SECURITY ARCHITECTURE AND DESIGN | FORMAL CORRESPONDENCE } \\
\text { The organization requires the developer of the information system, system component, or information system } \\
\text { service to: } \\
\text { (a) Produce, as an integral part of the development process, a formal top-level specification that specifies the } \\
\text { interfaces to security-relevant hardware, software, and firmware in terms of exceptions, error messages, and } \\
\text { effects. }\end{array}$ \\
\hline SA-17(3)(c) & $\begin{array}{l}\text { DEVELOPER SECURITY ARCHITECTURE AND DESIGN | FORMAL CORRESPONDENCE } \\
\text { The organization requires the developer of the information system, system component, or information system } \\
\text { service to: } \\
\text { (c) Show via informal demonstration, that the formal top-level specification completely covers the interfaces } \\
\text { to security-relevant hardware, software, and firmware. }\end{array}$ \\
\hline SA-17(3)(d) & $\begin{array}{l}\text { DEVELOPER SECURITY ARCHITECTURE AND DESIGN | FORMAL CORRESPONDENCE } \\
\text { The organization requires the developer of the information system, system component, or information system } \\
\text { service to: } \\
\text { (d) Show that the formal top-level specification is an accurate description of the implemented security- } \\
\text { relevant hardware, software, and firmware. }\end{array}$ \\
\hline
\end{tabular}




\begin{tabular}{|c|c|}
\hline SP $800-53$ Control Item & Control Text \\
\hline SA-17(3)(e) & $\begin{array}{l}\text { DEVELOPER SECURITY ARCHITECTURE AND DESIGN | FORMAL CORRESPONDENCE } \\
\text { The organization requires the developer of the information system, system component, or information system } \\
\text { service to: } \\
\text { (e) Describe the security-relevant hardware, software, and firmware mechanisms not addressed in the formal } \\
\text { top-level specification but strictly internal to the security-relevant hardware, software, and firmware. }\end{array}$ \\
\hline SA-17(4)(a) & $\begin{array}{l}\text { DEVELOPER SECURITY ARCHITECTURE AND DESIGN | INFORMAL CORRESPONDENCE } \\
\text { The organization requires the developer of the information system, system component, or information system } \\
\text { service to: } \\
\text { (a) Produce, as an integral part of the development process, an informal descriptive top-level specification } \\
\text { that specifies the interfaces to security-relevant hardware, software, and firmware in terms of exceptions, } \\
\text { error messages, and effects. }\end{array}$ \\
\hline SA-17(4)(c) & $\begin{array}{l}\text { DEVELOPER SECURITY ARCHITECTURE AND DESIGN | INFORMAL CORRESPONDENCE } \\
\text { The organization requires the developer of the information system, system component, or information system } \\
\text { service to: } \\
\text { (c) Show via informal demonstration, that the descriptive top-level specification completely covers the } \\
\text { interfaces to security-relevant hardware, software, and firmware. }\end{array}$ \\
\hline SA-17(4)(d) & $\begin{array}{l}\text { DEVELOPER SECURITY ARCHITECTURE AND DESIGN | INFORMAL CORRESPONDENCE } \\
\text { The organization requires the developer of the information system, system component, or information system } \\
\text { service to: } \\
\text { (d) Show that the descriptive top-level specification is an accurate description of the interfaces to security- } \\
\text { relevant hardware, software, and firmware. }\end{array}$ \\
\hline SA-17(4)(e) & $\begin{array}{l}\text { DEVELOPER SECURITY ARCHITECTURE AND DESIGN | INFORMAL CORRESPONDENCE } \\
\text { The organization requires the developer of the information system, system component, or information system } \\
\text { service to: } \\
\text { (e) Describe the security-relevant hardware, software, and firmware mechanisms not addressed in the } \\
\text { descriptive top-level specification but strictly internal to the security-relevant hardware, software, and } \\
\text { firmware. }\end{array}$ \\
\hline SA-17(5)(a) & $\begin{array}{l}\text { DEVELOPER SECURITY ARCHITECTURE AND DESIGN / CONCEPTUALLY SIMPLE DESIGN } \\
\text { The organization requires the developer of the information system, system component, or information system } \\
\text { service to: } \\
\text { (a) Design and structure the security-relevant hardware, software, and firmware to use a complete, } \\
\text { conceptually simple protection mechanism with precisely defined semantics. }\end{array}$ \\
\hline
\end{tabular}




\begin{tabular}{|c|c|}
\hline SP $800-53$ Control Item & Control Text \\
\hline SA-17(5)(b) & $\begin{array}{l}\text { DEVELOPER SECURITY ARCHITECTURE AND DESIGN I CONCEPTUALLY SIMPLE DESIGN } \\
\text { The organization requires the developer of the information system, system component, or information system } \\
\text { service to: } \\
\text { (b) Internally structure the security-relevant hardware, software, and firmware with specific regard for this } \\
\text { mechanism. }\end{array}$ \\
\hline SA-17(6) & $\begin{array}{l}\text { DEVELOPER SECURITY ARCHITECTURE AND DESIGN I STRUCTURE FOR TESTING } \\
\text { The organization requires the developer of the information system, system component, or information system } \\
\text { service to structure security-relevant hardware, software, and firmware to facilitate testing. }\end{array}$ \\
\hline SA-17(7) & $\begin{array}{l}\text { DEVELOPER SECURITY ARCHITECTURE AND DESIGN I STRUCTURE FOR LEAST PRIVILEGE } \\
\text { The organization requires the developer of the information system, system component, or information system } \\
\text { service to structure security-relevant hardware, software, and firmware to facilitate controlling access with } \\
\text { least privilege. }\end{array}$ \\
\hline SA-18 & $\begin{array}{l}\text { TAMPER RESISTANCE AND DETECTION } \\
\text { Control: The organization implements a tamper protection program for the information system, system } \\
\text { component, or information system service. }\end{array}$ \\
\hline SA-18(1) & $\begin{array}{l}\text { TAMPER RESISTANCE AND DETECTION | MULTIPLE PHASES OF SDLC } \\
\text { The organization employs anti-tamper technologies and techniques during multiple phases in the system } \\
\text { development life cycle including design, development, integration, operations, and maintenance. }\end{array}$ \\
\hline SA-18(2) & $\begin{array}{l}\text { TAMPER RESISTANCE AND DETECTION | INSPECTION OF INFORMATION SYSTEMS, COMPONENTS, } \\
\text { OR DEVICES } \\
\text { The organization inspects [Assignment: organization-defined information systems, system components, or } \\
\text { devices] [Selection (one or more): at random; at [Assignment: organization-defined frequency], upon } \\
\text { [Assignment: organization-defined indications of need for inspection]] to detect tampering. }\end{array}$ \\
\hline SA-19(a) & $\begin{array}{l}\text { COMPONENT AUTHENTICITY } \\
\text { Control: The organization: } \\
\text { a. Develops and implements anti-counterfeit policy and procedures that include the means to detect and } \\
\text { prevent counterfeit components from entering the information system. }\end{array}$ \\
\hline SA-19(1) & $\begin{array}{l}\text { COMPONENT AUTHENTICITY | ANTI-COUNTERFEIT TRAINING } \\
\text { The organization trains [Assignment: organization-defined personnel or roles] to detect counterfeit } \\
\text { information system components (including hardware, software, and firmware). }\end{array}$ \\
\hline SA-19(4) & $\begin{array}{l}\text { COMPONENT AUTHENTICITY | ANTI-COUNTERFEIT TRAINING } \\
\text { The organization scans for counterfeit information system components [Assignment: organization-defined } \\
\text { frequency]. }\end{array}$ \\
\hline
\end{tabular}




\begin{tabular}{|c|c|}
\hline SP $800-53$ Control Item & Control Text \\
\hline SA-22(a) & $\begin{array}{l}\text { UNSUPPORTED SYSTEM COMPONENTS } \\
\text { Control: The organization: } \\
\text { a. Replaces information system components when support for the components is no longer available from } \\
\text { the developer, vendor, or manufacturer. }\end{array}$ \\
\hline SA-22(b) & $\begin{array}{l}\text { UNSUPPORTED SYSTEM COMPONENTS } \\
\text { Control: The organization: } \\
\text { b. Provides justification and documents approval for the continued use of unsupported system components } \\
\text { required to satisfy mission/business needs. }\end{array}$ \\
\hline SA-22(1) & $\begin{array}{l}\text { UNSUPPORTED SYSTEM COMPONENTS | ALTERNATIVE SOURCES FOR CONTINUED SUPPORT } \\
\text { The organization provides [Selection (one or more): in-house support; [Assignment: organization-defined } \\
\text { support from external providers]] for unsupported information system components. }\end{array}$ \\
\hline SC-3(1) & $\begin{array}{l}\text { SECURITY FUNCTION ISOLATION | HARDWARE SEPARATION } \\
\text { The information system utilizes underlying hardware separation mechanisms to implement security function } \\
\text { isolation. }\end{array}$ \\
\hline SC-3(2) & $\begin{array}{l}\text { SECURITY FUNCTION ISOLATION I ACCESS / FLOW CONTROL FUNCTIONS } \\
\text { The information system isolates security functions enforcing access and information flow control from } \\
\text { nonsecurity functions and from other security functions. }\end{array}$ \\
\hline SC-3(3) & $\begin{array}{l}\text { SECURITY FUNCTION ISOLATION | MINIMIZE NONSECURITY FUNCTIONALITY } \\
\text { The organization minimizes the number of nonsecurity functions included within the isolation boundary } \\
\text { containing security functions. }\end{array}$ \\
\hline SC-3(4) & $\begin{array}{l}\text { SECURITY FUNCTION ISOLATION | MODULE COUPLING AND COHESIVENESS } \\
\text { The organization implements security functions as largely independent modules that maximize internal } \\
\text { cohesiveness within modules and minimize coupling between modules. }\end{array}$ \\
\hline SC-3(5) & $\begin{array}{l}\text { SECURITY FUNCTION ISOLATION I LAYERED STRUCTURES } \\
\text { The organization implements security functions as a layered structure minimizing interactions between layers } \\
\text { of the design and avoiding any dependence by lower layers on the functionality or correctness of higher } \\
\text { layers. }\end{array}$ \\
\hline SC-18(1) & $\begin{array}{l}\text { MOBILE CODE I IDENTIFY UNACCEPTABLE CODE / TAKE CORRECTIVE ACTIONS } \\
\text { The information system identifies [Assignment: organization-defined unacceptable mobile code] and takes } \\
\text { [Assignment: organization-defined corrective actions]. }\end{array}$ \\
\hline
\end{tabular}




\begin{tabular}{|c|c|}
\hline SP $800-53$ Control Item & Control Text \\
\hline SC-18(2) & $\begin{array}{l}\text { MOBILE CODE I ACQUISITION / DEVELOPMENT / USE } \\
\text { The organization ensures that the acquisition, development, and use of mobile code to be deployed in the } \\
\text { information system meets [Assignment: organization-defined mobile code requirements]. }\end{array}$ \\
\hline SC-18(3) & $\begin{array}{l}\text { MOBILE CODE I PREVENT DOWNLOADING / EXECUTION } \\
\text { The information system prevents the download and execution of [Assignment: organization-defined } \\
\text { unacceptable mobile code]. }\end{array}$ \\
\hline SC-18(4) & $\begin{array}{l}\text { MOBILE CODE I PREVENT AUTOMATIC EXECUTION } \\
\text { The information system prevents the automatic execution of mobile code in [Assignment: organization- } \\
\text { defined software applications] and enforces [Assignment: organization-defined actions] prior to executing the } \\
\text { code. }\end{array}$ \\
\hline SC-18(5) & $\begin{array}{l}\text { MOBILE CODE I ALLOW EXECUTION ONLY IN CONFINED ENVIRONMENTS } \\
\text { The organization allows execution of permitted mobile code only in confined virtual machine environments. }\end{array}$ \\
\hline SC-27 & $\begin{array}{l}\text { PLATFORM-INDEPENDENT APPLICATIONS } \\
\text { Control: The information system includes: [Assignment: organization-defined platform-independent } \\
\text { applications]. }\end{array}$ \\
\hline SC-29 & $\begin{array}{l}\text { HETEROGENEITY } \\
\text { Control: The organization employs a diverse set of information technologies for [Assignment: organization- } \\
\text { defined information system components] in the implementation of the information system. }\end{array}$ \\
\hline SC-29(1) & $\begin{array}{l}\text { HETEROGENEITY | VIRTUALIZATION TECHNIQUES } \\
\text { The organization employs virtualization techniques to support the deployment of a diversity of operating } \\
\text { systems and applications that are changed [Assignment: organization-defined frequency]. }\end{array}$ \\
\hline SC-34(1) & $\begin{array}{l}\text { NON-MODIFIABLE EXECUTABLE PROGRAMS | NO WRITABLE STORAGE } \\
\text { The organization employs [Assignment: organization-defined information system components] with no } \\
\text { writeable storage that is persistent across component restart or power on/off. }\end{array}$ \\
\hline SC-34(3)(a) & $\begin{array}{l}\text { NON-MODIFIABLE EXECUTABLE PROGRAMS I HARDWARE-BASED PROTECTION } \\
\text { The organization: } \\
\text { (a) Employs hardware-based, write-protect for [Assignment: organization-defined information system } \\
\text { firmware components]. }\end{array}$ \\
\hline
\end{tabular}




\begin{tabular}{|c|c|}
\hline SP $800-53$ Control Item & Control Text \\
\hline SC-34(3)(b) & $\begin{array}{l}\text { NON-MODIFIABLE EXECUTABLE PROGRAMS | HARDWARE-BASED PROTECTION } \\
\text { The organization: } \\
\text { (b) Implements specific procedures for [Assignment: organization-defined authorized individuals] to manually } \\
\text { disable hardware write-protect for firmware modifications and re-enable the write-protect prior to returning to } \\
\text { operational mode. }\end{array}$ \\
\hline SC-35 & $\begin{array}{l}\text { HONEYCLIENTS } \\
\text { Control: The information system includes components that proactively seek to identify malicious websites } \\
\text { and/or web-based malicious code. }\end{array}$ \\
\hline SC-39(1) & $\begin{array}{l}\text { PROCESS ISOLATION | HARDWARE SEPARATION } \\
\text { The information system implements underlying hardware separation mechanisms to facilitate process } \\
\text { separation. }\end{array}$ \\
\hline SC-39(2) & $\begin{array}{l}\text { PROCESS ISOLATION I THREAD ISOLATION } \\
\text { The information system maintains a separate execution domain for each thread in [Assignment: organization- } \\
\text { defined multi-threaded processing]. }\end{array}$ \\
\hline SE-1(a) & $\begin{array}{l}\text { INVENTORY OF PERSONALLY IDENTIFIABLE INFORMATION } \\
\text { Control: The organization: } \\
\text { a. Establishes, maintains, and updates [Assignment: organization-defined frequency] an inventory that } \\
\text { contains a listing of all programs and information systems identified as collecting, using, maintaining, or } \\
\text { sharing personally identifiable information (PII). }\end{array}$ \\
\hline SE-1(b) & $\begin{array}{l}\text { INVENTORY OF PERSONALLY IDENTIFIABLE INFORMATION } \\
\text { Control: The organization: } \\
\text { b. Provides each update of the PII inventory to the CIO or information security official [Assignment: } \\
\text { organization-defined frequency] to support the establishment of information security requirements for all new } \\
\text { or modified information systems containing PII. }\end{array}$ \\
\hline $\mathrm{SI}-2(3)(\mathrm{a})$ & $\begin{array}{l}\text { FLAW REMEDIATION | TIME TO REMEDIATE FLAWS / BENCHMARKS FOR CORRECTIVE ACTIONS } \\
\text { The organization: } \\
\text { (a) Measures the time between flaw identification and flaw remediation. }\end{array}$ \\
\hline $\mathrm{SI}-2(3)(\mathrm{b})$ & $\begin{array}{l}\text { FLAW REMEDIATION | TIME TO REMEDIATE FLAWS / BENCHMARKS FOR CORRECTIVE ACTIONS } \\
\text { The organization: } \\
\text { (b) Establishes [Assignment: organization-defined benchmarks] for taking corrective actions. }\end{array}$ \\
\hline
\end{tabular}




\begin{tabular}{|c|c|}
\hline SP $800-53$ Control Item & Control Text \\
\hline SI-2(5) & $\begin{array}{l}\text { FLAW REMEDIATION I AUTOMATIC SOFTWARE / FIRMWARE UPDATES } \\
\text { The organization installs [Assignment: organization-defined security-relevant software and firmware updates] } \\
\text { automatically to [Assignment: organization-defined information system components]. }\end{array}$ \\
\hline $\mathrm{SI}-2(6)$ & $\begin{array}{l}\text { FLAW REMEDIATION | REMOVAL OF PREVIOUS VERSIONS OF SOFTWARE / FIRMWARE } \\
\text { The organization removes [Assignment: organization-defined software and firmware components] after } \\
\text { updated versions have been installed. }\end{array}$ \\
\hline $\mathrm{SI}-3(4)$ & $\begin{array}{l}\text { MALICIOUS CODE PROTECTION I UPDATES ONLY BY PRIVILEGED USERS } \\
\text { The information system updates malicious code protection mechanisms only when directed by a privileged } \\
\text { user. [MAPCAT-ACPR] }\end{array}$ \\
\hline SI-3(6)(a) & $\begin{array}{l}\text { MALICIOUS CODE PROTECTION I TESTING / VERIFICATION } \\
\text { The organization: } \\
\text { (a) Tests malicious code protection mechanisms [Assignment: organization-defined frequency] by introducing } \\
\text { a known benign, non-spreading test case into the information system. }\end{array}$ \\
\hline SI-3(6)(b) & $\begin{array}{l}\text { MALICIOUS CODE PROTECTION I TESTING / VERIFICATION } \\
\text { The organization: } \\
\text { (b) Verifies that both detection of the test case and associated incident reporting occur. }\end{array}$ \\
\hline SI-3(7) & $\begin{array}{l}\text { MALICIOUS CODE PROTECTION | NONSIGNATURE-BASED DETECTION } \\
\text { The information system implements nonsignature-based malicious code detection mechanisms. }\end{array}$ \\
\hline $\mathrm{SI}-3(8)$ & $\begin{array}{l}\text { MALICIOUS CODE PROTECTION | DETECT UNAUTHORIZED COMMANDS } \\
\text { The information system detects [Assignment: organization-defined unauthorized operating system } \\
\text { commands] through the kernel application programming interface at [Assignment: organization-defined } \\
\text { information system hardware components] and [Selection (one or more): issues a warning; audits the } \\
\text { command execution; prevents the execution of the command]. }\end{array}$ \\
\hline SI-3(9) & $\begin{array}{l}\text { MALICIOUS CODE PROTECTION | AUTHENTICATE REMOTE COMMANDS } \\
\text { The information system implements [Assignment: organization-defined security safeguards] to authenticate } \\
\text { [Assignment: organization-defined remote commands]. }\end{array}$ \\
\hline SI-3(10)(a) & $\begin{array}{l}\text { MALICIOUS CODE PROTECTION | MALICIOUS CODE ANALYSIS } \\
\text { The organization: } \\
\text { (a) Employs [Assignment: organization-defined tools and techniques] to analyze the characteristics and } \\
\text { behavior of malicious code. }\end{array}$ \\
\hline
\end{tabular}




\begin{tabular}{|c|c|}
\hline SP 800-53 Control Item & Control Text \\
\hline SI-3(10)(b) & $\begin{array}{l}\text { MALICIOUS CODE PROTECTION | MALICIOUS CODE ANALYSIS } \\
\text { The organization: } \\
\text { (b) Incorporates the results from malicious code analysis into organizational incident response and flaw } \\
\text { remediation processes. }\end{array}$ \\
\hline SI-7(3) & $\begin{array}{l}\text { SOFTWARE, FIRMWARE, AND INFORMATION INTEGRITY | CENTRALLY-MANAGED INTEGRITY } \\
\text { TOOLS } \\
\text { The organization employs centrally managed integrity verification tools. }\end{array}$ \\
\hline SI-7(6) & $\begin{array}{l}\text { SOFTWARE, FIRMWARE, AND INFORMATION INTEGRITY I CRYPTOGRAPHIC PROTECTION } \\
\text { The information system implements cryptographic mechanisms to detect unauthorized changes to software, } \\
\text { firmware, and information. }\end{array}$ \\
\hline SI-7(8) & $\begin{array}{l}\text { SOFTWARE, FIRMWARE, AND INFORMATION INTEGRITY | AUDITING CAPABILITY FOR SIGNIFICANT } \\
\text { EVENTS } \\
\text { The information system, upon detection of a potential integrity violation, provides the capability to audit the } \\
\text { event and initiates the following actions: [Selection (one or more): generates an audit record; alerts current } \\
\text { user; alerts [Assignment: organization-defined personnel or roles]; [Assignment: organization-defined other } \\
\text { actions]]. }\end{array}$ \\
\hline SI-7(9) & $\begin{array}{l}\text { SOFTWARE, FIRMWARE, AND INFORMATION INTEGRITY I VERIFY BOOT PROCESS } \\
\text { The information system verifies the integrity of the boot process of [Assignment: organization-defined } \\
\text { devices]. }\end{array}$ \\
\hline SI-7(10) & $\begin{array}{l}\text { SOFTWARE, FIRMWARE, AND INFORMATION INTEGRITY | PROTECTION OF BOOT FIRMWARE } \\
\text { The information system implements [Assignment: organization-defined security safeguards] to protect the } \\
\text { integrity of boot firmware in [Assignment: organization-defined devices]. }\end{array}$ \\
\hline SI-7(11) & $\begin{array}{l}\text { SOFTWARE, FIRMWARE, AND INFORMATION INTEGRITY | CONFINED ENVIRONMENTS WITH } \\
\text { LIMITED PRIVILEGES } \\
\text { The organization requires that [Assignment: organization-defined user-installed software] execute in a } \\
\text { confined physical or virtual machine environment with limited privileges. }\end{array}$ \\
\hline SI-7(12) & $\begin{array}{l}\text { SOFTWARE, FIRMWARE, AND INFORMATION INTEGRITY | INTEGRITY VERIFICATION } \\
\text { The organization requires that the integrity of [Assignment: organization-defined user-installed software] be } \\
\text { verified prior to execution. }\end{array}$ \\
\hline
\end{tabular}




\begin{tabular}{|l|l|}
\hline \multicolumn{1}{|c|}{ SP 800-53 Control Item } & \multicolumn{1}{c|}{ Control Text } \\
\hline SI-7(13) & $\begin{array}{l}\text { SOFTWARE, FIRMWARE, AND INFORMATION INTEGRITY | CODE EXECUTION IN PROTECTED } \\
\text { ENVIRONMENTS } \\
\text { The organization allows execution of binary or machine-executable code obtained from sources with limited } \\
\text { or no warranty and without the provision of source code only in confined physical or virtual machine } \\
\text { environments and with the explicit approval of [Assignment: organization-defined personnel or roles]. }\end{array}$ \\
\hline SI-7(15) & $\begin{array}{l}\text { SOFTWARE, FIRMWARE, AND INFORMATION INTEGRITY | CODE AUTHENTICATION } \\
\text { The information system implements cryptographic mechanisms to authenticate [Assignment: organization- } \\
\text { defined software or firmware components] prior to installation. }\end{array}$ \\
\hline SI-7(16) & $\begin{array}{l}\text { SOFTWARE, FIRMWARE, AND INFORMATION INTEGRITY | TIME LIMIT ON PROCESS EXECUTION } \\
\text { W/O SUPERVISION } \\
\text { The organization does not allow processes to execute without supervision for more than [Assignment: } \\
\text { organization-defined time period]. }\end{array}$ \\
\hline SI-14 & $\begin{array}{l}\text { NON-PERSISTENCE } \\
\text { Control: The organization implements non-persistent [Assignment: organization-defined information system } \\
\text { components and services] that are initiated in a known state and terminated [Selection (one or more): upon } \\
\text { end of session of use; periodically at [Assignment: organization-defined frequency]]. }\end{array}$ \\
\hline SI-14(1) & $\begin{array}{l}\text { NON-PERSISTENCE I REFRESH FROM TRUSTED SOURCES } \\
\text { The organization ensures that software and data employed during information system component and } \\
\text { service refreshes are obtained from [Assignment: organization-defined trusted sources]. }\end{array}$ \\
\hline
\end{tabular}




\section{Appendix E. SWAM-Specific Acronyms and Abbreviations*}
DLL
Dynamic Link Library
SWID
Software Identification
TPM
Trusted Platform Module

*Note that acronyms common to multiple capabilities are addressed in Volume 1 of this NISTIR. 


\section{Appendix F. Glossary}

Core Software

Cryptographic Hash Value

Digital Fingerprint

Digital Signature

Installation (as used herein)

Message Digest
An organizationally defined set of software that, at a minimum, includes firmware and root operating system elements used to boot the system. Core software merits specialized monitoring as it may be difficult for commonly used whitelisting software to check.

The result of applying a cryptographic hash function to data (e.g., a message). (Source: SP 800-57). ${ }^{28}$ Also see Message Digest.

See Message Digest.

An asymmetric key operation where the private key is used to digitally sign data and the public key is used to verify the signature. Digital signatures provide authenticity protection, integrity protection, and non-repudiation, but not confidentiality protection. (Source: SP 800-63). ${ }^{29}$

Any of the following actions:

- Executing an installer to load software.

- Listing software in the operating system software directory

- (Merely) placing executable software files on a medium from which it can be executed, even if no installer software is run and there is no listing for it in the operating system software directory.

- Any other action that allows an executable software file to be loaded into the CPU (e.g., browsing a website that downloads software; opening an e-mail (or attachment) that downloads software; etc.)

The result of applying a hash function to a message. Also known as a "hash value" or "hash output". (Source: SP 800-107). ${ }^{30}$

A digital signature that uniquely identifies data and has the property that changing a single bit in the data will cause a completely different message digest to be generated. (Source: SP 800-92). ${ }^{31}$

\footnotetext{
${ }^{28} \mathrm{https}: / /$ doi.org/10.6028/NIST.SP.800-57pt1r4

${ }^{29}$ https://doi.org/10.6028/NIST.SP.800-63-3

30 https://doi.org/10.6028/NIST.SP.800-107r1

31 https://doi.org/10.6028/NIST.SP.800-92
} 
SWID Tag

Zero-Day Attack
A cryptographic checksum, typically generated for a file that can be used to detect changes to the file. Synonymous with hash value/result. (Source: CNSSI-4009). ${ }^{32}$

A SWID tag is an ISO 19770-2 compliant XML file describing a software product. It is typically digitally signed by the software manufacturer to verify its validity. Ideally, for purposes of software asset management, the SWID tag will contain the digests (digital fingerprints) of each software file installed or placed on the device with the product.

An attack that exploits a previously unknown hardware, firmware, or software vulnerability.

\footnotetext{
32 https://www.cnss.gov/CNSS/issuances/Instructions.cfm
} 


\section{Appendix G. Control Items Affecting Desired and/or Actual State from All Defect Checks in this Volume}

This table is to support root cause analysis when a specific defect check fails. Such a failure might be caused not only by a failure of the specific control items mapped to that defect check in the defect check narratives, but also by a failure in any of the following control items. As used here, these controls apply to potential defects in the desired state (DS) and/or actual state (AS). The rationale column explains how a defect in the control item might cause the defect check to fail.

Note: These items are not explicitly included in the control item assessment narratives, unless they also apply to CM of items other than the desired and actual states, for assessment.

\begin{tabular}{|l|l|l|l|l|}
\hline \multicolumn{1}{|c|}{$\begin{array}{c}\text { Determination } \\
\text { Statement ID }\end{array}$} & \multicolumn{1}{|c|}{ Determination Statement Text } & \multicolumn{1}{|c|}{$\begin{array}{c}\text { Impact } \\
\text { Level }\end{array}$} & $\begin{array}{c}\text { Affects DS } \\
\text { and/or AS }\end{array}$ & Rationale \\
\hline CM-2\{1\} & $\begin{array}{l}\text { Determine if the organization: develops, } \\
\text { documents, and maintains under } \\
\text { configuration control, a current baseline } \\
\text { configuration of the information system. }\end{array}$ & Low & DS & $\begin{array}{l}\text { Otherwise, there is no desired state for } \\
\text { testing. }\end{array}$ \\
\hline CM-2(1)(a)\{1\} & $\begin{array}{l}\text { Determine if the organization: reviews and } \\
\text { updates the baseline configuration of the } \\
\text { information system: } \\
\text { (a) [Assignment: organization-defined } \\
\text { frequency]. }\end{array}$ & $\begin{array}{l}\text { Moderate } \\
\text { Determine if the organization: reviews and } \\
\text { updates the baseline configuration of the } \\
\text { information system: } \\
\text { (b) When required due to [Assignment } \\
\text { organization-defined circumstances]. }\end{array}$ & DS & $\begin{array}{l}\text { Otherwise, the desired state might not be } \\
\text { updated as needed to maintain appropriate } \\
\text { security. }\end{array}$ \\
\hline CM-2(1)(b)\{1\} & $\begin{array}{l}\text { Determine if the organization: reviews and } \\
\text { updates the baseline configuration of the } \\
\text { information system: } \\
\text { (c) As an integral part of information } \\
\text { system component installations and } \\
\text { upgrades. }\end{array}$ & DS & $\begin{array}{l}\text { Otherwise, desired state might not be } \\
\text { updated based on the organization-defined } \\
\text { circumstances. }\end{array}$ \\
\hline CM-2(1)(c)\{1\} & DS & $\begin{array}{l}\text { Otherwise, desired state might not be } \\
\text { updated as appropriate when component } \\
\text { installations and updates occur. }\end{array}$ \\
\hline
\end{tabular}




\begin{tabular}{|c|c|c|c|c|}
\hline $\begin{array}{l}\text { Determination } \\
\text { Statement ID }\end{array}$ & Determination Statement Text & $\begin{array}{l}\text { Impact } \\
\text { Level }\end{array}$ & $\begin{array}{l}\text { Affects DS } \\
\text { and/or AS }\end{array}$ & Rationale \\
\hline CM-2(2)\{1\} & $\begin{array}{l}\text { Determine if the organization: employs } \\
\text { automated mechanisms to maintain an up- } \\
\text { to-date, complete, accurate, and readily } \\
\text { available baseline configuration of the } \\
\text { information system. }\end{array}$ & High & DS & $\begin{array}{l}\text { Otherwise accurate testing information } \\
\text { might not be provided. }\end{array}$ \\
\hline CM-3(a) $\{1\}$ & $\begin{array}{l}\text { Determine if the organization: employs } \\
\text { automated mechanisms to determine the } \\
\text { types of changes to the system \{installed } \\
\text { software\} that are configuration-controlled. }\end{array}$ & Moderate & DS & $\begin{array}{l}\text { Otherwise, the desired state might not } \\
\text { specify all \{machine-readable\} data } \\
\text { needed for implemented defect checks. }\end{array}$ \\
\hline CM-3(b) $\{1\}$ & $\begin{array}{l}\text { Determine if the organization: reviews } \\
\text { proposed configuration-controlled changes } \\
\text { to the \{software of the\} system and } \\
\text { approves or disapproves such changes. }\end{array}$ & Moderate & DS & $\begin{array}{l}\text { Otherwise, the decisions on desired state } \\
\text { might not adequately reflect security } \\
\text { impact of changes. }\end{array}$ \\
\hline CM-3(b) $\{2\}$ & $\begin{array}{l}\text { Determine if the organization: explicitly } \\
\text { considers security impact analysis when } \\
\text { reviewing proposed configuration- } \\
\text { controlled changes to the \{software of the } \\
\text { system. }\end{array}$ & Moderate & DS & $\begin{array}{l}\text { Otherwise, the decisions on desired state } \\
\text { might not adequately reflect security } \\
\text { impact of changes. }\end{array}$ \\
\hline CM-3(c) $\{1\}$ & $\begin{array}{l}\text { Determine if the organization: documents } \\
\text { configuration change decisions associated } \\
\text { with the system \{installed software\}. }\end{array}$ & Moderate & DS & $\begin{array}{l}\text { Otherwise changes to the desired state } \\
\text { specification might not be documented and } \\
\text { available } \text { as machine-readable data\}. }\end{array}$ \\
\hline CM-3(d)\{1\} & $\begin{array}{l}\text { Determine if the organization: implements } \\
\text { approved configuration-controlled changes } \\
\text { to the system \{installed software\}. }\end{array}$ & Moderate & AS & $\begin{array}{l}\text { Otherwise, defect checks might fail } \\
\text { because changes were not implemented in } \\
\text { the actual state. }\end{array}$ \\
\hline CM-3(f) $\{1\}$ & $\begin{array}{l}\text { Determine if the organization: audits } \\
\text { activities associated with configuration- } \\
\text { controlled changes to the \{software of the } \\
\text { system. }\end{array}$ & Moderate & DS & $\begin{array}{l}\text { Otherwise, errors in the desired state might } \\
\text { not be detected. }\end{array}$ \\
\hline CM-3(f) $\{2\}$ & $\begin{array}{l}\text { Determine if the organization: reviews } \\
\text { activities associated with configuration- } \\
\text { controlled changes to the \{software of the\} } \\
\text { system. }\end{array}$ & Moderate & DS & $\begin{array}{l}\text { Otherwise, errors in the desired state might } \\
\text { not be detected. }\end{array}$ \\
\hline
\end{tabular}




\begin{tabular}{|c|c|c|c|c|}
\hline $\begin{array}{l}\text { Determination } \\
\text { Statement ID }\end{array}$ & Determination Statement Text & $\begin{array}{l}\text { Impact } \\
\text { Level }\end{array}$ & $\begin{array}{l}\text { Affects DS } \\
\text { and/or AS }\end{array}$ & Rationale \\
\hline CM-3(g) $\{1\}$ & $\begin{array}{l}\text { Determine if the organization: coordinates } \\
\text { configuration change control activities \{of } \\
\text { software\} through [Assignment: } \\
\text { organization-defined configuration change } \\
\text { control element (e.g., committee, board)] } \\
\text { that convenes [Selection (one or more): } \\
\text { [Assignment: organization-defined } \\
\text { frequency]; [Assignment: organization- } \\
\text { defined configuration change conditions]. }\end{array}$ & Moderate & DS & $\begin{array}{l}\text { Otherwise, the persons authorized to make } \\
\text { change approval decisions, and the scope } \\
\text { of their authority, might not be clearly } \\
\text { defined to enable knowing what decisions } \\
\text { are authorized. }\end{array}$ \\
\hline CM-3(g)\{2\} & $\begin{array}{l}\text { Determine if the organization: provides } \\
\text { oversight for configuration change control } \\
\text { activities } \text { of software\} through } \\
\text { [Assignment: organization-defined } \\
\text { configuration change control element (e.g., } \\
\text { committee, board)] that convenes } \\
\text { [Selection (one or more): [Assignment: } \\
\text { organization-defined frequency]; } \\
\text { [Assignment: organization-defined } \\
\text { configuration change conditions]. }\end{array}$ & Moderate & DS & $\begin{array}{l}\text { Otherwise, the persons authorized to make } \\
\text { change approval decisions, and the scope } \\
\text { of their authority, might not be clearly } \\
\text { defined to enable knowing what decisions } \\
\text { are authorized. }\end{array}$ \\
\hline CM-3(1)(a)\{1\} & $\begin{array}{l}\text { Determine if the organization: employs } \\
\text { automated mechanisms to document } \\
\text { proposed changes to the system \{installed } \\
\text { software\}. }\end{array}$ & High & DS & $\begin{array}{l}\text { Otherwise changes to the desired state } \\
\text { specification might not be documented and } \\
\text { available for assessment. }\end{array}$ \\
\hline CM-3(1)(b)\{1\} & $\begin{array}{l}\text { Determine if the organization: employs } \\
\text { automated mechanisms to notify } \\
\text { [Assignment: organized-defined approval } \\
\text { authorities] of proposed changes to the } \\
\text { system \{installed software } \text { and request } \\
\text { change approval. }\end{array}$ & High & DS & $\begin{array}{l}\text { Otherwise, needed changes might not be } \\
\text { reviewed in a timely manner. }\end{array}$ \\
\hline CM-3(1)(c)\{1\} & $\begin{array}{l}\text { Determine if the organization: employs } \\
\text { automated mechanisms to highlight } \\
\text { proposed changes to the system \{installed } \\
\text { software\} that have not been approved or } \\
\text { disapproved by [Assignment: organization- } \\
\text { defined time period]. }\end{array}$ & High & DS & $\begin{array}{l}\text { Otherwise, needed changes might not be } \\
\text { reviewed in a timely manner. }\end{array}$ \\
\hline
\end{tabular}




\begin{tabular}{|c|c|c|c|c|}
\hline $\begin{array}{l}\text { Determination } \\
\text { Statement ID }\end{array}$ & Determination Statement Text & $\begin{array}{l}\text { Impact } \\
\text { Level }\end{array}$ & $\begin{array}{l}\text { Affects DS } \\
\text { and/or AS }\end{array}$ & Rationale \\
\hline $\mathrm{CM}-3(1)(\mathrm{d})\{1\}$ & $\begin{array}{l}\text { Determine if the organization: employs } \\
\text { automated mechanisms to prohibit } \\
\text { changes to the system \{installed software\} } \\
\text { until designated approvals are received. }\end{array}$ & High & DS & $\begin{array}{l}\text { Otherwise, unapproved changes might be } \\
\text { implemented. }\end{array}$ \\
\hline CM-3(1)(e)\{1\} & $\begin{array}{l}\text { Determine if the organization: employs } \\
\text { automated mechanisms to document all } \\
\text { changes to the system \{installed software\}. }\end{array}$ & High & AS & $\begin{array}{l}\text { Otherwise, documented changes might not } \\
\text { reflect the actual state of the system. }\end{array}$ \\
\hline $\mathrm{CM}-3(1)(\mathrm{f})\{1\}$ & $\begin{array}{l}\text { Determine if the organization: employs } \\
\text { automated mechanisms to notify } \\
\text { [Assignment: organization-defined } \\
\text { personnel] when approved changes to the } \\
\text { system \{installed software }\} \text { are completed. }\end{array}$ & High & DS & $\begin{array}{l}\text { Otherwise, required changes might be } \\
\text { missed. }\end{array}$ \\
\hline $\mathrm{CM}-3(2)\{1\}$ & $\begin{array}{l}\text { Determine if the organization: tests, } \\
\text { validates, and documents changes to the } \\
\text { \{software of the\} system before } \\
\text { implementing the changes on the } \\
\text { operational system. } \\
\text { Not applicable in the operational } \\
\text { environment. } \\
\text { This should be assessed via manual } \\
\text { reauthorization prior to placing policy in the } \\
\text { desired state. Because it occurs as part of } \\
\text { system engineering, it is outside the scope } \\
\text { of this operational capability. }\end{array}$ & Moderate & DS and AS & $\begin{array}{l}\text { Otherwise, changes might increase risk by } \\
\text { creating operational or security defects. }\end{array}$ \\
\hline CM-8(a)\{1\} & $\begin{array}{l}\text { Determine if the organization: develops } \\
\text { and documents an inventory of system } \\
\text { components for software\} that: (1) } \\
\text { accurately reflects the current system; and } \\
\text { (2) includes all components within the } \\
\text { authorization boundary of the system. }\end{array}$ & Low & DS and AS & $\begin{array}{l}\text { Otherwise the desired state and actual } \\
\text { state inventories might have errors related } \\
\text { to accuracy, completeness, and/or content. }\end{array}$ \\
\hline
\end{tabular}




\begin{tabular}{|c|c|c|c|c|}
\hline $\begin{array}{l}\text { Determination } \\
\text { Statement ID }\end{array}$ & Determination Statement Text & $\begin{array}{l}\text { Impact } \\
\text { Level }\end{array}$ & $\begin{array}{l}\text { Affects DS } \\
\text { and/or AS }\end{array}$ & Rationale \\
\hline CM-8(a)\{2\} & $\begin{array}{l}\text { Determine if the organization: develops } \\
\text { and documents an inventory of system } \\
\text { components }\{\text { for software\} that is at the } \\
\text { level of granularity deemed necessary for } \\
\text { tracking and reporting [by the } \\
\text { organization]. }\end{array}$ & Low & DS and AS & $\begin{array}{l}\text { Otherwise the desired state and actual } \\
\text { state inventories might have errors related } \\
\text { to level of detail. }\end{array}$ \\
\hline CM-8(b) $\{1\}$ & $\begin{array}{l}\text { Determine if the organization: updates the } \\
\text { system component inventory \{for software } \\
\text { [Assignment: organization-defined } \\
\text { frequency]. }\end{array}$ & Low & DS and AS & $\begin{array}{l}\text { Otherwise, defects in the desired state and } \\
\text { actual state inventories, and related } \\
\text { processes, might not be detected. }\end{array}$ \\
\hline CM-8(b) $\{2\}$ & $\begin{array}{l}\text { Determine if the organization: reviews the } \\
\text { system component inventory \{for software } \\
\text { [Assignment: organization-defined } \\
\text { frequency]. }\end{array}$ & Low & DS and AS & $\begin{array}{l}\text { Otherwise, defects in the desired state and } \\
\text { actual state inventories, and related } \\
\text { processes might not be detected. }\end{array}$ \\
\hline CM-8(1)\{1\} & $\begin{array}{l}\text { Determine if the organization: updates the } \\
\text { inventory of system \{installed software\} } \\
\text { components as an integral part of } \\
\text { component installations, removals, and } \\
\text { system updates. }\end{array}$ & Moderate & DS and AS & $\begin{array}{l}\text { Otherwise, defects in desired state and } \\
\text { actual state inventories and related } \\
\text { processes might not be detected. }\end{array}$ \\
\hline CM-8(2)\{1\} & $\begin{array}{l}\text { Determine if the organization: employs } \\
\text { automated mechanisms to help maintain } \\
\text { an up-to-date, complete, accurate, and } \\
\text { readily available inventory of system } \\
\text { \{installed software }\} \text { components. }\end{array}$ & High & DS and AS & $\begin{array}{l}\text { Otherwise, an up to date and accurate } \\
\text { desired state and actual state inventories } \\
\text { might not be available for automated } \\
\text { assessment. }\end{array}$ \\
\hline CM-8(3)(a)\{1\} & $\begin{array}{l}\text { Determine if the organization: employs } \\
\text { automated mechanisms [Assignment: } \\
\text { organization-defined frequency] to detect } \\
\text { the presence of unauthorized software and } \\
\text { firmware components within the system. }\end{array}$ & Moderate & AS & $\begin{array}{l}\text { Otherwise, inventory accuracy (e.g., } \\
\text { completeness and timeliness) might be } \\
\text { difficult or impossible to maintain. }\end{array}$ \\
\hline
\end{tabular}




\begin{tabular}{|l|l|l|l|l|}
\hline \multicolumn{1}{|c|}{$\begin{array}{c}\text { Determination } \\
\text { Statement ID }\end{array}$} & \multicolumn{1}{|c|}{ Determination Statement Text } & $\begin{array}{c}\text { Impact } \\
\text { Level }\end{array}$ & $\begin{array}{c}\text { Affects DS } \\
\text { and/or AS }\end{array}$ & \multicolumn{1}{c|}{ Rationale } \\
\hline CM-8(3)(b)\{1\} & $\begin{array}{l}\text { Determine if the organization: takes the } \\
\text { following actions when unauthorized } \\
\text { installed software\} components are } \\
\text { detected: [Selection (one or more): } \\
\text { disables network access by such } \\
\text { components; isolates the components; } \\
\text { notifies [Assignment: organization-defined } \\
\text { personnel or roles]]. }\end{array}$ & Moderate & AS & $\begin{array}{l}\text { Otherwise, detected security defects might } \\
\text { not be mitigated. }\end{array}$ \\
\hline CM-8(4)\{1\} & $\begin{array}{l}\text { Determine if the organization: includes in } \\
\text { the \{installed software\} system component } \\
\text { inventory information, a means for } \\
\text { identifying by [Selection (one or more): } \\
\text { name; position; role], individuals } \\
\text { responsible/accountable for administering } \\
\text { those components. }\end{array}$ & High & DS & $\begin{array}{l}\text { Otherwise, when defects are detected, the } \\
\text { automated systems cannot know what } \\
\text { persons or groups to notify to take } \\
\text { appropriate action. }\end{array}$ \\
\hline
\end{tabular}


Control Allocation Table for Appendix $\mathbf{G}^{\mathrm{a}}$

\begin{tabular}{|c|c|c|c|c|c|c|c|c|c|}
\hline $\begin{array}{c}\text { Determination } \\
\text { Statement ID }\end{array}$ & $\begin{array}{c}\text { Implemented } \\
\text { By }\end{array}$ & $\begin{array}{l}\text { Assessment } \\
\text { Boundary }\end{array}$ & $\begin{array}{l}\text { Assessment } \\
\text { Responsibility }\end{array}$ & $\begin{array}{c}\text { Assessment } \\
\text { Methods }\end{array}$ & Selected & $\begin{array}{c}\text { Rationale for } \\
\text { Risk } \\
\text { Acceptance }\end{array}$ & $\begin{array}{c}\begin{array}{c}\text { Frequency } \\
\text { of } \\
\text { Assessment }\end{array} \\
\end{array}$ & $\begin{array}{l}\text { Impact of Not } \\
\text { Implementing }\end{array}$ & Level \\
\hline CM-2\{1\} & DSM & ISCM-TN & ISCM-Sys & Test & & & & & Low \\
\hline CM-2(1)(a)\{1\} & DSM & ISCM-TN & ISCM-Sys & Test & & & & & Moderate \\
\hline CM-2(1)(b)\{1\} & DSM & ISCM-TN & ISCM-Sys & Test & & & & & Moderate \\
\hline CM-2(1)(c)\{1\} & DSM & ISCM-TN & ISCM-Sys & Test & & & & & Moderate \\
\hline CM-2(2)\{1\} & DSM & ISCM-TN & ISCM-Sys & Test & & & & & High \\
\hline CM-3(a) $\{1\}$ & DSM & ISCM-TN & MAN & TBD & & & & & Moderate \\
\hline CM-3(b) $\{1\}$ & DSM & ISCM-TN & ISCM-Sys & Test & & & & & Moderate \\
\hline CM-3(b)\{2\} & DSM & ISCM-TN & MAN & TBD & & & & & Moderate \\
\hline CM-3(c) $\{1\}$ & DSM & ISCM-TN & ISCM-Sys & Test & & & & & Moderate \\
\hline CM-3(d)\{1\} & SWMan & ISCM-TN & ISCM-Sys & Test & & & & & Moderate \\
\hline CM-3(f) $\{1\}$ & ISCM-Sys & ISCM-TN & ISCM-Sys & Test & & & & & Moderate \\
\hline CM-3(f)\{2\} & DSM & ISCM-TN & ISCM-Sys & Test & & & & & Moderate \\
\hline CM-3(g) $\{1\}$ & DSM & ISCM-TN & ISCM-Sys & Test & & & & & Moderate \\
\hline CM-3(g)\{2\} & DSM & ISCM-TN & ISCM-Sys & Test & & & & & Moderate \\
\hline $\mathrm{CM}-3(1)(\mathrm{a})\{1\}$ & DSM & ISCM-TN & ISCM-Sys & Test & & & & & High \\
\hline CM-3(1)(b)\{1\} & ISCM-Sys & ISCM-TN & ISCM-Sys & Test & & & & & High \\
\hline CM-3(1)(c)\{1\} & ISCM-Sys & ISCM-TN & ISCM-Sys & Test & & & & & High \\
\hline $\mathrm{CM}-3(1)(\mathrm{d})\{1\}$ & ISCM-Sys & ISCM-TN & ISCM-Sys & Test & & & & & High \\
\hline CM-3(1)(e)\{1\} & ISCM-Sys & ISCM-TN & MAN & TBD & & & & & High \\
\hline CM-3(1)(f) $\{1\}$ & ISCM-Sys & ISCM-TN & ISCM-Sys & Test & & & & & High \\
\hline CM-3(2)\{1\} & DSM & ISCM-TN & MAN & TBD & & & & & Moderate \\
\hline CM-8(a) $\{1\}$ & DSM & ISCM-TN & ISCM-Sys & Test & & & & & Low \\
\hline CM-8(a)\{2\} & ISCM-Sys & ISCM-TN & ISCM-Sys & Test & & & & & Low \\
\hline CM-8(b)\{1\} & ISCM-Sys & ISCM-TN & ISCM-Sys & Test & & & & & Low \\
\hline CM-8(b)\{2\} & DSM & ISCM-TN & ISCM-Sys & Test & & & & & Low \\
\hline
\end{tabular}




\begin{tabular}{|c|c|c|c|c|c|c|c|c|c|}
\hline $\begin{array}{c}\text { Determination } \\
\text { Statement ID }\end{array}$ & $\begin{array}{c}\text { Implemented } \\
\text { By }\end{array}$ & $\begin{array}{l}\text { Assessment } \\
\text { Boundary }\end{array}$ & $\begin{array}{c}\text { Assessment } \\
\text { Responsibility }\end{array}$ & $\begin{array}{l}\text { Assessment } \\
\text { Methods }\end{array}$ & Selected & $\begin{array}{c}\text { Rationale for } \\
\text { Risk } \\
\text { Acceptance }\end{array}$ & $\begin{array}{c}\text { Frequency } \\
\text { of } \\
\text { Assessment }\end{array}$ & $\begin{array}{l}\text { Impact of Not } \\
\text { Implementing }\end{array}$ & Level \\
\hline CM-8(1)\{1\} & ISCM-Sys & ISCM-TN & ISCM-Sys & Test & & & & & Moderate \\
\hline CM-8(2)\{1\} & ISCM-Sys & ISCM-TN & ISCM-Sys & Test & & & & & High \\
\hline CM-8(3)(a)\{1\} & ISCM-Sys & ISCM-TN & ISCM-Sys & Test & & & & & Moderate \\
\hline CM-8(3)(b)\{1\} & SWMan & ISCM-TN & ISCM-Sys & Test & & & & & Moderate \\
\hline CM-8(4)\{1\} & DSM & ISCM-TN & ISCM-Sys & Test & & & & & High \\
\hline
\end{tabular}

a The control allocation table is provided as a partially completed security assessment plan template. Organizations may leverage the template by documenting organization- and/or system-specific information in the blank columns. 